\title{
Interventions To Decrease Hospital Length of Stay
}


Number $\mathbf{4 0}$

\section{Interventions To Decrease Hospital Length of Stay}

Prepared for:

Agency for Healthcare Research and Quality

U.S. Department of Health and Human Services

5600 Fishers Lane

Rockville, MD 20857

www.ahrq.gov

Contract No. 75Q80120D00002

Prepared by:

ECRI-Penn Medicine Evidence-based Practice Center

Philadelphia, PA

Investigators:

Kelley Tipton, M.P.H.

Brian F. Leas, M.S., M.A.

Nikhil K. Mull, M.D.

Shazia M. Siddique, M.D., M.S.H.P.

S. Ryan Greysen, M.D., M.H.S.

Meghan B. Lane-Fall, M.D., M.S.H.

Amy Y. Tsou, M.D., M.Sc.

AHRQ Publication No. 21-EHC015

September 2021 


\section{Key Messages}

\section{Purpose}

The goals of this Technical Brief are to 1) categorize and evaluate current knowledge regarding strategies to reduce length of stay (LOS) for medically complex, high-risk, or vulnerable patients at increased risk of extended LOS; 2) examine contextual factors (e.g., resources, costs, staffing, technology) that affect implementation of LOS-focused interventions; 3) identify emerging concepts or initiatives that may merit future research; and 4) develop a series of evidence maps to inform health systems' strategic efforts for LOS reduction in these populations.

\section{Key Messages}

- Few studies have evaluated system-level interventions focused on medically complex, high-risk, or vulnerable patient populations, including frail elderly patients and those with complex chronic illness. Strategies assessed in multiple systematic reviews include geriatric consultation services and early specialized discharge planning.

- Substantial research gaps need to be addressed, including interventions for socially or economically vulnerable populations and patients with psychiatric or substance use disorders, contextual factors affecting feasibility of implementation, and the resources and potential savings associated with interventions to reduce LOS.

- Hospital administrative leaders, researchers, and policymakers can work to reduce LOS by improving research practice, developing targeted health system interventions, and collaboratively addressing the social care needs of medically complex and vulnerable patient populations.

- Two interventions (clinical pathways and case management) improved key outcomes for patients with heart failure. Clinical pathways reduced LOS, readmission, and mortality (low to moderate quality evidence from a single systematic review). Similarly, case management decreased LOS and readmissions (moderate quality evidence from a single systematic review). More research is needed to confirm these findings (Figure i).

- For other interventions, evidence for LOS reduction was inconsistent. Only limited evidence was available for other post-discharge adverse outcomes (hospital readmission, mortality).

- The evidence base examining strategies for reducing LOS is large but focuses primarily on average-risk patients undergoing elective surgery or specialized procedures, who were not the focus of this Technical Brief. 
Figure i. Evidence map for length of stay, readmissions, and mortality outcomes

\begin{tabular}{|c|c|c|c|c|c|}
\hline \multirow{2}{*}{ Interventions } & & \multicolumn{3}{|c|}{ Key Outcomes } & Patient Population \\
\hline & \multirow{3}{*}{$\begin{array}{r}\text { Mabire 2017, } 2016 \\
\text { Mabire 2017, } 2016 \\
\text { (transitional care) }\end{array}$} & Length of Stay & Readmissions & Mortality & Population \\
\hline \multirow{10}{*}{$\begin{array}{l}\text { Discharge } \\
\text { Planning }\end{array}$} & & $\mathbf{L}$ & $\mathbf{M}$ & & Older \\
\hline & & & $\leftrightarrow^{\mathrm{L}}$ & & Older \\
\hline & Goncalves-Bradley 2016 & M & M & & Older \\
\hline & Goncalves-Bradley 2016 & $\leftrightarrow^{\mathbf{L}}$ & & & Older surgical patients \\
\hline & Bryant-Lukosius 2015 & $\leftrightarrow^{\mathrm{L}}$ & & $\leftrightarrow \mathrm{L}$ & Older \\
\hline & Bryant-Lukosius 2015 & $\overline{\mathbf{M}}$ & & & High-risk pregnant women \\
\hline & Bryant-Lukosius 2015 & & $\leftrightarrow \mathbf{L}$ & $\leftrightarrow \mathbf{L}$ & Heart failure \\
\hline & Bryant-Lukosius 2015 & & $\leftrightarrow \mathbf{L}$ & & Infants \\
\hline & Zhu 2015 & $\leftrightarrow{ }^{\mathbf{M}}$ & M & $\downarrow^{\mathbf{H}}$ & Chronic conditions \\
\hline & Zhu 2015 & & $\mathbf{M}$ & & Younger $(<65$ years $)$ \\
\hline \multirow{3}{*}{$\begin{array}{l}\text { Geriatric } \\
\text { Assessment }\end{array}$} & \multirow{2}{*}{$\begin{array}{r}\text { Eagles } 2020 \\
\text { Ellis } 2017\end{array}$} & $\mathbf{M}$ & & $\downarrow^{\mathbf{M}}$ & Older \\
\hline & & & & $\leftrightarrow$ & Older \\
\hline & Van Craen 2010 & $\leftrightarrow^{\mathbf{H}}$ & $\leftrightarrow{ }^{\mathbf{M}}$ & $\leftrightarrow^{\mathbf{H}}$ & Older \\
\hline $\begin{array}{l}\text { Medication } \\
\text { Management }\end{array}$ & Gillaizeau 2013 & $\leftrightarrow \mathbf{L}$ & & & Chronic conditions \\
\hline $\begin{array}{l}\text { Clinical } \\
\text { Pathways } \\
\end{array}$ & Kul 2012 & $\downarrow^{\mathbf{L}}$ & $\downarrow^{\mathbf{M}}$ & $\downarrow^{\mathbf{M}}$ & Heart failure \\
\hline \multirow{2}{*}{$\begin{array}{l}\text { Interdisciplinary } \\
\text { Care }\end{array}$} & \multirow{2}{*}{$\begin{array}{r}\text { Pannick 2015 } \\
\text { (altering team composition) } \\
\text { Pannick 2015 } \\
\text { (altering team practice) }\end{array}$} & $\leftrightarrow{ }^{\mathbf{M}}$ & $\uparrow^{L}$ & $\leftrightarrow^{\mathbf{M}}$ & Chronic conditions \\
\hline & & $\leftrightarrow^{\mathbf{M}}$ & $\leftrightarrow^{\mathrm{L}}$ & $\downarrow^{\mathbf{M}}$ & Not reported \\
\hline $\begin{array}{l}\text { Case } \\
\text { Management }\end{array}$ & Huntley 2016 & $\downarrow^{\mathbf{M}}$ & $\downarrow^{\mathbf{M}}$ & & Heart failure \\
\hline \multirow[t]{4}{*}{ Telehealth } & Baratloo 2018 & $\downarrow^{\mathbf{M}}$ & & $\leftrightarrow{ }^{\mathbf{M}}$ & Other \\
\hline & \multirow{3}{*}{$\begin{array}{r}\text { Direction of } \\
\text { Effect: (arrow } \\
\text { direction) }\end{array}$} & & \multirow{3}{*}{$\begin{array}{l}\text { Strength of } \\
\text { Evidence: } \\
\text { (superscript } \\
\text { letter) }\end{array}$} & H High & \\
\hline & & $\downarrow$ Decrease & & M Moderate & \\
\hline & & $\leftrightarrow$ Inconclusive & & L Low/Very low & \\
\hline
\end{tabular}


This report is based on research conducted by the ECRI-Penn Medicine Evidence-based Practice Center contract to the Agency for Healthcare Research and Quality (AHRQ), Rockville, MD (Contract No. 75Q80120D00002). The findings and conclusions in this document are those of the authors, who are responsible for its contents; the findings and conclusions do not necessarily represent the views of AHRQ. Therefore, no statement in this report should be construed as an official position of AHRQ or of the U.S. Department of Health and Human Services.

\section{None of the investigators have any affiliations or financial involvement that conflicts with the material presented in this report.}

The information in this report is intended to help healthcare decision makers - patients and clinicians, health system leaders, and policymakers, among others-make well-informed decisions and thereby improve the quality of healthcare services. This report is not intended to be a substitute for the application of clinical judgment. Anyone who makes decisions concerning the provision of clinical care should consider this report in the same way as any medical reference and in conjunction with all other pertinent information, i.e., in the context of available resources and circumstances presented by individual patients.

This report is made available to the public under the terms of a licensing agreement between the author and the Agency for Healthcare Research and Quality. This report may be used and reprinted without permission except those copyrighted materials that are clearly noted in the report. Further reproduction of those copyrighted materials is prohibited without the express permission of copyright holders.

AHRQ or U.S. Department of Health and Human Services endorsement of any derivative products that may be developed from this report, such as clinical practice guidelines, other quality-enhancement tools, or reimbursement or coverage policies, may not be stated or implied.

AHRQ appreciates appropriate acknowledgment and citation of its work. Suggested language for acknowledgment: This work was based on an evidence report, Interventions To Decrease Hospital Length of Stay, by the Evidence-based Practice Center Program at the Agency for Healthcare Research and Quality.

Suggested citation: Tipton K, Leas BF, Mull NK, Siddique SM, Greysen SR, Lane-Fall MB, Tsou AY. Interventions To Decrease Hospital Length of Stay. Technical Brief No. 40. (Prepared by the ECRI-Penn Medicine Evidence-based Practice Center under Contract No.

75Q80120D00002.) AHRQ Publication No. 21-EHC015. Rockville, MD: Agency for Healthcare Research and Quality; September 2021. DOI: https://doi.org/10.23970/AHRQEPCTB40. Posted final reports are located on the Effective Health Care Program search page. 


\section{Preface}

The Agency for Healthcare Research and Quality (AHRQ), through its Evidence-based Practice Centers (EPCs), sponsors the development of evidence reports and technology assessments to assist public- and private-sector organizations in their efforts to improve the quality of healthcare in the United States. The reports and assessments provide organizations with comprehensive, science-based information on common, costly medical conditions and new healthcare technologies and strategies. The EPCs systematically review the relevant scientific literature on topics assigned to them by AHRQ and conduct additional analyses when appropriate prior to developing their reports and assessments.

This EPC evidence report is a Technical Brief. A Technical Brief is a rapid report, typically on an emerging medical technology, strategy, or intervention. It provides an overview of key issues related to the intervention - for example, current indications, relevant patient populations and subgroups of interest, outcomes measured, and contextual factors that may affect decisions regarding the intervention. Although Technical Briefs generally focus on interventions for which there are limited published data and too few completed protocol-driven studies to support definitive conclusions, the decision to request a Technical Brief is not based solely on the availability of clinical studies. The goals of the Technical Brief are to provide an early objective description of the state of the science, a potential framework for assessing the applications and implications of the intervention, a summary of ongoing research, and information on future research needs. In particular, through the Technical Brief, AHRQ hopes to gain insight on the appropriate conceptual framework and critical issues that will inform future research.

AHRQ expects that the EPC evidence reports and technology assessments will inform individual health plans, providers, and purchasers as well as the healthcare system as a whole by providing important information to help improve healthcare quality.

If you have comments on this Technical Brief, they may be sent by mail to the Task Order Officer named below at: Agency for Healthcare Research and Quality, 5600 Fishers Lane, Rockville, MD 20857, or by email to epc@ahrq.hhs.gov.

David Meyers, M.D.

Acting Director

Agency for Healthcare Research and Quality

Craig Umscheid, M.D., M.P.H.

Director

Evidence-based Practice Center Program

Center for Evidence and Practice

Improvement

Agency for Healthcare Research and Quality
Arlene S. Bierman, M.D., M.S.

Director

Center for Evidence and Practice

Improvement

Agency for Healthcare Research and Quality

Elise Berliner, Ph.D.

Task Order Officer

Center for Evidence and Practice Improvement

Agency for Healthcare Research and Quality 


\section{Acknowledgments}

The authors gratefully acknowledge the following individuals at ECRI for their contributions to this project: Janice Kaczmarek, M.S., EPC Project Manager; Jacquelyn Hostetter, M.B.A., EPC Program Coordinator; Kristina McShea, M.S.L.I.S.; Jennifer Maslin; Katherine Donahue; and Michael Phillips. We also thank AHRQ Task Order Officer Elise Berliner, Ph.D.

\section{Key Informants}

In designing the study questions, the EPC consulted a panel of Key Informants who represent subject experts and end-users of research. Key Informant input can inform key issues related to the topic of the Technical Brief. Key Informants are not involved in the analysis of the evidence or the writing of the report. Therefore, in the end, study questions, design, methodological approaches, and/or conclusions do not necessarily represent the views of individual Key Informants.

Key Informants must disclose any financial conflicts of interest greater than $\$ 5,000$ and any other relevant business or professional conflicts of interest. Because of their role as end-users, individuals with potential conflicts may be retained. The Task Order Officer and the EPC work to balance, manage, or mitigate any conflicts of interest.

The list of Key Informants who provided input to this report follows:

Beth Anctil, R.N., M.S.N.

Principal, Strategy Innovation and Population Health

Premier, Inc.

Charlotte, NC

Lauran Hardin, M.S.N., FAAN*

Senior Advisor, National Center for Complex Health and Social Needs

Camden Coalition of Healthcare Providers

Camden, NJ

Mark Humowiecki, J.D.

Senior Director, National Center for Complex Health and Social Needs

Camden Coalition of Healthcare Providers

Camden, NJ

Kedar Mate, M.D.

Chief Innovation and Education Officer

Institute for Healthcare Improvement

Boston, MA

Michael Mittelman*

Patient Advocate

Patient-Centered Outcomes Research Institute (PCORI) Ambassador

Philadelphia, PA 
Nancy Myers, Ph.D.*

Vice President, Leadership and System Innovation

American Hospital Association

Chicago, IL

Janis Orlowski, M.D.

Chief Health Care Officer

Association of American Medical Colleges

Washington, DC

*Provided input on Draft Report.

\section{Peer Reviewers}

Prior to publication of the final evidence report, the EPC sought input from independent Peer Reviewers without financial conflicts of interest. However, the conclusions and synthesis of the scientific literature presented in this report do not necessarily represent the views of individual reviewers.

Peer Reviewers must disclose any financial conflicts of interest greater than $\$ 5,000$ and any other relevant business or professional conflicts of interest. Because of their unique clinical or content expertise, individuals with potential nonfinancial conflicts may be retained. The Task Order Officer and the EPC work to balance, manage, or mitigate any potential nonfinancial conflicts of interest identified.

The list of Peer Reviewers follows:

John Bulger, D.O., M.B.A.

Chief Medical Officer, Insurance Operations and Strategic Partnerships

Geisinger Health

Danville, PA

Daniel I. Chu, M.D., M.S.P.H.

Associate Professor of Surgery and Associate Director of Health Services Research

University of Alabama at Birmingham

Birmingham, AL 


\section{Interventions To Decrease Hospital Length of Stay}

\section{Structured Abstract}

Background. Timely discharge of hospitalized patients can prevent patient harm, improve patient satisfaction and quality of life, and reduce costs. Numerous strategies have been tested to improve the efficiency and safety of patient recovery and discharge, but hospitals continue to face challenges.

Purpose. This Technical Brief aimed to identify and synthesize current knowledge and emerging concepts regarding systematic strategies that hospitals and health systems can implement to reduce length of stay (LOS), with emphasis on medically complex or vulnerable patients at high risk for prolonged LOS due to clinical, social, or economic barriers to timely discharge.

Methods. We conducted a structured search for published and unpublished studies and conducted interviews with Key Informants representing vulnerable patients, hospitals, health systems, and clinicians. The interviews provided guidance on our research protocol, search strategy, and analysis. Due to the large and diverse evidence base, we limited our evaluation to systematic reviews of interventions to decrease hospital LOS for patients at potentially higher risk for delayed discharge; primary research studies were not included, and searches were restricted to reviews published since 2010. We cataloged the characteristics of relevant interventions and assessed evidence of their effectiveness.

Findings. Our searches yielded 4,364 potential studies. After screening, we included 19 systematic reviews reported in 20 articles. The reviews described eight strategies for reducing LOS: discharge planning; geriatric assessment or consultation; medication management; clinical pathways; inter- or multidisciplinary care; case management; hospitalist services; and telehealth. All reviews included adult patients, and two reviews also included children. Interventions were frequently designed for older (often frail) patients or patients with chronic illness. One review included pregnant women at high risk for premature delivery. No reviews focused on factors linking patient vulnerability with social determinants of health.

The reviews reported few details about hospital setting, context, or resources associated with the interventions studied. Evidence for effectiveness of interventions was generally not robust and often inconsistent-for example, we identified six reviews of discharge planning; three found no effect on LOS, two found LOS decreased, and one reported an increase. Many reviews also reported patient readmission rates and mortality but with similarly inconsistent results.

Conclusions. A broad range of strategies have been employed to reduce LOS, but rigorous systematic reviews have not consistently demonstrated effectiveness within medically complex, high-risk, and vulnerable populations. Health system leaders, researchers, and policymakers must collaborate to address these needs. 


\section{Contents}

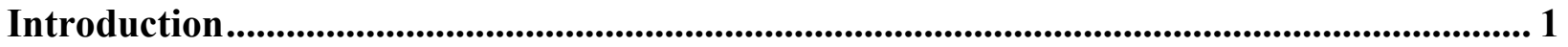

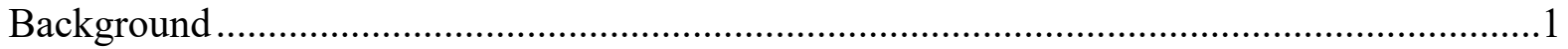

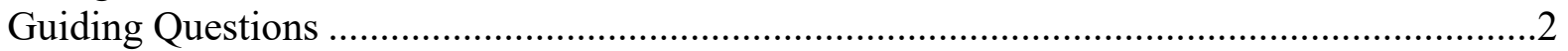

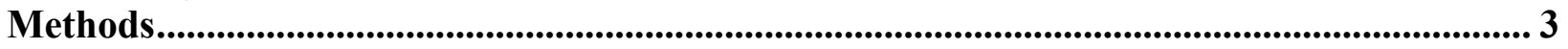

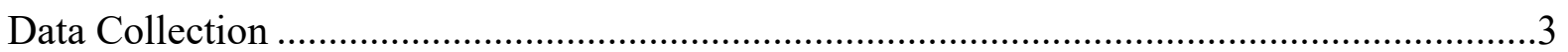

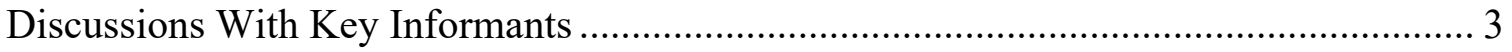

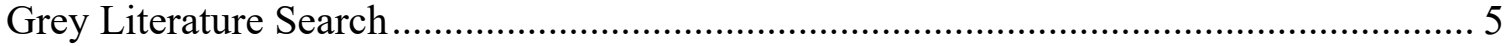

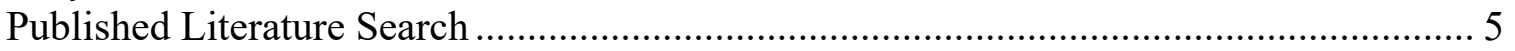

Inclusion of Published Literature ............................................................................. 5

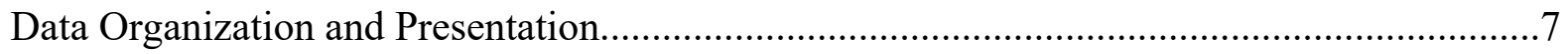

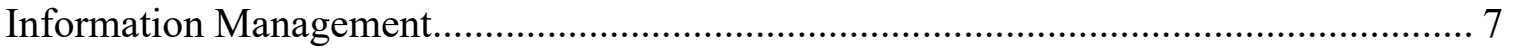

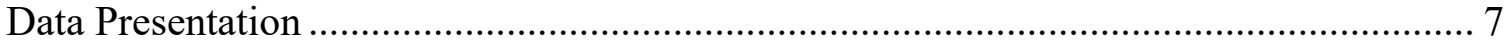

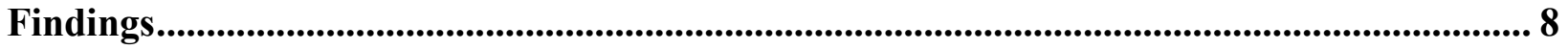

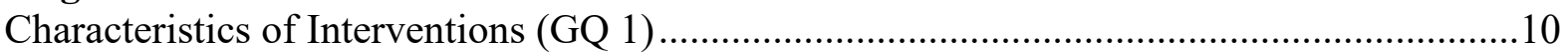

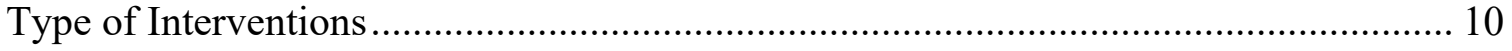

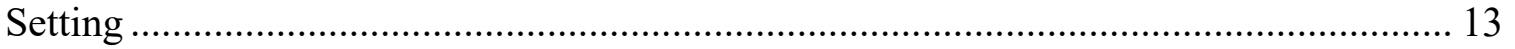

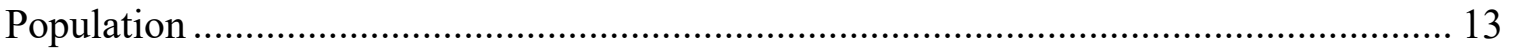

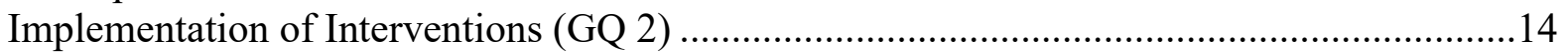

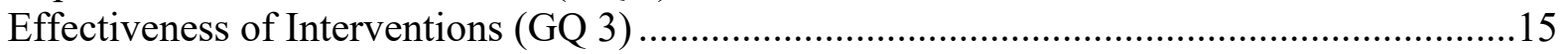

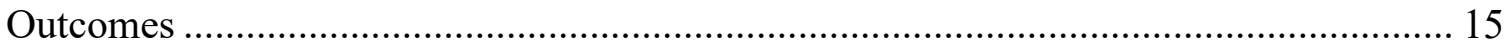

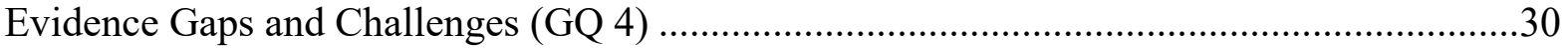

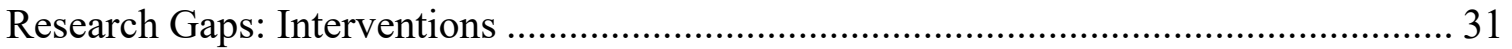

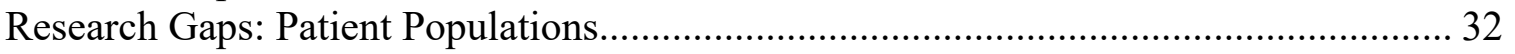

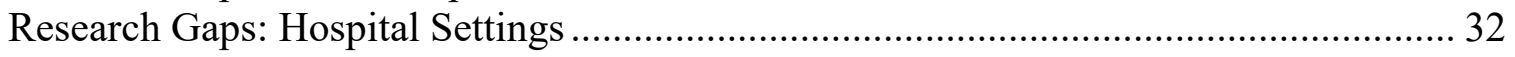

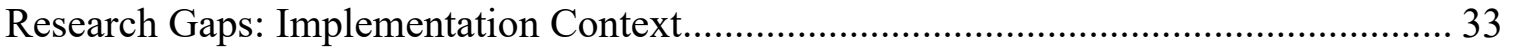

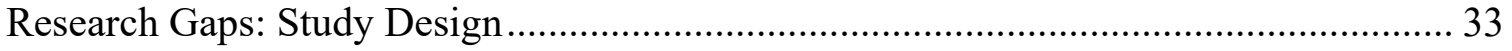

Summary and Implications ............................................................................................. 34

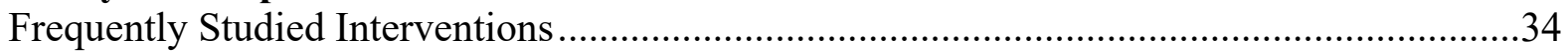

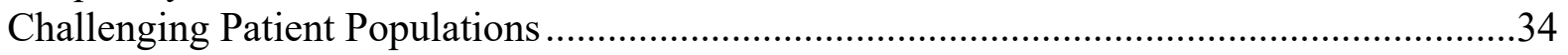

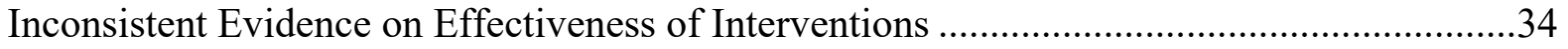

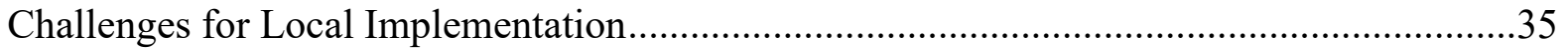

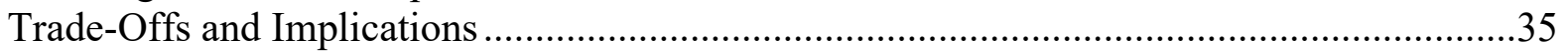

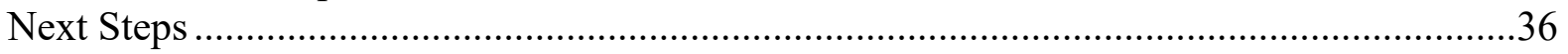

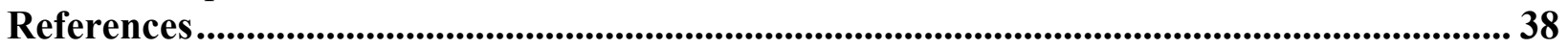

\section{Tables}

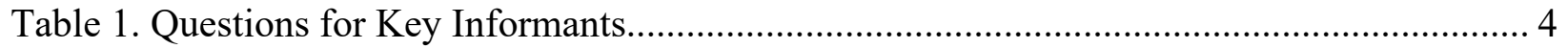

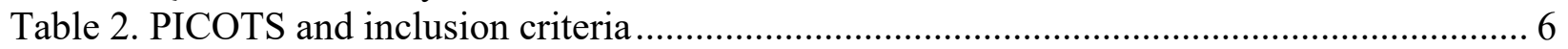

Table 3. Outcomes reported in the systematic reviews........................................................ 16

Table 4. Summary of findings for length of stay meta-analyses ........................................ 20

Table 5. Summary of findings for readmissions meta-analyses .............................................. 22

Table 6. Summary of findings for patient harms meta-analyses ........................................... 24

Table 7. Summary of findings for patient functional return and patient/family experience metaanalyses 


\section{Figures}

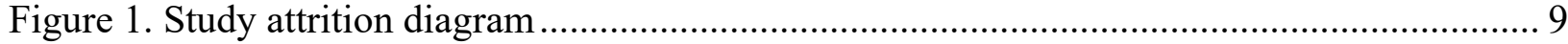

Figure 2. Publication year of included systematic reviews.................................................... 10

Figure 3. Number of systematic reviews per intervention type ............................................ 11

Figure 4. Number of systematic reviews examining each patient population category .............. 14

Figure 5. Number of randomized controlled trials (RCTs) and non-RCTs in systematic reviews

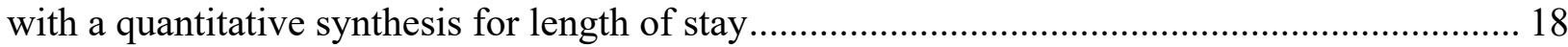

Figure 6. Evidence map for length of stay, readmissions, mortality, and other adverse events... 19

\section{Appendixes}

Appendix A. Methods

Appendix B. List of Excluded Studies

Appendix C. Evidence Tables 


\section{Introduction}

\section{Background}

In 2018, there were 36.4 million inpatient hospital stays in the United States. ${ }^{1}$ The average length of stay (LOS) for a hospitalization is $5 \frac{1 / 2}{2}$ days. ${ }^{2}$ Unnecessary days in hospital may lead to increased hospital-acquired patient complications (e.g., healthcare-associated infections, falls) and increased costs for patients and healthcare systems. In addition, prolonged LOS may negatively affect both patient and staff experience. ${ }^{3}$ Delays in hospital discharge may be related to unnecessary waiting, poor organization of care, delays in decision-making, or difficulties related to discharge planning. ${ }^{3,4}$

A broad array of interventions have been developed to reduce hospital LOS, and they differ in design, intent, and focal point. While some interventions primarily aim at improving clinical care (enhanced recovery programs,${ }^{5-7}$ clinical pathways, ${ }^{8}$ and early patient mobility programs ${ }^{9}$ ), other approaches address logistical factors (care coordination, transition and discharge planning, ${ }^{10-12}$ case management, ${ }^{13}$ medication management, ${ }^{14}$ or specialized units for high-risk populations $\left.{ }^{15,16}\right)$. Other interventions target the workforce, such as multidisciplinary care teams ${ }^{17}$ or redesigned staffing models. ${ }^{18}$

Interventions have the potential to create trade-offs between outcomes. Reducing LOS might increase concerns for readmission risk or shifting costs of care to the outpatient setting. ${ }^{3}$ Conversely, interventions might be ineffective in reducing LOS but yield significant improvements in other patient-centered outcomes, such as patient satisfaction. Further, interventions to reduce LOS may differ for those needing treatment for exacerbation of a complex chronic condition and those needing treatment for an acute illness or undergoing an elective surgical procedure.

Particular patient populations, such as patients who are socioeconomically vulnerable, affected by healthcare disparities, or with medically complex needs, may be at increased risk for unnecessary delays in discharge. ${ }^{19-21}$ These patients are typically at greater risk for adverse events during and after hospitalization. ${ }^{22}$ Interventions that address the distinctive challenges of LOS reduction in these populations might increase efficiency of patient throughput, reduce health inequities, and improve the delivery of safe and effective care.

Successful hospital-based interventions may significantly depend on environmental factors, including the unique resources, personnel, leadership, and infrastructure specific to each setting. A hospital or health system-based approach could therefore address the multiple factors (e.g., admission process, discharge disposition) contributing to unnecessary delays in hospital discharge. ${ }^{3}$ We categorized and evaluated current knowledge regarding the many strategies to reduce LOS; examined contextual factors (e.g., resources, costs, staffing, technology) that may affect implementation of LOS-focused interventions; identified emerging concepts or initiatives that merit future research; and developed a series of evidence maps to inform health systems' strategic efforts. 


\section{Guiding Questions}

Guiding Question (GQ) 1: What are the characteristics of interventions to decrease length of hospital stay, and how do they vary?

GQ 2: What are the contextual factors (e.g., resources, staffing, technology) that impact implementation of interventions to decrease hospital length of stay?

GQ 3: What is the current evidence addressing interventions to decrease hospital length of stay?

GQ 4: What future research is needed to close evidence gaps regarding interventions to decrease length of hospital stay? 


\section{Methods}

AHRQ's Learning Health System panel nominated this topic to inform current and future patient safety efforts and access to care initiatives. We generated a protocol that included preliminary Guiding Questions (GQs) and inclusion/exclusion criteria in the form of PICOTS (populations, interventions, comparators, outcomes, timing, and settings). We interviewed Key Informants (KIs) representing a broad range of stakeholders (described below) and incorporated their feedback into a final protocol that was posted on the Effective Healthcare website (https://effectivehealthcare.ahrq.gov). The protocol was also submitted to the PROSPERO database but was not prioritized for immediate inclusion due to the COVID-19 pandemic.

\section{Data Collection}

\section{Discussions With Key Informants}

The intent of KI interviews is to provide context and guidance on areas most important to consider for this Technical Brief. Seven KIs provided input on this review, representing diverse leadership experiences, including hospital administration, patient safety organizations, community-based healthcare initiatives, policy analysis, and patient advocacy. KI expertise included care model transformation (e.g., co-design, coaching), healthcare delivery processes, managed care and risk management, and hospital quality and safety. Additionally, KIs had firsthand experience of working with medically complex, high-risk, and vulnerable populations at their institutions. We sought KI feedback on the review's scope, including the proposed PICOTS. We asked about vulnerable populations at risk for unnecessary increases in length of stay (LOS), such as those with specific clinical conditions and demographic risk factors. We similarly requested KI input on key components to capture organizational interventions focused on LOS reduction. Most of the KI discussions were real-time interviews. However, due to scheduling challenges during the COVID-19 pandemic, two KIs provided responses by email instead.

The KIs provided key insights on defining patient populations at high-risk for prolonged hospitalization. First, we presented to the KIs two potential conditions of interest: acute exacerbations of chronic obstructive pulmonary disease and decompensated congestive heart failure. KI input led to the inclusion of high-volume chronic diseases with a significant risk of exacerbation or complications, including the addition of chronic kidney disease and diabetes mellitus. Second, KIs helped identify additional characteristics of medically complex patients. Several KIs highlighted that patients with multiple medical and psychiatric diagnoses are at much higher risk than those with a single clinical diagnosis. Therefore, we included comorbid psychiatric or behavioral health conditions, comorbid substance use disorder, frailty, and multimorbidity in our patient population. Third, KI input allowed further definition of vulnerable populations, including those with high levels of socioeconomic risk. Specifically, socioeconomic risk factors were expanded to include patients with housing instability, social isolation and vulnerability, limited social mobility, lack of social network or support, limited access to healthcare or social services, and living in rural settings. These factors were added to other proposed factors, such as underinsured or uninsured patients and those with limited English proficiency. Finally, the KIs highlighted the importance of distinguishing conditions that require acute care as opposed to hospitalizations planned for elective procedures. Based on KI input, we 
narrowed our population to exclude those specifically hospitalized for nonemergent elective procedures or surgeries because KIs felt that they were at lower risk for prolonged LOS.

The KIs agreed with our proposal to focus on interventions that are initiated within the hospital and designed to evaluate LOS as our primary outcome. A few KIs highlighted the importance of including initiatives with both an inpatient and outpatient component, given that multidisciplinary transitional partnership can be powerful and effective. Therefore, our final protocol included multicomponent interventions initiated within an inpatient hospital setting to directly affect LOS, even if several other facets occurred as an outpatient. However, studies with interventions solely occurring in an outpatient setting (e.g., isolated community-based interventions) were excluded; KIs agreed that in those cases, the primary goal was to reduce readmissions, as opposed to LOS reduction.

Regarding outcomes, the KIs agreed that LOS metrics that provide a standardized comparison among hospitals are important; therefore, we included LOS index as a primary outcome. Additionally, secondary and surrogate outcomes were expanded based on KI input, such as patient experience, functional return, and inclusion of discharge disposition.

$\mathrm{KI}$ input informed GQs 1, 2, and 4. In addition, input was also used to refine the systematic literature search, identify grey literature resources, provide information about ongoing research, confirm evidence limitations, recommend approaches to help fill these gaps, and provide input on the potential design, focus, and audience for the evidence maps featured in this Technical Brief. Table 1 presents the questions for the KIs.

Table 1. Questions for Key Informants

\begin{tabular}{|c|c|}
\hline Number & Question \\
\hline 1. & $\begin{array}{l}\text { What clinical conditions are top priorities for you when thinking about efforts to reduce length of stay } \\
\text { (LOS)? How do you decide on prioritization for these efforts? }\end{array}$ \\
\hline 2. & $\begin{array}{l}\text { Based on national admissions and LOS data, some of the chronic conditions for specific focus include: } \\
\text { acute exacerbations of chronic obstructive pulmonary disease (COPD), acute exacerbations of } \\
\text { chronic congestive heart failure. } \\
\text { a. Are there other chronic conditions with frequent decompensations often requiring inpatient } \\
\text { admission missing from this list that are of particular interest? }\end{array}$ \\
\hline 3. & $\begin{array}{l}\text { Can you describe characteristics of medically complex patients for which interventions to reduce LOS } \\
\text { would be particularly helpful? }\end{array}$ \\
\hline 4. & $\begin{array}{l}\text { How would you describe vulnerable populations within a hospital setting as it relates to LOS? } \\
\text { a. Are there interventions of interest that would be specific and/or different to LOS in these at- } \\
\text { risk populations? }\end{array}$ \\
\hline 5. & $\begin{array}{l}\text { How would you define a hospital or health system-based organizational intervention to reduce LOS? } \\
\text { What are the most important elements of such interventions? }\end{array}$ \\
\hline 6. & $\begin{array}{l}\text { What characteristics of interventions are important for you to know or understand so that you can } \\
\text { judge feasibility of implementation? (e.g., staffing requirements, infrastructure, resource utilization) } \\
\text { a. How do emerging or existing payment models affect approaches to operationalizing or } \\
\text { prioritizing LOS interventions? }\end{array}$ \\
\hline 7. & $\begin{array}{l}\text { The information about interventions we glean from studies will be presented in evidence maps. For } \\
\text { example, https://www.ncbi.nlm.nih.gov/books/NBK379312/figure/findings.f7/?report=objectonly } \\
\text { a. What are your thoughts about } 2 \text { or } 3 \text { key variables that would be most helpful for you to see } \\
\text { graphically presented? } \\
\text { b. What types of categories of interventions or conditions would be useful to highlight or group } \\
\text { together? }\end{array}$ \\
\hline 8. & $\begin{array}{l}\text { What outcomes other than LOS, including potential positive or negative effects to a system or care } \\
\text { team are of particular interest for interventions to decrease LOS? What outcomes are important to } \\
\text { patients? }\end{array}$ \\
\hline 9. & $\begin{array}{l}\text { Where do you think are the most important gaps in current knowledge, and can you recommend } \\
\text { approaches to help fill and/or identify these gaps? }\end{array}$ \\
\hline 10. & In addition to published literature, what unpublished resources could help inform our analysis? \\
\hline
\end{tabular}




\section{Grey Literature Search}

Multiple grey literature sources were searched, including websites of relevant stakeholder organizations (e.g., American Hospital Association, Institute for Healthcare Improvement, The Joint Commission), healthcare consulting firms (e.g., Premier, Vizient, Socially Determined), and government agencies (e.g., ClinicalTrials.gov, Agency for Healthcare Research and Quality (AHRQ), Centers for Medicare \& Medicaid Services). The information from this search helped to orient the team to work being conducted to reduce hospital LOS.

\section{Published Literature Search}

Evidence from the published literature helped inform GQ 3. Medical librarians searched bibliographic databases, including MEDLINE ${ }^{\circledR}$, PubMed $^{\circledR}$ (unprocessed records only), Embase ${ }^{\circledR}$, CINAHL $^{\circledR}$, and the Cochrane Library using controlled vocabulary and text words. Searches covered the literature published from January 1, 2010, through September 30, 2020. A complete list of the resources searched, as well as search concepts and strategies, are available in Appendix A. Reference lists from systematic reviews were reviewed and compared against our retrieved articles. If a systematic review contained references that appeared to meet our inclusion criteria, but had not been captured by our initial search results, we reviewed the search strategy to determine whether we needed to refine the search strategy to include these articles. We also requested additional studies through AHRQ's Supplemental Evidence and Data process.

Literature screening was performed using the database Distiller SR (Evidence Partners, Ottawa, Canada). Literature search results were initially screened for relevancy based on predetermined eligibility criteria (see Table 2). Full text of relevant abstracts were then requested and screened. We structured literature screening to ensure that both a clinician and a methodologist reviewed every abstract and full-text report. All disagreements were resolved by consensus discussion among the two original screeners.

\section{Inclusion of Published Literature}

Published systematic reviews (SRs) of both randomized and nonrandomized primary studies were included if they met the inclusion criteria in Table 2 and certain methodologic standards, such as providing search criteria, explicit inclusion/exclusion criteria, and risk-of-bias assessment. SRs were excluded if they focused solely on patients undergoing nonemergent elective procedures or exclusively set in intensive care units, emergency departments, or managed or implemented by entities external to the hospital setting, such as community organizations. Interventions not intended or expected to reduce LOS were not evaluated. Systematic reviews were also excluded if they did not include LOS data. Finally, we excluded SRs of primary studies that were either conducted solely outside the United States or if 50 percent or more of the studies reporting hospital LOS were conducted outside the United States. Appendix B lists excluded studies, organized by reason for exclusion. 
Table 2. PICOTS and inclusion criteria

\begin{tabular}{|c|c|}
\hline Category & Criteria \\
\hline Population & $\begin{array}{l}\text { Include hospitalized children and adults (including pregnant women) with one or more of the } \\
\text { following risk factors for prolonged length of stay (LOS), harms, or adverse outcomes: } \\
\text { Vulnerable populations: } \\
\text { - high levels of socioeconomic risk (e.g., housing instability, social isolation, social } \\
\text { vulnerability, social mobility, lack of social network, lack of social support, limited access to } \\
\text { - healthcare services or social services, rural settings) } \\
\text { - } \text { medically uninsured, underinsured } \\
\text { - } \quad \text { limited English proficiency } \\
\text { Medically complex patients: } \\
\text { - comorbid psychiatric or behavioral health conditions } \\
\text { - comorbid substance use disorder } \\
\text { - } \text { frailty } \\
\text { - multimorbidity ( } \geq 2 \text { chronic health conditions) } \\
\text { - high volume chronic disease conditions with significant risk of exacerbation or } \\
\text { complications, including chronic kidney disease, diabetes, congestive heart failure, and } \\
\text { chronic obstructive pulmonary disease } \\
\text { Exclude patients undergoing non-emergent or elective procedures }\end{array}$ \\
\hline Interventions & $\begin{array}{l}\text { Include interventions that are: } \\
\text { - initiated within the hospital; and } \\
\text { - designed (at least in part) to evaluate LOS } \\
\text { Examples include but are not limited to: clinical pathways, enhanced recovery programs, discharge } \\
\text { planning, case management, multidisciplinary teams } \\
\text { Exclude interventions that are: } \\
\qquad \text { initiated, managed, or implemented by entities wholly external to the hospital setting; or } \\
\text { - are not intended or expected to reduce LOS } \\
\text { Examples include but are not limited to ambulatory clinic follow-up visits, community-based } \\
\text { support resources, regulatory policies, third-party reimbursement programs }\end{array}$ \\
\hline Comparators & Include: Usual care; any comparison; other active intervention \\
\hline Outcomes & $\begin{array}{l}\frac{\text { Include }}{\text { Primary: }} \\
\text { - Length of stay, length of stay index } \\
\text { Secondary: } \\
\text { - Readmission } \\
\text { - Patient harms, such as hospital-acquired conditions and medical errors } \\
\text { - Patient experience/satisfaction } \\
\text { - Patient functional return } \\
\text { - Resource use including patient flow and discharge disposition } \\
\text { Exclude studies that only describe cost-related outcomes without reporting LOS, exclude cost } \\
\text { related outcomes that do not quantify valuations of both comparisons or alternative interventions } \\
\text { (including usual or standard of care) and both of their associated outcomes }\end{array}$ \\
\hline Timing & Include: All \\
\hline Setting & $\begin{array}{l}\text { Include } \\
\text { - acute care hospitalizations in general or pediatric hospitals } \\
\text { - reviews of studies conducted in the United States } \\
\text { Exclude } \\
\text { - reviews focused solely on intensive care unit stays, emergency departments, or observation } \\
\text { units } \\
\text { - } \text { specialty hospitals (e.g., psychiatric, ophthalmologic, orthopedic, cancer, rehabilitation, } \\
\text { long-term acute care) } \\
\text { reviews of studies conducted solely outside the U.S. }\end{array}$ \\
\hline
\end{tabular}




\section{Data Organization and Presentation}

\section{Information Management}

We abstracted and tabled descriptive characteristics from published SRs. Factors abstracted from published studies included PICOTS categories (population, intervention, comparator, outcomes, timing, setting). We highlighted outcome measures used in these studies and the applicability of results to various populations. KI interviews helped refine data points for abstraction and how they might be organized. A designated project team member documented KI interviews during each call.

- Patient population (age; sex; primary language; primary diagnosis and comorbidities; medical insurance or lack of coverage; housing type; other measures of social isolation and/or vulnerability as reported by systematic reviews)

- Hospital characteristics (adult/pediatric; bed size; location [urban, rural, etc.]; type of hospital [academic medical center, community hospital]; health system affiliation or standalone hospital)

- Intervention characteristics (description of intervention; resources needed; implementation factors including durability, if described)

- Comparators (description of comparison group, including models of care for controlled trials or cohort studies, or preexisting hospital care factors for pre-post studies)

- Outcomes (LOS or LOS index; sustainment of LOS changes; readmission rates; measures of hospital-related harms as reported in SRs; patient functional status and time to functional return; patient satisfaction/experience; clinician/staff experience; resource use; patient throughput)

\section{Data Presentation}

We designed a series of evidence maps that summarize the volume and quality of existing research for each intervention category and describe their effects on LOS, readmissions, mortality, and other outcomes as reported. Characteristics of published systematic reviews of randomized and nonrandomized primary studies are presented in searchable evidence tables. Where available, we included strength of evidence (SOE) ratings provided by SRs; if not provided, we used AHRQ Evidence-based Practice Center guidance by Berkman et al. $2013^{23}$ to appraise SOE (see Appendix C). We also highlighted the current state of knowledge regarding implementation of interventions and important evidence gaps that require further study and assessment using visualization approaches as appropriate. Finally, we narratively summarized significant perspectives and insights gathered from KIs. 


\section{Findings}

Our search of the published literature identified 4,364 potentially relevant studies, of which we excluded 1,227 at the title level (not relevant). We excluded 2,725 studies during abstract screening for one of the following reasons: intervention, population, or care setting was not relevant, the study design did not meet our inclusion criteria (e.g., narrative review), the abstract did not address one of the Guiding Questions (GQs), key outcomes were not reported, or studies in the systematic review were either conducted solely outside the United States or 50 percent or more of the studies reporting hospital length of stay (LOS) were conducted outside the United States. The most common reason a described intervention was considered "not relevant" was because it was not a hospital or health system-led intervention. This resulted in full-text screening of 412 articles. We excluded 392 studies at the full-text level. Reasons for exclusion at this level were similar to reasons listed for the abstract level (see Appendix B). We also received three studies through the Agency for Healthcare Research and Quality (AHRQ's) Supplemental Evidence and Data submission process. We excluded all three studies because they were not systematic reviews.

We included 19 systematic reviews in 20 publications, 1 of which was identified in our grey literature search. ${ }^{12,15,24-41}$ Figure 1 presents a PRISMA (Preferred Reporting Items for Systematic Reviews and Meta-Analyses) flow diagram of our study screening. 
Figure 1. Study attrition diagram

\begin{tabular}{|c|c|}
\hline $\begin{array}{l}\text { Articles identified through database and gray } \\
\text { literature searches } \\
\qquad(n=4,364)\end{array}$ & \\
\hline & \multirow[t]{2}{*}{$\begin{array}{l}\text { Articles excluded at title level } \\
\qquad(n=1,227)\end{array}$} \\
\hline $\begin{array}{l}\text { Abstracts assessed } \\
\qquad(n=3,137)\end{array}$ & \\
\hline & $\begin{array}{l}\quad \text { Articles excluded at abstract level }(n=2,725) \\
\text { - Intervention not relevant ( } n=1,352) \\
\text { - No intervention, e.g., risk factor study ( } n=523) \\
\text { - Narrative review or limited to uncontrolled studies } \\
\text { - }(n=284) \\
\text { - Patient population not relevant }(n=261) \\
\text { - Care setting not relevant ( } n=147) \\
\text { - Does not address Guiding Questions }(n=90) \\
\text { - Key outcomes not reported ( } n=45) \\
\text { - All included studies not conducted in U.S. }(n=15) \\
\text { - Other }(n=8)\end{array}$ \\
\hline $\begin{array}{l}\text { Full-text articles assessed } \\
\qquad(\mathrm{n}=412)\end{array}$ & \\
\hline & $\begin{array}{l}\quad \text { Articles excluded at full-text level }(n=392) \\
\text { - All or majority of included studies not conducted in } \\
\text { U.S. }(n=106) \\
\text { - Narrative review }(n=30) \\
\text { - Systematic review with no risk of bias assessment } \\
\text { ( } n=56) \\
\text { - Care setting not relevant }(n=55) \\
\text { - Key outcomes not reported }(n=36) \\
\text { - Patient population not relevant }(n=37) \\
\text { - Intervention not relevant }(n=34) \\
\text { - Duplicate, redundant, or superseded by other reviews } \\
\text { - }(n=15) \\
\text { - Full-text not available or not published in English } \\
\text { - Oth=11) }\end{array}$ \\
\hline
\end{tabular}

19 included systematic reviews in 20 publications 
Ten systematic reviews included a mix of study designs (e.g., randomized controlled trials [RCTs], observational cohort studies), ${ }^{15,24-33}$ eight included RCTs, ${ }^{12,34-40}$ and one included retrospective cohort studies. ${ }^{41}$

Our searches were limited to articles published since 2010, and Figure 2 summarizes the distribution of systematic reviews by year of publication. Comprehensive evidence tables summarizing each systematic review are in Appendix C, and summary tables of key outcomes are included below under GQ 3.

Figure 2. Publication year of included systematic reviews

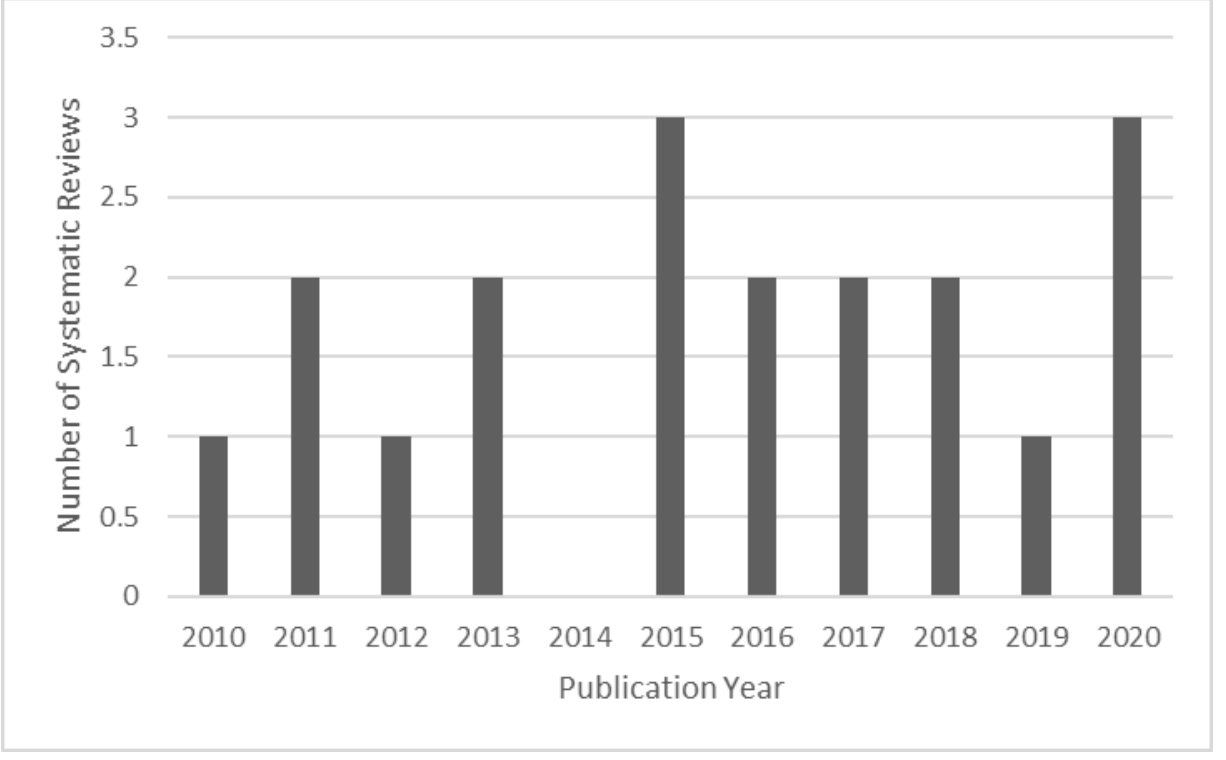

A search of ClinicalTrials.gov and a Patient-Centered Outcomes Research Institute (PCORI) database identified 11 trials of interventions to decrease LOS that are currently underway in the United States. Four trials are evaluating system-level interventions and include high-risk patient populations. These trials are listed in Appendix C.

\section{Characteristics of Interventions (GQ 1)}

\section{Type of Interventions}

The interventions reported in the systematic reviews were organizational interventions within hospitals or health systems and included:

- Discharge planning $12,15,30,35,38$

- Geriatric assessment or consultation $26,31,36,39,41$

- Medication management $t^{24,27,37}$

- Clinical pathways 29,34

- Inter- or multidisciplinary care ${ }^{32,40}$

- Case management ${ }^{28}$

- Hospitalist services ${ }^{33}$

- Telehealth ${ }^{25}$ 
Figure 3 summarizes the number of systematic reviews examining the various types of interventions included in the evidence base. Evidence tables summarizing each systematic review and describing the interventions are in Appendix C. Interventions identified in excluded reviews are summarized under GQ 4.

Figure 3. Number of systematic reviews per intervention type

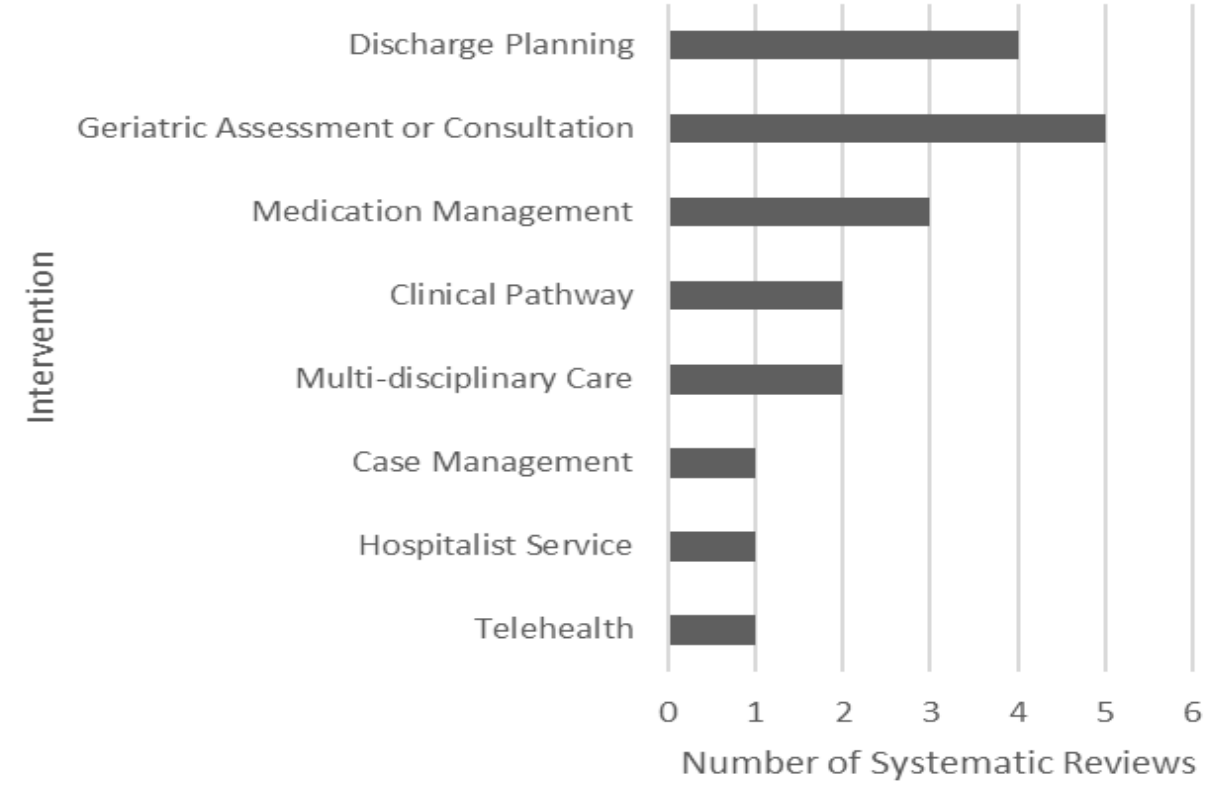

\section{Discharge Planning}

Four systematic reviews in five publications examined discharge planning. ${ }^{12,15,30,35,38}$ In general, discharge planning was delivered by a nurse (e.g., master's level prepared, specialist, advanced practice) or another healthcare professional (e.g., case manager, volunteer supported by a social worker) and included an assessment (e.g., suitability for early discharge), planning, implementation (e.g., in-hospital visits, patient education), and/or postdischarge followup. Followup care involved a phone call within 24 hours of discharge, scheduling outpatient visits, home visits, and/or on-call services.

\section{Geriatric Assessment or Consultation}

Five systematic reviews assessed geriatric assessment or consultation. ${ }^{26,31,36,39,41}$ This type of intervention often included a geriatrician or a multidisciplinary healthcare professional team (e.g., geriatrician, advanced nurse, physicians, pharmacist, social workers) consulting on patient management or participating in various stages of care (e.g., initial assessment, developing treatment plans, goal setting, postdischarge plan). Patel et al. $2020^{31}$ assessed a co-managed orthopedic-led and geriatric-led intervention that included prompt admission and surgical optimization (e.g., fast-tracking hip fracture), evaluating patients' social and dynamic needs from the first day of admission, and coordinating postoperative followup for patients with comorbidities. 


\section{Medication Management}

Two systematic reviews examined systemic support of anticoagulant prescribing compared with routine care, such as a physician-led anticoagulation service. Austin et al. $2020^{24}$ included studies assessing computerized provider order entry (CPOE), clinical decision support systems (CDSS), dashboard utilization, and electronic medical record implementation. In studies assessing CPOE interventions, providers used computer assistance to enter orders from a computer or mobile device and some specifically assessed discharge reconciliation processes, medication errors and preventable adverse events, or CPOE's appropriateness on pathology information. ${ }^{24}$ In studies examining CDSS, CDSS alerts were the most frequently assessed methods. Frazer et al. $2019^{37}$ examined pharmacist-led anticoagulation consultation services, various decision supported warfarin dosing algorithms (e.g., computer-dosing, genotype and clinical information dosing), heparin monitoring systems (e.g., point-of-care), other CDSSs (e.g., alert system requiring active response, hard-stop alert), and systematic education and feedback programs (e.g., multifaceted safety program, enhanced feedback intervention).

One systematic review by Gillaizeau et al. $2013^{27}$ evaluated CDSS compared with usual care. Included studies used real-time computer support to guide drug-dosing (e.g., theophylline, aminoglycoside).

\section{Clinical Pathways}

In the two systematic reviews examining clinical pathways, Agarwal et al. $2018^{34}$ included studies on multicomponent interventions, such as quality-improvement initiatives, including inpatient critical pathway for heart failure management, standardized admission orders, education for staff and patients, or telephone surveillance postdischarge. A description of the interventions in studies included in the systematic review by Kul et al. $2012^{29}$ was not provided. The authors reported that pathways had to meet the definition of a pathway according to the European Pathway Association ${ }^{29}$

\section{Inter- or Multidisciplinary Care}

Pannick et al. $2015^{32}$ and Zhang et al. $2013^{40}$ examined inter- or multidisciplinary interventions to decrease LOS compared with usual care. The interventions assessed in the systematic review by Pannick et al. included an altered team composition that required additional specialists (e.g., psychiatry, stroke) or professionals to provide advice or embedding specialists in rounding teams. The authors also assessed an interdisciplinary intervention addressing team practice, such as the logistics of working together (e.g., location of team members, communication program). In Zhang et al. $2013,{ }^{40}$ the intervention included consultation service and implementation of targeted recommendations, staff education, and/or individual care planning.

\section{Case Management}

The systematic review by Huntley et al. $2016^{28}$ assessed case management compared with usual care. The intervention was directed by nurse case managers and included various strategies, such as medication review, family conferencing, education, home environment assessment, or referral to other services. 


\section{Hospitalist Services}

White et al. $2011^{33}$ assessed hospitalist physician structures that have significantly redesigned delivery of inpatient care over the past 25 years. Comparators included staffing by communitybased physicians and traditional academic attending physicians. The hospitalist staffing intervention was evaluated based on assessments of physician performance on quality of care provided.

\section{Telehealth}

Baratloo et al. $2018^{25}$ examined telestroke systems that support hospital-based care of patients with stroke by linking healthcare providers at the point of care to clinical expertise outside of a hospital setting. This might be accomplished by telephone, videoconferencing, or teleradiology. These interventions differ from the increasingly widespread telehealth initiatives that support outpatient care.

\section{Setting}

Systematic reviews reported limited information regarding the setting of included studies. Thirteen reviews all described interventions conducted in multiple types of hospitals, including academic medical centers, community hospitals, and less frequently, Veterans Affairs hospitals. One systematic review focused on trauma centers, and six reviews did not report hospital type. Only five reviews reported whether all included studies were conducted in urban, suburban, or rural settings: three included urban and rural hospitals, one was limited to urban settings, and one included only rural hospitals. Few reviews reported hospital bed size or affiliation with a health system. Of the five systematic reviews that indicated a health system affiliation of included studies, only Bryant-Lukosius et al. $2015^{35}$ specified the states in which the health systems operated, which included Pennsylvania and Vermont.

\section{Population}

This report's population of interest included medically complex, high-risk, and vulnerable hospitalized children and adults. Only two systematic reviews included pediatric populations, while most included studies with patients at least 60 years of age or older. We organized patient populations into five categories for analysis: older patients (e.g., $>60$ years), patients with multimorbidity, patients with heart failure, vulnerable patients (e.g., low socioeconomic status), and patients with other conditions (e.g., stroke).

Nine systematic reviews in 10 publications included older patients, ${ }^{15,26,30,31,35,36,38-41}$ and four of these focused on frail elderly patients. Five reviews included patients with at least one chronic illness (e.g., diabetes, chronic obstructive pulmonary disease, renal disease, congestive heart failure, psychiatric illness), ${ }^{12,27,32,33,37}$ while four other reviews included studies focused exclusively on patients with congestive heart failure. ${ }^{28,29,34,35}$ One systematic review included studies with a vulnerable population of high-risk pregnant women. ${ }^{35}$ Other populations addressed by the reviews included low-birthweight infants, ${ }^{35}$ patients with acute ischemic stroke, ${ }^{25}$ and patients prescribed anticoagulants. ${ }^{24}$ Figure 4 summarizes the number of systematic reviews examining each patient population category; note that the total number exceeds 19 because 1 review included populations from multiple categories. ${ }^{35}$ Evidence tables describing the populations in each systematic review are in Appendix C. 
Figure 4. Number of systematic reviews examining each patient population category

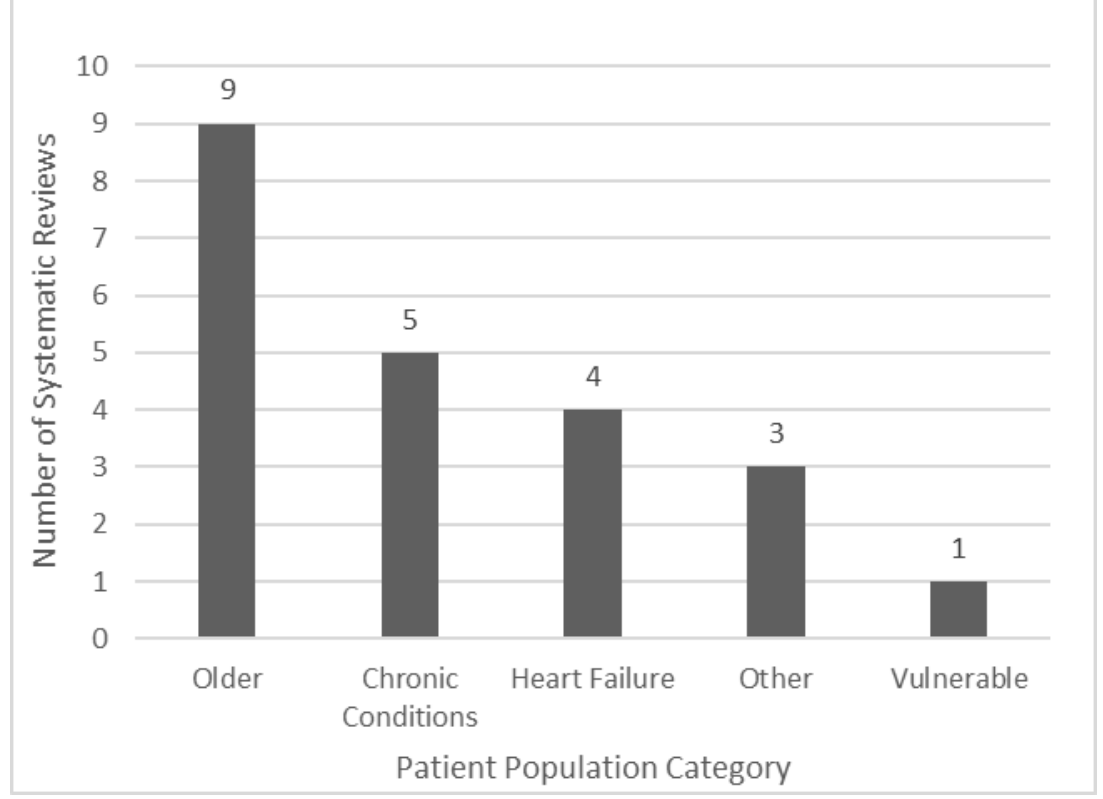

Very few reviews addressed nonclinical factors that might be associated with prolonged LOS. Only two systematic reviews provided details about the medical insurance status of included patients. ${ }^{12,35}$ Coverage included Medicare, Medicaid, or public health insurance. However, this information was not reported for all included studies in these reviews. BryantLukosius et al. $2015^{35}$ indicated that most patients in the studies they reviewed had an annual income level of less than $\$ 20,000$, while no other reviews reported patients' socioeconomic status. Gonçalves-Bradley et al. $2016^{38}$ and Huntley et al. $2016^{28}$ included studies with patients whose first language was not English. No reviews addressed populations struggling with homelessness or housing instability, isolation, poverty, or other social determinants of health.

\section{Implementation of Interventions (GQ 2)}

Of the 19 systematic reviews identified in our literature search, four reviews examining geriatric assessment or discharge planning provided some level of detail about the implementation process (e.g., location, personnel involved). In the review by Ellis et al. 2017, ${ }^{36}$ studies implemented comprehensive geriatric assessment in a dedicated geriatric ward or through the use of a mobile team on a general ward. Van Craen et al. $2010^{39}$ reported that studies admitted patients directly to the geriatric evaluation unit from home, the emergency department, or other hospitals. In addition, patient management teams met at various time points (e.g., daily, weekly). Gonçalves-Bradley et al. $2016^{38}$ indicated that discharge planning interventions were implemented from admission to three days before discharge, and Zhu et al. $2015^{12}$ reported that, at times, hospital staff, family members, caregivers, or volunteers supported by social workers provided support to nurse-led discharge planning. The resources used to support implementation were often not reported. However, several systematic reviews reported the position of the individual(s) either implementing or participating in the intervention's delivery (e.g., physician, nurse, multidisciplinary team). 


\section{Effectiveness of Interventions (GQ 3)}

\section{Outcomes}

All included systematic reviews met our requirement to report LOS. Most reviews also reported readmissions, although the definition varied across reviews (e.g., 30-day readmissions, unscheduled readmissions) $)^{12,15,24,26,28-39}$ and patient harms, specifically mortality. ${ }^{12,24-26,29,31-39,41}$ Similarly, reviews defined mortality measurements inconsistently (e.g., early mortality, mortality at discharge). Ten systematic reviews reported resource use, , $^{12,26-29,33,35-38}$ six reported patient/family experience,,${ }^{12,15,30,33-35,38}$ three reported patient functional return, ${ }^{26,34,39}$ and two reported clinician/staff satisfaction. ${ }^{24,38}$

Not all the systematic reviews quantitatively synthesized their results; instead, some presented either a narrative synthesis or data from individual studies. Table 3 summarizes reported outcomes for included systematic reviews according to type of synthesis performed. Interventions are organized alphabetically, and letters indicate the type of synthesis performed for each reported outcome, as follows:

- Q indicates a quantitative synthesis.

- QN indicates the authors conducted a quantitative synthesis and either narratively synthesized some findings or reported individual study data.

- N indicates only a narrative synthesis or reporting of individual study data.

- NR indicates the authors did not report this outcome. 
Table 3. Outcomes reported in the systematic reviews

\begin{tabular}{|c|c|c|c|c|c|c|c|c|c|}
\hline Type of Intervention & $\begin{array}{l}\text { Author } \\
\text { Year }\end{array}$ & $\begin{array}{l}\text { Population } \\
\text { Category }\end{array}$ & LOS & \begin{tabular}{|l|} 
Patient \\
Functional \\
Return \\
\end{tabular} & Readmissions & $\begin{array}{l}\text { Patient } \\
\text { Harms }\end{array}$ & \begin{tabular}{|l|} 
Patient/ \\
Family \\
Experience \\
\end{tabular} & \begin{tabular}{|l} 
Clinician/ \\
Staff \\
Satisfaction \\
\end{tabular} & $\begin{array}{l}\text { Resource } \\
\text { Use }\end{array}$ \\
\hline Discharge planning & $\begin{array}{l}\text { Mabire et al } 2017^{30} \\
\text { Mabire et al. } 2016^{15}\end{array}$ & Older & $\mathbf{Q}$ & NR & $\mathbf{Q}$ & NR & NR & NR & NR \\
\hline Discharge planning & $\begin{array}{l}\text { Gonçalves-Bradley } \\
\text { et al. } 2016^{38} \\
\end{array}$ & Older & $\mathbf{Q}$ & NR & $\mathbf{Q}$ & NR & $\mathbf{N}$ & $\mathbf{N}$ & $\mathbf{N}$ \\
\hline Discharge planning & $\begin{array}{l}\text { Bryant-Lukosius } \\
\text { et al. } 2015^{35}\end{array}$ & $\begin{array}{l}\text { Older, heart failure, } \\
\text { vulnerable (high-risk } \\
\text { pregnant women), } \\
\text { other (infants) }\end{array}$ & QN & NR & QN & $\mathbf{Q}$ & $\mathbf{Q}$ & NR & $\mathbf{N}$ \\
\hline Discharge planning & Zhu et al. $2015^{12}$ & Chronic conditions & $\mathbf{Q}$ & NR & $\mathbf{Q}$ & $\mathbf{Q}$ & $\mathbf{N}$ & NR & $\mathbf{N}$ \\
\hline $\begin{array}{l}\text { Geriatric assessment or } \\
\text { consultation }\end{array}$ & Bakker et al. $2011^{26}$ & Older & $\mathbf{N}$ & $\mathbf{N}$ & $\mathbf{N}$ & $\mathbf{N}$ & NR & NR & $\mathbf{N}$ \\
\hline $\begin{array}{l}\text { Geriatric assessment or } \\
\text { consultation }\end{array}$ & Eagles et al. $2020^{41}$ & Older & $\mathbf{Q}$ & NR & NR & QN & NR & NR & NR \\
\hline $\begin{array}{l}\text { Geriatric assessment or } \\
\text { consultation }\end{array}$ & Ellis et al. $2017^{36}$ & Older & $\mathbf{N}$ & NR & NR & $\mathbf{Q}$ & NR & NR & NR \\
\hline $\begin{array}{l}\text { Geriatric assessment or } \\
\text { consultation }\end{array}$ & Patel et al. $2020^{31}$ & Older & $\mathbf{N}$ & NR & $\mathbf{N}$ & $\mathbf{N}$ & NR & NR & NR \\
\hline $\begin{array}{l}\text { Geriatric assessment or } \\
\text { consultation }\end{array}$ & $\begin{array}{l}\text { Van Craen et al. } \\
2010^{39}\end{array}$ & Older & $\mathbf{Q}$ & $\mathbf{Q}$ & $\mathbf{Q}$ & $\mathbf{Q}$ & NR & NR & NR \\
\hline $\begin{array}{l}\text { Medication } \\
\text { management }\end{array}$ & Austin et al. $2020^{24}$ & $\begin{array}{l}\text { Other (prescribed } \\
\text { anticoagulants) }\end{array}$ & $\mathbf{N}$ & NR & $\mathbf{N}$ & $\mathbf{N}$ & NR & $\mathbf{N}$ & NR \\
\hline $\begin{array}{l}\text { Medication } \\
\text { management }\end{array}$ & Frazer et al. $2019^{37}$ & Chronic conditions & $\mathbf{N}$ & NR & $\mathbf{N}$ & $\mathbf{N}$ & NR & NR & $\mathbf{N}$ \\
\hline $\begin{array}{l}\text { Medication } \\
\text { management }\end{array}$ & $\begin{array}{l}\text { Gillaizeau et al. } \\
2013^{27}\end{array}$ & Chronic conditions & $\mathbf{Q}$ & NR & NR & NR & NR & NR & $\mathbf{N}$ \\
\hline Clinical pathways & \begin{tabular}{|l} 
Agarwal et al. \\
$2018^{34}$
\end{tabular} & Heart failure & $\mathbf{N}$ & $\mathbf{N}$ & $\mathbf{N}$ & $\mathbf{N}$ & $\mathbf{N}$ & NR & NR \\
\hline Clinical pathways & Kul et al. $2012^{29}$ & Heart failure & $\mathbf{Q}$ & NR & $\mathbf{Q}$ & $\mathbf{Q}$ & NR & NR & $\mathbf{N}$ \\
\hline $\begin{array}{l}\text { Inter- or multi- } \\
\text { disciplinary care }\end{array}$ & $\begin{array}{l}\text { Pannick et al. } \\
2015^{32}\end{array}$ & Chronic conditions & $\mathbf{Q}$ & NR & $\mathbf{Q}$ & $\mathbf{Q}$ & NR & NR & NR \\
\hline
\end{tabular}




\begin{tabular}{|c|c|c|c|c|c|c|c|c|c|}
\hline Type of Intervention & $\begin{array}{l}\text { Author } \\
\text { Year }\end{array}$ & $\begin{array}{l}\text { Population } \\
\text { Category }\end{array}$ & LOS & \begin{tabular}{|l|} 
Patient \\
Functional \\
Return \\
\end{tabular} & Readmissions & $\begin{array}{l}\text { Patient } \\
\text { Harms }\end{array}$ & \begin{tabular}{|l|} 
Patient/ \\
Family \\
Experience
\end{tabular} & $\begin{array}{l}\text { Clinician/ } \\
\text { Staff } \\
\text { Satisfaction }\end{array}$ & $\begin{array}{l}\text { Resource } \\
\text { Use }\end{array}$ \\
\hline $\begin{array}{l}\text { Inter- or multi- } \\
\text { disciplinary care }\end{array}$ & Zhang et al. $2013^{40}$ & Older & $\mathbf{N}$ & NR & NR & NR & NR & NR & NR \\
\hline Case management & Huntley et al. $2016^{28}$ & Heart failure & $\mathbf{Q}$ & NR & $\mathbf{Q}$ & NR & NR & NR & $\mathbf{N}$ \\
\hline Hospitalist service & White et al. $2011^{33}$ & Chronic conditions & $\mathbf{N}$ & NR & $\mathbf{N}$ & $\mathbf{N}$ & $\mathbf{N}$ & NR & $\mathbf{N}$ \\
\hline Telehealth & $\begin{array}{l}\text { Baratloo et al. } \\
2018^{25}\end{array}$ & Other (stroke) & $\mathbf{Q}$ & NR & NR & $\mathbf{Q}$ & NR & NR & NR \\
\hline
\end{tabular}

LOS = length of stay; $\mathrm{Q}=$ quantitative synthesis; $\mathrm{QN}$ = quantitative synthesis and narrative synthesis or results from and individual trial for other outcomes; $\mathrm{N}$ = narrative synthesis or results from an individual trial; $\mathrm{NR}=$ not reported. 
Below, we present effectiveness from SRs providing quantitative synthesis of outcomes of interest (e.g., LOS, readmissions), organized by intervention type. Figure 5 displays a distribution of the number and type of study designs included in the systematic reviews conducting meta-analyses for LOS. The distribution is organized by intervention type.

The main quantitative findings for LOS, readmissions, mortality, and other outcomes are displayed in Figure 6. This evidence map provides an overview of direction of effect, strength of evidence (SOE) for key outcomes, and patient population addressed for each intervention. In the left panel, direction of effect on the outcome of interest is represented by an arrow pointing up (an increase), down (a decrease), or a horizontal arrow (inconclusive). The SOE is represented by letters $\mathrm{H}, \mathrm{M}$, and L, specifically: High SOE (H); Moderate SOE (M); Low/Very Low SOE (L). The right panel denotes each SR's patient population.

Further details from findings presented in the evidence map can be found in the Summary of Findings tables (Tables 4 through 7). Subgroup analyses not captured in the evidence map are also listed in the tables. We include tables for LOS (Table 4), readmissions (Table 5), patient harms (Table 6), and other outcomes (Table 7).

Figure 5. Number of randomized controlled trials (RCTs) and non-RCTs in systematic reviews with a quantitative synthesis for length of stay

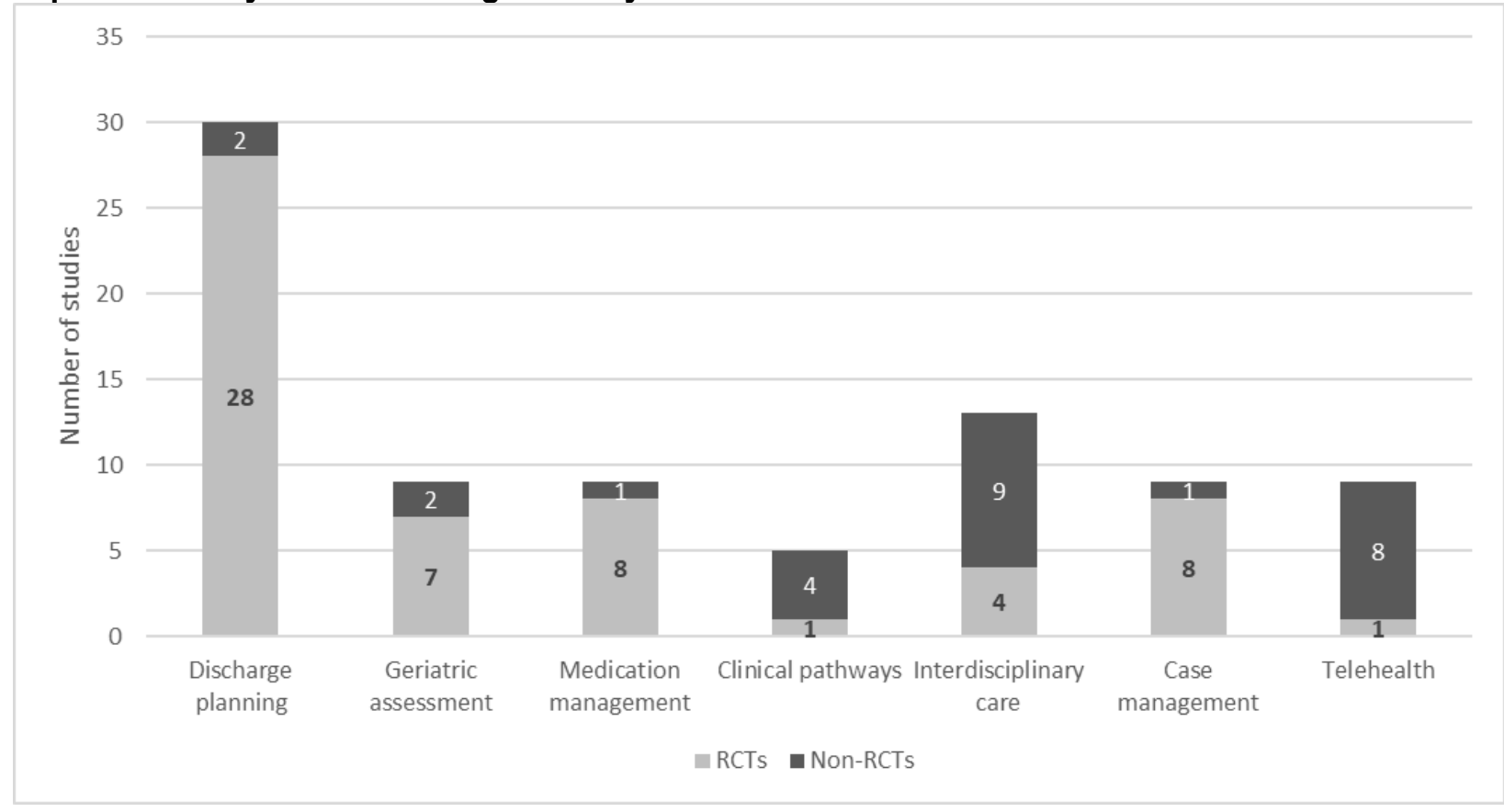


Figure 6. Evidence map for length of stay, readmissions, mortality, and other adverse events Interventions

\begin{tabular}{|c|c|c|c|c|c|c|c|c|c|c|c|c|c|}
\hline \multirow{11}{*}{$\begin{array}{l}\text { Discharge } \\
\text { Planning }\end{array}$} & \multirow[b]{2}{*}{ Mabire 2017, 2016} & $\begin{array}{l}\text { Length } \\
\text { of Stay }\end{array}$ & Readmissions & Mortality & $\begin{array}{l}\text { Other } \\
\text { AEs }\end{array}$ & Older & $\begin{array}{c}\text { Older } \\
\text { (Surgical } \\
\text { Patients) }\end{array}$ & $\begin{array}{l}\text { Younger } \\
(<65 \\
\text { Years })\end{array}$ & $\begin{array}{l}\text { Heart } \\
\text { Failure }\end{array}$ & $\begin{array}{c}\text { High- } \\
\text { Risk } \\
\text { Pregnant } \\
\text { Women } \\
\end{array}$ & \multirow[t]{2}{*}{ Infants } & \multirow[t]{2}{*}{$\begin{array}{l}\text { Chronic } \\
\text { Conditions }\end{array}$} & Other \\
\hline & & $\mathbf{L}$ & $\downarrow^{\mathbf{M}}$ & & & $\sqrt{ }$ & & & & & & & \\
\hline & $\begin{array}{r}\text { Mabire 2017, } 2016 \\
\text { (transitional care) }\end{array}$ & & $\leftrightarrow^{\mathbf{L}}$ & & & $\sqrt{ }$ & & & & & & & \\
\hline & $\begin{array}{r}\text { Goncalves-Bradley } \\
2016\end{array}$ & $\downarrow^{\mathbf{M}}$ & $\downarrow^{\mathbf{M}}$ & & & $\sqrt{ }$ & & & & & & & \\
\hline & $\begin{array}{r}\text { Goncalves-Bradley } \\
2016\end{array}$ & $\leftrightarrow^{\mathrm{L}}$ & & & & & $\sqrt{ }$ & & & & & & \\
\hline & $\begin{array}{r}\text { Bryant-Lukosius } \\
2015\end{array}$ & $\leftrightarrow^{\mathbf{L}}$ & & $\leftrightarrow^{\mathbf{L}}$ & & $\sqrt{ }$ & & & & & & & \\
\hline & $\begin{array}{r}\text { Bryant-Lukosius } \\
2015\end{array}$ & $\downarrow^{\mathbf{M}}$ & & & & & & & & $\sqrt{ }$ & & & \\
\hline & $\begin{array}{r}\text { Bryant-Lukosius } \\
2015\end{array}$ & & $\leftrightarrow^{\mathrm{L}}$ & $\leftrightarrow^{\mathbf{L}}$ & & & & & $\sqrt{ }$ & & & & \\
\hline & $\begin{array}{r}\text { Bryant-Lukosius } \\
2015\end{array}$ & & $\leftrightarrow^{\mathbf{L}}$ & & & & & & & & $\sqrt{ }$ & & $\sqrt{ }$ \\
\hline & Zhu 2015 & $\leftrightarrow{ }^{\mathbf{M}}$ & M & $\downarrow^{\mathbf{H}}$ & & & & & & & & $\sqrt{ }$ & \\
\hline & Zhu 2015 & & M & & & & & $\sqrt{ }$ & & & & & \\
\hline & Eagles 2020 & $\downarrow^{\mathbf{M}}$ & & $\downarrow^{\mathbf{M}}$ & & $\sqrt{ }$ & & & & & & & \\
\hline $\begin{array}{l}\text { Geriatric } \\
\text { Assessment }\end{array}$ & Ellis 2017 & & & $\leftrightarrow^{\mathrm{H}}$ & & $\sqrt{ }$ & & & & & & & \\
\hline & Van Craen 2010 & $\leftrightarrow^{\mathrm{H}}$ & $\leftrightarrow^{\mathbf{M}}$ & $\leftrightarrow^{\mathrm{H}}$ & & $\sqrt{ }$ & & & & & & & \\
\hline $\begin{array}{l}\text { Medication } \\
\text { Management }\end{array}$ & Gillaizeau 2013 & $\leftrightarrow^{\mathrm{L}}$ & & & & & & & & & & $\sqrt{ }$ & \\
\hline $\begin{array}{l}\text { Clinical } \\
\text { Pathways }\end{array}$ & Kul 2012 & $\downarrow^{L}$ & $\downarrow^{\mathbf{M}}$ & $\downarrow^{\mathbf{M}}$ & & & & & $\sqrt{ }$ & & & & \\
\hline Interdisciplinary & $\begin{array}{r}\text { Pannick } 2015 \\
\text { (altering team } \\
\text { composition) }\end{array}$ & $\leftrightarrow^{\mathbf{M}}$ & $\uparrow \mathbf{L}$ & $\leftrightarrow^{\mathbf{M}}$ & & & & & & & & $\sqrt{ }$ & \\
\hline Care & $\begin{array}{r}\text { Pannick } 2015 \\
\text { (altering team } \\
\text { practice) }\end{array}$ & $\leftrightarrow^{\mathbf{M}}$ & $\leftrightarrow^{\mathbf{L}}$ & $\downarrow^{\mathbf{M}}$ & & & & & & & & & NR \\
\hline $\begin{array}{l}\text { Case } \\
\text { Management }\end{array}$ & Huntley 2016 & $\downarrow^{\mathbf{M}}$ & $\downarrow^{\mathbf{M}}$ & & & & & & $\sqrt{ }$ & & & & \\
\hline Telehealth & Baratloo 2018 & $\downarrow^{\mathbf{M}}$ & & $\leftrightarrow^{\mathbf{M}}$ & $\leftrightarrow^{\mathbf{M}}$ & & & & & & & & $\sqrt{ }$ \\
\hline & & & & & & & & & & \multirow{4}{*}{\multicolumn{4}{|c|}{$\mathrm{AE}=$ adverse events; $\mathrm{NR}=$ not reported }} \\
\hline & & \multirow{3}{*}{\multicolumn{2}{|c|}{$\begin{array}{r}\text { Direction of } \\
\text { Effect: (arrow } \\
\text { direction) }\end{array}$}} & rease & & \multirow{3}{*}{\multicolumn{2}{|c|}{$\begin{array}{r}\text { Strength of } \\
\text { Evidence: } \\
\text { (superscript } \\
\text { letter) }\end{array}$}} & \multirow{3}{*}{\multicolumn{2}{|c|}{$\begin{array}{l}\text { H High } \\
\text { M Moderate } \\
\text { L Low/Very low }\end{array}$}} & & & & \\
\hline & & & & crease & & & & & & & & & \\
\hline & & & & conclusive & & & & & & & & & \\
\hline
\end{tabular}


Table 4. Summary of findings for length of stay meta-analyses

\begin{tabular}{|c|c|c|c|c|c|c|}
\hline $\begin{array}{l}\text { Type of } \\
\text { Intervention }\end{array}$ & $\begin{array}{l}\text { Author } \\
\text { Year }\end{array}$ & Comparison & Population & $\begin{array}{l}\text { Study Design: No. } \\
\text { Studies (N) }\end{array}$ & $\begin{array}{l}\text { Findings and Direction of } \\
\text { Effect }\end{array}$ & $\begin{array}{l}\text { Strength } \\
\text { of } \\
\text { Evidence }\end{array}$ \\
\hline $\begin{array}{l}\text { Discharge } \\
\text { planning }\end{array}$ & $\begin{array}{l}\text { Mabire et al. } \\
2017^{15,30}\end{array}$ & $\begin{array}{l}\text { Nursing discharge } \\
\text { planning } \\
\text { interventions vs. } \\
\text { usual care }\end{array}$ & $\begin{array}{l}\text { Older patients with or } \\
\text { without comorbidities }\end{array}$ & $\begin{array}{l}4 \text { RCTs, } 1 \text { pre-post, } \\
\text { and } 1 \text { cohort }(3 \text { of } \\
6 \text { US) ( } n=2,370)\end{array}$ & $\begin{array}{l}\text { WMD: } 0.29 \text { days, } 95 \% \mathrm{Cl} \text { : } \\
0.24 \text { to } 0.35, \mathrm{I}^{2}=0 \% \text {, } \\
\text { intervention increases LOS }\end{array}$ & Low \\
\hline $\begin{array}{l}\text { Discharge } \\
\text { planning }\end{array}$ & $\begin{array}{l}\text { Goncalves- } \\
\text { Bradley et al. } \\
2016^{38}\end{array}$ & $\begin{array}{l}\text { Discharge } \\
\text { planning vs. usual } \\
\text { care }\end{array}$ & $\begin{array}{l}\text { Older patients with a } \\
\text { medical condition }\end{array}$ & $\begin{array}{l}12 \text { RCTs }(6 \text { of } 12 \text { US) } \\
(n=2,193)\end{array}$ & $\begin{array}{l}\text { MD: }-0.73 \text { days, } 95 \% \mathrm{Cl} \text { : } \\
-1.33 \text { to }-0.12, \mathrm{I}^{2}=9.44 \% \\
\text { favors intervention }\end{array}$ & Moderate \\
\hline $\begin{array}{l}\text { Discharge } \\
\text { planning }\end{array}$ & $\begin{array}{l}\text { Goncalves- } \\
\text { Bradley et al. } \\
2016^{38}\end{array}$ & $\begin{array}{l}\text { Discharge } \\
\text { planning vs. usual } \\
\text { care }\end{array}$ & Older surgical patients & $\begin{array}{l}2 \text { RCTs ( } 1 \text { of } 2 \text { US) } \\
(n=184)\end{array}$ & $\begin{array}{l}\text { MD: }-0.06,95 \% \mathrm{Cl}:-1.23 \text { to } \\
1.11, \mathrm{I}^{2}=0 \%, \text { no difference }\end{array}$ & Very Low \\
\hline $\begin{array}{l}\text { Discharge } \\
\text { planning }\end{array}$ & $\begin{array}{l}\text { Bryant- } \\
\text { Lukosius } \\
\text { et al. } 2015^{35}\end{array}$ & $\begin{array}{l}\text { Clinical nurse } \\
\text { specialists } \\
\text { transitional care } \\
\text { vs. usual care }\end{array}$ & Elderly hospitalized patients & 3 US RCTs $(n=396)$ & $\begin{array}{l}\text { MD: }-0.69 \text { days, } 95 \% \mathrm{Cl} \text { : } \\
-1.95 \text { to } 0.56, p=0.28, \text { no } \\
\text { difference }\end{array}$ & Low \\
\hline $\begin{array}{l}\text { Discharge } \\
\text { planning }\end{array}$ & $\begin{array}{l}\text { Bryant- } \\
\text { Lukosius } \\
\text { et al. } 2015^{35}\end{array}$ & $\begin{array}{l}\text { Clinical nurse } \\
\text { specialists } \\
\text { transitional care } \\
\text { vs. usual care } \\
\end{array}$ & High-risk pregnant women & 2 US RCTs $(n=215)$ & $\begin{array}{l}\text { MD: }-1.19 \text { days, } 95 \% \mathrm{Cl}: \\
-1.55 \text { to }-0.83, p<0.00001, \\
\text { favors intervention (reduces } \\
\text { maternal postpartum LOS) }\end{array}$ & Moderate \\
\hline $\begin{array}{l}\text { Discharge } \\
\text { planning }\end{array}$ & $\begin{array}{l}\text { Zhu et al. } \\
2015^{12}\end{array}$ & $\begin{array}{l}\text { Nurse-led early } \\
\text { discharge planning } \\
\text { vs. usual care }\end{array}$ & $\begin{array}{l}\text { Mix includes older patients, } \\
\text { decompensated heart } \\
\text { failure, hip fracture, rehab, } \\
\text { congestive heart disease, } \\
\text { hospitalized psychiatric } \\
\text { patients }\end{array}$ & $\begin{array}{l}5 \text { RCTs (4 of } 5 \text { US) } \\
(n=1,912)\end{array}$ & $\begin{array}{l}\text { SMD: } 0.03,95 \% \mathrm{Cl}:-0.06 \text { to } \\
0.12, p=0.540, \mathrm{I}^{2}=0 \%, \text { no } \\
\text { difference in LOS }\end{array}$ & Moderate \\
\hline $\begin{array}{l}\text { Geriatric } \\
\text { assessment }\end{array}$ & $\begin{array}{l}\text { Eagles et al. } \\
2020^{41}\end{array}$ & $\begin{array}{l}\text { Geriatric trauma } \\
\text { consultation vs. } \\
\text { usual trauma care }\end{array}$ & $\begin{array}{l}\text { Older adults admitted to } \\
\text { trauma center }\end{array}$ & $\begin{array}{l}2 \text { US retrospective } \\
\text { cohort studies } \\
(n=5,414)\end{array}$ & $\begin{array}{l}\text { MD: }-1.11 \text { days, } 95 \% \mathrm{Cl}: \\
-1.43 \text { to }-0.79, \mathrm{I}^{2}=0 \% \text {, favors } \\
\text { intervention }\end{array}$ & Moderate \\
\hline $\begin{array}{l}\text { Geriatric } \\
\text { assessment }\end{array}$ & $\begin{array}{l}\text { Van Craen } \\
\text { et al. } 2010^{39}\end{array}$ & $\begin{array}{l}\text { Geriatric } \\
\text { evaluation unit vs. } \\
\text { usual care }\end{array}$ & Frail elderly & 7 RCTs $(n=4,759)$ & $\begin{array}{l}\text { Mean reduction measured by } \\
\text { Hedges g } 0.07 \text { days, } 95 \% \mathrm{Cl} \text { : } \\
-0.11 \text { to } 0.26 \text {, no difference }\end{array}$ & High* $^{*}$ \\
\hline $\begin{array}{l}\text { Medication } \\
\text { management }\end{array}$ & $\begin{array}{l}\text { Gillaizeau } \\
\text { et al. } 2013^{27}\end{array}$ & $\begin{array}{l}\text { Computerized } \\
\text { decision support } \\
\text { vs. usual care }\end{array}$ & $\begin{array}{l}\text { Mix includes diabetes, } \\
\text { COPD, renal disease, etc. }\end{array}$ & $\begin{array}{l}8 \text { RCTs and } \\
1 \text { observational study } \\
(n=18,507)\end{array}$ & $\begin{array}{l}\text { SMD: }-0.15,95 \% \mathrm{Cl}:-0.33 \text { to } \\
0.02, \mathrm{I}^{2}=57 \% \text {, no difference in } \\
\text { reduction of LOS, but leans } \\
\text { toward favoring intervention }\end{array}$ & Very Low \\
\hline
\end{tabular}




\begin{tabular}{|c|c|c|c|c|c|c|}
\hline $\begin{array}{l}\text { Type of } \\
\text { Intervention }\end{array}$ & $\begin{array}{l}\text { Author } \\
\text { Year }\end{array}$ & Comparison & Population & $\begin{array}{l}\text { Study Design: No. } \\
\text { Studies (N) }\end{array}$ & $\begin{array}{l}\text { Findings and Direction of } \\
\text { Effect }\end{array}$ & $\begin{array}{l}\text { Strength } \\
\text { of } \\
\text { Evidence }\end{array}$ \\
\hline $\begin{array}{l}\text { Clinical } \\
\text { pathways }\end{array}$ & $\begin{array}{l}\text { Kul et al. } \\
2012^{29}\end{array}$ & $\begin{array}{l}\text { Clinical pathways } \\
\text { vs. usual care }\end{array}$ & Congestive heart failure & $\begin{array}{l}1 \text { RCT and } \\
4 \text { observational } \\
\text { studies }(n=2,095)\end{array}$ & $\begin{array}{l}\text { Mean reduction: } 1.89 \text { days, } \\
95 \% \mathrm{Cl}: 1.33 \text { to } 2.44, \mathrm{I}^{2}=42 \% \text {, } \\
\text { favors intervention }\end{array}$ & Low $^{*}$ \\
\hline $\begin{array}{l}\text { Interdisciplinary } \\
\text { care }\end{array}$ & $\begin{array}{l}\text { Pannick et al. } \\
2015^{32}\end{array}$ & $\begin{array}{l}\text { Altering } \\
\text { interdisciplinary } \\
\text { team composition } \\
\text { vs. usual care }\end{array}$ & $\begin{array}{l}\text { Mixed patient population - } \\
\text { geriatric, liver transplant, } \\
\text { psychiatric, delirium, } \\
\text { infectious diseases }\end{array}$ & $\begin{array}{l}2 \text { RCTs, } 2 \text { non-RCT } \\
\text { cluster studies, } \\
2 \text { before/after studies } \\
(4 \text { of } 6 \text { US) (n=NR) }\end{array}$ & $\begin{array}{l}\text { WMD: } 0.087 \text { days, } 95 \% \mathrm{Cl} \text { : } \\
-0.083 \text { to } 0.257 \text {, no } \\
\text { difference }\end{array}$ & Low $^{*}$ \\
\hline $\begin{array}{l}\text { Interdisciplinary } \\
\text { care }\end{array}$ & $\begin{array}{l}\text { Pannick et al. } \\
2015^{32}\end{array}$ & $\begin{array}{l}\text { Altering } \\
\text { interdisciplinary } \\
\text { team practice vs. } \\
\text { usual care }\end{array}$ & $\begin{array}{l}\text { Most studies did not specify } \\
\text { patient population, } 1 \text { study } \\
\text { include geriatric patients } \\
\text { and } 1 \text { study's setting VA } \\
\text { hospital }\end{array}$ & $\begin{array}{l}2 \text { cluster RCTs, } \\
3 \text { non RCT cluster } \\
\text { studies, } 2 \text { interrupted } \\
\text { time series ( } 6 \text { of } \\
7 \text { US) (n=NR) }\end{array}$ & $\begin{array}{l}\text { WMD: } 0.001 \text { days, } 95 \% \mathrm{Cl} \text { : } \\
-0.035 \text { to } 0.037 \text {, no } \\
\text { difference }\end{array}$ & $\operatorname{Low}^{*}$ \\
\hline $\begin{array}{l}\text { Case } \\
\text { management }\end{array}$ & $\begin{array}{l}\text { Huntley et al. } \\
2016^{28}\end{array}$ & $\begin{array}{l}\text { Case management } \\
\text { vs. usual care }\end{array}$ & Congestive heart failure & $\begin{array}{l}8 \text { RCTs and } \\
1 \text { observational study } \\
(n=1,765)\end{array}$ & $\begin{array}{l}\text { Mean reduction: } 1.28 \text { days, } \\
95 \% \mathrm{Cl}: 0.52 \text { to } 2.04, \mathrm{I}^{2}=63 \% \text {, } \\
\text { favors intervention } \\
\text { Subgroup analysis, excluding } \\
\text { studies at high risk of bias: } \\
\text { Mean reduction: } 1.76 \text { days, } \\
95 \% \mathrm{Cl}: 1.23 \text { to } 2.29, \mathrm{I}^{2}=14 \% \text {, } \\
\text { favors intervention }\end{array}$ & Moderate* \\
\hline Telehealth & $\begin{array}{l}\text { Baratloo et al. } \\
2018^{25}\end{array}$ & $\begin{array}{l}\text { Telestroke-based } \\
\text { systems vs. } \\
\text { bedside (face-to- } \\
\text { face) }\end{array}$ & $\begin{array}{l}\text { Tissue plasminogen } \\
\text { activator treated patients } \\
\text { with acute ischemic stroke }\end{array}$ & $\begin{array}{l}6 \text { retrospective } \\
\text { controlled studies, } \\
2 \text { prospective } \\
\text { controlled studies, } \\
1 \mathrm{RCT}(6 \text { of } 9 \text { US) } \\
(\mathrm{n}=2,850)\end{array}$ & $\begin{array}{l}\text { MD: }-0.55 \text { days, } 95 \% \mathrm{Cl} \\
-1.02 \text { to }-0.07, p=0.02 \\
\mathrm{I}^{2}=38 \%, \text { favors intervention }\end{array}$ & $\operatorname{Low}^{*}$ \\
\hline
\end{tabular}

controlled trial; $\mathrm{RR}=$ risk ratio; $\mathrm{US}=$ United States; $\mathrm{VA}=$ Veteran Affairs; $\mathrm{WMD}=$ weighted mean difference

${ }^{*}$ Authors of systematic reviews did not assess the strength of evidence for this outcome. Strength of evidence rating is based on guidance from Berkman et al. $2013 .{ }^{23}$ 
Table 5. Summary of findings for readmissions meta-analyses

\begin{tabular}{|c|c|c|c|c|c|c|}
\hline $\begin{array}{l}\text { Type of } \\
\text { Intervention }\end{array}$ & $\begin{array}{l}\text { Author } \\
\text { Year }\end{array}$ & Comparison & Population & $\begin{array}{l}\text { Study Design: No. } \\
\text { Studies (N) }\end{array}$ & $\begin{array}{l}\text { Findings and Direction of } \\
\text { Effect }\end{array}$ & $\begin{array}{l}\text { Strength } \\
\text { of } \\
\text { Evidence }\end{array}$ \\
\hline $\begin{array}{l}\text { Discharge } \\
\text { planning }\end{array}$ & $\begin{array}{l}\text { Mabire et } \\
\text { al. } 2017^{15,30}\end{array}$ & $\begin{array}{l}\text { Nursing discharge } \\
\text { planning interventions } \\
\text { vs. usual care }\end{array}$ & $\begin{array}{l}\text { Older patients with or } \\
\text { without comorbidities }\end{array}$ & $\begin{array}{l}3 \text { US RCTs/pre-post } \\
\text { studies }(n=465)\end{array}$ & $\begin{array}{l}\text { OR: } 0.57,95 \% \mathrm{Cl}: 0.40 \text { to } 0.81, \\
p=0.01, I^{2}=0 \%, \text { favors } \\
\text { intervention }\end{array}$ & Moderate $^{*}$ \\
\hline $\begin{array}{l}\text { Discharge } \\
\text { planning }\end{array}$ & $\begin{array}{l}\text { Mabire et } \\
\text { al. } 2017^{15,30}\end{array}$ & $\begin{array}{l}\text { Nursing discharge } \\
\text { planning intervention } \\
\text { (transitional care) vs. } \\
\text { usual care }\end{array}$ & $\begin{array}{l}\text { Older patients with or } \\
\text { without comorbidities }\end{array}$ & $\begin{array}{l}4 \text { RCTs }(3 \text { of } 4 \text { US }) \\
(n=1,030)\end{array}$ & $\begin{array}{l}\text { OR: } 0.70,95 \% \mathrm{Cl}: 0.38 \text { to } 1.27 \\
\mathrm{I}^{2}=69.2 \%, \text { no difference }\end{array}$ & Low $^{*}$ \\
\hline $\begin{array}{l}\text { Discharge } \\
\text { planning }\end{array}$ & $\begin{array}{l}\text { Gonçalves- } \\
\text { Bradley } \\
\text { et al. } \\
2016^{38}\end{array}$ & $\begin{array}{l}\text { Discharge planning vs. } \\
\text { standard care }\end{array}$ & $\begin{array}{l}\text { Older patients with a } \\
\text { medical condition }\end{array}$ & $\begin{array}{l}15 \text { RCTs ( } 9 \text { of } 15 \text { US) } \\
(n=4,743)\end{array}$ & $\begin{array}{l}\text { Unscheduled readmission within } \\
3 \text { months: RR: } 0.87,95 \% \mathrm{Cl} \text { : } \\
0.79 \text { to } 0.97, \mathrm{I}^{2}=28.26 \% \text {, favors } \\
\text { intervention }\end{array}$ & Moderate \\
\hline $\begin{array}{l}\text { Discharge } \\
\text { planning }\end{array}$ & $\begin{array}{l}\text { Bryant- } \\
\text { Lukosius } \\
\text { et al. } \\
2015^{35}\end{array}$ & $\begin{array}{l}\text { Clinical nurse } \\
\text { specialists transitional } \\
\text { care vs. usual care }\end{array}$ & $\begin{array}{l}\text { Patients with heart } \\
\text { failure }\end{array}$ & 2 US RCTs $(n=495)$ & $\begin{array}{l}\text { Re-hospitalization more than } \\
\text { once for any reason at } 90 \text { days } \\
\text { and } 52 \text { weeks: RR: } 0.81,95 \% \\
\mathrm{Cl}: 0.57 \text { to } 1.13, p=0.21 \text {, no } \\
\text { difference }\end{array}$ & Low \\
\hline $\begin{array}{l}\text { Discharge } \\
\text { planning }\end{array}$ & $\begin{array}{l}\text { Bryant- } \\
\text { Lukosius } \\
\text { et al. } \\
2015^{35}\end{array}$ & $\begin{array}{l}\text { Clinical nurse } \\
\text { specialists transitional } \\
\text { care vs. usual care }\end{array}$ & Infants & 2 US RCTs $(n=202)$ & $\begin{array}{l}\text { Rehospitalizations at } 2-\text { and } \\
\text { 8-weeks postdischarge: } \\
\text { RR: } 0.56,95 \% \mathrm{Cl}: 0.21 \text { to } 1.44 \text {, } \\
p=0.23 \text {, no difference }\end{array}$ & Low \\
\hline $\begin{array}{l}\text { Discharge } \\
\text { planning }\end{array}$ & $\begin{array}{l}\text { Zhu et al. } \\
2015^{12}\end{array}$ & $\begin{array}{l}\text { Nurse-led early } \\
\text { discharge planning vs. } \\
\text { usual care }\end{array}$ & $\begin{array}{l}\text { Mix includes older } \\
\text { patients, decompensated } \\
\text { heart failure, hip fracture, } \\
\text { rehab, congestive heart } \\
\text { disease, hospitalized } \\
\text { psychiatric patients }\end{array}$ & $\begin{array}{l}10 \text { RCTs ( } 5 \text { of } 10 \text { US) } \\
(n=3,376)\end{array}$ & $\begin{array}{l}\text { RR: } 0.72,95 \% \mathrm{Cl}: 0.58 \text { to } 0.89 \\
p=0.002, I^{2}=66 \% \text {, favors } \\
\text { intervention }\end{array}$ & Moderate \\
\hline $\begin{array}{l}\text { Discharge } \\
\text { planning }\end{array}$ & $\begin{array}{l}\text { Zhu et al. } \\
2015^{12}\end{array}$ & $\begin{array}{l}\text { Nurse-led early } \\
\text { discharge planning vs. } \\
\text { usual care }\end{array}$ & $\begin{array}{l}\text { Non-older adults } \\
(<65 \text { years })\end{array}$ & 2 US RCTs $(n=768)$ & $\begin{array}{l}\text { RR: } 0.69,95 \% \mathrm{Cl}: 0.51 \text { to } 0.92, \\
p=0.010, I^{2}=0 \% \text {, favors } \\
\text { intervention }\end{array}$ & Moderate \\
\hline $\begin{array}{l}\text { Discharge } \\
\text { planning }\end{array}$ & $\begin{array}{l}\text { Zhu et al. } \\
2015^{12}\end{array}$ & $\begin{array}{l}\text { Nurse-led early } \\
\text { discharge planning vs. } \\
\text { usual care }\end{array}$ & $\begin{array}{l}\text { Mix includes older } \\
\text { patients, decompensated } \\
\text { heart failure, hip fracture, } \\
\text { rehab, congestive heart } \\
\text { disease, hospitalized } \\
\text { psychiatric patients }\end{array}$ & $\begin{array}{l}3 \text { RCTs ( } 2 \text { of } 3 \text { US) } \\
(n=2,013)\end{array}$ & $\begin{array}{l}\text { Readmissions at } 1 \text { month: } \\
\text { RR: } 0.73,95 \% \mathrm{Cl}: 0.46 \text { to } 1.15 \text {, } \\
p=0.170, I^{2}=75 \% \text {, no difference }\end{array}$ & Moderate \\
\hline
\end{tabular}




\begin{tabular}{|c|c|c|c|c|c|c|}
\hline $\begin{array}{l}\text { Type of } \\
\text { Intervention }\end{array}$ & $\begin{array}{l}\text { Author } \\
\text { Year }\end{array}$ & Comparison & Population & $\begin{array}{l}\text { Study Design: No. } \\
\text { Studies (N) }\end{array}$ & $\begin{array}{l}\text { Findings and Direction of } \\
\text { Effect }\end{array}$ & $\begin{array}{l}\text { Strength } \\
\text { of } \\
\text { Evidence }\end{array}$ \\
\hline $\begin{array}{l}\text { Discharge } \\
\text { planning }\end{array}$ & $\begin{array}{l}\text { Zhu et al. } \\
2015^{12}\end{array}$ & $\begin{array}{l}\text { Nurse-led early } \\
\text { discharge planning vs. } \\
\text { usual care }\end{array}$ & $\begin{array}{l}\text { Mix includes older } \\
\text { patients, decompensated } \\
\text { heart failure, hip fracture, } \\
\text { rehab, congestive heart } \\
\text { disease, hospitalized } \\
\text { psychiatric patients }\end{array}$ & 2 US RCTs $(n=393)$ & $\begin{array}{l}\text { Readmissions at } 6 \text { months: } \\
\text { RR: } 0.48,95 \% \mathrm{Cl}: 0.37 \text { to } 0.63 \text {, } \\
\text { p<0.001, }\left.\right|^{2}=0 \% \text {, favors } \\
\text { intervention }\end{array}$ & Moderate \\
\hline $\begin{array}{l}\text { Geriatric } \\
\text { assessment }\end{array}$ & $\begin{array}{l}\text { Van Craen } \\
\text { et al. } \\
2010^{39}\end{array}$ & $\begin{array}{l}\text { Geriatric evaluation } \\
\text { unit vs. usual care }\end{array}$ & Frail elderly & 2 RCTs $(n=668)$ & $\begin{array}{l}\text { RR: } 0.85,95 \% \mathrm{Cl}: 0.65 \text { to } 1.11 \text {, } \\
\text { no difference }\end{array}$ & Moderate $^{*}$ \\
\hline $\begin{array}{l}\text { Clinical } \\
\text { pathways }\end{array}$ & $\begin{array}{l}\text { Kul et al. } \\
2012^{29}\end{array}$ & $\begin{array}{l}\text { Clinical pathways vs. } \\
\text { usual care }\end{array}$ & Congestive heart failure & $\begin{array}{l}2 \text { RCTs and } \\
3 \text { observational } \\
\text { studies }(n=3,006)\end{array}$ & $\begin{array}{l}\text { RR: } 0.81,95 \% \mathrm{Cl}: 0.66 \text { to } 0.99 \text {, } \\
\mathrm{I}^{2}=16 \% \text {, favors intervention }\end{array}$ & Moderate $^{*}$ \\
\hline $\begin{array}{l}\text { Interdisciplinary } \\
\text { care }\end{array}$ & $\begin{array}{l}\text { Pannick } \\
\text { et al. } \\
2015^{32}\end{array}$ & $\begin{array}{l}\text { Altering } \\
\text { interdisciplinary team } \\
\text { composition vs. usual } \\
\text { care }\end{array}$ & $\begin{array}{l}\text { Mixed patient } \\
\text { population - infectious } \\
\text { diseases, pneumonia, or } \\
\text { not specified }\end{array}$ & $\begin{array}{l}2 \text { cluster RCTs, } \\
1 \text { non-RCT (all US) } \\
\text { (n=NR) }\end{array}$ & $\begin{array}{l}\text { Early readmissions: RR: } 1.341 \text {, } \\
95 \% \mathrm{Cl}: 1.120 \text { to } 1.607, \\
\text { intervention tended to increase } \\
\text { early readmissions (authors } \\
\text { noted there were important } \\
\text { confounding factors, factors not } \\
\text { specified) }\end{array}$ & Low $^{*}$ \\
\hline $\begin{array}{l}\text { Interdisciplinary } \\
\text { care }\end{array}$ & $\begin{array}{l}\text { Pannick } \\
\text { et al. } \\
2015^{32}\end{array}$ & $\begin{array}{l}\text { Altering } \\
\text { interdisciplinary team } \\
\text { practice vs. usual care }\end{array}$ & $\begin{array}{l}\text { Mixed patient } \\
\text { population - geriatric, VA } \\
\text { hospital, or not specified }\end{array}$ & $\begin{array}{l}2 \text { non-RCT cluster } \\
\text { studies, } 2 \text { interrupted } \\
\text { time series, } 1 \text { before/ } \\
\text { after study (all US) } \\
\text { (n=NR) }\end{array}$ & $\begin{array}{l}\text { Early readmissions: RR: } 0.995 \text {, } \\
95 \% \mathrm{Cl}: 0.912 \text { to } 1.085, \text { no } \\
\text { difference }\end{array}$ & Low $^{*}$ \\
\hline $\begin{array}{l}\text { Case } \\
\text { management }\end{array}$ & $\begin{array}{l}\text { Huntley } \\
\text { et al. } \\
2016^{28}\end{array}$ & $\begin{array}{l}\text { Case management vs. } \\
\text { usual care }\end{array}$ & Congestive heart failure & $\begin{array}{l}12 \text { RCTs and } \\
1 \text { observation study } \\
(n=3,346)\end{array}$ & $\begin{array}{l}\text { RR: } 0.74,95 \% \mathrm{Cl}: 0.60 \text { to } 0.92 \text {, } \\
\mathrm{I}^{2}=69 \% \text {, favors intervention } \\
\text { Subgroup analysis, excluding } \\
\text { studies at high risk of bias } \\
\text { RR: } 0.77,95 \% \mathrm{Cl}: 0.61 \text { to } 0.96 \text {, } \\
\mathrm{I}^{2}=68 \% \text {, favors intervention }\end{array}$ & Moderate $^{*}$ \\
\hline
\end{tabular}

$\mathrm{CI}=$ confidence interval; $\mathrm{MD}=$ mean difference; $\mathrm{NR}=$ not reported; $\mathrm{OR}=$ odds ratio; $\mathrm{RCT}=$ randomized controlled trial; $\mathrm{RR}=$ risk ratio; $\mathrm{US}=\mathrm{United}$ States; $\mathrm{VA}=\mathrm{Veteran}$ Affairs; WMD = weighted mean difference

${ }^{*}$ Authors of systematic reviews did not assess the strength of evidence for this outcome. Strength of evidence rating is based on guidance from Berkman et al. $2013^{23}$ 
Table 6. Summary of findings for patient harms meta-analyses

\begin{tabular}{|c|c|c|c|c|c|c|}
\hline $\begin{array}{l}\text { Type of } \\
\text { Intervention }\end{array}$ & $\begin{array}{l}\text { Author } \\
\text { Year }\end{array}$ & Comparison & Population & $\begin{array}{l}\text { Study Design: No. } \\
\text { Studies (N) }\end{array}$ & Findings and Direction of Effect & $\begin{array}{l}\text { Strength } \\
\text { of } \\
\text { Evidence } \\
\end{array}$ \\
\hline $\begin{array}{l}\text { Discharge } \\
\text { planning }\end{array}$ & $\begin{array}{l}\text { Bryant- } \\
\text { Lukosius } \\
\text { et al. } 2015^{35}\end{array}$ & $\begin{array}{l}\text { Clinical nurse } \\
\text { specialists } \\
\text { transitional care vs. } \\
\text { usual care }\end{array}$ & $\begin{array}{l}\text { Patients with heart } \\
\text { failure }\end{array}$ & $\begin{array}{l}2 \text { RCTs ( } 1 \text { of } 2 \text { US) } \\
(n=345)\end{array}$ & $\begin{array}{l}\text { Mortality at } 6 \text { months and } 52 \text { weeks of } \\
\text { followup } \\
\text { RR: } 0.76,95 \% \mathrm{Cl}: 0.41 \text { to } 1.42, p=0.40 \text {, } \\
\text { no difference }\end{array}$ & Low \\
\hline $\begin{array}{l}\text { Discharge } \\
\text { planning }\end{array}$ & $\begin{array}{l}\text { Bryant- } \\
\text { Lukosius } \\
\text { et al. } 2015^{35}\end{array}$ & $\begin{array}{l}\text { Clinical nurse } \\
\text { specialists } \\
\text { transitional care vs. } \\
\text { usual care }\end{array}$ & $\begin{array}{l}\text { Elderly hospitalized } \\
\text { patients }\end{array}$ & 2 US RCTs $(n=443)$ & $\begin{array}{l}\text { Mortality during index hospitalization and } \\
\text { 6- and } 8 \text {-weeks postdischarge } \\
\text { RR: } 1.05,95 \% \mathrm{Cl}: 0.48 \text { to } 2.28, p=0.90 \text {, } \\
\text { no difference }\end{array}$ & Low \\
\hline $\begin{array}{l}\text { Discharge } \\
\text { planning }\end{array}$ & $\begin{array}{l}\text { Zhu et al. } \\
2015^{12}\end{array}$ & $\begin{array}{l}\text { Nurse-led early } \\
\text { discharge planning } \\
\text { vs. usual care }\end{array}$ & $\begin{array}{l}\text { Mix includes older } \\
\text { patients, decompensated } \\
\text { heart failure, hip fracture, } \\
\text { rehab, congestive heart } \\
\text { disease, hospitalized } \\
\text { psychiatric patients } \\
\end{array}$ & $\begin{array}{l}5 \text { RCTs ( } 3 \text { of } 5 \text { US) } \\
(n=2,729)\end{array}$ & $\begin{array}{l}\text { All-cause mortality (index admission to } \\
\text { within } 30 \text { days) } \\
\text { RR: } 0.70,95 \% \mathrm{Cl}: 0.52 \text { to } 0.95, p=0.020 \text {, } \\
\mathrm{I}^{2}=0 \% \text {, favors intervention }\end{array}$ & High \\
\hline $\begin{array}{l}\text { Geriatric } \\
\text { assessment }\end{array}$ & $\begin{array}{l}\text { Eagles et al. } \\
2020^{41}\end{array}$ & $\begin{array}{l}\text { Geriatric trauma } \\
\text { consultation (GTC) } \\
\text { vs. standard trauma } \\
\text { care }\end{array}$ & $\begin{array}{l}\text { Older adults admitted to } \\
\text { trauma center }\end{array}$ & $\begin{array}{l}6 \text { retrospective cohort } \\
\text { studies (5 of } 6 \text { US) } \\
(n=7,408)\end{array}$ & $\begin{array}{l}\text { In-hospital mortality after vs. before } \\
\text { implementation of GTC service } \\
\text { Unadjusted OR: } 0.91,95 \% \mathrm{Cl}: 0.70 \text { to } \\
1.18, \mathrm{I}^{2}=18 \% \text {, no difference }\end{array}$ & Moderate \\
\hline $\begin{array}{l}\text { Geriatric } \\
\text { assessment }\end{array}$ & $\begin{array}{l}\text { Eagles et al. } \\
2020^{41}\end{array}$ & $\begin{array}{l}\text { GTC vs. standard } \\
\text { trauma care }\end{array}$ & $\begin{array}{l}\text { Older adults admitted to } \\
\text { trauma center }\end{array}$ & $\begin{array}{l}2 \text { US retrospective } \\
\text { cohort studies } \\
(n=482)\end{array}$ & $\begin{array}{l}\text { In-hospital mortality with GTC vs. without } \\
\text { GTC } \\
\text { Unadjusted OR: } 0.24,95 \% \mathrm{Cl}: 0.12 \text { to } \\
0.52, \mathrm{I}^{2}=0 \% \text {, favors intervention }\end{array}$ & Moderate \\
\hline $\begin{array}{l}\text { Geriatric } \\
\text { assessment }\end{array}$ & $\begin{array}{l}\text { Ellis et al. } \\
2017^{36}\end{array}$ & $\begin{array}{l}\text { Comprehensive } \\
\text { geriatric assessment } \\
\text { vs. usual care }\end{array}$ & $\begin{array}{l}\text { Frail or at-risk/older } \\
\text { patients }\end{array}$ & $\begin{array}{l}11 \text { RCTs (7 of } 11 \text { US) } \\
(n=4346)\end{array}$ & $\begin{array}{l}\text { Mortality at discharge } \\
\text { RR: } 1.04,95 \% \mathrm{Cl}: 0.82 \text { to } 1.32, \mathrm{I}^{2}=16 \% \text {, } \\
\text { no difference }\end{array}$ & High \\
\hline $\begin{array}{l}\text { Geriatric } \\
\text { assessment }\end{array}$ & $\begin{array}{l}\text { Ellis et al. } \\
2017^{36}\end{array}$ & $\begin{array}{l}\text { Comprehensive } \\
\text { geriatric assessment } \\
\text { vs. usual care }\end{array}$ & $\begin{array}{l}\text { Frail or at-risk/older } \\
\text { patients }\end{array}$ & $\begin{array}{l}21 \text { RCTs }(12 \text { of } \\
21 \text { US) }(n=10,023)\end{array}$ & $\begin{array}{l}\text { Mortality at } 3 \text { - to } 12-\text { month followup } \\
\text { RR: } 1.00,95 \% \mathrm{Cl}: 0.93 \text { to } 1.07, \mathrm{I}^{2}=0 \% \text {, } \\
\text { no difference }\end{array}$ & High \\
\hline $\begin{array}{l}\text { Geriatric } \\
\text { assessment }\end{array}$ & $\begin{array}{l}\text { Van Craen } \\
\text { et al. } 2010^{39}\end{array}$ & $\begin{array}{l}\text { Geriatric evaluation } \\
\text { unit vs. usual care }\end{array}$ & Frail elderly & 6 RCTs $(n=4,108)$ & $\begin{array}{l}\text { Mortality at } 12 \text { months } \\
\text { RR: } 0.97,95 \% \mathrm{Cl}: 0.88 \text { to } 1.08 \text {, no } \\
\text { difference }\end{array}$ & High $^{*}$ \\
\hline
\end{tabular}




\begin{tabular}{|c|c|c|c|c|c|c|}
\hline $\begin{array}{l}\text { Type of } \\
\text { Intervention }\end{array}$ & $\begin{array}{l}\text { Author } \\
\text { Year }\end{array}$ & Comparison & Population & $\begin{array}{l}\text { Study Design: No. } \\
\text { Studies (N) }\end{array}$ & Findings and Direction of Effect & $\begin{array}{l}\text { Strength } \\
\text { of } \\
\text { Evidence }\end{array}$ \\
\hline $\begin{array}{l}\text { Clinical } \\
\text { pathways }\end{array}$ & $\begin{array}{l}\text { Kul et al. } \\
2012^{29}\end{array}$ & $\begin{array}{l}\text { Clinical pathways } \\
\text { vs. usual care }\end{array}$ & Congestive heart failure & $\begin{array}{l}3 \text { RCTs and } \\
2 \text { observational } \\
\text { studies }(n=2,343)\end{array}$ & $\begin{array}{l}\text { Hospital mortality } \\
\text { RR: } 0.45,95 \% \mathrm{Cl}: 0.21 \text { to } 0.94, \mathrm{I}^{2}=73 \% \text {, } \\
\text { favors intervention }\end{array}$ & Low $^{*}$ \\
\hline $\begin{array}{l}\text { Interdisciplinary } \\
\text { care }\end{array}$ & $\begin{array}{l}\text { Pannick } \\
\text { et al. } 2015^{32}\end{array}$ & $\begin{array}{l}\text { Altering } \\
\text { interdisciplinary } \\
\text { team composition } \\
\text { vs. usual care }\end{array}$ & $\begin{array}{l}\text { Mixed patient } \\
\text { population - delirium, } \\
\text { infectious diseases }\end{array}$ & $\begin{array}{l}4 \text { cluster RCTs, } \\
2 \text { non-RCTs, } 1 \text { RCT } \\
(4 \text { of } 7 \text { US) (n=NR) }\end{array}$ & $\begin{array}{l}\text { Early mortality } \\
\text { RR: } 0.925,95 \% \mathrm{Cl}: 0.816 \text { to } 1.049 \text {, no } \\
\text { difference }\end{array}$ & Low $^{*}$ \\
\hline $\begin{array}{l}\text { Interdisciplinary } \\
\text { care }\end{array}$ & $\begin{array}{l}\text { Pannick } \\
\text { et al. } 2015^{32}\end{array}$ & $\begin{array}{l}\text { Altering } \\
\text { interdisciplinary } \\
\text { team practice vs. } \\
\text { usual care }\end{array}$ & Population not specified & $\begin{array}{l}2 \text { non-RCT cluster } \\
\text { studies ( } 1 \text { of } 2 \text { US) } \\
(n=N R)\end{array}$ & $\begin{array}{l}\text { Early mortality } \\
\text { RR: } 0.665,95 \% \mathrm{Cl}: 0.449 \text { to } 0.986 \text {, } \\
\text { intervention tended to reduce early } \\
\text { mortality }\end{array}$ & $\operatorname{Low}^{*}$ \\
\hline Telehealth & $\begin{array}{l}\text { Baratloo } \\
\text { et al. } 2018^{25}\end{array}$ & $\begin{array}{l}\text { Telestroke-based } \\
\text { systems vs. bedside } \\
\text { (face-to-face) }\end{array}$ & $\begin{array}{l}\text { Tissue plasminogen } \\
\text { activator-treated patients } \\
\text { with acute ischemic } \\
\text { stroke }\end{array}$ & $\begin{array}{l}15 \text { retrospective } \\
\text { controlled: studies, } \\
2 \text { prospective } \\
\text { controlled studies, } \\
1 \mathrm{RCT}(10 \text { of } 18 \text { US) } \\
(\mathrm{n}=4,907)\end{array}$ & $\begin{array}{l}\text { In-hospital mortality } \\
\text { OR: } 1.21,95 \% \mathrm{Cl}: 0.98 \text { to } 1.49, \mathrm{p}=0.08 \text {, } \\
\mathrm{I}^{2}=0 \% \text {, no difference }\end{array}$ & $\operatorname{Low}^{*}$ \\
\hline Telehealth & $\begin{array}{l}\text { Baratloo } \\
\text { et al. } 2018^{25}\end{array}$ & $\begin{array}{l}\text { Telestroke-based } \\
\text { systems vs. bedside } \\
\text { (face-to-face) }\end{array}$ & $\begin{array}{l}\text { Tissue plasminogen } \\
\text { activator-treated patients } \\
\text { with acute ischemic } \\
\text { stroke }\end{array}$ & $\begin{array}{l}14 \text { retrospective } \\
\text { controlled studies, } \\
6 \text { prospective } \\
\text { controlled studies, } \\
1 \text { RCT }(10 \text { of } 21 \text { US) } \\
(n=4,022)\end{array}$ & $\begin{array}{l}\text { Symptomatic intracranial Hemorrhage } \\
\text { OR: } 1.10,95 \% \mathrm{Cl}: 0.79 \text { to } 1.53, p=0.58 \text {, } \\
I^{2}=0 \% \text {, no difference }\end{array}$ & Low $^{*}$ \\
\hline
\end{tabular}

$\mathrm{CI}=$ confidence interval; $\mathrm{NR}=$ not reported; $\mathrm{OR}=$ odds ratio; $\mathrm{RCT}=$ randomized controlled trial; $\mathrm{RR}=$ risk ratio; US = United States

${ }^{*}$ Authors of systematic reviews did not assess the strength of evidence for this outcome. Strength of evidence rating is based on guidance from Berkman et al. $2013 .{ }^{23}$ 
Table 7. Summary of findings for patient functional return and patient/family experience meta-analyses

\begin{tabular}{|c|c|c|c|c|c|c|}
\hline $\begin{array}{l}\text { Type of } \\
\text { Intervention }\end{array}$ & $\begin{array}{l}\text { Author } \\
\text { Year }\end{array}$ & Comparison & Population & $\begin{array}{l}\text { Study Design: } \\
\text { No. Studies (N) }\end{array}$ & Findings and Direction of Effect & $\begin{array}{l}\text { Strength of } \\
\text { Evidence }\end{array}$ \\
\hline $\begin{array}{l}\text { Discharge } \\
\text { planning }\end{array}$ & $\begin{array}{l}\text { Bryant-Lukosius } \\
\text { et al. } 2015^{35}\end{array}$ & $\begin{array}{l}\text { Clinical nurse } \\
\text { specialists } \\
\text { transitional care } \\
\text { vs. usual care }\end{array}$ & $\begin{array}{l}\text { Patients with } \\
\text { heart failure }\end{array}$ & $\begin{array}{l}2 \text { US RCTs } \\
(n=403)\end{array}$ & $\begin{array}{l}\text { Patient satisfaction with care at } 4 \text { and } 6 \text { weeks } \\
\text { MD: } 6.09,95 \% \mathrm{Cl}: 3.55 \text { to } 8.63, p<0.00001 \\
\text { favors intervention }\end{array}$ & Moderate \\
\hline $\begin{array}{l}\text { Discharge } \\
\text { planning }\end{array}$ & $\begin{array}{l}\text { Bryant-Lukosius } \\
\text { et al. } 2015^{35}\end{array}$ & $\begin{array}{l}\text { Clinical nurse } \\
\text { specialists } \\
\text { transitional care } \\
\text { vs. usual care }\end{array}$ & $\begin{array}{l}\text { High-risk } \\
\text { pregnant women }\end{array}$ & $\begin{array}{l}2 \text { US RCTs } \\
(n=218)\end{array}$ & $\begin{array}{l}\text { Maternal satisfaction with care at discharge and } \\
\text { 8-weeks postpartum } \\
\text { MD: } 18.15,95 \% \mathrm{Cl}: 11.9 \text { to } 24.4, \mathrm{p}<0.00001 \text {, } \\
\text { favors intervention (authors noted considerable } \\
\text { heterogeneity for this outcome) }\end{array}$ & Low \\
\hline $\begin{array}{l}\text { Geriatric } \\
\text { assessment }\end{array}$ & $\begin{array}{l}\text { Van Craen et al. } \\
2010^{39}\end{array}$ & $\begin{array}{l}\text { Geriatric } \\
\text { evaluation unit } \\
\text { vs. usual care }\end{array}$ & Frail elderly & $\begin{array}{l}2 \text { RCTs } \\
(n=2,182)\end{array}$ & $\begin{array}{l}\text { Functional decline at discharge } \\
\text { RR: } 0.87,95 \% \mathrm{Cl}: 0.77 \text { to } 0.99 \text {, favors } \\
\text { intervention }\end{array}$ & High $^{*}$ \\
\hline $\begin{array}{l}\text { Geriatric } \\
\text { assessment }\end{array}$ & $\begin{array}{l}\text { Van Craen et al. } \\
2010^{39}\end{array}$ & $\begin{array}{l}\text { Geriatric } \\
\text { evaluation unit } \\
\text { vs. usual care }\end{array}$ & Frail elderly & $\begin{array}{l}2 \text { RCTs } \\
(n=1,654)\end{array}$ & $\begin{array}{l}\text { Functional decline at } 12 \text { months } \\
\text { RR: } 0.84,95 \% \mathrm{Cl}: 0.69 \text { to } 1.03 \text {, no difference }\end{array}$ & Moderate \\
\hline
\end{tabular}

$\mathrm{CI}=$ confidence interval; $\mathrm{MD}=$ mean difference; $\mathrm{OR}=$ odds ratio; $\mathrm{RCT}=$ randomized controlled trial; $\mathrm{RR}=$ risk ratio; $\mathrm{US}=\mathrm{United}$ States

${ }^{*}$ Authors of systematic reviews did not assess the strength of evidence for this outcome. Strength of evidence rating is based on guidance from Berkman et al. $2013 .{ }^{23}$ 
Below, we describe reported outcomes for each intervention (e.g., discharge planning). Systematic review authors may have decided against conducting meta-analysis for various reasons, such as limited data reported by the primary studies or heterogeneity across studies, such as differences in patient populations or components of the intervention. If an intervention category held findings that the authors summarized narratively or reported individual trial data (e.g., hospitalist services), we included this information in the summary below. Furthermore, some authors did not assess the SOE for the quantitative findings of a given outcome. Therefore, we used AHRQ Evidence-based Practice Center guidance ${ }^{23}$ to assess the SOE for these outcomes.

\section{Discharge Planning}

Four systematic reviews in five publications assessed discharge planning. All the reviews included older adults; one review also included high-risk pregnant woman and low-birthweight infants, while another review also included patients with chronic illnesses and psychiatric comorbidities. Results for older patients were inconsistent. One review found a reduction in LOS for older patients with comorbidity, based on 12 RCTs (SOE: Moderate), but no difference for older patients undergoing surgery based on 2 RCTs (SOE: Very Low) ${ }^{38}$ Another review found no difference in LOS for older patients based on three RCTs (SOE: Low), ${ }^{35}$ while an additional review reported that LOS increased for older patients, based on four RCTs and two observational studies (SOE: Low). ${ }^{15,30}$ A review that combined results for older adults, patients with chronic disease, and patients with psychiatric illness found no difference in LOS based on five RCTs (SOE: Moderate). ${ }^{12}$ Finally, one review found a reduction in LOS in high-risk pregnant women based on two RCTs (SOE: Moderate) and in very-low-birthweight infants based on one RCT (SOE: Low). ${ }^{35}$

These four systematic reviews also examined readmissions but measured the outcome differently, such as unscheduled readmissions within 3 months or rehospitalization more than once for any reason at a given time point. Three systematic reviews in four publications found that discharge planning decreased readmissions in older adults and patients with a mixture of conditions (SOE: Moderate). ${ }^{12,15,30,38}$ However, there was substantial heterogeneity within reviews, and some of the findings from subgroup analyses suggested no difference in readmission. A fourth review ${ }^{35}$ indicated no difference in readmissions in patients with heart failure based on two RCTs (SOE: Low) or infants (2 RCTs, SOE: Low). In addition, the authors reported no difference between discharge planning and usual care for high-risk pregnant women, although this was based on one small RCT (SOE: Low).

Two systematic reviews reported on mortality. One review reported a lower risk of all-cause mortality within 30 days of admission in a combination of older adults and patients with chronic disease or psychiatric illness, based on 5 RCTs in the discharge planning intervention groups (SOE: High). ${ }^{12}$ Conversely, Bryant-Lukosius et al. $2015^{35}$ found no difference in mortality at 6 months or 1 year for patients with heart failure based on two RCTs (SOE: Low), and no difference at 6- and 8-weeks postdischarge in older patients, based on two RCTs (SOE: Low).

Two reviews examined patient satisfaction. One review found that patients with heart failure had better satisfaction with care at 4 and 6 weeks in the intervention group, based on two RCTs (SOE: Moderate) ${ }^{35}$ Furthermore, the findings suggest that high-risk pregnant women in the discharge planning group were more satisfied with care at discharge and 8-weeks postpartum, based on two RCTs (SOE: Low). Gonçalves-Bradley et al. $2016^{38}$ reported that discharge planning "may lead to increased satisfaction for patients and healthcare professionals. However, 
satisfaction was measured in different ways and findings were inconsistent across six studies (SOE: Low)."

Lastly, two reviews addressed resource use. One reported that none of the studies included in their review assessed costs and outcomes jointly, but "there was no instance when resource use or costs were higher with the clinical nurse specialists care but there were instances when the intervention reduced resource use and costs, despite the [fact that the intervention] was an add-on cost. ${ }^{\prime 35}$ In the other review, ${ }^{38}$ the authors indicated that lower direct hospital costs or charges costs may be associated with a reduction in readmissions, based on five studies (SOE: Very Low).

\section{Geriatric Assessment}

Four systematic reviews that examined geriatric assessment reported LOS. Two of the reviews performed meta-analyses, while the other two synthesized their findings qualitatively, and results were mixed across the systematic reviews. Eagles et al. $2020^{41}$ found a reduction in LOS in older adults based on two observational studies (SOE: Moderate). ${ }^{41}$ In comparison, Van Craen et al. $2010^{39}$ suggested no difference in LOS in a frail elderly population based on seven RCTs (SOE: High). Of note, the interventions assessed by Van Craen et al. appeared to be more comprehensive and often included several components, such as assessment of medical, functional, nutritional, cognitive and psychiatric status, social situation, and quality of life. Bakker et al. ${ }^{26}$ evaluated six studies of older patients and found that three studies reported no difference in LOS, while three studies did not provide a statistical analysis of results. Finally, Patel et al. $2020^{31}$ described 10 studies showing a reduction in LOS in older patients but also found two studies that reported no difference and one study that found an increase in LOS.

Three systematic reviews evaluated readmissions, but only one performed meta-analyses. Van Craen et al. $2010^{39}$ found no difference in readmission risk in a frail and elderly population based on two RCTs (SOE: Moderate). Bakker et al. 2011 ${ }^{26}$ assessed two studies of older patients and reported that one study found a reduction in readmissions while the other did not provide a statistical analysis of the results. ${ }^{26}$ Patel et al. $2020^{31}$ reported that three studies showed no difference in readmission rates, one study found a decrease in readmission rates, and one study found an increase in readmission rates.

Five systematic reviews reported on mortality. Eagles et al. $2020^{41}$ found patients admitted to a trauma center that received a geriatric consultation had a decreased risk of in-hospital mortality compared with those receiving standard trauma care, based on two observational studies (SOE: Moderate). Conversely, this review also analyzed six other observational studies in trauma center patients and found no difference in mortality (SOE: Moderate). The findings from Ellis et al. $2017^{36}$ suggested no difference between comprehensive geriatric assessment and usual care in the risk of mortality at discharge (11 RCTs, SOE: High) or at 3 to 12 months after discharge (21 RCTs, SOE: High). Van Craen et al. $2010^{39}$ suggested there is no difference in mortality risk at 12 months, based on 6 RCTs (SOE: High).

Two systematic reviews did not conduct a meta-analysis. ${ }^{26,31}$ Bakker et al. $2011^{26}$ identified 1 study with 197 patients that found no difference in mortality between specialized geriatric teams or units and usual care. Patel et al. $2020^{31}$ reported that 5 studies showed a decrease in postoperative mortality rates, while 11 studies showed no difference in surgical patients receiving geriatric assessment.

Two systematic reviews examined patient functional return. One review ${ }^{39}$ suggested a lower risk of functional decline at discharge in frail elderly patients based on two RCTs (SOE: High). 
However, at 12 months, the effect was no longer observed (SOE: Moderate). Another review ${ }^{26}$ assessed patient functional return using multiple measures in four studies. Most functional measures found no difference in older patients, but one study favored the intervention using the Self Rating Depression Scale, and one study favored the intervention using the Mini-Mental State Examination. ${ }^{42}$

Finally, only one study within one review addressed resource use. ${ }^{26}$ The study found no difference in cost between geriatric specialty teams and usual care.

\section{Medication Management}

Two systematic reviews examined strategies for managing anticoagulant prescribing compared with usual care. ${ }^{24,37}$ One review assessed CPOE systems and CDSS and found no difference in LOS or 30-day readmission, based mainly on observational studies. ${ }^{24}$ Another review found that anticoagulation consultation services had no effect on LOS but were associated with reduced readmissions, while decision-supported dosing was associated with reduced LOS in one RCT. ${ }^{37}$

Anticoagulant medication management was associated with reduced 90-day mortality in 1 large observational study but no difference in 3 smaller studies in the same review. ${ }^{24}$ The other review also found no effect on mortality. ${ }^{37}$ One review viewed medication management as having a positive effect on patient safety. ${ }^{24}$

A systematic review of eight RCTs and one observational study examined computerized decision support for drug dosing in patients with chronic illnesses, such as diabetes, chronic kidney disease, and chronic obstructive pulmonary disease (COPD) ${ }^{27}$ The authors found no difference in LOS reduction, although the findings leaned toward favoring the intervention (SOE: Very Low).

\section{Clinical Pathways}

Two systematic reviews examined clinical pathways for patients with congestive heart failure. One review ${ }^{29}$ found that pathways reduced LOS, based on one RCT and four observational studies (SOE: Low) and reduced readmissions, based on two RCTs and three observational studies (SOE: Moderate). Mortality was also reduced in the clinical pathways group, based on three RCTs and two observational studies (SOE: Low). This review found no difference in costs between groups.

Another systematic review ${ }^{34}$ found a decrease in LOS when implementing a clinical pathway along with other quality-improvement initiatives, based on a single but large RCT with 2,906 patients. Readmissions within 90 days of discharge decreased in 2 of 3 studies included in this review, while the remaining study found no difference. No difference was observed in mortality in three studies reporting this outcome. Finally, one RCT reported improved quality of life, while two RCTs found no difference.

\section{Interdisciplinary Care}

Two systematic reviews evaluated models of interdisciplinary care. One review ${ }^{32}$ included studies that assessed either the composition of care teams or the processes they used to provide care; high-risk populations were included, such as patients with psychiatric illness and geriatric patients. No difference in LOS was reported (SOE: Low). The authors found that altering the composition of interdisciplinary teams tended to increase the readmission risk (SOE: Low) but had no effect on mortality (SOE: Low), while changes to team processes were not associated 
with changes in readmissions (SOE: Low) but may be associated with reduction in mortality (SOE: Low).

Another systematic review ${ }^{40}$ examined multicomponent interventions that included teambased approaches as well as staff education, individual care planning, and other strategies. Metaanalysis was not performed, and results were not consistent across studies.

\section{Case Management}

Case management in patients with congestive heart failure was examined in a systematic review of eight RCTs and one observational study. ${ }^{28}$ Case management reduced LOS (SOE: Moderate) and suggested a lower readmission risk (SOE: Moderate). The authors also described direct hospital costs and cost-effectiveness reported in the primary studies but did not perform a meta-analysis of these data. One study found that direct hospital costs were reduced; however, limited details were provided. Another study found that case management saved a hospital \$225 in direct costs associated with caring for each Medicare patient. A third study reported that the overall net savings after 18 months of implementing the intervention across 3 hospitals totaled \$1.6 million, primarily due to reduced hospital days. Six studies found no difference in direct hospital costs, charges, or cost-effectiveness measures between case management and usual care.

\section{Hospitalist Services}

One systematic review ${ }^{33}$ examined hospitalist services compared with traditional attending physician structures in patients with chronic conditions, such as heart failure, COPD, psychiatric illness, and substance use disorder. The authors reported that the intervention was associated with LOS reduction in 40 studies, while 13 studies found no difference and 5 studies found that LOS increased in the hospitalist groups. Six studies found that hospitalists were associated with a reduction in readmissions, but 34 studies found no difference and 3 studies found that readmissions increased. Eight studies found a reduction in mortality associated with hospitalists, while 29 studies found no difference. Two studies reported a reduction in complications, while 5 found no difference, and 1 study reported that complications increased. Patient satisfaction improved in one study but yielded no difference in seven studies. Finally, 30 studies found that hospitalist services reduced costs or charges, while 10 studies found no difference, and 3 studies reported higher costs or charges.

\section{Telehealth}

One systematic review compared telestroke-based systems with bedside (face-to-face) care. ${ }^{25}$ The authors found reduced LOS in patients with acute ischemic stroke treated with tissue plasminogen activator, based on one RCT and eight observational studies (SOE: Low). No difference in mortality risk was reported, based on 1 RCT and 17 observational studies (SOE: Low), and evidence from $1 \mathrm{RCT}$ and 20 observational studies indicated there was no difference in symptomatic intracranial hemorrhage (SOE: Low).

\section{Evidence Gaps and Challenges (GQ 4)}

This Technical Brief was designed to focus on structural interventions that health systems can implement broadly across departments or entities, rather than strategies that solely reflect point-of-care clinical decision-making. Moreover, we narrowed our scope to include only patients who require both acute and immediate medical care and populations that may present 
substantial challenges to timely discharge. These patients may have complex and comorbid medical conditions and might face significant social or economic barriers to achieving safe and effective recovery. We also limited our search to systematic reviews that meet a minimal quality standard and include primary studies of which at least a majority were conducted in the United States. These limits on our scope resulted in 19 systematic reviews that addressed our GQs out of over 4,000 studies screened by our searches. Many of the excluded reviews met at least one, but not all, of our inclusion criteria.

To understand the most important gaps in the evidence base, it is useful to examine why such a large body of research - most of which evaluates interventions to reduce hospital LOS - did not satisfy all of our criteria for inclusion. The next five sections discuss the pertinent reasons.

\section{Research Gaps: Interventions}

The most common reason we excluded systematic reviews was failure to assess structural interventions that could be implemented at a system level. Many hundreds of reviews focused on one type of medication's effectiveness compared with that of another, such as various anesthesia regimens or analgesic drugs to improve patient recovery times and thus reduce LOS. While these studies are important, they address issues that are fundamentally clinical rather than structural and are generally managed by hospital formulary committees, clinical departments, and individual physicians.

We also excluded 268 reviews of laparoscopic and/or robot-assisted surgical techniques. These reviews often focused on the potential for minimally invasive or robotic surgery to accelerate time to hospital discharge, and such interventions may contribute substantially to reduced LOS. However, they were beyond this Technical Brief's scope.

Another common strategy designed largely to reduce LOS is a bundle of surgical processes often referred to as enhanced recovery programs (ERP) or enhanced recovery after surgery $\left(\right.$ ERAS $^{\circledR}$ ). Our searches identified 123 articles that examined ERP protocols; however, we found this literature base consisted mainly of elective abdominal or orthopedic surgical procedures, or surgical treatment for cancer, and did not include our populations of interest. Additionally, numerous articles were narrative reviews or brief summaries of ERPs rather than systematic reviews. We did not identify any systematic reviews of ERPs applied to medically complex, high-risk, or otherwise vulnerable patients.

In contrast to the large body of work published on ERPs, we also sought to assess the smaller but evolving evidence base on patient mobility programs. These strategies aim to encourage patient ambulation early during a hospitalization to prevent loss of muscle tone and reduce risk of pressure ulcers, blood clots, and other adverse events. We identified five reviews of mobility programs, but they were mainly limited to studies of patients without chronic or complex illness. None of the reviews met all of our inclusion criteria.

We also excluded more than 100 reviews that examined interventions similar or identical to those included in the evidence maps, tables, and figures under GQ 1, 2, and 3. For example, we excluded 30 reviews of discharge planning, 24 reviews of clinical pathways, and 18 reviews of interdisciplinary teams. We also excluded 13 reviews of geriatric assessment programs, 10 reviews of case management, 8 reviews of decision support tools, and 6 reviews of medication management. We excluded these reviews because they did not involve a relevant patient population, did not report LOS, were conducted in an excluded setting such as the emergency department, or did not consist mainly of studies based in the United States. 


\section{Research Gaps: Patient Populations}

We found two primary challenges in evaluating the evidence base for reducing LOS in the patient populations of interest. First, many reviews that focused on our included populations were nevertheless excluded due to the intervention type, setting, or research design. We identified 101 reviews of patients with congestive heart failure, 83 reviews of patients over age 60, 71 reviews of patients with diabetes, 67 reviews of patients with COPD, and 19 reviews of patients with chronic kidney disease. We did not include these reviews because they focused on nonstructural interventions, were conducted in outpatient or specialized inpatient settings (such as intensive care units), or lacked sufficient methodologic rigor.

The second main challenge presented by the current state of evidence is the almost complete lack of research focused on patients who face severe social or economic barriers to achieving and maintaining wellness before, during, and after hospitalization. Our searches identified no reviews- regardless of whether they were included or excluded from our analysis - that explicitly limited the population to patients enduring housing instability or food insecurity, discrimination or isolation, language or cultural barriers, or other challenges that increase vulnerability and risk.

We did, however, find many reviews relied wholly or in large part on studies conducted outside the United States. We excluded 119 reviews because at least half their primary studies were not based in the United States. This highlights the need for additional funding of both primary research and evidence synthesis that is applicable to the unique characteristics of U.S. healthcare delivery.

Finally, we note that only two reviews addressed pediatric populations. While children are much less likely to fit into the complex or chronic illness categories we have highlighted, they are unfortunately susceptible to many sources of social and economic vulnerability. Little is known about how health systems can address those unique challenges.

\section{Research Gaps: Hospital Settings}

This review was limited to interventions in general hospital settings. We excluded studies focused on emergency departments, intensive care units, specialty hospitals (e.g., psychiatric, rehabilitation), and outpatient, community, and home-based care. This resulted in exclusion of 200 systematic reviews. Of these, 123 interventions were based in intensive care settings, while 51 were in the emergency department and did not report on hospital LOS. This suggests strong interest in designing interventions to improve patient flow through the bottleneck of the emergency department and resource-intense critical care units, but further research is needed on interventions that affect the entire hospitalization and subsequent LOS rather than solely emergency department LOS or intensive care unit LOS.

Additionally, an inherent limitation of using systematic reviews in this Technical Brief is our limited ability to describe in detail the local hospital settings where initiatives to reduce LOS have been implemented. Reviews rarely reported demographic data on patient volume, bed size, or payer mix. We did not examine the primary studies to determine whether they occurred in urban, suburban, or rural regions or whether hospitals were part of a large integrated care network or were a standalone safety-net facility. Inclusion of these factors in future systematic reviews would provide valuable context for learning health systems seeking to adopt new interventions. 


\section{Research Gaps: Implementation Context}

The lack of detail regarding hospital settings is mirrored by the dearth of information about how interventions were implemented. We sought to describe key contextual factors specific to the interventions, such as resource allocation, staffing needs, role of leadership, organizational culture, sustainability, and assessment of progress. However, the systematic reviews generally lacked a description of these factors, aside from several reviews that identified the core personnel responsible for implementation (e.g., nurses, case managers). It is unclear whether these types of details were absent from the primary studies or if they were reported initially but later excluded from the systematic reviews. Future research on hospital-based interventions should aim to provide sufficient operational context to enable other hospitals to reach informed conclusions about implementation.

\section{Research Gaps: Study Design}

This Technical Brief was limited at the outset to identifying and evaluating systematic reviews rather than primary studies, but we found that many potential articles were not rigorous systematic reviews. We excluded 372 articles that were narrative reviews, reported only on uncontrolled trials, or did not assess the quality or risk of bias of included primary studies. Future efforts to synthesize this evidence base with well-designed systematic reviews would serve an important need for health system leaders.

We also found that surprisingly many primary studies informing systematic reviews were conducted outside the United States. We excluded 114 reviews because at least half of the studies they assessed were not based in the United States. Moreover, most of the reviews we included featured studies from both U.S.- and non-U.S.-based hospitals. Therefore, despite the overall breadth of the published literature, a need remains for additional primary research on interventions to reduce hospital LOS specific to the United States. 


\section{Summary and Implications}

In this report, we summarize evidence from systematic reviews (SRs) assessing structural interventions that health systems can implement broadly for medically complex, high-risk, or vulnerable patients requiring acute medical care. We identified 19 systematic reviews in 20 articles that assessed 8 interventions: discharge planning, geriatric assessment or consultation, medication management, clinical pathways, inter- or multidisciplinary care, case management, hospitalist services, and telehealth. ${ }^{12,15,24-41}$ Interventions primarily assessed older patients (i.e., > 60 years of age) or patients with chronic conditions. Limited evidence was identified for vulnerable populations, and no SRs addressed key vulnerable populations, such as underinsured, uninsured, patients experiencing homelessness, those with low socioeconomic status, or those with psychiatric comorbidities.

\section{Frequently Studied Interventions}

Identifying a broad system-level intervention or approach to reduce length of stay (LOS) is of interest to most hospitals and health systems. Geriatric assessment and discharge planning were the most frequently reported interventions in our evidence base. Five systematic reviews examined geriatric assessment, and this intervention often included a patient management consultation by a geriatrician or multidisciplinary healthcare team to assess needs, develop or review treatment plans, set goals, and/or develop postdischarge plans. Four systematic reviews assessed discharge planning, and this intervention was often nurse-led and included an initial assessment and plan for in-hospital care, patient education, and a plan for postdischarge care and followup (e.g., phone calls, home visits, outpatient appointments).

\section{Challenging Patient Populations}

All hospitals face the perennial challenge of providing high-quality care for medically complex and vulnerable populations, ideally without incurring significant costs or penalties due to unnecessarily prolonged LOS. These patients are typically at greater risk for adverse events during and after hospitalization. ${ }^{22}$ This report identified only limited information on systematic interventions that address these challenging populations. Most reviews focused on nonsystematic interventions. Only two systematic reviews included pediatric populations, ${ }^{33,35}$ while most included studies with patients at least 60 years of age or older. Our searches identified a large volume of reviews conducting research in medically complex patient populations (e.g., chronic obstructive pulmonary disease [COPD], diabetes). We identified very few reviews that addressed nonclinical factors, such as socioeconomic status, that might be associated with prolonged LOS. Only two systematic reviews provided details about the medical insurance status of included patients. ${ }^{12,35}$ No reviews addressed populations struggling with homelessness or housing instability, isolation, poverty, or other social determinants of health.

\section{Inconsistent Evidence on Effectiveness of Interventions}

The evidence base highlights inconsistencies on the effectiveness of interventions to reduce LOS; no intervention demonstrated a clear direction of effect. For example, three systematic reviews evaluating discharge planning compared with usual care in either older adults or patients with chronic conditions found no difference between groups for LOS, ${ }^{12,35,38}$ while two found that discharge planning decreased LOS, ${ }^{35,38}$ and one found that discharge planning increased 
$\operatorname{LOS}^{15,30}$. Similarly, findings varied for readmissions and mortality. Reviews examining geriatric assessment, decision support, interdisciplinary care, and telehealth also reported heterogeneous and sometimes inconsistent findings for quantitative syntheses.

However, one SR examining case management ${ }^{28}$ and one SR assessing clinical pathways ${ }^{29}$ in patients with heart failure found a reduction in LOS, a lower risk of readmissions, and a lower risk or odds of mortality compared with usual care. The findings suggest that case management or clinical pathways may have a consistent direction of effect for these outcomes in patients with heart failure, but more research is needed.

\section{Challenges for Local Implementation}

To gauge to what extent these interventions might be successfully implemented for reducing LOS and improving other outcomes in a local setting, hospital administrators benefit from details about the local context and implementation factors (e.g., process and resources required). However, SRs provided only limited information. Thirteen reviews (in 14 articles) all described interventions conducted in multiple types of hospitals, including academic medical centers, community hospitals, and less frequently, Veterans Affairs hospitals. ${ }^{15,26-28,30,32-39,41}$ Only five reviews reported whether all included studies were conducted in urban, suburban, or rural settings, ${ }^{25,34-36,38}$ and few reviews reported hospital bed size or affiliation with a health system.

In addition, the process and resources used to support implementation were often not reported. Not all primary studies informing the systematic reviews provided details about the expertise of staff leading and implementing interventions. For instance, for discharge planning interventions, only one review specified that included study interventions were led by a nurse practitioner. Otherwise, systematic reviews simply indicated a provider (e.g., nurse, clinician) or multidisciplinary team led or participated in implementing the intervention. Availability of current resources, such as staff with particular expertise, will undoubtedly affect the feasibility of successfully implementing many interventions. For example, several systematic reviews evaluated geriatric assessment, which often involved specialized assessment by a geriatrician. However, hospitals or health systems may not necessarily have a geriatrician to lead this intervention and may instead engage staff members for training to deliver this intervention, which may affect ultimate success.

Ultimately, we did not find evidence that most interventions have been widely replicated or scaled with sufficient detail or context to adequately inform local implementation.

\section{Trade-Offs and Implications}

System-level interventions have the potential to create trade-offs between outcomes, such as LOS and postdischarge adverse outcomes (e.g., hospital readmission, mortality). All systematic reviews in our evidence base reported LOS, and most reported readmissions and mortality. However, the manner in which outcomes were measured varied. Not only is it important for studies to evaluate these outcomes collectively, but also to standardize the way outcomes are reported.

Our findings suggest that, at present, no existing intervention or approach can be implemented to decrease LOS for broad populations of medically complex, high-risk, or otherwise vulnerable patient populations. Attempting to implement an unfocused broad-based intervention across varied populations may have unintended consequences and lead to worse outcomes. Hospitals and health systems may need to carefully consider their own local contexts and populations when assessing whether particular interventions would be a good fit. Input from 
our Key Informants emphasized the importance of considering factors associated with social care needs and ways to address these needs when seeking to reduce LOS with a system-level intervention. Building relationships and establishing partnerships with community organizations may help hospitals and health systems leverage resources to support and manage needs of medically complex, high-risk, and vulnerable patients postdischarge.

Finally, interpretation of these findings should also consider several key additional factors. Systematic review design lags behind primary research. Thus, our evidence base may not reflect the most recent findings or evolving interventions yet to be synthesized in published reviews. Moreover, the evidence we reviewed was generated before the COVID-19 pandemic. It is likely that the pandemic has led hospitals to innovate in myriad ways that may affect hospital care, LOS, and other critical outcomes that we cannot yet assess. Additionally, we focused on medically complex, high-risk, and vulnerable patient populations, including those at high socioeconomic risk of poor medical outcomes, but found little direct evidence on socioeconomically disadvantaged patients. Emerging efforts to address longstanding social, economic, and health inequities may yield new insights on how to best design care to benefit these patients.

Overall, understanding the unique challenges and needs of a hospital or health system and its surrounding community may help inform the development of a strategic plan to implement a system-level intervention to reduce hospital LOS and provide high-quality care for the patient populations served.

\section{Next Steps}

\section{Hospital Administrative Leaders Can Do the Following:}

- Understand different populations with varying risk levels within hospitals attempting to reduce LOS.

- Explore specific interventions matched to medically complex, high-risk, and vulnerable populations with higher LOS.

- Maximize expertise of current staff when identifying and implementing system-level intervention (e.g., clinical pathways, geriatric assessment).

- Understand tradeoffs between reducing LOS in medically complex, high-risk, and vulnerable populations and other patient-centered outcomes (e.g., functional decline, patient experience, mortality, readmissions) and patient safety and quality metrics.

- Evaluate opportunities to support research and implementation of system-level interventions targeting medically complex, high-risk, or vulnerable populations.

- Work with policymakers to identify best approaches to reducing hospital LOS in U.S. healthcare delivery systems.

\section{Researchers Can Do the Following:}

- Conduct research focused on general medical and surgical ward inpatients.

- Provide sufficient operational context about how interventions were implemented in primary studies and evidence syntheses.

- Report details about local hospital settings where initiatives to reduce LOS have been implemented (e.g., patient volume, bed size, payer mix) in primary studies and evidence syntheses. 
- Assess health information technology's role in supporting interventions to reduce LOS and identify opportunities to develop or adapt technology to support new initiatives.

- Include and subgroup patients facing severe social and economic barriers to achieving and maintaining wellness before, during, and after hospitalization in primary studies evaluating system-level interventions to decrease LOS.

- Evaluate how health systems can address the unique challenges pediatric populations' face, specifically those that are susceptible to many sources of social and economic vulnerability.

- Examine enhanced recovery programs and patient mobility programs in medically complex or otherwise vulnerable patient populations.

- Conduct well-designed systematic reviews, such as those assessing both the risk of bias of primary studies and providing the strategy for the literature search.

\section{Policymakers Can Do the Following:}

- Support new research and development with additional funding of both primary research and evidence synthesis applicable to the unique characteristics of the U.S. healthcare delivery system.

- Address the role of LOS - as both a metric and a concept - in value-based reimbursement systems. 


\section{References}

1. American Hospital Association. Fast facts on U.S. hospitals, 2020. [internet]. Chicago (IL): American Hospital Association (AHA); 2020 [updated 2020 Mar 01]; [accessed 2020 Aug 17]. [4 p]. Available: https://www.aha.org/statistics/fast-facts-ushospitals.

2. OECD. OECD data: length of hospital stay (indicator). [internet]. Paris (France): Organisation for Economic Co-operation and Development (OECD); 2020 [accessed 2020 Aug 17]. [6 p]. Available: https://data.oecd.org/healthcare/length-ofhospital-stay.htm\#indicator-chart.

3. Rojas-García A, Turner S, Pizzo E, et al. Impact and experiences of delayed discharge: a mixed-studies systematic review. Health Expect. 2018 Feb;21(1):4156. Also available:

http://dx.doi.org/10.1111/hex.12619. PMID: 28898930.

4. Ragavan MV, Svec D, Shieh L. Barriers to timely discharge from the general medicine service at an academic teaching hospital. Postgrad Med J. 2017 Sep;93(1103):528-33. Also available:

http://dx.doi.org/10.1136/postgradmedj2016-134529. PMID: 28450581.

5. Greer NL, Gunnar WP, Dahm P, et al. Enhanced recovery protocols for adults undergoing colorectal surgery: a systematic review and meta-analysis. Dis Colon Rectum. 2018 Sep;61(9):1108-18. Also available:

http://dx.doi.org/10.1097/DCR.0000000000 001160. PMID: 30086061.

6. Lee Y, Yu J, Doumouras AG, et al. Enhanced Recovery After Surgery (ERAS) versus standard recovery for elective gastric cancer surgery: a meta-analysis of randomized controlled trials. Surg Oncol. 2019 Nov 25;32:75-87. Also available: http://dx.doi.org/10.1016/j.suronc.2019.11.0 04. PMID: 31786352.

7. Dietz N, Sharma M, Adams S, et al. Enhanced Recovery After Surgery (ERAS) for spine surgery: a systematic review. World Neurosurg. 2019 Oct;130:415-26. Also available: http://dx.doi.org/10.1016/j.wneu.2019.06.18 1. PMID: 31276851.
8.

Rotter T, Kinsman L, James E, et al. Clinical pathways: effects on professional practice, patient outcomes, length of stay and hospital costs. Cochrane Database Syst Rev.

2010;(3):CD006632. Also available: https://doi.org/10.1002/14651858.CD00663 2.pub2. PMID: 20238347.

9. Hoyer EH, Friedman M, Lavezza A, et al. Promoting mobility and reducing length of stay in hospitalized general medicine patients: a quality-improvement project. J Hosp Med. 2016 May;11(5):341-7. Also available:

http://dx.doi.org/10.1002/jhm.2546. PMID: 26849277.

10. Ridwan ES, Hadi H, Wu YL, et al. Effects of transitional care on hospital readmission and mortality rate in subjects with COPD: a systematic review and meta-analysis. Respir Care. 2019 Sep;64(9):1146-56. Also available:

http://dx.doi.org/10.4187/respcare.06959. PMID: 31467155.

11. Van Spall HG, Rahman T, Mytton O, et al. Comparative effectiveness of transitional care services in patients discharged from the hospital with heart failure: a systematic review and network meta-analysis. Eur J Heart Fail. 2017 Nov;19(11):1427-43. Also available: http://dx.doi.org/10.1002/ejhf.765. PMID: 28233442.

12. Zhu QM, Liu J, Hu HY, et al. Effectiveness of nurse-led early discharge planning programmes for hospital inpatients with chronic disease or rehabilitation needs: a systematic review and meta-analysis. J Clin Nurs. 2015 Oct;24(19-20):2993-3005. Also available:

http://dx.doi.org/10.1111/jocn.12895. PMID: 26095175.

13. Grover CA, Sughair J, Stoopes S, et al. Case management reduces length of stay, charges, and testing in emergency department frequent users. West J Emerg Med. 2018 Mar;19(2):238-44. Also available: http://dx.doi.org/10.5811/westjem.2017.9.34 710. PMID: 29560049.

14. Okere AN, Renier CM, Frye A. Predictors of hospital length of stay and readmissions in ischemic stroke patients and the impact of inpatient medication management. J Stroke 
Cerebrovasc Dis. 2016 Aug;25(8):1939-51. Also available: http://dx.doi.org/10.1016/j.jstrokecerebrovas dis.2016.04.011. PMID: 27199200.

15. Mabire C, Dwyer A, Garnier A, et al. Effectiveness of nursing discharge planning interventions on health-related outcomes in discharged elderly inpatients: a systematic review. JBI Database System Rev Implement Rep. 2016 Sep;14(9):217-61. Also available: http://dx.doi.org/10.11124/JBISRIR-2016003085. PMID: 27755325.

16. Segers E, Ockhuijsen H, Baarendse $P$, et al. The impact of family centred care interventions in a neonatal or paediatric intensive care unit on parents' satisfaction and length of stay: a systematic review. Intensive Crit Care Nurs. 2019 Feb;50:6370. Epub 2018 Sep 22. Also available: http://dx.doi.org/10.1016/j.iccn.2018.08.008. PMID: 30249426.

17. Mercedes A, Fairman P, Hogan L, et al. Effectiveness of structured multidisciplinary rounding in acute care units on length of stay and satisfaction of patients and staff: a quantitative systematic review. JBI Database Syst Rev Implement Rep. 2016 Jul;14(7):131-68. Also available: http://dx.doi.org/10.11124/JBISRIR-2016003014. PMID: 27532795.

18. Butler M, Schultz TJ, Halligan P, et al. Hospital nurse-staffing models and patientand staff-related outcomes. Cochrane Database Syst Rev. 2019 Apr 23;(4):CD007019. Also available: http://dx.doi.org/10.1002/14651858.CD0070 19.pub3. PMID: 31012954.

19. Gruneir A, Bronskill SE, Maxwell CJ, et al. The association between multimorbidity and hospitalization is modified by individual demographics and physician continuity of care: a retrospective cohort study. BMC Health Serv Res. 2016 Apr 27;16:154. Also available: http://dx.doi.org/10.1186/s12913016-1415-5. PMID: 27122051.

20. Moore L, Cisse B, Batomen Kuimi BL, et al. Impact of socio-economic status on hospital length of stay following injury: a multicenter cohort study. BMC Health Serv Res. 2015 Jul 25;15:285. Also available: http://dx.doi.org/10.1186/s12913-015-09492. PMID: 26204932.
21. Wadhera RK, Choi E, Shen C, et al. Trends, causes, and outcomes of hospitalizations for homeless individuals: a retrospective cohort study. Med Care. 2019 Jan;57(1):21-7. Also available:

http://dx.doi.org/10.1097/MLR.0000000000 001015. PMID: 30461584

22. Naessens JM, Campbell CR, Shah N, et al. Effect of illness severity and comorbidity on patient safety and adverse events. Am J Med Qual. 2012 Jan-Feb;27(1):48-57. Also available:

http://dx.doi.org/10.1177/106286061141345 6. PMID: 22031176.

23. Berkman ND, Lohr KN, Ansari M, et al. Grading the strength of a body of evidence when assessing health care interventions for the Effective Health Care Program of the Agency for Healthcare Research and Quality: an update (Prepared by the RTIUNC Evidence-based Practice Center under contract No. 290-2007-10056-I). Rockville (MD): Agency for Healthcare Research and Quality (AHRQ); 2013 Nov. 44 p. (Methods Guide for Effectiveness and Comparative Effectiveness Reviews [Internet]; Also available:

https://effectivehealthcare.ahrq.gov/topics/m ethods-guidance-grading-evidence/methods. PMID: 24404627.

24. Austin J, Barras M, Sullivan C. Interventions designed to improve the safety and quality of therapeutic anticoagulation in an inpatient electronic medical record. Int $\mathbf{J}$ Med Inform. 2020 Mar;135:104066. Also available:

http://dx.doi.org/10.1016/j.ijmedinf.2019.10 4066. PMID: 31923817.

25. Baratloo A, Rahimpour L, Abushouk AI, et al. Effects of telestroke on thrombolysis times and outcomes: a meta-analysis. Prehosp Emerg Care. 2018 Jul 1;22(4):47284. Also available: http://dx.doi.org/10.1080/10903127.2017.14 08728. PMID: 29345529.

26. Bakker FC, Robben SHM, Olde Rikkert MG. Effects of hospital-wide interventions to improve care for frail older inpatients: a systematic review. BMJ Qual Saf. 2011 Aug;20(8):680-91. Epub 2011 Feb 25. Also available:

http://dx.doi.org/10.1136/bmjqs.2010.04718 3. PMID: 21355019. 
27. Gillaizeau F, Chan E, Trinquart L, et al. Computerized advice on drug dosage to improve prescribing practice. Cochrane Database Syst Rev. 2013 Nov 12;(11):CD002894. Also available: http://dx.doi.org/10.1002/14651858.CD0028 94.pub3. PMID: 24218045.

28. Huntley AL, Johnson R, King A, et al. Does case management for patients with heart failure based in the community reduce unplanned hospital admissions? A systematic review and meta-analysis. BMJ Open. 2016 May 10;6(5):e010933. Also available:

http://dx.doi.org/10.1136/bmjopen-2015010933. PMID: 27165648.

29. Kul S, Barbieri A, Milan E, et al. Effects of care pathways on the in-hospital treatment of heart failure: a systematic review. BMC Cardiovasc Disord. 2012 Sep 25;12:81. Also available: http://dx.doi.org/10.1186/14712261-12-81. PMID: 23009030.

30. Mabire C, Dwyer A, Garnier A, et al. Metaanalysis of the effectiveness of nursing discharge planning interventions for older inpatients discharged home. J Adv Nurs. 2018 Apr 1;74(4):788-99. Also available: http://dx.doi.org/10.1111/jan.13475. PMID: 28986920.

31. Patel JN, Klein DS, Sreekumar S, et al. Outcomes in multidisciplinary team-based approach in geriatric hip fracture care: a systematic review. J Am Acad Orthop Surg. $2020 \mathrm{Feb}$;28(3):128-33. Also available: http://dx.doi.org/10.5435/JAAOS-D-1800425. PMID: 31977613.

32. Pannick S, Davis R, Ashrafian H, et al. Effects of interdisciplinary team care interventions on general medical wards: a systematic review. JAMA Intern Med. 2015 Aug;175(8):1288-98. Also available: http://dx.doi.org/10.1001/jamainternmed.20 15.2421. PMID: 26076428.

33. White HL, Glazier RH. Do hospitalist physicians improve the quality of inpatient care delivery? A systematic review of process, efficiency and outcome measures. BMC Med. 2011 May 18;9:58. Also available: http://dx.doi.org/10.1186/17417015-9-58. PMID: 21592322.

34. Agarwal A, Bahiru E, Yoo SGK, et al. Hospital-based quality improvement interventions for patients with heart failure: a systematic review. Heart. 2019 Mar;105(6):431-8. Also available: http://dx.doi.org/10.1136/heartjnl-2018314129. PMID: 30700515.

35. Bryant-Lukosius D, Carter N, Reid K, et al. The clinical effectiveness and costeffectiveness of clinical nurse specialist-led hospital to home transitional care: a systematic review. J Eval Clin Pract. 2015 Oct;21(5):763-81. Also available: http://dx.doi.org/10.1111/jep.12401. PMID: 26135524.

36. Ellis G, Gardner M, Tsiachristas A, et al. Comprehensive geriatric assessment for older adults admitted to hospital. Cochrane Database Syst Rev. 2017 Sep 12;(9):CD006211. Also available: http://dx.doi.org/10.1002/14651858.CD0062 11.pub3. PMID: 28898390.

37. Frazer A, Rowland J, Mudge A, et al. Systematic review of interventions to improve safety and quality of anticoagulant prescribing for therapeutic indications for hospital inpatients. Eur J Clin Pharmacol. 2019 Dec;75(12):1645-57. Also available: http://dx.doi.org/10.1007/s00228-01902752-8. PMID: 31511939.

38. Shepperd S, McClaran J, Phillips CO, et al. Discharge planning from hospital to home. Cochrane Database Syst Rev. 2010;(1):CD000313. Also available: http://dx.doi.org/10.1002/14651858.CD0003 13.pub5. PMID: 20091507.

39. Van Craen K, Braes T, Wellens N, et al. The effectiveness of inpatient geriatric evaluation and management units: a systematic review and meta-analysis. J Am Geriatr Soc. 2010 Jan;58(1):83-92. Also available: http://dx.doi.org/10.1111/j.15325415.2009.02621.x. PMID: 20002509.

40. Zhang H, Lu Y, Liu M, et al. Strategies for prevention of postoperative delirium: a systematic review and meta-analysis of randomized trials. Crit Care. 2013 Mar 18;17(2):R47. Also available: http://dx.doi.org/10.1186/cc12566. PMID: 23506796.

41. Eagles D, Godwin B, Cheng W, et al. A systematic review and meta-analysis evaluating geriatric consultation on older trauma patients. J Trauma Acute Care Surg. 
2020 Mar 1;88(3):446-53. Also available: http://dx.doi.org/10.1097/TA.000000000000 2571. PMID: 31876691.

42. Wang HQ, Yang JY, Yan LN. Hemihepatic versus total hepatic inflow occlusion during hepatectomy: a systematic review and metaanalysis. World J Gastroenterol. $2011 \mathrm{Jul}$ 14;17(26):3158-64. Also available: http://dx.doi.org/10.3748/wjg.v17.i26.3158. PMID: 21912460. 


\section{Appendix A. Methods}

\section{Resources Searched}

ECRI Institute information specialists searched the following bibliographic databases and websites for relevant information. Detailed search strategies for each bibliographic database appear below.

Table A-1. Bibliographic databases

\begin{tabular}{|l|l|l|}
\hline Name & Date Limits & Platform/Provider \\
\hline $\begin{array}{l}\text { Cochrane Database of Systematic Reviews } \\
\text { (Cochrane Reviews) }\end{array}$ & January 1, 2010 through May 12, 2020 & Wiley \\
\hline $\begin{array}{l}\text { Cumulative Index of Nursing and Allied } \\
\text { Health Literature (CINAHL) }\end{array}$ & January 1, 2010 through September 30, 2020 & EBSCOhost \\
\hline EMBASE.com (Excerpta Medica) & January 1, 2010 through September 30, 2020 & Embase.com \\
\hline MEDLINE (via Embase.com) & January 1, 2010 through September 30, 2020 & Embase.com \\
\hline $\begin{array}{l}\text { PubMed (publisher supplied/in process } \\
\text { citations) }\end{array}$ & January 1, 2010 through September 30, 2020 & NLM \\
\hline
\end{tabular}

Table A-2. Grey literature resources

\begin{tabular}{|l|l|l|}
\hline Name & Date Limits & Platform/Provider \\
\hline $\begin{array}{l}\text { Agency for Healthcare Research } \\
\text { and Quality (AHRQ) }\end{array}$ & January 1, 2010 through May 15, 2020 & $\begin{array}{l}\text { Department of Health and Human } \\
\text { Services - Web }\end{array}$ \\
\hline American Hospital Association & January 1, 2010 through May 18, 2020 & Web \\
\hline The Camden Coalition & January 1, 2020 through May 15, 2020 & Web \\
\hline Clinicaltrials.gov & January 1, 2010 through May 18, 2020 & National Library of Medicine - Web \\
\hline Centers for Medicare and Medicaid & January 1, 2010 through May 18, 2020 & Web \\
\hline $\begin{array}{l}\text { Institute for Healthcare } \\
\text { Improvement }\end{array}$ & January 1, 2020 through May 18, 2020 & Web \\
\hline The Joint Commission & January 1, 2020 through May 18, 2020 & Web \\
\hline Root Cause Coalition & January 1, 2020 through May 15, 2020 & Web \\
\hline $\begin{array}{l}\text { Social Interventions Research and } \\
\text { Evaluation Network (SIGN) }\end{array}$ & January 1, 2020 through May 15, 2020 & Web \\
\hline Socially Determined & January 1, 2020 through May 15, 2020 & Web \\
\hline
\end{tabular}

\section{Grey Literature}

Websites from professional organizations and government agencies were also screened for relevant grey literature. (Grey literature consists of reports, educational materials, promotional documents, and articles produced by government agencies, professional associations and educational facilities. These documents do not appear in the peer-reviewed journal literature.) 


\section{Search Strategies}

Table A-3. Embase/MEDLINE (searched via Embase.com)

\begin{tabular}{|c|c|c|}
\hline $\begin{array}{l}\text { Set } \\
\text { Number }\end{array}$ & Concept & Search Statement \\
\hline \#1 & $\begin{array}{l}\text { Length of stay - highly } \\
\text { specific search } \\
\text { (controlled terms } \\
\text { searched as major } \\
\text { concepts and } \\
\text { keywords searched in } \\
\text { the title only) }\end{array}$ & $\begin{array}{l}\text { 'length of stay'/exp/mj OR ('hospital discharge'/exp/mj AND 'time } \\
\text { factor'/exp/mj) OR 'los':ti OR (((length OR duration) NEXT/3 stay):ti) OR 'bed } \\
\text { days':ti OR (((length OR duration OR days) NEAR/3 hospital*):ti) OR } \\
\text { (((inpatient OR patient OR short) NEAR/1 (stay* OR throughput OR flow* } \\
\text { OR days)):ti) OR (((discharge* OR stay) NEAR/4 (delay* OR timely OR } \\
\text { timeliness OR fast OR faster OR sooner OR quick* OR haste* OR rapid* OR } \\
\text { early OR earlier OR reduc* OR decrease OR lessen OR speed*)):ti) OR } \\
\text { ((fast NEXT/1 track):ti) }\end{array}$ \\
\hline$\# 2$ & $\begin{array}{l}\text { Length of stay - less } \\
\text { specific search } \\
\text { (controlled terms } \\
\text { searches as both } \\
\text { major and minor } \\
\text { concepts and } \\
\text { keywords searched in } \\
\text { title and abstract) }\end{array}$ & $\begin{array}{l}\text { 'length of stay'/exp OR ('hospital discharge'/exp AND 'time factor'/exp) OR } \\
\text { ('los':ti,ab OR (((length OR duration) NEXT/3 stay):ti,ab) OR 'bed days':ti,ab } \\
\text { OR (((length OR duration OR days) NEAR/3 hospital*):ti,ab) OR (((inpatient } \\
\text { OR patient OR short) NEAR/1 (stay* OR throughput OR flow* OR } \\
\text { days)):ti,ab) OR (((discharge* OR stay) NEAR/4 (delay* OR timely OR } \\
\text { timeliness OR fast OR faster OR sooner OR quick* OR haste* OR rapid* OR } \\
\text { early OR earlier OR reduc* OR decrease OR lessen OR speed*)):ti,ab) OR } \\
\text { ((fast NEXT/1 track):ti,ab)) }\end{array}$ \\
\hline \#3 & $\begin{array}{l}\text { Socially vulnerable } \\
\text { populations - } \\
\text { controlled terms }\end{array}$ & $\begin{array}{l}\text { 'vulnerable population'/exp OR 'frail elderly'/exp OR 'homelessness'/exp } \\
\text { OR 'homeless person'/exp OR 'poverty'/exp OR 'sexual and gender } \\
\text { minority'/exp OR 'minority group'/exp OR 'household economic status'/exp } \\
\text { OR 'lowest income group'/exp OR 'social status'/exp OR 'health } \\
\text { disparity'/exp OR 'health equity'/exp OR 'income group'/exp OR 'safety net } \\
\text { hospital'/exp OR 'medically uninsured'/exp OR 'health literacy'/exp OR } \\
\text { 'educational status'/exp OR 'literacy'/exp OR 'employment'/exp OR } \\
\text { 'employment status'/exp OR 'veteran'/exp OR 'veterans health'/exp OR } \\
\text { 'migrant'/exp OR 'English as a second language'/exp OR 'limited English } \\
\text { proficiency'/exp OR 'language ability'/exp OR 'prisoner'/exp OR 'social } \\
\text { environment'/exp OR 'health care access'/exp OR 'socioeconomics'/de OR } \\
\text { 'social isolation'/exp }\end{array}$ \\
\hline$\# 4$ & $\begin{array}{l}\text { Socially vulnerable } \\
\text { populations - } \\
\text { keywords }\end{array}$ & $\begin{array}{l}\text { (((vulnerable OR marginalized) NEAR/2 (population* OR patient* OR } \\
\text { person*)):ti,ab) OR homeless*:ti,ab OR poverty*:ti,ab OR } \\
\text { impoverished:ti,ab OR indigent:ti,ab OR ((poor NEAR/3 (people OR } \\
\text { persons)):ti,ab) OR 'low income':ti,ab OR (((sexual OR gender OR ethnic } \\
\text { OR racial) NEAR/3 minorit*):ti,ab) OR socioeconomic*:ti,ab OR ((social } \\
\text { NEAR/2 (class* OR health* OR status OR support OR mobility OR } \\
\text { isolation)):ti,ab) OR ((health* NEAR/4 (disparit* OR equit* OR inequalit* } \\
\text { OR literacy OR illiteracy OR literate OR illiterate* OR inequit* OR } \\
\text { access*)):ti,ab) OR ((('safety net' OR 'safety-net' OR tertiary OR } \\
\text { quaternary) NEAR/3 (provider* OR hospital*)):ti,ab) OR uninsured:ti,ab OR } \\
\text { 'un insured':ti,ab OR 'under insured':ti,ab OR 'under-insured':ti,ab OR } \\
\text { underinsured:ti,ab OR ((without NEXT/3 insurance):ti,ab) OR } \\
\text { unemploy*:ti,ab OR underemploy*:ti,ab OR 'working poor':ti,ab OR } \\
\text { veteran*:ti,ab OR immigrant*:ti,ab OR migrant*:ti,ab OR refugee*:ti,ab OR } \\
((\text { english NEAR/3 (proficien* OR second)):ti,ab) OR (non NEXT/1 } \\
\text { english):ti,ab OR (((language OR communication) NEAR/3 barrier*):ti,ab) } \\
\text { OR prison*:ti,ab OR incarcerat*:ti,ab OR jail*:ti,ab }\end{array}$ \\
\hline$\# 5$ & $\begin{array}{l}\text { Medically vulnerable } \\
\text { populations - } \\
\text { controlled terms }\end{array}$ & $\begin{array}{l}\text { 'disabled person'/exp OR 'disability'/exp OR 'developmental disorder'/exp } \\
\text { OR 'mental disease'/exp OR 'communication barrier'/exp OR 'drug } \\
\text { dependence'/exp OR 'multiple chronic conditions'/exp OR 'rare } \\
\text { disease'/exp OR 'chronic disease'/exp OR 'substance use'/de OR 'alcohol } \\
\text { consumption'/exp OR 'cannabis use'/exp OR 'addiction'/de OR 'chronic } \\
\text { obstructive lung disease'/exp OR 'heart failure'/exp OR 'dementia'/exp OR } \\
\text { 'diabetes mellitus'/exp OR 'chronic kidney failure'/exp OR } \\
\text { comorbidity/exp/mj }\end{array}$ \\
\hline
\end{tabular}




\begin{tabular}{|c|c|c|}
\hline $\begin{array}{l}\text { Set } \\
\text { Number }\end{array}$ & Concept & Search Statement \\
\hline \#6 & $\begin{array}{l}\text { Medically vulnerable } \\
\text { populations - } \\
\text { keywords }\end{array}$ & 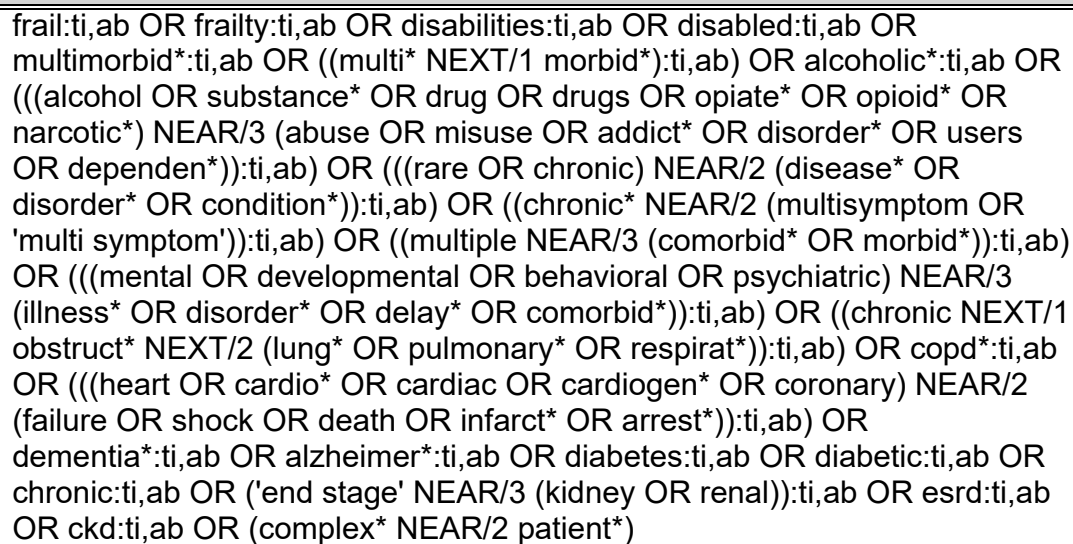 \\
\hline$\# 7$ & Combine sets - & \#1 OR (\#2 AND (\#3 OR \#4 OR \#5 OR \#6)) \\
\hline
\end{tabular}

Table A-3a. Add-on search for organizational interventions to decrease length of stay

\begin{tabular}{|c|c|c|}
\hline $\begin{array}{l}\text { Set } \\
\text { Number }\end{array}$ & Concept & Search Statement \\
\hline$\# 8$ & Length of Stay - & $\begin{array}{l}\text { 'length of stay'/exp/mj OR 'los':ti,ab OR ((length OR duration) NEXT/3 } \\
\text { stay):ti,ab OR 'bed days':ti,ab OR ((length OR duration OR days) NEAR/3 } \\
\left.\text { hospital* }{ }^{\star}\right): t i, a b\end{array}$ \\
\hline$\# 9$ & $\begin{array}{l}\text { Organizational } \\
\text { interventions }\end{array}$ & $\begin{array}{l}\text { 'health program'/exp/mj OR 'care coordination'/exp/mj OR 'case } \\
\text { management'/exp/mj OR 'interdisciplinary communication'/exp/mj OR } \\
\text { 'hospital policy'/exp/mj OR 'clinical decision making'/exp/mj OR 'hospital } \\
\text { readmission reduction program'/exp/mj OR 'clinical pathway'/exp/mj OR } \\
\text { 'personnel management'/exp/mj OR 'hospital personnel'/exp/mj OR 'care } \\
\text { bundle'/exp/mj OR 'health care quality'/exp/mj OR 'multidisciplinary } \\
\text { team'/exp/mj OR 'patient care'/exp/mj OR (((case NEXT/1 manag*):ti,ab) OR } \\
\text { (((interdisciplin* OR multdisciplin*) NEAR/3 (rounds OR rounding OR } \\
\text { communicat*)):ti,ab) OR (((organizat* OR organisat* OR hospital*) NEAR/5 } \\
\text { (policy OR policies OR program* OR intervention*)):ti,ab) OR staff:ti,ab OR } \\
\text { staffing:ti,ab OR bundl*:ti,ab OR model*:ti,ab OR pathway*:ti,ab OR } \\
\text { personnel:ti,ab OR 'system level':ti,ab OR 'hospital wide':ti,ab OR ('lean } \\
\text { process' OR 'eras' OR ((enhanced NEXT/1 recovery):ti,ab) OR 'hospital } \\
\text { elder life program' OR 'goal-directed achievement through geographic } \\
\text { location' OR gagl OR 'older people assessment liason' OR opal OR 'early } \\
\text { supported discharge' OR 'early home supported discharge'):ti,ab OR (six } \\
\text { NEXT/1 sigma):ti,ab OR (OASIS NEXT/4 framework*):ti,ab) }\end{array}$ \\
\hline$\# 10$ & $\begin{array}{l}\text { Combine sets - } \\
\text { organizational } \\
\text { interventions }\end{array}$ & \#8 AND \#9 \\
\hline$\# 11$ & Combine sets & \#7 OR \#10 \\
\hline$\# 12$ & $\begin{array}{l}\text { Remove unwanted } \\
\text { publication types }\end{array}$ & $\begin{array}{l}\text { \#11 NOT (abstract:nc OR annual:nc OR book/de OR 'case report'/de OR } \\
\text { 'case study'/de OR conference:nc OR 'conference abstract':it OR } \\
\text { 'conference paper'/de OR 'conference paper':it OR 'conference } \\
\text { proceeding':pt OR 'conference review':it OR congress:nc OR editorial/de OR } \\
\text { editorial:it OR erratum/de OR letter:it OR note/de OR note:it OR meeting:nc } \\
\text { OR sessions:nc OR 'short survey'/de OR symposium:nc) }\end{array}$ \\
\hline$\# 13$ & $\begin{array}{l}\text { Limit to systematic } \\
\text { reviews and meta- } \\
\text { analyses }\end{array}$ & $\begin{array}{l}\text { \#12 AND ('systematic review'/de OR 'meta analysis'/de OR (systematic* } \\
\text { NEAR/2 review*) OR metaanalysis OR metaanalyses OR (meta NEXT/1 } \\
\text { (analysis OR analyses)) OR Cochrane) }\end{array}$ \\
\hline \#14 & $\begin{array}{l}\text { Limit to English, } \\
\text { Human studies }\end{array}$ & Limit \#13 to English, Human, py:01/01/2010-09/30/2020 \\
\hline
\end{tabular}




\section{EMBASE.com Syntax:}

* $\quad=$ truncation character (wildcard)

lexp $=$ denotes a subject heading that has been searched to include narrower terms/concepts

$/ \mathrm{mj}=$ denotes a term that has been searched as a major subject heading

/py $\quad=$ limit to publication year(s)

:ti $\quad=$ limit to title

:ti,ab $=$ limit to title and abstract

Table A-4. CINAHL

\begin{tabular}{|c|c|c|}
\hline $\begin{array}{l}\text { Set } \\
\text { Number }\end{array}$ & Concept & Search Statement \\
\hline \#1 & $\begin{array}{l}\text { Length of stay - } \\
\text { highly specific search } \\
\text { (controlled terms } \\
\text { searched as major } \\
\text { concepts and } \\
\text { keywords searched in } \\
\text { the title only) }\end{array}$ & $\begin{array}{l}\text { ((MM "Length of Stay") OR (MM "Patient Discharge+") AND (MM } \\
\text { "Time Factors")) OR (TI ((length OR duration OR days) W3 (stay OR } \\
\text { hospital*))) OR (TI "bed days") OR (TI ((inpatient OR patient OR } \\
\text { short) N1 (stay* OR throughput OR flow* OR days))) OR (TI } \\
((\text { Discharge* OR stay) N3 (delay* OR timely OR timeliness OR fast } \\
\text { OR faster OR sooner OR quick* OR haste* OR rapid* OR early OR } \\
\text { earlier OR reduc* OR decrease OR lessen))) OR (TI (fast N1 track)) }\end{array}$ \\
\hline \#2 & $\begin{array}{l}\text { Length of stay - less } \\
\text { specific (controlled } \\
\text { terms searches as } \\
\text { both major and minor } \\
\text { concepts and } \\
\text { keywords searched in } \\
\text { title) }\end{array}$ & $\begin{array}{l}\text { (MH "Length of Stay") OR (TI ((length OR duration OR days) W3 } \\
\left.\left.\text { (stay OR hospital }{ }^{*}\right)\right) \text { OR (TI "bed days") OR (TI ((inpatient OR patient } \\
\text { OR short) N1 (stay* OR throughput OR flow* OR days))) OR (TI } \\
\text { ((Discharge* OR stay) N3 (delay* OR timely OR timeliness OR fast } \\
\text { OR faster OR sooner OR quick* OR haste* OR rapid* OR early OR } \\
\text { earlier OR reduc* OR decrease OR lessen))) OR (TI (fast N1 track)) }\end{array}$ \\
\hline \#3 & $\begin{array}{l}\text { Socially vulnerable } \\
\text { populations - } \\
\text { controlled terms }\end{array}$ & $\begin{array}{l}\text { (MH "Special Populations") OR (MH "Sex Factors") OR (MH "Race } \\
\text { Factors") OR (MH "Homeless Persons") OR (MH "Homelessness") } \\
\text { OR (MH "Frail Elderly") OR (MH "Poverty") OR (MH "Poverty } \\
\text { Areas") OR (MH "Health Services for the Indigent") OR (MH } \\
\text { "Indigent Persons") OR (MH "Minority Groups") OR (MH "Social } \\
\text { Isolation") OR (MH "Social Environment") OR (MH "Socioeconomic } \\
\text { Factors") OR (MH "Illiteracy") OR (MH "Substance Abusers") OR } \\
\text { (MH "Veterans") OR (MH "Health Status Disparities") OR (MH } \\
\text { "Safety-Net Providers") OR (MH "Medically Uninsured") OR (MH } \\
\text { "Health Literacy") OR (MH "Educational Status") OR (MH } \\
\text { "Transients and Migrants") OR (MH "Immigrants+") OR (MH } \\
\text { "English as a Second Language") OR (MH "Articulation Disorders") } \\
\text { OR (MH "Prisoners") OR (MH "Healthcare Disparities") OR (MH } \\
\text { "Tertiary Health Care") }\end{array}$ \\
\hline$\# 4$ & $\begin{array}{l}\text { Socially vulnerable } \\
\text { populations - } \\
\text { keywords }\end{array}$ & $\begin{array}{l}\text { (TI ((vulnerable OR marginalized) N2 (population* OR patient* OR } \\
\text { person*))) OR (TI (homeless* OR poverty*)) OR (TI (poor N3 } \\
\text { (people OR persons))) OR (TI "low income") OR (TI ((sexual OR } \\
\text { gender OR ethnic OR racial) N3 minorit*))) OR (TI socioeconomic*) } \\
\text { OR (TI (social N2 (class* OR health* OR status OR support OR } \\
\text { mobility OR isolation))) OR (TI (health* N4 (disparit* OR equit* OR } \\
\text { inequalit* OR literacy OR illiteracy OR literate OR illiterate* OR } \\
\text { inequit* OR access*))) OR (TI (('safety net' OR 'safety-net' OR } \\
\text { tertiary OR quaternary) N4 (provider* OR hospital*))) OR (TI } \\
\text { (uninsured OR 'un insured' OR 'under insured' OR 'under-insured' } \\
\text { OR underinsured)) OR (TI (without N3 insurance)) OR unemploy* } \\
\text { OR (TI underemploy* OR "working poor" OR veteran* OR } \\
\text { immigrant* OR migrant* OR refugee*) OR (TI (english N3 } \\
\text { (proficien* OR second))) OR (TI (non W1 english)) OR (TI } \\
\text { ((language OR communication) N3 barrier*)) OR (TI (prison* OR } \\
\text { incarcerat* OR jail* OR indigent* OR impoverished)) }\end{array}$ \\
\hline
\end{tabular}




\begin{tabular}{|c|c|c|}
\hline $\begin{array}{l}\text { Set } \\
\text { Number }\end{array}$ & Concept & Search Statement \\
\hline \#5 & $\begin{array}{l}\text { Medically vulnerable } \\
\text { populations - } \\
\text { controlled terms }\end{array}$ & $\begin{array}{l}\text { (MH "Mentally Disabled Persons") OR (MH "Intellectual Disability+") } \\
\text { OR (MH "Developmental Disabilities") OR (MH "Mental Disorders") } \\
\text { OR (MH "Behavioral and Mental Disorders+") OR (MH } \\
\text { "Communication Barriers") OR (MH "Communicative Disorders") } \\
\text { OR (MH "Substance Use Disorders+") OR (MH "Rare Diseases") } \\
\text { OR (MH "Chronic Disease+") OR (MH "Substance Dependence+") } \\
\text { OR (MH "Pulmonary Disease, Chronic Obstructive+") OR (MH } \\
\text { "Heart Failure+") OR (MH "Dementia+") OR (MH "Diabetes } \\
\text { Mellitus+") OR (MH "Kidney Failure, Chronic+") OR (MH } \\
\text { "Comorbidity") }\end{array}$ \\
\hline \#6 & $\begin{array}{l}\text { Medically vulnerable } \\
\text { populations - } \\
\text { keywords }\end{array}$ & 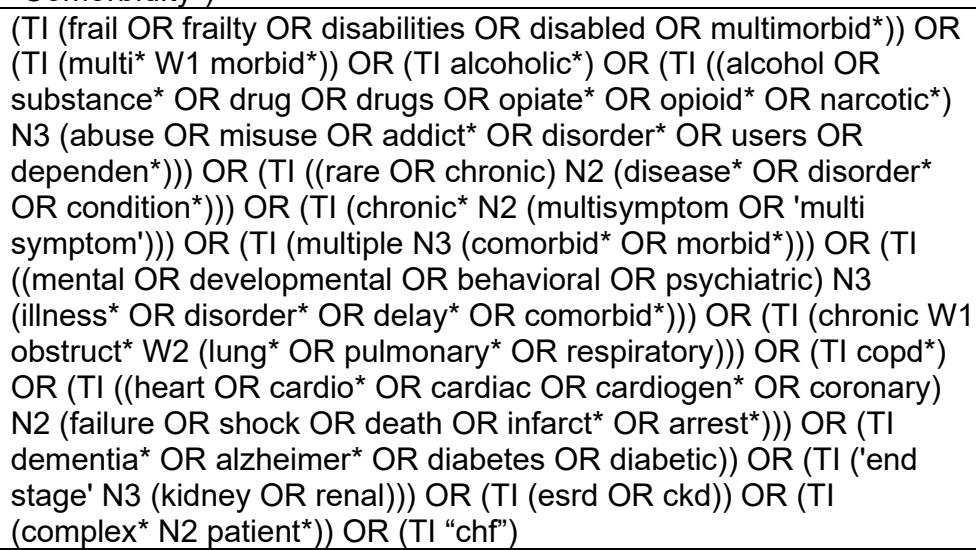 \\
\hline$\# 7$ & Combine sets & \#1 OR (\#2 AND (\#3 OR \#4 OR \#5 OR \#6)) \\
\hline
\end{tabular}

Table A-4a. Add-on search for organizational interventions to decrease length of stay

\begin{tabular}{|c|c|c|}
\hline $\begin{array}{l}\text { Set } \\
\text { Number }\end{array}$ & Concept & Search Statement \\
\hline$\# 8$ & Length of Stay & $\begin{array}{l}\text { (MM "Length of Stay") OR (TI ((length OR duration) W3 stay)) OR (TI 'bed } \\
\text { days') OR (TI (length OR days) N3 hospital*)) }\end{array}$ \\
\hline$\# 9$ & $\begin{array}{l}\text { Organizational } \\
\text { interventions }\end{array}$ & $\begin{array}{l}\text { (MM "Case Management") OR (MM "Case Managers") OR (MM } \\
\text { "Multidisciplinary Care Team+") OR (MM "Patient Centered Care") OR (MM } \\
\text { "Hospital Policies+") OR (MM "Organizational Policies+") OR (MM "Decision } \\
\text { Making, Clinical") OR (MM "Decision Making, Shared") OR (MM "Personnel } \\
\text { Management+") OR (MM "Personnel Staffing and Scheduling+") OR (MM } \\
\text { "Nursing Care Plans+") OR (MM "Quality of Health Care+") OR (MM "Patient } \\
\text { Care Plans+") OR (MM "Patient Care+") OR (TI (case W1 manag*)) OR (TI } \\
\text { ((interdisciplin* OR multdisciplin*) N3 (rounds OR rounding OR } \\
\text { communicat*))) OR (TI ((organization* OR hospital*) N3 (policy OR policies } \\
\text { OR program* OR intervention*))) OR (TI (staff OR staffing OR bundl* OR } \\
\text { model* OR pathway* OR personnel)) OR (TI ("system level" OR "hospital } \\
\text { wide")) OR (TI ('lean process' OR 'eras')) OR (TI (enhanced W1 recovery)) } \\
\text { OR (TI 'hospital elder life program') OR (TI ('goal-directed achievement } \\
\text { through geographic location' OR gagl OR 'older people assessment liason' } \\
\text { OR opal OR 'early supported discharge' OR 'early home supported } \\
\text { discharge')) OR (TI (six W1 sigma)) OR (TI (OASIS N4 framework*)) }\end{array}$ \\
\hline$\# 10$ & $\begin{array}{l}\text { Combine sets } \\
- \\
\text { organizational } \\
\text { interventions }\end{array}$ & \#8 AND \#9 \\
\hline$\# 11$ & Combine sets & \#7 OR \#10 \\
\hline$\# 12$ & $\begin{array}{l}\text { Limit to } \\
\text { systematic } \\
\text { reviews and } \\
\text { meta- } \\
\text { analyses }\end{array}$ & $\begin{array}{l}\text { \#11 AND ((MH "Systematic Review") OR (MH "Cochrane Library") OR } \\
\text { (systematic* N2 review*) OR metaanalysis OR 'meta analysis' OR Cochrane) } \\
\text { OR (MH "Meta Analysis") }\end{array}$ \\
\hline
\end{tabular}




\begin{tabular}{|l|l|l|}
\hline $\begin{array}{l}\text { Set } \\
\text { Number }\end{array}$ & Concept & Search Statement \\
\hline$\# 13$ & Exclude & Exclude MEDLINE records; Published Date: 20100101-20201231; Limit to: \\
MEDLINE & $\begin{array}{l}\text { Academic journals } \\
\text { records; limit } \\
\text { to academic } \\
\text { journals and } \\
\text { publication } \\
\text { date 2010- } \\
\text { 2020 }\end{array}$ & \\
\hline
\end{tabular}

\section{CINAHL Syntax:}

*

$+$

$\mathrm{MH}=$ denotes a term that has been searched as a subject heading

$\mathrm{MM}=$ denotes a term that has been searched as a major subject heading

TI $\quad=$ limit to title

:ti,ab $=$ limit to title and abstract* $=$ truncation character (wildcard)

Table A-5. PubMed publisher-supplied/in-process citations

\begin{tabular}{|c|c|c|}
\hline $\begin{array}{l}\text { Set } \\
\text { Number }\end{array}$ & Concept & Search Statement \\
\hline \#1 & $\begin{array}{l}\text { Length of stay - } \\
\text { highly specific } \\
\text { search }\end{array}$ & ((length[ti] OR duration[ti]) AND stay[ti]) OR “LOS”[ti] \\
\hline \#2 & $\begin{array}{l}\text { Length of stay - } \\
\text { less specific } \\
\text { search }\end{array}$ & $\begin{array}{l}\text { "length of stay"[tiab] OR "length of hospital stay"[tiab] OR "LOS"[tiab] OR } \\
\text { "duration of stay"[tiab] OR "duration of hospital stay"[tiab] OR "hospital } \\
\text { days"[tiab] OR "hospitalization days"[tiab] OR "days of } \\
\text { hospitalization"[tiab] OR "days in the hospital"[tiab] }\end{array}$ \\
\hline \#3 & $\begin{array}{l}\text { Socially } \\
\text { vulnerable } \\
\text { populations }\end{array}$ & $\begin{array}{l}\text { ((vulnerable[tiab] OR marginalized[tiab]) AND (population*[tiab] OR } \\
\text { patient*[tiab] OR person*[tiab])) OR homeless*[tiab] OR poverty*[tiab] } \\
\text { OR impoverished[tiab] OR "poor person"[tiab] OR "poor people"[tiab] OR } \\
\text { "low income"[tiab] OR ((sexual[tiab] OR gender[tiab] OR ethnic[tiab] OR } \\
\text { racial[tiab]) AND minorit*[tiab]) OR socioeconomic*[tiab] OR "social } \\
\text { class"[tiab] OR "social support"[tiab] OR "social mobility"[tiab] OR "social } \\
\text { isolation"[tiab] OR ((health[tiab] OR healthcare[tiab]) AND (disparit*[tiab] } \\
\text { OR equit*[tiab] OR inequalit*[tiab] OR literacy[tiab]OR illiteracy[tiab] OR } \\
\text { literate[tiab] OR illiterate*[tiab] OR inequit*[tiab] OR access*[tiab])) OR } \\
\text { (('safety net'[tiab] OR 'safety-net'[tiab] OR tertiary[tiab] OR } \\
\text { quaternary[tiab]) AND (provider*[tiab] OR hospital*[tiab])) OR } \\
\text { uninsured[tiab] OR 'un insured'[tiab] OR 'under insured'[tiab] OR } \\
\text { underinsured[tiab] OR unemploy*[tiab] OR underemploy*[tiab] OR } \\
\text { 'working poor'[tiab] OR veteran*[tiab] OR immigrant*[tiab] OR } \\
\text { migrant*[tiab] OR refugee*[tiab] OR "language barrier"[tiab] OR } \\
\text { "language barriers"[tiab] OR "communication barrier"[tiab] OR } \\
\text { "communication barriers"[tiab] OR Non-English[tiab] OR (English[tiab] } \\
\text { AND language[tiab] AND (proficien* OR speak*[tiab] OR second[tiab])) } \\
\text { OR prison* [tiab] OR incarcerat*[tiab] OR jail*[tiab] }\end{array}$ \\
\hline
\end{tabular}




\begin{tabular}{|c|c|c|}
\hline $\begin{array}{l}\text { Set } \\
\text { Number }\end{array}$ & Concept & Search Statement \\
\hline "\#4 & $\begin{array}{l}\text { Medically } \\
\text { vulnerable } \\
\text { populations }\end{array}$ & 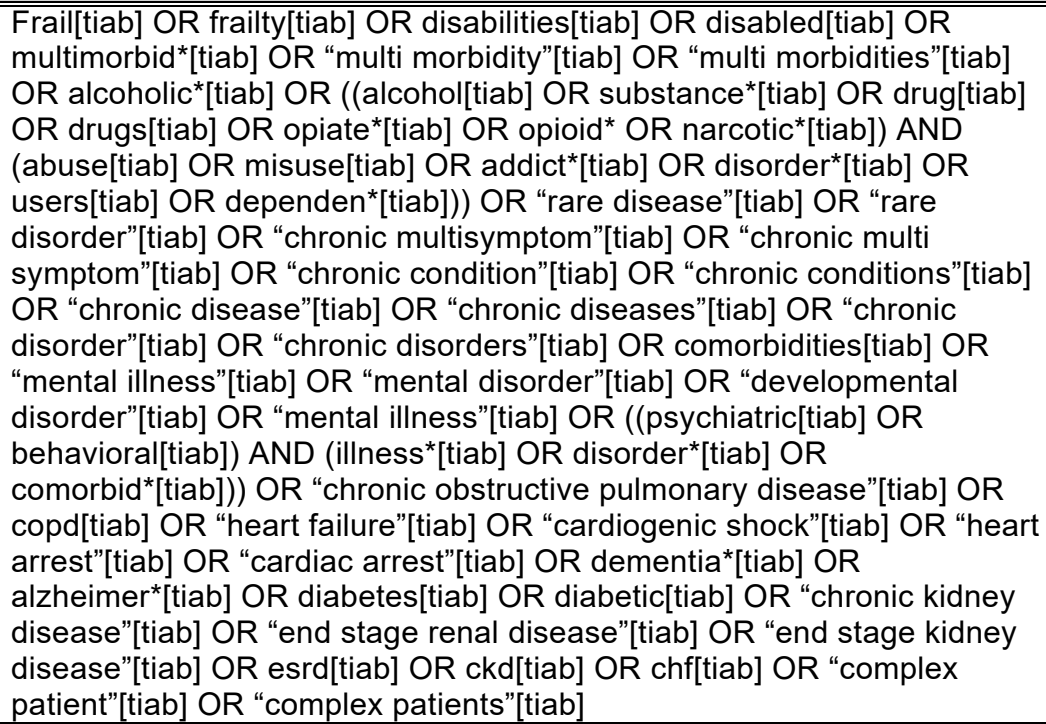 \\
\hline$\# 5$ & $\begin{array}{l}\text { Organizational } \\
\text { interventions }\end{array}$ & 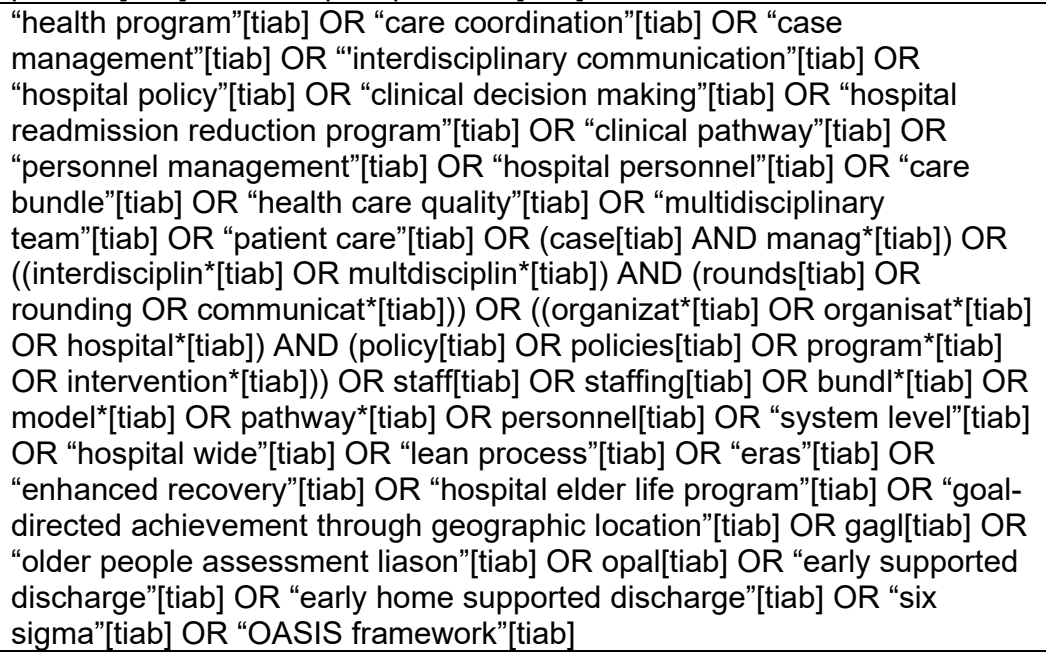 \\
\hline \#6 & Combine sets & $\# 1$ OR (\#2 AND (\#3 OR \#4 OR \#5)) \\
\hline \#7 & $\begin{array}{l}\text { Remove } \\
\text { unwanted } \\
\text { publication } \\
\text { types }\end{array}$ & 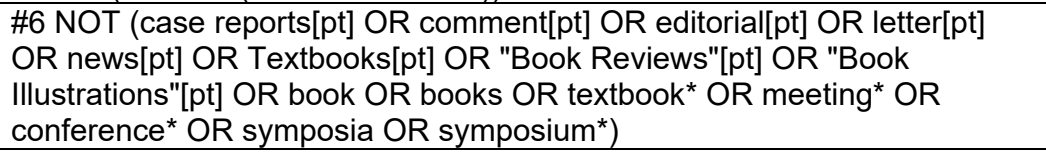 \\
\hline \#8 & $\begin{array}{l}\text { Limit to } \\
\text { systematic } \\
\text { reviews and } \\
\text { meta-analyses }\end{array}$ & $\begin{array}{l}\text { \#7 AND (meta-analysis OR meta-analysis[pt] OR meta-analyses OR } \\
\text { metaanalysis OR metaanalyses OR "Systematic Review"[pt] OR } \\
\text { (systematic*[tiab] AND review*[tiab])) }\end{array}$ \\
\hline \#9 & $\begin{array}{l}\text { Limit to in- } \\
\text { process } \\
\text { citations }\end{array}$ & \#8 AND ("inprocess"[sb] OR publisher[sb] OR pubmednotmedline[sb]) \\
\hline
\end{tabular}

\section{PubMed Syntax:}

* $\quad=$ truncation character (wildcard)

[edat] $=$ entrez date (date added to database)

[sb] $=$ subset

[ti] = limit to title field

[tiab] $=$ limit to title and abstract fields 


\section{Appendix B. List of Excluded Studies}

\section{Not U.S.-Based}

1. Abdelaal E, Rao SV, Gilchrist IC, Bernat I, Shroff A, Caputo R, Costerousse O, Pancholy SB, Bertrand OF. Same-day discharge compared with overnight hospitalization after uncomplicated percutaneous coronary intervention: a systematic review and metaanalysis. Jacc. Cardiovascular Interventions. Feb 2013. 6:99-112. Also available:

https://doi.org/10.1016/j.suronc.2019.11.004. PMID: 23352820.

2. Abraha I, Trotta F, Rimland JM, Cruz-Jentoft A, Lozano-Montoya I, Soiza RL, Pierini V, Fulgheri PD, Lattanzio F, O'Mahony D, Cherubini A. Efficacy of non-pharmacological interventions to prevent and treat delirium in older patients: A systematic overview. The SENATOR project ONTOP series. Plos One. 10 Jun 2015. 10. Also available: https://doi.org/10.1371/journal.pone.0123090. PMID: 26062023.

3. Adam Camila Thaís, Teixeira Vieira Cintia, da Costa Aguiar Susana, Bündchen Daiana, Soares Rocha Vieira Danielle. Non-invasive mechanical ventilation weaning protocols: a systematic review. Fisioterapia E Pesquisa. Oct 2017. 24:453-461. Also available: https://doi.org/10.1590/18092950/17542224042017.

4. Alam N, Hobbelink EL, van Tienhoven AJ, van de Ven PM, Jansma EP, Nanayakkara PWB. The impact of the use of the Early Warning Score (EWS) on patient outcomes: A systematic review. Resuscitation. May 2014. 85:587-594. Also available:

https://doi.org/10.1016/j.resuscitation.2014.01.01 3. PMID: 24467882.

5. Allen J, Hutchinson AM, Brown R, Livingston PM. Quality care outcomes following transitional care interventions for older people from hospital to home: a systematic review. Bmc Health Services Research. 2014. Also available: https://doi.org/10.1186/1472-6963-14-346. PMID: 25128468.
6. Auger KA, Kenyon CC, Feudtner C, Davis MM. Pediatric hospital discharge interventions to reduce subsequent utilization: A systematic review. Journal Of Hospital Medicine. April 2014. 9:251-260. Also available: https://doi.org/10.1002/jhm.2134. PMID: 24357528.

7. Bettger JP, Alexander KP, Dolor RJ, Olson DM, Kendrick AS, Wing L, Coeytaux RR, Graffagnino C, Duncan PW. Transitional care after hospitalization for acute stroke or myocardial infarction: A systematic review. Annals Of Internal Medicine. 18 Sep 2012. 157:407-416. Also available: https://doi.org/10.7326/0003-4819-157-6201209180-00004. PMID: 22986378.

8. Biesty LM, Egan AM, Dunne F, Dempsey E, Meskell P, Smith V, Ni Bhuinneain GM, Devane D. Planned birth at or near term for improving health outcomes for pregnant women with gestational diabetes and their infants. Cochrane Database Of Systematic Reviews. 5 Jan 2018. 2018. Also available: https://doi.org/10.1002/14651858.cd012910. PMID: 29303230.

9. Bond-Smith G, Belgaumkar AP, Davidson BR, Gurusamy KS. Enhanced recovery protocols for major upper gastrointestinal, liver and pancreatic surgery. The Cochrane Database Of Systematic Reviews. 1 Feb 2016. 2016. Also available: https://doi.org/10.1002/14651858.cd011382.pub 2. PMID: 26829903.

10. Brooke Joanne, Pendlebury Sarah T, Jackson Debra, Hall Claire L. What is the Impact of Volunteers Providing Care and Support for People with Dementia in Acute Hospitals? A Systematic Review. Dementia. May 2019. 18:1410-1427. Also available: https://doi.org/10.1177/1471301217713325. PMID: 28587482.

11. Bruns ERJ, van den Heuvel B, Buskens CJ, van Duijvendijk P, Festen S, Wassenaar EB, van der Zaag ES, Bemelman WA, van Munster BC. The effects of physical prehabilitation in elderly patients undergoing colorectal surgery: a systematic review. Colorectal Disease. 1 Aug 2016. 18. Also available: https://doi.org/10.1111/codi.13429. PMID: 27332897. 
12. Buecking B, Timmesfeld N, Riem S, Bliemel C, Hartwig E, Friess T, Liener U, Ruchholtz S, Eschbach D. Early orthogeriatric treatment of trauma in the elderly: A systematic review and metaanalysis. Deutsches Arzteblatt International. 12 Apr 2013. 110:255-262. Also available: https://doi.org/10.3238/arztebl.2013.0255. PMID: 23667392.

13. Buggy A. The impact of the multidisciplinary team in the management of individuals with diabetic foot ulcers: a systematic review. Journal Of Wound Care. Jun 2017. 26:324-338. Also available:

https://doi.org/10.12968/jowc.2017.26.6.324. PMID: 28598756.

14. Burlet KJDE, Ing AJ, Larsen PD, Dennett ER. Systematic review of diagnostic pathways for patients presenting with acute abdominal pain. International Journal For Quality In Health Care. 2018. 30:678-683. Also available: https://doi.org/10.1093/intqhe/mzy079. PMID: 29668935.

15. Butler M, Schultz TJ, Halligan P, Sheridan A, Kinsman L, Rotter T, Beaumier J, Kelly RG, Drennan J. Hospital nurse-staffing models and patient-and staff-related outcomes. Cochrane Database Of Systematic Reviews. 2019 Apr 23:CD007019. Also available:

https://doi.org/10.1002/14651858.cd007019.pub 2: PMID: 21735407.

16. Cao SJ, Chen D, Yang L, Zhu T. Effects of an abnormal mini-mental state examination score on postoperative outcomes in geriatric surgical patients: A meta-analysis. Bmc Anesthesiology. 15 May 2019. 19. Also available: https://doi.org/10.1186/s12871-019-0735-5.

17. Collins CT, Makrides M, Mcphee AJ. Early discharge with home support of gavage feeding for stable preterm infants who have not established full oral feeds. Cochrane Database Of Systematic Reviews. 8 Jul 2015. Also available: https://doi.org/10.1002/14651858.cd003743.pub 2. PMID: 26154426.

18. Connell CJ, Endacott R, Jackman JA, Kiprillis NR, Sparkes LM, Cooper SJ. The effectiveness of education in the recognition and management of deteriorating patients: A systematic review. Nurse Education Today. 1 Sep 2016:133-145. Also available: https://doi.org/10.1016/j.nedt.2016.06.001. PMID: 27429343.
19. Cuevas-Lara C, Izquierdo M, Gutiérrez-Valencia M, Marín-Epelde I, Zambom-Ferraresi F, Contreras-Escámez B, Martínez-Velilla N. Effectiveness of occupational therapy interventions in acute geriatric wards: A systematic review. Maturitas. 1 Sep 2019:43-50. Also available: https://doi.org/10.1016/j.maturitas.2019.06.005. PMID: 31351519.

20. Daghash H, Lim Abdullah K, Ismail MD. The effect of acute coronary syndrome care pathways on in-hospital patients: A systematic review. Journal Of Evaluation In Clinical Practice. 2019. Also available: https://doi.org/10.1111/jep.13280. PMID: 31489762 .

21. Damiani G, Pinnarelli L, Sommella L, Vena V, Magrini P, Ricciardi W. The short stay unit as a new option for hospitals: A review of the scientific literature. Medical Science Monitor. 2011. 17. Also available: https://doi.org/10.12659/msm.881791. PMID: 21629205.

22. Dave C, Shen J, Chaudhuri D, Herritt B, Fernando SM, Reardon PM, Tanuseputro P, Thavorn K, Neilipovitz D, Rosenberg E, Kubelik D, Kyeremanteng K. Dynamic Assessment of Fluid Responsiveness in Surgical ICU Patients Through Stroke Volume Variation is Associated With Decreased Length of Stay and Costs: A Systematic Review and Meta-Analysis. Journal Of Intensive Care Medicine. 1 Jan 2020. 35:1423. Also available: https://doi.org/10.1177/0885066618805410. PMID: 30309279.

23. Degirolamo K, Murphy PB, D'Souza K, Zhang JX, Parry N, Haut E, Robert Leeper W, Leslie K, Vogt KN, Morad Hameed S. Processes of health care delivery, education, and provider satisfaction in acute care surgery: A systematic review. American Surgeon. 1 Dec 2017. 83:1438-1446. PMID: 29336769.

24. Dehkordi A, Sarokhani D, Ghafari M, Mikelani M, Mahmoodnia L. Effect of palliative care on quality of life and survival after cardiopulmonary resuscitation: A systematic review. International Journal Of Preventive Medicine. 1 Jan 2019. 10. Also available: https://doi.org/10.4103/ijpvm.ijpvm_191_18. PMID: 31579159. 
25. Delardes B, McLeod L, Chakraborty S, Bowles $\mathrm{KA}$. What is the effect of electronic clinical handovers on patient outcomes? A systematic review. Health Informatics Journal. 29 Feb 2020. Also available:

https://doi.org/10.1177\%2F1460458220905162. PMID: 32114869.

26. Davey P, Marwick CA, Scott CL, Charani E, Mcneil K, Brown E, Gould IM, Ramsay CR, Michie S. Interventions to improve antibiotic prescribing practices for hospital inpatients. Cochrane Database Of Systematic Reviews. 9 Feb 2017. 2017. Also available: https://doi.org/10.1002/14651858.cd003543.pub 4. PMID: 28178770.

27. Dawoud DM, Smyth M, Ashe J, Strong T, Wonderling D, Hill J, Varia M, Dyer P, Bion J. Effectiveness and cost effectiveness of pharmacist input at the ward level: a systematic review and meta-analysis. Research In Social \& Administrative Pharmacy : Rsap. 2019 Oct. 15:1212-1222. Also available: https://doi.org/10.1016/j.sapharm.2018.10.006. PMID: 30389320.

28. Eamer G, Saravana-Bawan B, van der Westhuizen B, Chambers T, Ohinmaa A, Khadaroo RG. Economic evaluations of comprehensive geriatric assessment in surgical patients: a systematic review. Journal Of Surgical Research. 1 Oct 2017:9-17. Also available:

https://doi.org/10.1016/j.jss.2017.03.041. PMID: 28985882.

29. Eamer G, Taheri A, Chen SS, Daviduck Q, Chambers T, Shi X, Khadaroo RG.

Comprehensive geriatric assessment for older people admitted to a surgical service. Cochrane Database Of Systematic Reviews. 31 Jan 2018. Also available:

https://doi.org/10.1002/14651858.cd012485.pub 2. PMID: 29385235.

30. Echevarria C, Brewin K, Horobin H, Bryant A, Corbett S, Steer J, Bourke SC. Early Supported Discharge/Hospital At Home For Acute Exacerbation of Chronic Obstructive Pulmonary Disease: A Review and Meta-Analysis. Copd: Journal Of Chronic Obstructive Pulmonary Disease. 3 Jul 2016. 13:523-533. Also available: https://doi.org/10.3109/15412555.2015.1067885. PMID: 26854816.
31. Feast AR, White N, Candy B, Kupeli N, Sampson EL. The effectiveness of interventions to improve the care and management of people with dementia in general hospitals: A systematic review. International Journal Of Geriatric Psychiatry. 1 May 2020. 35:463-488. Also available: https://doi.org/10.1002/gps.5280. PMID: 32011033.

32. Fox MT, Persaud M, Maimets I, O'Brien K, Brooks D, Tregunno D, Schraa E. Effectiveness of acute geriatric unit care using acute care for elders components: A systematic review and meta-analysis. Journal Of The American Geriatrics Society. December 2012. 60:22372245. Also available: https://doi.org/10.1111/jgs.12028. PMID: 23176020 .

33. Fukumoto M, Watanabe T, Yasufuku Y, Furudate K, Momosaki R. Home visits by occupational therapists in acute hospital care: a systematic review. International Journal Of Rehabilitation Research. 1 Sep 2019. 42:205210. Also available: https://doi.org/10.1097/mrr.0000000000000350. PMID: 30973422.

34. Furlan AD, Olson DM, Bettger JP, Alexander KP, Kendrick AS, Irvine JR, Wing L, Coeytaux RR, Dolor RJ, Duncan PW, Graffagnino C. Transition of care for acute stroke and myocardial infarction patients: from hospitalization to rehabilitation, recovery, and secondary prevention. Evidence Report/Technology Assessment. Oct 2011:1197. PMID: 23126647.

35. Gomes F, Baumgartner A, Bounoure L, Bally M, Deutz NE, Greenwald JL, Stanga Z, Mueller B, Schuetz P. Association of Nutritional Support with Clinical Outcomes among Medical Inpatients Who Are Malnourished or at Nutritional Risk: An Updated Systematic Review and Meta-analysis. Jama Network Open. 20 Nov 2019. 2. Also available: https://doi.org/10.1001/jamanetworkopen.2019.1 5138. PMID: 31747030.

36. Gonçalves-Bradley DC, Iliffe S, Doll HA, Broad J, Gladman J, Langhorne P, Richards SH, Shepperd S. Early discharge hospital at home. Cochrane Database Of Systematic Reviews. 26 Jun 2017. Also available: https://doi.org/10.1002/14651858.cd000356.pub 4. PMID: 28651296. 
37. Gong W, Li A, Ai H, Shi H, Wang X, Nie S. Safety of early discharge after primary angioplasty in low-risk patients with ST-segment elevation myocardial infarction: A meta-analysis of randomised controlled trials. European Journal Of Preventive Cardiology. 1 May 2018. 25:807-815. Also available: https://doi.org/10.1177/2047487318763823. PMID: 29537296.

38. Grigoryan KV, Javedan H, Rudolph JL. Orthogeriatric care models and outcomes in hip fracture patients: A systematic review and metaanalysis. Journal Of Orthopaedic Trauma. March 2014. 28:e49-e55. Also available: https://doi.org/10.1097/bot.0b013e3182a5a045. PMID: 23912859.

39. Guo P. Preoperative education interventions to reduce anxiety and improve recovery among cardiac surgery patients: a review of randomised controlled trials. Journal Of Clinical Nursing. 1 Jan 2015. 24:34-46. Also available: https://doi.org/10.1111/jocn.12618. PMID: 24894181.

40. Hajibandeh S, Hajibandeh S, Bill V, Satyadas T. Meta-analysis of Enhanced Recovery After Surgery (ERAS) Protocols in Emergency Abdominal Surgery. World Journal Of Surgery. 1 May 2020. 44:1336-1348. Also available: https://doi.org/10.1007/s00268-019-05357-5. PMID: 31897698.

41. Hamline MY, Speier RL, Vu PD, Tancredi D, Broman AR, Rasmussen LN, Tullius BP, Shaikh U, Li STT. Hospital-to-home interventions, use, and satisfaction: A meta-analysis. Pediatrics. 1 Nov 2018. 142. Also available: https://doi.org/10.1542/peds.2018-0442. PMID: 30352792 .

42. Hill-Taylor B, Walsh KA, Stewart SA, Hayden J, Byrne S, Sketris IS. Effectiveness of the STOPP/START (Screening Tool of Older Persons' potentially inappropriate Prescriptions/Screening Tool to Alert doctors to the Right Treatment) criteria: Systematic review and meta-analysis of randomized controlled studies. Journal Of Clinical Pharmacy And Therapeutics. 1 Apr 2016. 41:158-169. Also available: https://doi.org/10.1111/jept.12372. PMID: 26990017.
43. Hohl CM, Wickham ME, Sobolev B, Perry JJ, Sivilotti MLA, Garrison S, Lang E, Brasher P, Doyle-Waters MM, Brar B, Rowe BH, Lexchin J, Holland R. The effect of early in-hospital medication review on health outcomes: A systematic review. British Journal Of Clinical Pharmacology. 1 Jul 2015. 80:51-61. Also available: https://doi.org/10.1111/bcp.12585. PMID: 25581134.

44. Hopfe M, Stucki G, Marshall R, Twomey CD, Üstün TB, Prodinger B. Capturing patients' needs in casemix: a systematic literature review on the value of adding functioning information in reimbursement systems. Bmc Health Services Research. 3 Feb 2016. Also available: https://dx.doi.org/10.1186\%2Fs12913-016-1277x. PMID: 26847062.

45. Hshieh TT, Yang T, Gartaganis SL, Yue J, Inouye SK. Hospital Elder Life Program: Systematic Review and Meta-analysis of Effectiveness. American Journal Of Geriatric Psychiatry. 1 Oct 2018. 26:1015-1033. Also available:

https://doi.org/10.1016/j.jagp.2018.06.007. PMID: 30076080.

46. Hshieh TT, Yue J, Oh E, Puelle M, Dowal S, Travison T, Inouye SK. Effectiveness of multicomponent nonpharmacological delirium interventions: A meta-analysis. Jama Internal Medicine. 1 Apr 2015. 175:512-520. Also available:

https://doi.org/10.1001/jamainternmed.2014.777 9. PMID: 25643002.

47. Huang D, Song X, Tian J, Cui Q, Yang K. Effects of clinical pathways in stroke management: A meta-analysis. Neurology Asia. 1 Dec 2015. 20:335-342.

48. Huntley AL, Thomas R, Mann M, Huws D, Elwyn G, Paranjothy S, Purdy S. Is case management effective in reducing the risk of unplanned hospital admissions for older people? A systematic review and meta-analysis. Family Practice. June 2013. 30:266-275. Also available: https://doi.org/10.1093/fampra/cms081. PMID: 23315222.

49. Hussain M, Seitz D. Integrated Models of Care for Medical Inpatients With Psychiatric Disorders: A Systematic Review. Psychosomatics. July 2014. 55:315-325. Also available: https://doi.org/10.1016/j.psym.2013.08.003. PMID: 24735866. 
50. Jayasundera R, Neilly M, Smith TO, Myint PK. Are Early Warning Scores Useful Predictors for Mortality and Morbidity in Hospitalised Acutely Unwell Older Patients? A Systematic Review. Journal Of Clinical Medicine. 2018 Sep 28. 7. Also available: https://doi.org/10.3390/jcm7100309. PMID: 30274205 .

51. Kaki R, Elligsen M, Walker S, Simor A, Palmay L, Daneman N. Impact of antimicrobial stewardship in critical care: A systematic review. Journal Of Antimicrobial Chemotherapy. June 2011. 66:1223-1230. Also available: https://doi.org/10.1093/jac/dkr137. PMID: 21460369.

52. Karanika S, Paudel S, Grigoras C, Kalbasi A, Mylonakis E. Systematic review and metaanalysis of clinical and economic outcomes from the implementation of hospital-based antimicrobial stewardship programs. Antimicrobial Agents And Chemotherapy. 1 Aug 2016. 60:4840-4852. Also available: https://doi.org/10.1128/aac.00825-16. PMID: 27246783.

53. Launay-Savary MV, Mathonnet M, Theissen A, Ostermann S, Raynaud-Simon A, Slim K. Are enhanced recovery programs in colorectal surgery feasible and useful in the elderly? A systematic review of the literature. Journal Of Visceral Surgery. 1 Feb 2017. 154:29-35. Also available:

https://doi.org/10.1016/j.jviscsurg.2016.09.016. PMID: 27842907.

54. Larsen T, Lee A, Brooks D, Michieli S, Robson M, Veens J, Vokes O, Lucy SD. Effect of Early Mobility as a Physiotherapy Treatment for Pneumonia: A Systematic Review and MetaAnalysis. Physiotherapy Canada. 2019 Winter. 71:82-89. Also available:

https://doi.org/10.3138/ptc.2017-51.ep. PMID: 30787503.

55. Laver K, Lannin NA, Bragge P, Hunter P, Holland AE, Tavender E, OConnor D, Khan F, Teasell R, Gruen R. Organising health care services for people with an acquired brain injury: an overview of systematic reviews and randomised controlled trials. Bmc Health Services Research. 2014 Sep 17. 14:397. Also available: https://doi.org/10.1186/1472-6963-14397. PMID: 25228157.
56. Lee SY, Fisher J, Wand APF, Milisen K, Detroyer E, Sockalingam S, Agar M, Hosie A, Teodorczuk A. Developing delirium best practice: a systematic review of education interventions for healthcare professionals working in inpatient settings. European Geriatric Medicine. 1 Feb 2020. 11. Also available: https://doi.org/10.1007/s41999-019-00278-x.

57. Legg RG, Little M. Inpatient toxicology services improve resource utilization for intoxicated patients: a systematic review. British Journal of Clinical Pharmacology. 1 Jan 2019. 85:11-19.

Also available: https://doi.org/10.1111/bcp.13768. PMID: 30238503.

58. Li Z, Yuan X, Yu L, Wang B, Gao F, Ma J, Liu J. Procalcitonin-guided antibiotic therapy in acute exacerbation of chronic obstructive pulmonary disease: An updated meta-analysis. Medicine. 1 Aug 2019. 98. Also available: https://doi.org/10.1097/md.0000000000016775. PMID: 31393400.

59. Lodewijckx C, Sermeus W, Panella M, Deneckere S, Leigheb F, Decramer M, Vanhaecht K. Impact of care pathways for inhospital management of COPD exacerbation: a systematic review. International Journal of Nursing Studies. 2011 Nov. 48:1445-56. Also available: https://doi.org/10.1016/j.ijnurstu.2011.06.006. PMID: 21798538.

60. MacMillan KDL, Rendon CP, Verma K, Riblet $\mathrm{N}$, Washer DB, Volpe Holmes A. Association of rooming-in with outcomes for neonatal abstinence syndrome: A systematic review and meta-analysis. Jama Pediatrics. 1 Apr 2018. 172:345-351. Also available: https://doi.org/10.1001/jamapediatrics.2017.5195 . PMID: 29404599.

61. Martinez F, Tobar C, Hill N. Preventing delirium: Should non-pharmacological, multicomponent interventions be used? A systematic review and meta-analysis of the literature. Age And Ageing. 1 Mar 2015. 44:196204. Also available: https://doi.org/10.1093/ageing/afu173. PMID: 25424450 . 
62. Mathioudakis AG, Chatzimavridou-Grigoriadou V, Corlateanu A, Vestbo J. Procalcitonin to guide antibiotic administration in COPD exacerbations: A meta-analysis. European Respiratory Review. 1 Jan 2017. 26. Also available:

https://doi.org/10.1183/16000617.0073-2016. PMID: 28143877.

63. Matthaiou DK, Ntani G, Kontogiorgi M, Poulakou G, Armaganidis A, Dimopoulos G. An ESICM systematic review and meta-analysis of procalcitonin-guided antibiotic therapy algorithms in adult critically ill patients. Intensive Care Medicine. June 2012. 38:940-949. Also available: https://doi.org/10.1007/s00134012-2563-7. PMID: 22538461.

64. McCausland BMS, Patel HP, Amin J, Baldwin DS, Loughran K, Osman-Hicks VC. A systematic review of specialist inpatient dementia care services versus standard inpatient dementia care in acute hospitals. Aging Clinical And Experimental Research. 3 May 2019. 31:595-610. Also available: https://doi.org/10.1007/s40520-018-1021-y. PMID: 30259497.

65. McGinigle KL, Eldrup-Jorgensen J, McCall R, Freeman NL, Pascarella L, Farber MA, Marston WA, Crowner JR. A systematic review of enhanced recovery after surgery for vascular operations. Journal Of Vascular Surgery. 1 Aug 2019. 70. Also available: https://doi.org/10.1016/j.jvs.2019.01.050. PMID: 30922754.

66. McKelvie S, Hall AM, Richmond HR, Finnegan $\mathrm{S}$, Lasserson D. Improving the rehabilitation of older people after emergency hospital admission. Maturitas. 1 May 2018:20-30. Also available: https://doi.org/10.1016/j.maturitas.2018.02.011. PMID: 29673829.

67. McKenzie J, Joy A. Family intervention improves outcomes for patients with delirium: Systematic review and meta-analysis. Australasian Journal On Ageing. 2020 Mar. 39:21-30. Also available: https://doi.org/10.1111/ajag.12688. PMID: 31250961 .

68. McNeill G, Bryden D. Do either early warning systems or emergency response teams improve hospital patient survival? A systematic review. Resuscitation. December 2013. 84:1652-1667. Also available: https://doi.org/10.1016/j.resuscitation.2013.08.00 6. PMID: 23962485.
69. Morgan JE, Cleminson J, Stewart LA, Phillips RS, Atkin K. Meta-ethnography of experiences of early discharge, with a focus on paediatric febrile neutropenia. Supportive Care In Cancer. 1 Apr 2018. 26:1039-1050. Also available: https://doi.org/10.1007/s00520-017-3983-2. PMID: 29285558.

70. Oberai T, Laver K, Crotty M, Killington M, Jaarsma R. Effectiveness of multicomponent interventions on incidence of delirium in hospitalized older patients with hip fracture: A systematic review. International Psychogeriatrics. 1 Apr 2018. 30:481-492. Also available:

https://doi.org/10.1017/s1041610217002782. PMID: 29295719.

71. Osborne Candice L, Neville Marsha. Understanding the Experience of Early Supported Discharge from the Perspective of Patients with Stroke and Their Carers and Health Care Providers: A Qualitative Review. Nursing Clinics Of North America. Sep 2019. 54:367385. Also available: https://doi.org/10.1016/j.cnur.2019.04.006. PMID: 31331624.

72. Paduraru M, Ponchietti L, Casas IM, Svenningsen P, Pereira J, Landaluce-Olavarria A, Font RF, Miguel IP, Ugarte-Sierra B. Enhanced Recovery After Surgery (ERAS) - The Evidence in Geriatric Emergency Surgery: A Systematic Review. Chirurgia. 1 Sep 2017. 112:546-557. Also available: https://doi.org/10.21614/chirurgia.112.5.546. PMID: 29088554.

73. Peiris CL, Shields N, Brusco NK, Watts JJ, Taylor NF. Additional Physical Therapy Services Reduce Length of Stay and Improve Health Outcomes in People With Acute and Subacute Conditions: An Updated Systematic Review and Meta-Analysis. Archives Of Physical Medicine And Rehabilitation. 1 Nov 2018. 99:2299-2312. Also available: https://doi.org/10.1016/j.apmr.2018.03.005. PMID: 29634915.

74. Peiris CL, Taylor NF, Shields N. Extra physical therapy reduces patient length of stay and improves functional outcomes and quality of life in people with acute or subacute conditions: A systematic review. Archives Of Physical Medicine And Rehabilitation. September 2011. 92:1490-1500. Also available:

https://doi.org/10.1016/j.apmr.2011.04.005. PMID: 21878220. 
75. Peng L, Ren PW, Liu XT, Zhang C, Zuo HX, Kang DY, Niu YM. Use of noninvasive ventilation at the pulmonary infection control window for acute respiratory failure in AECOPD patients A systematic review and meta-analysis based on GRADE approach. Medicine. 21 Jun 2016. 95. Also available: https://doi.org/10.1097/md.0000000000003880. PMID: 27310978.

76. Plishka CT, Rotter T, Penz ED, Hansia MR, Fraser SA, Marciniuk DD. Effects of Clinical Pathways for COPD on Patient, Professional, and Systems Outcomes: A Systematic Review. Chest. 2019 Nov. 156:864-877. Also available: https://doi.org/10.1016/j.chest.2019.04.131. PMID: 31150639.

77. Ramesh C, Nayak Baby S, Pai Vasudev Baburaya, Patil Nitin T, George Anice, George Linu Sara, Devi Elsa Sanatombi. Effect of Preoperative Education on Postoperative Outcomes Among Patients Undergoing Cardiac Surgery: A Systematic Review and MetaAnalysis. Journal Of Perianesthesia Nursing. Dec 2017. 32:518-519. Also available: https://doi.org/10.1016/j.jopan.2016.11.011. PMID: 29157759.

78. Renaudin P, Boyer L, Esteve MA, Bertault-Peres P, Auquier P, Honore S. Do pharmacist-led medication reviews in hospitals help reduce hospital readmissions? A systematic review and meta-analysis. British Journal Of Clinical Pharmacology. 2016. 82:1660-1673. Also available: https://doi.org/10.1111/bcp.13085. PMID: 27511835.

79. Robalino S, Nyakang'o SB, Beyer FR, Fox C, Allan LM. Effectiveness of interventions aimed at improving physical and psychological outcomes of fall-related injuries in people with dementia: A narrative systematic review. Systematic Reviews. 20 Feb 2018. 7. Also available: https://doi.org/10.1186/s13643-0180697-6. PMID: 29463292.

80. Rotter T, Kinsman L, James E, Machotta A, Gothe H, Willis J, Snow P, Kugler J. Clinical pathways: effects on professional practice, patient outcomes, length of stay and hospital costs. The Cochrane Database Of Systematic Reviews. 2010:CD006632. Also available: https://doi.org/10.1002/14651858.cd006632.pub 2. PMID: 20238347.
81. Ryrsø CK, Godtfredsen NS, Kofod LM, Lavesen M, Mogensen L, Tobberup R, FarverVestergaard I, Callesen HE, Tendal B, Lange P, Iepsen UW. Lower mortality after early supervised pulmonary rehabilitation following COPD-exacerbations: a systematic review and meta-analysis. Bmc Pulmonary Medicine. 2018 Sep 15. 18:154. Also available: https://doi.org/10.1186/s12890-018-0718-1. PMID: 30219047.

82. Sandall J, Soltani H, Gates S, Shennan A, Devane D. Midwife-led continuity models versus other models of care for childbearing women. Cochrane Database Of Systematic Reviews. 28 Apr 2016. Also available: https://doi.org/10.1002/14651858.cd004667.pub 5. PMID: 27121907.

83. Schuetz P, Müller B, Christ-Crain M, Stolz D, Tamm M, Bouadma L, Luyt CE, Wolff M, Chastre J, Tubach F, Kristoffersen KB, Burkhardt O, Welte T, Schroeder S, Nobre V, Wei L, Bhatnagar N, Bucher HC, Briel M. Procalcitonin to initiate or discontinue antibiotics in acute respiratory tract infections. Cochrane Database Of Systematic Reviews. 2012. Also available:

https://doi.org/10.1002/14651858.cd007498.pub 3. PMID: 29025194.

84. Shields L, Henderson V, Caslake R. Comprehensive Geriatric Assessment for Prevention of Delirium After Hip Fracture: A Systematic Review of Randomized Controlled Trials. Journal Of The American Geriatrics Society. 1 Jul 2017. 65:1559-1565. Also available: https://doi.org/10.1111/jgs.14846. PMID: 28407199.

85. Singh PM, Panwar R, Borle A, Goudra B, Trikha A, van Wagensveld BA, Sinha A. Efficiency and Safety Effects of Applying ERAS Protocols to Bariatric Surgery: a Systematic Review with Meta-Analysis and Trial Sequential Analysis of Evidence. Obesity Surgery. 1 Feb 2017. 27:489501. Also available: https://doi.org/10.1007/s11695-016-2442-3. PMID: 27878754 
86. Skjøt-Arkil H, Lundby C, Kjeldsen LJ, Skovgårds DM, Almarsdóttir AB, Kjølhede T, Duedahl TH, Pottegård A, Graabæk T. Multifaceted Pharmacist-led Interventions in the Hospital Setting: A Systematic Review. Basic And Clinical Pharmacology And Toxicology. 1 Oct 2018. 123:363-379. Also available: https://doi.org/10.1111/bcpt.13030. PMID: 29723934.

87. Smith MEB, Chiovaro JC, O'Neil M, Kansagara D, Quiñones AR, Freeman M, Motu'apuaka ML, Slatore CG. Early warning system scores for clinical deterioration in hospitalized patients: A systematic review. Annals Of The American Thoracic Society. 1 Nov 2014. 11:1454-1465. Also available: https://doi.org/10.1513/annalsats.201403-102oc. PMID: 25296111.

88. Smith TO, Gilbert AW, Sreekanta A, Sahota O, Griffin XL, Cross JL, Fox C, Lamb SE. Enhanced rehabilitation and care models for adults with dementia following hip fracture surgery. Cochrane Database Of Systematic Reviews. 7 Feb 2020. Also available: https://doi.org/10.1002/14651858.CD010569.pu b3.

89. Snowdon D, Haines TP, Skinner EH. Preoperative intervention reduces postoperative pulmonary complications but not length of stay in cardiac surgical patients: a systematic review. Journal Of Physiotherapy. 1 Jun 2014. 60:66-77. Also available:

https://doi.org/10.1016/j.jphys.2014.04.002. PMID: 24952833.

90. Stobaugh Heather C, Mayberry Amy, Lelijveld Natasha, McGrath Marie, Bahwere Paluku, Zagre Noël Marie, Manary Mark J, Black Robert. Relapse after severe acute malnutrition: A systematic literature review and secondary data analysis. Maternal \& Child Nutrition. Apr 2019. 15:N.PAG. Also available: https://doi.org/10.1111/mcn.12702. PMID: 30246929.

91. Sun Y, Paulus D, Eyssen M, Maervoet J, Saka O. A systematic review and meta-analysis of acute stroke unit care: what's beyond the statistical significance?. Bmc Medical Research Methodology. 2013. Also available: https://doi.org/10.1186/1471-2288-13-132. PMID: 24164771.
92. Takeda A, Taylor SJ, Taylor RS, Khan F, Krum $\mathrm{H}$, Underwood M. Clinical service organisation for heart failure. Cochrane Database Of Systematic Reviews. 2012. Also available: https://doi.org/10.1002/14651858.cd002752.pub 3. PMID: 22972058.

93. Tesfaye WH, Castelino RL, Wimmer BC, Zaidi STR. Inappropriate prescribing in chronic kidney disease: A systematic review of prevalence, associated clinical outcomes and impact of interventions. International Journal Of Clinical Practice. 1 Jul 2017. 71. Also available: https://doi.org/10.1111/ijcp.12960. PMID: 28544106.

94. Valenzuela PL, Morales JS, Castillo-García A, Mayordomo-Cava J, García-Hermoso A, Izquierdo M, Serra-Rexach JA, Lucia A. Effects of exercise interventions on the functional status of acutely hospitalised older adults: A systematic review and meta-analysis. Ageing Research Reviews. 2020 Apr 21:101076. Also available: https://doi.org/10.1016/j.arr.2020.101076.

95. Van Grootven BV, Flamaing J, De Casterlé BD, Dubois C, Fagard K, Herregods MC, Hornikx M, Laenen A, Meuris B, Rex S, Tournoy J, Milisen K, Deschodt M. Effectiveness of in-hospital geriatric co-management: A systematic review and meta-analysis. Age And Ageing. 2017. 46:903-910. Also available: https://doi.org/10.1093/ageing/afx051. PMID: 28444116.

96. Van Sluisveld N, Hesselink G, Van Der Hoeven JG, Westert G, Wollersheim H, Zegers M. Improving clinical handover between intensive care unit and general ward professionals at intensive care unit discharge. Intensive Care Medicine. 12 Feb 2015. Also available: https://doi.org/10.1007/s00134-015-3666-8. PMID: 25672275.

97. van Veenendaal NR, Heideman WH, Limpens J, van der Lee JH, van Goudoever JB, van Kempen AAMW, van der Schoor SRD. Hospitalising preterm infants in single family rooms versus open bay units: a systematic review and metaanalysis. The Lancet Child And Adolescent Health. 1 Mar 2019. 3:147-157. Also available: https://doi.org/10.1016/S2352-4642(18)30375-4. 
98. Wang H, Li C, Zhang Y, Jia Y, Zhu Y, Sun R, Li $\mathrm{W}$, Liu Y. The influence of inpatient comprehensive geriatric care on elderly patients with hip fractures: a meta-analysis of randomized controlled trials. International Journal Of Clinical And Experimental Medicine. 2015. 8:19815-30. PMID: 26884892.

99. Wong WT, Lai VKW, Chee YE, Lee A. Fasttrack cardiac care for adult cardiac surgical patients. Cochrane Database Of Systematic Reviews. 12 Sep 2016. 2016. Also available: https://doi.org/10.1002/14651858.cd003587.pub 3. PMID: 27616189.

100. Yeung J, Couper K, Ryan EG, Gates S, Hart N, Perkins GD. Non-invasive ventilation as a strategy for weaning from invasive mechanical ventilation: a systematic review and Bayesian meta-analysis. Intensive Care Medicine. 1 Dec 2018. 44:2192-2204. Also available: https://doi.org/10.1007/s00134-018-5434-z. PMID: 30382306.

101.Yousefinezhadi T, Mohamadi E, Palangi HS, Sari AA. The effect of ISO 9001 and the EFQM model on improving hospital performance: A systematic review. Iranian Red Crescent Medical Journal. 27 Dec 2015. 17. Also available: https://dx.doi.org/10.5812\%2Fircmj.23010. PMID: 26756012.

102. Chakraborty A, Pearson O, Schwartzkopff KM, O'rourke I, Ranasinghe I, Mann Mah P, Adams R, Boyd M, Wittert G. The effectiveness of inhospital interventions on reducing hospital length of stay and readmission of patients with Type 2 Diabetes Mellitus: a systematic review. Diabetes Research And Clinical Practice. 6 Aug 2020. Also available:

https://doi.org/10.1016/j.diabres.2020.108363. PMID: 32771487.

\section{Narrative Review}

1. Aarts MA, Okrainec A, Glicksman A, Pearsall E, Charles Victor J, McLeod RS. Adoption of enhanced recovery after surgery (ERAS) strategies for colorectal surgery at academic teaching hospitals and impact on total length of hospital stay. Surgical Endoscopy. February 2012. 26:442-450. Also available: https://doi.org/10.1007/s00464-011-1897-5. PMID: 22011937.

2. Albalawi Z, Laffin M, Gramlich L, Senior P, McAlister FA. Enhanced Recovery After

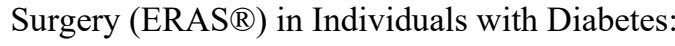

103. Snowdon DA, Storr B, Davis A, Taylor NF, Williams CM. The effect of delegation of therapy to allied health assistants on patient and organisational outcomes: a systematic review and meta-analysis. Bmc Health Services Research. 3 Jun 2020. 20. Also available: https://doi.org/10.1186/s12913-020-05312-4.

104.Pritchard E, Soh SE, Morello R, Berkovic D, Blair A, Anderson K, Bateman C, Moran C, Tsindos T, O'Donnell R, Ayton D. Volunteer programs supporting people with dementia/delirium in hospital: Systematic review and meta-analysis. The Gerontologist. 28 May 2020. Also available: https://doi.org/10.1093/geront/gnaa058. PMID: 32462186.

105.Thillainadesan J, Yumol MF, Hilmer S, Aitken SJ, Naganathan V. Interventions to Improve Clinical Outcomes in Older Adults Admitted to a Surgical Service: A Systematic Review and Meta-analysis. Journal Of The American Medical Directors Association. 2020. Also available: https://doi.org/10.1016/j.jamda.2020.03.023. PMID: 32417101.

106. Yasmeen I, Krewulak KD, Zhang C, Stelfox HT, Fiest KM. The Effect of Caregiver-Facilitated Pain Management Interventions in Hospitalized Patients on Patient, Caregiver, Provider, and Health System Outcomes: A Systematic Review. Journal Of Pain And Symptom Management. 2020. Also available: https://doi.org/10.1016/i.jpainsymman.2020.06.0 30. PMID: 32615297.

A Systematic Review. World Journal Of Surgery. 1 Aug 2017. 41:1927-1934. Also available: https://doi.org/10.1007/s00268-0173982-y. PMID: 28321553

3. Auckley D, Bolden N. Preoperative screening and perioperative care of the patient with sleepdisordered breathing. Current Opinion In Pulmonary Medicine. November 2012. 18:588595. Also available: https://doi.org/10.1097/mcp.0b013e3283589e6e. PMID: 22990655. 
4. Chow WB, Rosenthal RA, Merkow RP, Ko CY, Esnaola NF. Optimal preoperative assessment of the geriatric surgical patient: A best practices guideline from the American college of surgeons national surgical quality improvement program and the American geriatrics society. Journal Of The American College Of Surgeons. October 2012. 215:453-466. Also available:

https://doi.org/10.1016/j.jamcollsurg.2012.06.01 7. PMID: 22917646.

5. Copanitsanou Panagiota, Fotos Nikolaos, Brokalaki Hero. Effects of work environment on patient and nurse outcomes. British Journal Of Nursing. Feb 2017. 26:172-177. Also available: https://doi.org/10.12968/bjon.2017.26.3.172. PMID: 28185485.

6. Cropsey C, Kennedy J, Han J, Pandharipande P. Cognitive Dysfunction, Delirium, and Stroke in Cardiac Surgery Patients. Seminars In Cardiothoracic And Vascular Anesthesia. 1 Dec 2015. 19:309-317. Also available: https://doi.org/10.1177\%2F1089253215570062.

7. Freeman SC, Scott NW, Powell R, Johnston M, Sutton AJ, Cooper NJ. Component network meta-analysis identifies the most effective components of psychological preparation for adults undergoing surgery under general anesthesia. Journal Of Clinical Epidemiology. 1 Jun 2018:105-116. Also available: https://doi.org/10.1016/j.jclinepi.2018.02.012. PMID: 29476923.

8. Ginsberg GG, Chand B, Cote GA, Dallal RM, Edmundowicz SA, Nguyen NT, Pryor A, Thompson CC. A pathway to endoscopic bariatric therapies. A pathway to endoscopic bariatric therapies. 2011 Nov. 74:943-53. Also available:

https://doi.org/10.1016/j.soard.2011.09.008. PMID: 22082971.

9. Grocott MPW, Martin DS, Mythen MG. Enhanced recovery pathways as a way to reduce surgical morbidity. Current Opinion In Critical Care. August 2012. 18:385-392. Also available: https://doi.org/10.1097/mcc.0b013e3283558968. PMID: 22710280.

10. Halverson AL, Sellers MM, Bilimoria KY, Hawn MT, Williams MV, McLeod RS, Ko CY. Identification of process measures to reduce postoperative readmission. Journal Of Gastrointestinal Surgery : Official Journal Of The Society For Surgery Of The Alimentary Tract. 1 Aug 2014. 18:1407-1415. Also available: https://doi.org/10.1007/s11605-0132429-5. PMID: 24912913.
11. Herpertz-Dahlmann B. Treatment of eating disorders in child and adolescent psychiatry. Current Opinion In Psychiatry. 2017 Nov. 30:438-445. Also available: https://doi.org/10.1097/yco.0000000000000357. PMID: 28777106.

12. Hesselink G, Zegers M, Vernooij-Dassen M, Barach P, Kalkman C, Flink M, Öhlen G, Olsson $M$, Bergenbrant S, Orrego C, Suñol R, Toccafondi G, Venneri F, Dudzik-Urbaniak E, Kutryba B, Schoonhoven L, Wollersheim H. Improving patient discharge and reducing hospital readmissions by using Intervention Mapping. Bmc Health Services Research. 2014. Also available: https://doi.org/10.1186/14726963-14-389. PMID: 25218406.

13. Hirsch Calvin. 2015 - Review: Multicomponent nonpharmacologic interventions reduce incident delirium in inpatients. Acp Journal Club. Jul 2015. 163:3-4. Also available: https://doi.org/10.7326/acpjc-2015-163-2-004. PMID: 26192584.

14. James Lucy, Sweet Linda, Donnellan-Fernandez Roslyn. Breastfeeding initiation and support: A literature review of what women value and the impact of early discharge. Women \& Birth. Apr 2017. 30:87-100. Also available: https://doi.org/10.1016/j.wombi.2016.09.013. PMID: 27773608.

15. Kammerlander C, Roth T, Friedman SM, Suhm $\mathrm{N}$, Luger TJ, Kammerlander-Knauer U, Krappinger D, Blauth M. Ortho-geriatric servicea literature review comparing different models. Osteoporosis International. December 2010. 21. Also available: https://doi.org/10.1007/s00198010-1396-x. PMID: 21058004.

16. Kansagara D, Chiovaro JC, Kagen D, Jencks S, Rhyne K, O'Neil M, Kondo K, Relevo R, Motu'apuaka M, Freeman M, Englander H. So many options, where do we start? An overview of the care transitions literature. Journal Of Hospital Medicine. 1 Mar 2016. 11:221-230. Also available: https://doi.org/10.1002/jhm.2502. PMID: 26551918.

17. Lisby M, Thomsen A, Nielsen LP, Lyhne NM, Breum-Leer C, Fredberg U, Jørgensen H, Brock $B$. The effect of systematic medication review in elderly patients admitted to an acute ward of internal medicine. Basic And Clinical Pharmacology And Toxicology. May 2010. 106:422-427. Also available: https://doi.org/10.1111/j.17427843.2009.00511.x. PMID: 20059474. 
18. Mahan CE, Spyropoulos AC. Venous thromboembolism prevention: a systematic review of methods to improve prophylaxis and decrease events in the hospitalized patient. Hospital Practice. Feb 2010. 38:97-108. Also available: https://doi.org/10.3810/hp.2010.02.284. PMID: 20469630

19. Marcus KL, Henderson CM, Boss RD. Chronic critical illness in infants and children: A speculative synthesis on adapting ICU care to meet the needs of long-stay patients. Pediatric Critical Care Medicine. 1 Aug 2016. 17:743-752. Also available:

https://doi.org/10.1097/pcc.0000000000000792. PMID: 27295581.

20. Marino JM, Yegneswaran B. Delirium screening in the ICU. Nursing Critical Care. 2016. 11:1822. Also available: 10.1097/01.CCN.0000484685.15575.53.

21. Nowak M, Pfaff H, Karbach U. Does Value Stream Mapping affect the structure, process, and outcome quality in care facilities? A systematic review. Systematic Reviews. 24 Aug 2017. 6. Also available: https://doi.org/10.1186/s13643-017-0563-y. PMID: 28838320.

22. Rendell M, Saiprasad S, Trepp-Carrasco AG, Drincic A. The future of inpatient diabetes management: Glucose as the sixth vital sign. Expert Review Of Endocrinology And Metabolism. 2013. 8:195-205. Also available: https://doi.org/10.1586/eem.13.1. PMID: 30736179.

23. Rivosecchi RM, Kane-Gill SL, Svec S, Campbell S, Smithburger PL. The implementation of a nonpharmacologic protocol to prevent intensive care delirium. Journal Of Critical Care. 1 Feb 2016. 31:206-211. Also available: https://doi.org/10.1016/j.jcrc.2015.09.031. PMID: 26596509.

24. Saunders S, Killackey T, Kurahashi A, Walsh C, Wentlandt K, Lovrics E, Scott M, Mahtani R, Bernstein M, Howard M, Tanuseputro P,
Goldman R, Zimmermann C, Aslakson RA, Isenberg SR. Palliative Care Transitions From Acute Care to Community-Based Care-A Systematic Review. Journal Of Pain And Symptom Management. 1 Oct 2019. 58. Also available:

https://doi.org/10.1016/j.jpainsymman.2019.06.0 05. PMID: 31201875.

25. Seehusen DA. Clinical pathways: Effects on practice, outcomes, and costs. American Family Physician. December 1, 2010. 82:1338-1339. PMID: 21121516.

26. Shroff A, Kupfer J, Gilchrist IC, Caputo R, Speiser B, Bertrand OF, Pancholy SB, Rao SV. Same-day discharge after percutaneous coronary intervention: Current perspectives and strategies for implementation. Jama Cardiology. 1 May 2016. 1:216-223. Also available: https://doi.org/10.1001/jamacardio.2016.0148. PMID: 27437896

27. Soltani H, Sandall J. Organisation of maternity care and choices of mode of birth: A worldwide view. Midwifery. April 2012. 28:146-149. Also available:

https://doi.org/10.1016/j.midw.2012.01.009. PMID: 22365576.

28. Steinberg Daniel I. 2017 - Review: Interventions improve hospital antibiotic prescribing and reduce hospital stay but do not affect mortality. Acp Journal Club. May 2017. 166:10-11. Also available: https://doi.org/10.7326/acpjc-2017166-10-059. PMID: 28505643.

29. Swart E, Vasudeva E, Makhni EC, Macaulay W, Bozic KJ. Dedicated Perioperative Hip Fracture Comanagement Programs are Cost-effective in High-volume Centers: An Economic Analysis. Clinical Orthopaedics And Related Research. 1 Jan 2016. 474:222-233. Also available: https://doi.org/10.1007/s11999-015-4494-4. PMID: 26260393.

30. Theccanat SM. Integrating psychiatric nurse practitioners into psychiatric practice settings. Psychiatric Services. 1 Sep 2015. 66:913-915. Also available: https://doi.org/10.1176/appi.ps.201500040. 


\section{No Risk of Bias Assessment}

1. Reducing ICU Length of Stay: the Effect of Tele-ICU. Online Journal Of Nursing Informatics. Sep 2014. 18:1-2

2. Adrian Allison. Factors influencing healthcare providers' behaviors in the care of infants with neonatal abstinence syndrome (NAS): An integrative review. Journal Of Neonatal Nursing. Dec 2019. 25:304-311. Also available: https://doi.org/10.1016/j.jnn.2019.07.006.

3. Ahmed NN, Pearce SE. Acute care for the elderly: A literature review. Population Health Management. 1 Aug 2010. 13:219-225. Also available:

https://doi.org/10.1089/pop.2009.0058. PMID: 20735247.

4. Bellam H, Braithwaite SS. Hospital hypoglycemia: From observation to action. Insulin. January 2010. 5:16-36. Also available: https://doi.org/10.1016/S1557-0843(10)80007-7.

5. Benenson Irina, Jadotte Yuri T, Holly Cheryl. The need for care integration across hospital services for adults with sickle cell disease. Journal Of Integrated Care. Aug 2018. 26:309328. Also available: https://doi.org/10.1108/JICA-03-2018-0022.

6. Bosso JA, Drew RH. Application of antimicrobial stewardship to optimise management of community acquired pneumonia. International Journal Of Clinical Practice. July 2011. 65:775-783. Also available: https://doi.org/10.1111/j.17421241.2011.02704.x. PMID: 21676120.

7. Chan DKY, Cordato D, O'Rourke F, Chan DL, Pollack M, Middleton S, Levi C. Comprehensive stroke units: A review of comparative evidence and experience. International Journal Of Stroke. June 2013. 8:260-264. Also available: https://doi.org/10.1111/j.17474949.2012.00850.x. PMID: 22813237.

8. Clarke M, Shah A, Sharma U. Systematic review of studies on telemonitoring of patients with congestive heart failure: A meta-analysis. Journal Of Telemedicine And Telecare. January 2011. 17:7-14. Also available: https://doi.org/10.1258/jtt.2010.100113. PMID: 21097564.

9. Craven E, Conroy S. Hospital readmissions in frail older people. Reviews In Clinical Gerontology. 25 May 2015. 25:107-116. Also available: https://doi.org/10.1017/S0959259815000064.
10. Cuerda C, Vasiloglou MF, Arhip L. Nutritional management and outcomes in malnourished medical inpatients: Anorexia nervosa. Journal Of Clinical Medicine. 1 Jul 2019. 8. Also available: https://dx.doi.org/10.3390\%2Fjcm8071042. PMID: 31319585.

11. Cuncarr Christina, Skinner Joan. Quantity or quality of postnatal length of stay? A literature review examining the issues and the evidence. New Zealand College Of Midwives Journal. Apr 2011:12-17

12. Damery S, Flanagan S, Combes G. Does integrated care reduce hospital activity for patients with chronic diseases? An umbrella review of systematic reviews. Bmj Open. 1 Nov 2016. 6. Also available: https://doi.org/10.1136/bmjopen-2016-011952. PMID: 27872113.

13. Desser AS, Arentz-Hansen H, Fagerlund BF, Harboe I, Lauvrak V, Rostoft S. Integration of Geriatric Assessment in the Care of Patients with Gastrointestinal Malignancies. Visceral Medicine. 2017 Aug 25. 33:275-280. Also available: https://doi.org/10.1159/000475452. PMID: 29034256.

14. Edwards G, Nuckols T, Herrera N, Danovitch I, Ishak WW. Improving depression management in patients with medical illness using collaborative care: Linking treatment from the inpatient to the outpatient setting. Innovations In Clinical Neuroscience. 1 Nov 2019. 16:19-24. PMID: 32082938.

15. Everall Amanda C, Guilcher Sara J T, Cadel Lauren, Asif Maliha, Li Joyce, Kuluski Kerry. Patient and caregiver experience with delayed discharge from a hospital setting: A scoping review. Health Expectations. Oct 2019. 22:863874. Also available: https://doi.org/10.1111/hex.12916. PMID: 31099969.

16. Fox MT, Sidani S, Persaud M, Tregunno D, Maimets I, Brooks D, O'Brien K. Acute care for elders components of acute geriatric unit care: Systematic descriptive review. Journal Of The American Geriatrics Society. June 2013. 61:939946. Also available: https://doi.org/10.1111/jgs.12282. PMID: 23692509.

17. Gibson BL, Coe K, Bradshaw W. Pharmacologic Management of Neonatal Abstinence Syndrome Using a Protocol. Advances In Neonatal Care: Official Journal Of The National Association Of 
Neonatal Nurses. 1 Dec 2019. 19:482-489. Also available:

https://doi.org/10.1097/anc.0000000000000648. PMID: 31306237.

18. Griffiths Peter, Bridges Jackie, Sheldon Helen, Thompson Rachel. The role of the dementia specialist nurse in acute care: a scoping review. Journal Of Clinical Nursing. May 2015. 24:1394-1406. Also available: https://doi.org/10.1111/jocn.12717. PMID: 25469780.

19. Grisham LM, Stephen MM, Coykendall MR, Kane MF, Maurer JA, Bader MY. Eat, Sleep, Console Approach: A Family-Centered Model for the Treatment of Neonatal Abstinence Syndrome. Advances In Neonatal Care : Official Journal Of The National Association Of Neonatal Nurses. 1 Apr 2019. 19:138-144. Also available:

https://doi.org/10.1097/anc.0000000000000581. PMID: 30855311.

20. Grossman M, Seashore C, Holmes AV. Neonatal abstinence syndrome management: A review of recent evidence. Reviews On Recent Clinical Trials. 1 Dec 2017. 12:226-232. Also available: https://doi.org/10.2174/15748871126661708161 44818. PMID: 28814260.

21. Hart E, Nguyen M, Allen M, Clark CM, Jacobs DM. A systematic review of the impact of antifungal stewardship interventions in the United States. Annals Of Clinical Microbiology And Antimicrobials. 21 Aug 2019. 18. Also available: https://doi.org/10.1186/s12941-0190323-z. PMID: 31434563.

22. Holly C, Cantwell ER, Kamienski MC. Evidence-Based Practices for the Identification, Screening, and Prevention of Acute Delirium in the Hospitalized Elderly: An Overview of Systematic Reviews. Current Translational Geriatrics And Experimental Gerontology Reports. 2013. 2:7-15. Also available: https://doi.org/10.1007/s13670-012-0031-4.

23. Huebner C, Flessa S, Huebner NO. The economic impact of antimicrobial stewardship programmes in hospitals: a systematic literature review. Journal Of Hospital Infection. 1 Aug 2019. 102:369-376. Also available: https://doi.org/10.1016/j.jhin.2019.03.002. PMID: 30880265.

24. Kamal YA, Hassanein A. Do perioperative protocols of enhanced recovery after cardiac surgery improve postoperative outcome?. Interactive Cardiovascular And Thoracic Surgery. 1 Apr 2020. Also available: https://doi.org/10.1093/icvts/ivaa001. PMID: 32236541.

25. Kruse CS, Soma M, Pulluri D, Nemali NT, Brooks M. The effectiveness of telemedicine in the management of chronic heart disease - a systematic review. Jrsm Open. 1 Feb 2017. 8. Also available: https://dx.doi.org/10.1177\%2F20542704166817 47. PMID: 28321319.

26. Lapointe Luc, Lavallée-Bourget Marie-Hélène, Pichard-Jolicoeur Alexia, Turgeon-Pelchat Catherine, Fleet Richard. Impact of telemedicine on diagnosis, clinical management and outcomes in rural trauma patients: A rapid review.

Canadian Journal Of Rural Medicine. Jan 2020. 25:31-41. Also available: https://doi.org/10.4103/cjrm.cjrm 8 19. PMID: 31854340.

27. Lee A, Kerridge RK, Chui PT, Chiu CH, Gin T. Perioperative Systems as a quality model of perioperative medicine and surgical care. Health Policy. October 2011. 102:214-222. Also available:

https://doi.org/10.1016/j.healthpol.2011.05.009. PMID: 21680044.

28. Machado V, Leonidas C, Santos MA, Souza J. Psychiatric readmission: an integrative review of the literature. International Nursing Review. Dec 2012. 59:447-458. Also available:

https://doi.org/10.1111/j.14667657.2012.01011.x. PMID: 23134127.

29. Mewes JC, Pulia MS, Mansour MK, Broyles MR, Bryant Nguyen H, Steuten LM. The cost impact of PCT-guided antibiotic stewardship versus usual care for hospitalised patients with suspected sepsis or lower respiratory tract infections in the US: A health economic model analysis. Plos One. 1 Apr 2019. 14. Also available:

https://dx.doi.org/10.1371\%2Fjournal.pone.0214 222. PMID: 31013271.

30. Motta E, Luglio M, Delgado AF, Carvalho WB. Importance of the use of protocols for the management of analgesia and sedation in pediatric intensive care unit. Revista Da Associacao Medica Brasileira. 1 Sep 2016. 62:602-609. Also available: https://doi.org/10.1590/1806-9282.62.06.602. PMID: 27849239.

31. Nathwani D, Varghese D, Stephens J, Ansari W, Martin S, Charbonneau C. Value of hospital antimicrobial stewardship programs [ASPs]: A systematic review. Antimicrobial Resistance And Infection Control. 12 Feb 2019. 8. Also 
available: https://doi.org/10.1186/s13756-0190471-0.

32. Nunns M, Shaw L, Briscoe S, Thompson Coon J, Hemsley A, McGrath JS, Lovegrove CJ, Thomas D, Anderson R, Sutton K, Clark SE, Thompson J, Craypo L, Schwarte L, Kuo T. Contextual assessment of the breadth and level of investments made by prevention initiatives to improve nutrition and prevent obesity in Los Angeles County, 2010-2015. Preventive Medicine Reports. 2019 Dec. 15:100901. Also available: https://doi.org/10.1016/j.pmedr.2019.100901.

33. Okrainec K, Lau D, Abrams HB, Hahn-Goldberg S, Brahmbhatt R, Huynh T, Lam K, Bell CM. Impact of patient-centered discharge tools: A systematic review. Journal Of Hospital Medicine. 1 Feb 2017. 12:110-117. Also available: https://doi.org/10.12788/jhm.2692. PMID: 28182809.

34. Perri-Moore S, Kapsandoy S, Doyon K, Hill B, Archer M, Shane-McWhorter L, Bray BE, ZengTreitler Q. Automated alerts and reminders targeting patients: A review of the literature. Patient Education And Counseling. 1 Jun 2016. 99:953-959. Also available: https://doi.org/10.1016/j.pec.2015.12.010. PMID: 26749357.

35. Pillinger KE, Bouchard J, Withers ST, Mediwala $\mathrm{K}$, McGee EU, Gibson GM, Bland CM, Bookstaver PB. Inpatient Antibiotic Stewardship Interventions in the Adult Oncology and Hematopoietic Stem Cell Transplant Population: A Review of the Literature. Annals Of Pharmacotherapy. 2019. Also available: https://doi.org/10.1177/1060028019890886. PMID: 31771337.

36. Rachoin JS, Skaf J, Cerceo E, Fitzpatrick E, Milcarek B, Kupersmith E, Scheurer DB. The impact of hospitalists on length of stay and costs: Systematic review and meta-analysis. American Journal Of Managed Care. January 2012. 18:e23e30. PMID: 22435787.

37. Rivosecchi RM, Smithburger PL, Svec S, Campbell S, Kane-Gill SL. Nonpharmacological interventions to prevent delirium: an evidencebased systematic review. Critical Care Nurse. 1 Feb 2015. 35:39-51. Also available: https://doi.org/10.4037/ccn2015423. PMID: 25639576.

38. Ronco Monica, Iona Leo, Fabbro Carmen, Bulfone Giampiera, Palese Alvisa. Patient education outcomes in surgery: a systematic review from 2004 to 2010. International Journal
Of Evidence-Based Healthcare. Dec 2012. 10:309-324. Also available:

https://doi.org/10.1111/j.17441609.2012.00286.x. PMID: 23173656.

39. Salim SA, Elmaraezy A, Pamarthy A, Thongprayoon C, Cheungpasitporn W, Palabindala V. Impact of hospitalists on the efficiency of inpatient care and patient satisfaction: a systematic review and metaanalysis. Journal Of Community Hospital Internal Medicine Perspectives. 2019 Apr. 9:121-134. Also available:

https://dx.doi.org/10.1080\%2F20009666.2019.1 591901. PMID: 31044043.

40. Santos GC, Liljeroos M, Dwyer AA, Jaques C, Girard J, Strömberg A, Hullin R, Schäfer-Keller P. Symptom perception in heart failure Interventions and outcomes: A scoping review. International Journal Of Nursing Studies. 10 Jan 2020. Also available: https://doi.org/10.1016/j.ijnurstu.2020.103524.

41. Scott IA. Preventing the rebound: improving care transition in hospital discharge processes. Australian Health Review. 2010 Nov. 34:445-51. Also available: https://doi.org/10.1071/ah09777. PMID: 21108906.

42. Smart DA, Dermody G, Coronado ME, Wilson M. Mobility Programs for the Hospitalized Older Adult: A Scoping Review. Gerontology And Geriatric Medicine. 1 Jan 2018. Also available: https://doi.org/10.1177/2333721418808146. PMID: 30450367.

43. Stark Phyllis. Advancing Complex Case Management Competencies in a Health Care System. Professional Case Management. Jan 2020. 25:19-26. Also available: https://doi.org/10.1097/ncm.0000000000000361. PMID: 31764712.

44. Stemer G, Lemmens-Gruber R. Clinical pharmacy activities in chronic kidney disease and end-stage renal disease patients: A systematic literature review. Bmc Nephrology. 2011. 12. Also available: https://doi.org/10.1186/1471-2369-12-35. PMID: 21777480.

45. Stephens JR, Kimple KS, Steiner MJ, Berry JG. Discharge interventions and modifiable risk factors for preventing hospital readmissions in children with medical complexity. Reviews On Recent Clinical Trials. 1 Dec 2017. 12:290-297. Also available: https://doi.org/10.2174/15748871126661708161 44455. PMID: 28814257. 
46. Stephens JR, Liles EA, Dancel R, Gilchrist M, Kirsch J, Dewalt DA. Who needs inpatient detox? Development and implementation of a hospitalist protocol for the evaluation of patients for alcohol detoxification. Journal Of General Internal Medicine. April 2014. 29:587-593. Also available: https://dx.doi.org/10.1007\%2Fs11606013-2751-3. PMID: 24395104.

47. Sullivan DO, Mannix M, Timmons S. Integrated Care Pathways and Care Bundles for Dementia in Acute Care: Concept Versus Evidence. American Journal Of Alzheimer's Disease And Other Dementias. 1 Jun 2017. 32:189-193. Also available:

https://doi.org/10.1177/1533317517698791. PMID: 28403628.

48. Swant Lauren, Fairchild Roseanne. Placing the bottle or breast in their premature hands: A review of cue-based feeding research. Journal of Neonatal Nursing. Jun 2014. 20:122-129. Also available: https://doi.org/10.1016/j.jnn.2013.09.003.

49. Tang Liya, Li Kun, Wu Chiung-Jung Jo. Thirtyday readmission, length of stay and selfmanagement behaviour among patients with acute coronary syndrome and type 2 diabetes mellitus: A scoping review. Journal Of Clinical Nursing. Feb 2020. 29:320-330. Also available: https://doi.org/10.1111/jocn.15087.

50. Taylor JE, McDonald SJ, Tan K. Prevention of central venous catheter-related infection in the neonatal unit: A literature review. Journal of Maternal-Fetal And Neonatal Medicine. 3 Jul 2015. 28:1224-1230. Also available: https://doi.org/10.3109/14767058.2014.949663. PMID: 25076387.

51. Tersigni C, Venturini E, Montagnani C, Chiappini E, de Martino M, Galli L. Antimicrobial stewardship in children: more shadows than lights?. Expert Review Of AntiInfective Therapy. 2019. Also available:

\section{Setting Not Relevant}

1. Electronic tools for health information exchange: An evidence-based analysis. Ontario Health Technology Assessment Series. 2013. 13. PMID: 24194799. https://doi.org/10.1080/14787210.2019.1686355. PMID: 31661998.

52. Theofanidis D, Gibbon B. Nursing interventions in stroke care delivery: An evidence-based clinical review. Journal Of Vascular Nursing : Official Publication Of The Society For Peripheral Vascular Nursing. 1 Dec 2016. 34:144-151. Also available: https://doi.org/10.1016/j.jvn.2016.07.001. PMID: 27863592.

53. Thompson G, O'Horo JC, Pickering BW, Herasevich V. Impact of the Electronic Medical Record on Mortality, Length of Stay, and Cost in the Hospital and ICU: A Systematic Review and Metaanalysis. Critical Care Medicine. 20 Jun 2015. 43:1276-1282. Also available: https://doi.org/10.1097/ccm.0000000000000948. PMID: 25756413.

54. van der Wal- Huisman H, Dons KSK, Smilde R, Heineman E, van Leeuwen BL. The effect of music on postoperative recovery in older patients: A systematic review. Journal Of Geriatric Oncology. 1 Nov 2018. 9:550-559. Also available: https://doi.org/10.1016/j.jgo.2018.03.010. PMID: 29678668.

55. Baniasadi Tayebeh, Hassaniazad Mehdi, Niakan Kalhori Sharareh R, Shahi Mehraban, Ghazisaeedi Marjan. Optimized Patients' Length of Hospital Stay with Interventions Based on Health Information Technology: A Review Study. Studies In Health Technology \& Informatics. Jun 2020. 271:69-77. Also available: https://doi.org/10.3233/shti200077. PMID: 32578544.

56. Rostoft S, van Leeuwen B. Frailty assessment tools and geriatric assessment in older patients with hepatobiliary and pancreatic malignancies. European Journal Of Surgical Oncology. 2020. Also available: https://doi.org/10.1016/j.ejso.2020.08.024. PMID: 32933803.

2. Aitken LM, Bucknall T, Kent B, Mitchell M, Burmeister E, Keogh SJ. Protocol-directed sedation versus non-protocol-directed sedation to reduce duration of mechanical ventilation in mechanically ventilated intensive care patients. Cochrane Database Of Systematic Reviews. 7 Jan 2015. Also available: https://doi.org/10.1002/14651858.cd009771.pub 2. PMID: 25562750. 
3. Aslakson R, Cheng J, Vollenweider D, Galusca D, Smith TJ, Pronovost PJ. Evidence-based palliative care in the intensive care unit: A systematic review of interventions. Journal of Palliative Medicine. 1 Feb 2014. 17:219-235. Also available: https://doi.org/10.1089/jpm.2013.0409. PMID: 24517300 .

4. Babalola O, Gormez V, Alwan NA, Johnstone P, Sampson S. Length of hospitalisation for people with severe mental illness. Cochrane Database Of Systematic Reviews. 30 Jan 2014. 2014. Also available:

https://doi.org/10.1002/14651858.cd000384.pub 3. PMID: 24477710.

5. Blackwood B, Burns KEA, Cardwell CR, O'Halloran P. Protocolized versus nonprotocolized weaning for reducing the duration of mechanical ventilation in critically ill adult patients. Cochrane Database Of Systematic Reviews. 6 Nov 2014. Also available: https://doi.org/10.1002/14651858.cd006904.pub 2. PMID: 20464747.

6. Chatziefstratiou AA, Fotos NV, Giakoumidakis $\mathrm{K}$, Brokalaki H. The contribution of cardiac rehabilitation program in management of diabetes mellitus: A systematic review. Obesity Medicine. 1 Sep 2019. https://doi.org/10.1016/j.obmed.2019.100103.

7. Cline KM, Clement V, Rock-Klotz J, Kash BA, Steel C, Miller TR. Improving the cost, quality, and safety of perioperative care: A systematic review of the literature on implementation of the perioperative surgical home. Journal Of Clinical Anesthesia. 1 Aug 2020. Also available: https://doi.org/10.1016/j.jclinane.2020.109760. PMID: 32289554.

8. Collinsworth AW, Priest EL, Campbell CR, Vasilevskis EE, Masica AL. A Review of Multifaceted Care Approaches for the Prevention and Mitigation of Delirium in Intensive Care Units. Journal Of Intensive Care Medicine. $1 \mathrm{Feb}$ 2016. 31:127-141. Also available: https://doi.org/10.1177/0885066614553925. PMID: 25348864.
9. Conroy Simon Paul, Stevens Tony, Parker Stuart G, Gladman John R F. A systematic review of comprehensive geriatric assessment to improve outcomes for frail older people being rapidly discharged from acute hospital: 'interface geriatrics'. Age \& Ageing. Jul 2011. 40:436-444. Also available: https://doi.org/10.1093/ageing/afr060. PMID: 21616954.

10. Da Silva Soares D, Nunes CM, Gomes B. Effectiveness of Emergency Department Based Palliative Care for Adults with Advanced Disease: A Systematic Review. Journal Of Palliative Medicine. 1 Jun 2016. 19:601-609. Also available: https://doi.org/10.1089/jpm.2015.0369. PMID: 27115914.

11. Degani N. Impact of advanced (open) access scheduling on patients with chronic diseases: An evidence-based analysis. Ontario Health Technology Assessment Series. 2013. 13. PMID: 24133569.

12. Dol Justine, Delahunty-Pike Alannah, Siani Sheren Anwar, Campbell-Yeo Marsha. eHealth interventions for parents in neonatal intensive care units: a systematic review. Jbi Database Of Systematic Reviews \& Implementation Reports. Dec 2017. 15:2981-3006. Also available: https://doi.org/10.11124/jbisrir-2017-003439. PMID: 29219875.

13. Epstein Elizabeth G, Arechiga Jaqueline, Dancy Margaret, Simon Jordan, Wilson Daniel, Alhusen Jeanne L. Integrative Review of Technology to Support Communication With Parents of Infants in the NICU. Jognn: Journal Of Obstetric, Gynecologic \& Neonatal Nursing. May 2017. 46:357-367. Also available: https://doi.org/10.1016/j.jogn.2016.11.019. PMID: 28263727.

14. Frampton GK, Harris P, Cooper K, Cooper T, Cleland J, Jones J, Shepherd J, Clegg A, Graves $\mathrm{N}$, Welch K, Cuthbertson BH. Educational interventions for preventing vascular catheter bloodstream infections in critical care: Evidence map, systematic review and economic evaluation. Health Technology Assessment. March 2014. 18:1-365. Also available: https://doi.org/10.3310/hta18150. PMID: 24602781. 
15. Freeman Samantha, Yorke Janelle, Dark Paul. Patient agitation and its management in adult critical care: A integrative review and narrative synthesis. Journal Of Clinical Nursing. Apr 2018. 27:e1284. Also available: https://doi.org/10.1111/jocn.14258. PMID: 29314320 .

16. Fry M. Literature review of the impact of nurse practitioners in critical care services. Nursing In Critical Care. 2011 Mar-Apr. 16:58-66. Also available: https://doi.org/10.1111/j.14785153.2010.00437.x. PMID: 21299758.

17. Godard-Sebillotte C, Le Berre M, Schuster T, Trottier M, Vedel I. Impact of health service interventions on acute hospital use in community-dwelling persons with dementia: A systematic literature review and meta-analysis. Plos One. 1 Jun 2019. 14. Also available: https://doi.org/10.1371/journal.pone.0218426. PMID: 31226138.

18. Harding Katherine E, Taylor Nicholas F, Leggat Sandra G. Do triage systems in healthcare improve patient flow? A systematic review of the literature. Australian Health Review. Aug 2011. 35:371-384. Also available: https://doi.org/10.1071/ah10927. PMID: 21871201

19. Hunter Alex, Johnson Leslie, Coustasse Alberto. Reduction of Intensive Care Unit Length of Stay. Health Care Manager. Apr 2014. 33:128-136.

Also available:

https://doi.org/10.1097/hcm.0000000000000006. PMID: 24776831.

20. Joo JY, Huber DL. Case Management Effectiveness on Health Care Utilization Outcomes: A Systematic Review of Reviews. Western Journal Of Nursing Research. 1 Jan 2019. 41:111-133. Also available: https://doi.org/10.1177/0193945918762135. PMID: 29542405.

21. Kerlin MP, Adhikari NKJ, Rose L, Wilcox ME, Bellamy CJ, Costa DK, Gershengorn HB, Halpern SD, Kahn JM, Lane-Fall MB, Wallace DJ, Weiss CH, Wunsch H, Cooke CR. An official American thoracic society systematic review: The effect of nighttime intensivist staffing on mortality and length of stay among intensive care unit patients. American Journal Of Respiratory And Critical Care Medicine. 1 Feb 2017. 195:383-393. Also available: https://doi.org/10.1164/rccm.201611-2250st. PMID: 28145766.
22. Kynoch K, Anne C, Fiona C, Annie M. The effectiveness of interventions to meet family needs of critically ill patients in an adult intensive care unit: A systematic review update. Jbi Database Of Systematic Reviews And Implementation Reports. 2016. 14:179-232. Also available: https://doi.org/10.11124/jbisrir-20162477. PMID: 27532144.

23. Lenferink A, Brusse-Keizer M, van der Valk PDLPM, Frith PA, Zwerink M, Monninkhof EM, van der Palen J, Effing TW. Selfmanagement interventions including action plans for exacerbations versus usual care in patients with chronic obstructive pulmonary disease. Cochrane Database Of Systematic Reviews. 2017 Aug 4:CD011682. Also available: https://doi.org/10.1002/14651858.cd011682.pub 2. PMID: 28777450.

24. Liu X, Dawod Y, Wonnaparhown A, Shafi A, Doo L, Yoo JW, Ko E, Choi YS. Effects of hospital palliative care on health, length of stay, and in-hospital mortality across intensive and non-intensive-care units: A systematic review and metaanalysis. Palliative \& Supportive Care. 1 Dec 2017. 15:741-752. Also available: https://doi.org/10.1017/s1478951516001164. PMID: 28196551.

25. Lloyd C, Ludbrook G, Story D, Maddern G. 'Organisation of delivery of care in operating suite recovery rooms within 48 hours postoperatively and patient outcomes after adult non-cardiac surgery: A systematic review'. Bmj Open. 4 Mar 2020. 10. Also available: 10.1136/bmjopen-2018-027262.

26. Mackintosh N, Terblanche M, Maharaj R, Xyrichis A, Franklin K, Keddie J, Larkins E, Maslen A, Skinner J, Newman S, De Sousa Magalhaes JH, Sandall J. Telemedicine with clinical decision support for critical care: A systematic review. Systematic Reviews. 18 Oct 2016. 5. Also available: https://doi.org/10.1186/s13643-016-0357-7. PMID: 27756376.

27. Maru Shoko, Byrnes Joshua, Carrington Melinda J, Stewart Simon, Scuffham Paul A. Systematic review of trial-based analyses reporting the economic impact of heart failure management programs compared with usual care. European Journal Of Cardiovascular Nursing. Feb 2016. 15:82-91. Also available: https://doi.org/10.1177/1474515114556031. PMID: 25322749. 
28. Milligan Karen, Niccols Alison, Sword Wendy, Thabane Lehana, Henderson Joanna, Smith Ainsley. Length of stay and treatment completion for mothers with substance abuse issues in integrated treatment programmes. Drugs: Education, Prevention \& Policy. Jun 2011. 18:219-228. Also available: https://www.researchgate.net/deref/http $\% 3 \mathrm{~A} \% 2 \mathrm{~F}$ \%2Fdx.doi.org\%2F10.3109\%2F09687637.2010. 511638.

29. Nydahl P, Sricharoenchai T, Chandra S, Kundt FS, Huang M, Fischill M, Needham DM. Safety of patient mobilization and rehabilitation in the intensive care unit: Systematic review with metaanalysis. Annals Of The American Thoracic Society. 1 May 2017. 14:766-777. Also available:

https://doi.org/10.1513/annalsats.201611-843sr. PMID: 28231030.

30. O'Callaghan N, Dee A, Philip RK. Evidencebased design for neonatal units: a systematic review. Maternal Health, Neonatology And Perinatology. 2019. 5:6. Also available: https://doi.org/10.1186/s40748-019-0101-0. PMID: 31061714.

31. Okada Y, Unoki T, Matsuishi Y, Egawa Y, Hayashida K, Inoue S. Early versus delayed mobilization for in-hospital mortality and healthrelated quality of life among critically ill patients: A systematic review and meta-analysis. Journal Of Intensive Care. 9 Dec 2019. 7. Also available: https://doi.org/10.1186/s40560-0190413-1. PMID: 31867111.

32. Or CK, Tao D, Wang H. The effectiveness of the use of consumer health information technology in patients with heart failure: a meta-analysis and narrative review of randomized controlled trials. Journal Of Telemedicine And Telecare. 2017 Jan 1. 23:155-66. Also available: https://doi.org/10.1177/1357633x15625540. PMID: 26759365.

33. Packer R, Shlomo YB, Whiting P. Can nonpharmacological interventions reduce hospital admissions in people with dementia? A systematic review. Plos One. 2019. 14. Also available:

https://dx.doi.org/10.1371\%2Fjournal.pone.0223 717. PMID: 31634375.
34. Parent S, Barchi S, LeBreton M, Casha S, Fehlings MG. The impact of specialized centers of care for spinal cord injury on length of stay, complications, and mortality: A systematic review of the literature. Journal Of Neurotrauma. 1 Aug 2011. 28:1363-1370. Also available: https://dx.doi.org/10.1089\%2Fneu.2009.1151. PMID: 21410318.

35. Pedone C, Lelli D. Systematic review of telemonitoring in COPD: an update. [Review]. Pneumonologia I Alergologia Polska. 2015. 83:476-84. Also available: https://doi.org/10.5603/piap.2015.0077. PMID: 26559801.

36. Prgomet M, Li L, Niazkhani Z, Georgiou A, Westbrook JI. Impact of commercial computerized provider order entry (CPOE) and clinical decision support systems (CDSSs) on medication errors, length of stay, and mortality in intensive care units: A systematic review and meta-analysis. Journal Of The American Medical Informatics Association. 1 Mar 2017. 24:413422. Also available: https://doi.org/10.1093/jamia/ocw145. PMID: 28395016.

37. Rosenthal JL, Doiron R, Haynes SC, Daniels B, Li STT. The Effectiveness of Standardized Handoff Tool Interventions During Inter- and Intra-facility Care Transitions on Patient-Related Outcomes: A Systematic Review. American Journal Of Medical Quality : The Official Journal Of The American College Of Medical Quality. 1 Mar 2018. 33:193-206. Also available: https://doi.org/10.1177/1062860617708244. PMID: 28467104.

38. Roumeliotis N, Sniderman J, Adams-Webber T, Addo N, Anand V, Rochon P, Taddio A, Parshuram C. Effect of Electronic Prescribing Strategies on Medication Error and Harm in Hospital: a Systematic Review and Metaanalysis. Journal Of General Internal Medicine. 1 Oct 2019. 34:2210-2223. Also available: https://doi.org/10.1007/s11606-019-05236-8. PMID: 31396810. 
39. Salluh Jorge I F, Han Wang, Schneider Eric B, Nagaraja Neeraja, Yenokyan Gayane, Damluji Abdulla, Serafim Rodrigo B, Stevens Robert D. Outcome of delirium in critically ill patients: systematic review and meta-analysis. Bmj: British Medical Journal. Jun 2015. 350:h2538. Also available:

https://doi.org/10.1136/bmj.h2538. PMID: 26041151.

40. Segers E, Ockhuijsen H, Baarendse P, van Eerden I, van den Hoogen A. The impact of family centred care interventions in a neonatal or paediatric intensive care unit on parents' satisfaction and length of stay: a systematic review. Intensive \& Critical Care Nursing. 2019 Feb. 50:63-70. Also available: https://doi.org/10.1016/j.iccn.2018.08.008. PMID: 30249426.

41. Shahheidari M, Homer C. Impact of the design of neonatal intensive care units on neonates, staff, and families: A systematic literature review. Journal Of Perinatal And Neonatal Nursing. July-September 2012. 26:260-266. Also available:

https://doi.org/10.1097/jpn.0b013e318261ca1d. PMID: 22843008.

42. Son YJ, Lee Y, Lee HJ. Effectiveness of mobile phone-based interventions for improving health outcomes in patients with chronic heart failure: A systematic review and meta-analysis. International Journal Of Environmental Research And Public Health. 1 Mar 2020. 17. Also available:

https://doi.org/10.3390/ijerph17051749. PMID: 32156074.

43. Sultan P, Sharawi N, Blake L, Carvalho B. Enhanced recovery after caesarean delivery versus standard care studies: a systematic review of interventions and outcomes. International Journal Of Obstetric Anesthesia. 2020. Also available:

https://doi.org/10.1016/j.ijoa.2020.03.003. PMID: 32299662.

44. Tan K, Lai NM. Telemedicine for the support of parents of high-risk newborn infants. Cochrane Database Of Systematic Reviews. 2012. Also available: https://doi.org/10.1002/14651858.cd006818.pub 2. PMID: 22696360.
45. Taylor R, Ellis J, Gao W, Searle L, Heaps K, Davies R, Hawksworth C, Garcia-Perez A, Colclough G, Walker S, Wee B. A scoping review of initiatives to reduce inappropriate or non-beneficial hospital admissions and bed days in people nearing the end of their life: Much innovation, but limited supporting evidence. Bmc Palliative Care. 27 Feb 2020. 19. Also available: https://dx.doi.org/10.1186\%2Fs12904020-0526-2. PMID: 32103745.

46. Thorne F, Baldwin C. Multimodal interventions including nutrition in the prevention and management of disease-related malnutrition in adults: A systematic review of randomised control trials. Clinical Nutrition. June 2014. 33:375-384. Also available: https://doi.org/10.1016/j.clnu.2013.12.018. PMID: 24485001.

47. Tsakitzidis G, Timmermans O, Callewaert N, Verhoeven V, Lopez-Hartmann M, Truijen S, Meulemans H, Van Royen P. Outcome Indicators on Interprofessional Collaboration Interventions for Elderly. International Journal Of Integrated Care. 2016 May 16. 16:5. Also available: https://doi.org/10.5334/ijic.2017. PMID: 27616961.

48. Wilcox ME, Adhikari NKJ. The effect of telemedicine in critically ill patients: systematic review and meta-analysis. Critical Care. 18 Jul 2012. 16. Also available: https://doi.org/10.1186/cc11429. PMID: 22809335.

49. Wilcox ME, Chong CAKY, Niven DJ, Rubenfeld GD, Rowan KM, Wunsch H, Fan E. Do intensivist staffing patterns influence hospital mortality following icu admission? A systematic review and meta-analyses. Critical Care Medicine. October 2013. 41:2253-2274. Also available: https://doi.org/10.1097/ccm.0b013e318292313a. PMID: 23921275.

50. Wilson JG, English DP, Owyang CG, Chimelski EA, Grudzen CR, Wong HN, Aslakson RA, Aslakson R, Ast K, Carroll T, Dzeng E, Harrison KL, Kaye EC, LeBlanc TW, Lo SS, McKenna K, Nageswaran S, Powers J, Rotella J, Ullrich C, Vickey T. End-of-Life Care, Palliative Care Consultation, and Palliative Care Referral in the Emergency Department: A Systematic Review. Journal Of Pain And Symptom Management. 1 Feb 2020. 59. Also available: https://doi.org/10.1016/j.jpainsymman.2019.09.0 20. PMID: 31586580. 
51. Yeung CHT, Santesso N, Zeraatkar D, Wang A, Pai M, Sholzberg M, Schünemann HJ, Iorio A. Integrated multidisciplinary care for the management of chronic conditions in adults: an overview of reviews and an example of using indirect evidence to inform clinical practice recommendations in the field of rare diseases. Haemophilia. 1 Jul 2016:41-50. Also available: https://doi.org/10.1111/hae.13010. PMID: 27348400 .

52. Zhang X, Kurtz M, Lee SY, Liu H. Early Intervention for Preterm Infants and Their Mothers: A Systematic Review. The Journal Of Perinatal \& Neonatal Nursing. 2014 Nov 18. Also available:

https://doi.org/10.1097/jpn.0000000000000065. PMID: 25408293.

53. Zepeda-Lugo C, Tlapa D, Baez-Lopez Y, Limon-Romero J, Ontiveros S, Perez-Sanchez A, Tortorella G. Assessing the impact of lean healthcare on inpatient care: A systematic review. International Journal Of Environmental Research And Public Health. 1 Aug 2020. 17:124. Also available: https://dx.doi.org/10.3390\%2Fijerph17155609. PMID: 32759705.

\section{No Outcomes of Interest}

1. Alexiou KI, Roushias A, Evaritimidis S, Malizos $\mathrm{KN}$. Quality of life and psychological consequences in elderly patients after a hip fracture: A review. Clinical Interventions In Aging. 24 Jan 2018:143-150. Also available: https://doi.org/10.2147/cia.s150067. PMID: 29416322.

2. Bahji A, Bajaj N. The Value of Hospitalization in the Opioid Epidemic: A Scoping Review. Canadian Journal Of Addiction. 1 Jun 2019. 10:6-17. Also available: https://www.researchgate.net/deref/http\%3A\%2F \%2Fdx.doi.org\%2F10.1097\%2FCXA.00000000 00000049.

3. Bench Suzanne, Day Tina, Griffiths Peter. Effectiveness of Critical Care Discharge Information in Supporting Early Recovery From Critical Illness. Critical Care Nurse. Jun 2013. 33:41-53. Also available: https://doi.org/10.4037/ccn2013134. PMID: 23727851 .
54. Wang J, Ren D, Liu Y, Wang Y, Zhang B, Xiao Q. Effects of early mobilization on the prognosis of critically ill patients: A systematic review and meta-analysis. International Journal Of Nursing Studies. 11 Jul 2020. Also available: https://doi.org/10.1016/j.ijnurstu.2020.103708. PMID: 32736250.

55. Boylen S, Cherian S, Gill FJ, Leslie GD, Wilson $\mathrm{S}$. Impact of professional interpreters on outcomes for hospitalized children from migrant and refugee families with limited English proficiency: a systematic review. Jbi Evidence Synthesis. 1 Jul 2020. 18:1360-1388. Also available: https://doi.org/10.11124/jbisrir-d-1900300. PMID: 32813387.

4. Berthelsen CB, Kristensson J. The content, dissemination and effects of case management interventions for informal caregivers of older adults: a systematic review. International Journal Of Nursing Studies. 1 May 2015. 52:988-1002. Also available: https://doi.org/10.1016/j.ijnurstu.2015.01.006. PMID: 25661314.

5. Bohren MA, Hofmeyr GJ, Sakala C, Fukuzawa RK, Cuthbert A. Continuous support for women during childbirth. Cochrane Database Of Systematic Reviews. 6 Jul 2017. 2017. Also available:

https://doi.org/10.1002/14651858.cd003766.pub 6. PMID: 28681500.

6. Cairns AE, Pealing L, Duffy JMN, Roberts N, Tucker KL, Leeson P, MacKillop LH, McManus RJ. Postpartum management of hypertensive disorders of pregnancy: a systematic review. Bmj Open. 2017 Nov 28. 7:e018696. Also available: https://doi.org/10.1136/bmjopen-2017-018696. PMID: 29187414. 
7. Chen Y, Zhu LL, Zhou Q. Effects of drug pharmacokinetic/pharmacodynamic properties, characteristics of medication use, and relevant pharmacological interventions on fall risk in elderly patients. Therapeutics And Clinical Risk Management. 2014. 10:437-448. Also available: https://doi.org/10.2147/tcrm.s63756. PMID: 24966681.

8. Chipps J, Jarvis MA, Ramlall S. The effectiveness of e-Interventions on reducing social isolation in older persons: A systematic review of systematic reviews. Journal Of Telemedicine And Telecare. 1 Dec 2017. 23:817-827. Also available:

https://doi.org/10.1177/1357633x17733773. PMID: 28958209.

9. Daoud A, Duff JP, Joffe AR, Alberta Sepsis Network. Diagnostic accuracy of delirium diagnosis in pediatric intensive care: a systematic review. Critical Care. 2014. 18:489. Also available: https://dx.doi.org/10.1186\%2Fs13054014-0489-x. PMID: 25672219.

10. Domingo GRR, Reyes FC, Thompson FV, Johnson PM, Shortridge-Baggett LM. Effectiveness of structured discharge process in reducing hospital readmission of adult patients with community acquired pneumonia: A systematic review. Jbi Library Of Systematic Reviews. 2012. 10:1086-1121. Also available: https://doi.org/10.11124/01938924-20121018000001. PMID: 2782031.

11. EVANS CATHERINE J, ISON LUCY, ELLISSMITH CLARE, NICHOLSON CAROLINE, COSTA ALESSIA, OLUYASE ADEJOKE O, NAMISANGO EVE, BONE ANNA E, BRIGHTON LISA JANE, YI DEOKHEE, COMBES SARAH, BAJWAH SABRINA, GAO WEI, HARDING RICHARD, ONG PAUL, HIGGINSON IRENE J, MADDOCKS MATTHEW. Service Delivery Models to Maximize Quality of Life for Older People at the End of Life: A Rapid Review. Milbank Quarterly. Mar 2019. 97:113-176. Also available: https://doi.org/10.1111/14680009.12373. PMID: 30883956.
12. Fawole OA, Dy SM, Wilson RF, Lau BD, Martinez KA, Apostol CC, Vollenweider D, Bass EB, Aslakson RA. A systematic review of communication quality improvement interventions for patients with advanced and serious illness. Journal Of General Internal Medicine. April 2013. 28:570-577. Also available: https://doi.org/10.1007/s11606-0122204-4. PMID: 23099799.

13. Helfand M, Christensen V, Anderson J. Technology Assessment: Early Sense for Monitoring Vital Signs in Hospitalized Patients.2011. PMID: 27606394.

14. Hu RF, Jiang XY, Chen J, Zeng Z, Chen XY, Li $Y$, Huining X, Evans DJW. Nonpharmacological interventions for sleep promotion in the intensive care unit. Cochrane Database Of Systematic Reviews. 6 Oct 2015. Also available: https://doi.org/10.1002/14651858.cd008808.pub 2. PMID: 26439374.

15. Jefferies D, Johnson M, Ravens J. Nurturing and nourishing: the nurses' role in nutritional care. Journal Of Clinical Nursing. 2011 Feb. 20:31730. Also available: https://doi.org/10.1111/j.13652702.2010.03502.x. PMID: 21219515.

16. Johnson Norah L, Rodriguez Dana. Children with Autism Spectrum Disorder At a Pediatric Hospital: A Systematic Review of the Literature. Pediatric Nursing. May 2013. 39:131-142. PMID: 23926752.

17. Kotronias RA, Teitelbaum M, Webb JG, Mylotte D, Barbanti M, Wood DA, Ballantyne B, Osborne A, Solo K, Kwok CS, Mamas MA, Bagur R. Early Versus Standard Discharge After Transcatheter Aortic Valve Replacement: A Systematic Review and Meta-Analysis. 10 Sep 2018. 11:1759-1771. Also available: https://doi.org/10.1016/j.jcin.2018.04.042. PMID: 30190065.

18. Lambrinou E, Kalogirou F, Lamnisos D, Sourtzi P. Effectiveness of heart failure management programmes with nurse-led discharge planning in reducing re-admissions: A systematic review and meta-analysis. International Journal Of Nursing Studies. May 2012. 49:610-624. Also available: https://doi.org/10.1016/j.ijnurstu.2011.11.002. PMID: 22196054. 
19. Leroyer Elodie, Romieu Valérie, Mediouni Zakia, Bécour Bertrand, Descatha Alexis. Extended-duration hospital shifts, medical errors and patient mortality. British Journal Of Hospital Medicine. Feb 2014. 75:96-102. Also available: https://doi.org/10.12968/hmed.2014.75.2.96. PMID: 24521805.

20. Loeffen EAH, te Poele EM, Tissing WJE, Boezen HM, de Bont ESJM. Very early discharge versus early discharge versus nonearly discharge in children with cancer and febrile neutropenia. Cochrane Database Of Systematic Reviews. 22 Feb 2016. Also available:

https://doi.org/10.1002/14651858.cd008382.pub 2. PMID: 26899263.

21. McMartin K. Discharge planning in chronic conditions: An evidence-based analysis. Ontario Health Technology Assessment Series. 2013. 13:1-72. PMID: 24167538.

22. Ospina MB, Mrklas K, Deuchar L, Rowe BH, Leigh R, Bhutani M, Stickland MK. A systematic review of the effectiveness of discharge care bundles for patients with COPD. Thorax. 1 Jan 2017. 72:31-39. Also available: https://doi.org/10.1136/thoraxjnl-2016-208820. PMID: 27613539.

23. Pearson M, Hunt H, Cooper C, Shepperd S, Pawson R, Anderson R. Providing effective and preferred care closer to home: a realist review of intermediate care. Health \& Social Care In The Community. 1 Nov 2015. 23:577-593. Also available: https://doi.org/10.1111/hsc.12183. PMID: 25684035.

24. Pedersen PU, Ersgard KB, Soerensen TB, Larsen P. Effectiveness of structured planned post discharge support to patients with chronic obstructive pulmonary disease for reducing readmission rates: A systematic review. Jbi Database Of Systematic Reviews And Implementation Reports. 1 Aug 2017. 15:20602086. Also available: https://doi.org/10.11124/jbisrir-2016-003045. PMID: 28800056.

25. Peltonen LM, Mccallum L, Siirala E, Haataja M, Lundgrén-Laine H, Salanterä S, Lin F. An integrative literature review of organisational factors associated with admission and discharge delays in critical care. Biomed Research International. 2015. Also available: https://doi.org/10.1155/2015/868653. PMID: 26558286.
26. Perin DC, Erdmann AL, Higashi GD, Sasso GT. Evidence-based measures to prevent central lineassociated bloodstream infections: a systematic review. Revista Latino-Americana De Enfermagem. 1 Sep 2016. Also available: https://dx.doi.org/10.1590\%2F15188345.1233.2787. PMID: 27598378.

27. Peters Jessica S. Role of Transitional Care Measures in the Prevention of Readmission After Critical Illness. Critical Care Nurse. Feb 2017. 37:e10. Also available: https://doi.org/10.4037/ccn2017218. PMID: 28148626.

28. Riviere M, Dufoort H, Van Hecke A, Vandecasteele T, Beeckman D, Verhaeghe S. Core elements of the interpersonal care relationship between nurses and older patients without cognitive impairment during their stay at the hospital: A mixed-methods systematic review. International Journal Of Nursing Studies. Apr 2019. 92:154-173. Also available: https://doi.org/10.1016/j.ijnurstu.2019.02.004. PMID: 30826498.

29. Rushton M, Howarth M, Grant MJ, Astin F. Person-centred discharge education following coronary artery bypass graft: A critical review. Journal Of Clinical Nursing. 1 Dec 2017. 26:5206-5215. Also available: https://doi.org/10.1111/jocn.14071. PMID: 28881069.

30. Schoch M, Bennett P, Fiolet R, Kent B, Au C. Renal access coordinators' impact on hemodialysis patient outcomes and associated service delivery: A systematic review. Jbi Database Of Systematic Reviews And Implementation Reports. 2014. 12:319-353. Also available: https://doi.org/10.11124/01938924201210561-00019. PMID: 27820290.

31. Setiawan Jennifer, Mannix Trudi, Sweet Linda. Understanding the Effects of Neonatal Early Discharge on Parents: A Literature Review. Journal Of Perinatal \& Neonatal Nursing. Apr 2019. 33:170-189. Also available: https://doi.org/10.1097/jpn.0000000000000395. PMID: 31021943.

32. Sobolev Boris, Sanchez Victor, Vasilakis Christos. Systematic Review of the Use of Computer Simulation Modeling of Patient Flow in Surgical Care. Journal Of Medical Systems. Feb 2011. 35:1-17. Also available: https://doi.org/10.1007/s10916-009-9336-z. PMID: 20703590. 
33. Squires A, Murali KP, Greenberg SA, Herrmann LL, D'amico CO. A Scoping Review of the Evidence About the Nurses Improving Care for Healthsystem Elders (NICHE) Program. The Gerontologist. 4 Nov 2019. Also available: https://doi.org/10.1093/geront/gnz150. PMID: 31681955 .

34. Verhaegh KJ, MacNeil-Vroomen JL, Eslami S, Geerlings SE, de Rooij SE, Buurman BM. Transitional care interventions prevent hospital readmissions for adults with chronic illnesses. Health Affairs. 2014. 33:1531-1539. Also available:

https://doi.org/10.1377/hlthaff.2014.0160. PMID: 25201657.

\section{Not a Population of Interest}

1. Ahmed OS, Rogers AC, Bolger JC, Mastrosimone A, Robb WB. Meta-Analysis of Enhanced Recovery Protocols in Bariatric Surgery. Journal Of Gastrointestinal Surgery: Official Journal Of The Society For Surgery Of The Alimentary Tract. 1 Jun 2018. 22:964-972. Also available: https://doi.org/10.1007/s11605018-3709-x. PMID: 29488124.

2. Baysari MT, Lehnbom EC, Li L, Hargreaves A, Day RO, Westbrook JI. The effectiveness of information technology to improve antimicrobial prescribing in hospitals: A systematic review and meta-analysis. International Journal Of Medical Informatics. 1 Aug 2016:15-34. Also available: https://doi.org/10.1016/j.ijmedinf.2016.04.008. PMID: 27318068.

3. Bhamidipati VS, Elliott DJ, Justice EM, Belleh E, Sonnad SS, Robinson EJ. Structure and outcomes of interdisciplinary rounds in hospitalized medicine patients: A systematic review and suggested taxonomy. Journal of Hospital Medicine. 1 Jul 2016. 11:513-523. Also available: https://doi.org/10.1002/jhm.2575. PMID: 26991337.
35. Wang Y, Tang J, Zhou F, Yang L, Wu J. Comprehensive geriatric care reduces acute perioperative delirium in elderly patients with hip fractures: A meta-analysis. Medicine. 1 Jun 2017. 96. Also available: https://doi.org/10.1097/md.0000000000007361. PMID: 28658156.

36. Williams HM, Hunter K, Clapham K, Ryder C, Kimble R, Griffin B. Efficacy and cultural appropriateness of psychosocial interventions for paediatric burn patients and caregivers: a systematic review. Bmc Public Health. 4 Mar 2020. 20. Also available: https://doi.org/10.1186/s12889-020-8366-9.

4. Biccard BM, Rodseth RN, Cronje L, Agaba P, Chikumba E, du Toit L, Farina Z, Fischer S, Gopalan PD, Govender K, Kanjee J, Kingwill AC, Madzimbamuto F, Mashava D, Mrara B, Mudely M, Ninise E, Swanevelder J, Wabule A. A meta-analysis of the efficacy of preoperative surgical safety checklists to improve perioperative outcomes. South African Medical Journal. 1 Jun 2016. 106:592-597. Also available:

https://doi.org/10.7196/samj.2016.v106i6.9863. PMID: 27245725.

5. Chen J, Sun D, Yang W, Liu M, Zhang S, Peng $\mathrm{J}$, Ren C. Clinical and Economic Outcomes of Telemedicine Programs in the Intensive Care Unit: A Systematic Review and Meta-Analysis. Journal Of Intensive Care Medicine. 1 Jul 2018. 33:383-393. Also available: https://doi.org/10.1177/0885066617726942. PMID: 28826282.

6. Das JK, Kumar R, Salam RA, Lassi ZS, Bhutta ZA. Evidence from facility level inputs to improve quality of care for maternal and newborn health: Interventions and findings. Reproductive Health. 4 Sep 2014. Also available: https://doi.org/10.1186/1742-4755-11s2-s4. PMID: 25208539.

7. Dy SM, Aslakson R, Wilson RF, Fawole OA, Lau BD, Martinez KA, Vollenweider D, Apostol $\mathrm{C}$, Bass EB. Closing the quality gap: revisiting the state of the science (vol. 8: improving health care and palliative care for advanced and serious illness). Evidence Report/Technology Assessment. Oct 2012:1-249. PMID: 24423021. 
8. Enoch AJ, English M, Shepperd S. Does pulse oximeter use impact health outcomes? A systematic review. Archives Of Disease In Childhood. 1 Aug 2016. 101:694-700. Also available: https://doi.org/10.1136/archdischild2015-309638. PMID: 26699537.

9. Greer N, Rossom R, Anderson P, MacDonald R, Tacklind J, Rutks I, Wilt TJ, Daniele RM, Bova AM, LeGar M, Smith PJ, Shortridge-Baggett LM. Rapid response team composition effects on outcomes for adult hospitalised patients: A systematic review. Jbi Library Of Systematic Reviews. 2011 Sep. 9:1297-1340. Also available: https://doi.org/10.11124/01938924201109310-00001. PMID: 27820414.

10. Grocott MPW, Dushianthan A, Hamilton MA, Mythen MG, Harrison D, Rowan K.

Perioperative increase in global blood flow to explicit defined goals and outcomes after surgery: A cochrane systematic review. British Journal Of Anaesthesia. October 2013. 111:535548. Also available:

https://doi.org/10.1093/bja/aet155. PMID: 23661403.

11. Heyland DK, Johnson AP, Reynolds SC, Muscedere J. Procalcitonin for reduced antibiotic exposure in the critical care setting: A systematic review and an economic evaluation. Critical Care Medicine. July 2011. 39:1792-1799. Also available:

https://doi.org/10.1097/ccm.0b013e31821201a5. PMID: 21358400.

12. Higgins SD, Erdogan M, Coles SJ, Green RS. Early mobilization of trauma patients admitted to intensive care units: A systematic review and meta-analyses. Injury. 1 Nov 2019. 50:18091815. Also available: https://doi.org/10.1016/j.injury.2019.09.007. PMID: 31526602.

13. Joshi M, Ashrafian H, Arora S, Khan S, Cooke G, Darzi A. Digital Alerting and Outcomes in Patients With Sepsis: Systematic Review and Meta-Analysis. Journal Of Medical Internet Research. 2019 Dec 20. 21:e15166. Also available: https://doi.org/10.2196/15166. PMID: 31859672 .
14. Kernick LA, Hogg KJ, Millerick Y, Murtagh FEM, Djahit A, Johnson M. Does advance care planning in addition to usual care reduce hospitalisation for patients with advanced heart failure: A systematic review and narrative synthesis. Palliative Medicine. 1 Dec 2018. 32:1539-1551. Also available: https://doi.org/10.1177/0269216318801162. PMID: 30234421.

15. Laka M, Milazzo A, Merlin T. Can evidencebased decision support tools transform antibiotic management? A systematic review and metaanalyses. The Journal Of Antimicrobial Chemotherapy. 20 Jan 2020. Also available: https://doi.org/10.1093/jac/dkz543.

16. Lees-Deutsch L, Robinson J. A Systematic Review of Criteria-Led Patient Discharge. Journal Of Nursing Care Quality. 1 Apr 2019. 34:121-126. Also available: https://doi.org/10.1097/ncq.0000000000000356. PMID: 30198948.

17. Malczak P, Pisarska M, Piotr M, Wysocki M, Budzynski A, Pedziwiatr M. Enhanced Recovery after Bariatric Surgery: Systematic Review and Meta-Analysis. Obesity Surgery. 6 Nov 2016:1-10. Also available: https://doi.org/10.1007/s11695-016-2438-z. PMID: 27817086.

18. Mercedes A, Fairman P, Hogan L, Thomas R, Slyer JT. Effectiveness of structured multidisciplinary rounding in acute care units on length of stay and satisfaction of patients and staff: A quantitative systematic review. Jbi Database Of Systematic Reviews And Implementation Reports. 2016. 14:131-168. Also available: https://doi.org/10.11124/jbisrir-2016003014. PMID: 27532795.

19. Newhouse RP, Stanik-Hutt J, White KM, Johantgen M, Bass EB, Zangaro G, Wilson RF, Fountain L, Steinwachs DM, Heindel L, Weiner JP. Advanced practice nurse outcomes 19902008: a systematic review. Nursing Economics. 2011 Sep-Oct. 29. PMID: 22372080.

20. Nicholson A, Lowe MC, Parker J, Lewis SR, Alderson P, Smith AF. Systematic review and meta-analysis of enhanced recovery programmes in surgical patients. British Journal Of Surgery. February 2014. 101:172-188. Also available: https://doi.org/10.1002/bjs.9394. PMID: 24469618. 
21. Park M, Giap TTT, Lee M, Jeong H, Jeong M, Go Y. Patient- and family-centered care interventions for improving the quality of health care: A review of systematic reviews.

International Journal Of Nursing Studies. 1 Nov 2018:69-83. Also available:

https://doi.org/10.1016/j.ijnurstu.2018.07.006. PMID: 30056169.

22. Perrier L, Farrell A, Ayala AP, Lightfoot D, Kenny T, Aaronson E, Allee N, Brigham T, Connor E, Constantinescu T, Muellenbach J, Epstein HAB, Weiss A. Effects of librarianprovided services in healthcare settings: A systematic review. Journal Of The American Medical Informatics Association. 28 May 2014. 21:1118-1124. Also available:

https://doi.org/10.1136/amiajnl-2014-002825. PMID: 24872341.

23. Pucher PH, Aggarwal R, Singh P, Darzi A. Enhancing surgical performance outcomes through process-driven care: a systematic review. World Journal Of Surgery. 1 Jun 2014. 38:1362-1373. Also available: https://doi.org/10.1007/s00268-013-2424-8. PMID: 24370544.

24. Rittmann B, Stevens MP. Clinical Decision Support Systems and Their Role in Antibiotic Stewardship: a Systematic Review. Current Infectious Disease Reports. 1 Aug 2019. 21. Also available: https://doi.org/10.1007/s11908019-0683-8. PMID: 31342180.

25. Shabaninejad H, Alidoost S, Delgoshaei B. Identifying and classifying indicators affected by performing clinical pathways in hospitals: a scoping review. International Journal Of Evidence-Based Healthcare. 1 Mar 2018. 16:324. Also available: https://doi.org/10.1097/xeb.0000000000000126. PMID: 29176429.

26. Shaw SE, Preece R, Stenson KM, De Bruin JL, Loftus IM, Holt PJE, Patterson BO. Short Stay EVAR is Safe and Cost Effective. European Journal Of Vascular And Endovascular Surgery : The Official Journal Of The European Society For Vascular Surgery. 2019 Mar. 57:368-373. Also available: https://doi.org/10.1016/j.ejvs.2018.10.008.
27. Soril LJJ, Noseworthy TW, Dowsett LE, Memedovich K, Holitzki HM, Lorenzetti DL, Stelfox HT, Zygun DA, Clement FM. Behaviour modification interventions to optimise red blood cell transfusion practices: A systematic review and meta-analysis. Bmj Open. 1 May 2018. 8. Also available: https://doi.org/10.1136/bmjopen2017-019912. PMID: 29776919.

28. Strøm C, Stefansson JS, Fabritius ML, Rasmussen LS, Schmidt TA, Jakobsen JC. Hospitalisation in short-stay units for adults with internal medicine diseases and conditions. Cochrane Database Of Systematic Reviews. 13 Aug 2018. 2018. Also available: https://doi.org/10.1002/14651858.cd012370.pub 2. PMID: 30102428.

29. Timbrook TT, Morton JB, Mcconeghy KW, Caffrey AR, Mylonakis E, LaPlante KL. The effect of molecular rapid diagnostic testing on clinical outcomes in bloodstream infections: A systematic review and meta-analysis. Clinical Infectious Diseases. 2017. 64:15-23. Also available: https://doi.org/10.1093/cid/ciw649. PMID: 27678085.

30. Twigg DE, Kutzer Y, Jacob E, Seaman K. A quantitative systematic review of the association between nurse skill mix and nursing-sensitive patient outcomes in the acute care setting. Journal Of Advanced Nursing. 1 Dec 2019. 75:3404-3423. Also available: https://doi.org/10.1111/jan.14194. PMID: 31483509 .

31. Warttig S, Alderson P, Evans DJW, Lewis SR, Kourbeti IS, Smith AF. Automated monitoring compared to standard care for the early detection of sepsis in critically ill patients. Cochrane Database Of Systematic Reviews. 25 Jun 2018. 2018. Also available: https://doi.org/10.1002/14651858.cd012404.pub 2. PMID: 29938790.

32. Wood R, Wand APF. The effectiveness of consultation-liaison psychiatry in the general hospital setting: A systematic review. Journal of Psychosomatic Research. March 2014. 76:175192. Also available: https://doi.org/10.1016/j.jpsychores.2014.01.002. PMID: 24529036. 
33. Xiong Z, Chen $\mathrm{H}$. Interventions to reduce unnecessary central venous catheter use to prevent central-line-associated bloodstream infections in adults: A systematic review. Infection Control And Hospital Epidemiology. 1 Dec 2018. 39:1442-1448. Also available: https://doi.org/10.1017/ice.2018.250. PMID: 30305194.

34. Zhu F, Lee A, Chee YE. Fast-track cardiac care for adult cardiac surgical patients. Cochrane Database Of Systematic Reviews. 2012. Also available: https://doi.org/10.1002/14651858.cd003587.pub 2. PMID: 23076899.

35. Ludolph Paul, Stoffers-Winterling Jutta, Kunzler Angela M, Rösch Romina, Geschke Katharina, Vahl Christian Friedrich, Lieb Klaus. NonPharmacologic Multicomponent Interventions Preventing Delirium in Hospitalized People. Journal Of The American Geriatrics Society. Aug 2020. 68:1864-1872. Also available: https://doi.org/10.1111/jgs.16565.

\section{Not an Intervention of Interest}

1. Abeles A, Kwasnicki RM, Pettengell C, Murphy J, Darzi A. The relationship between physical activity and post-operative length of hospital stay: A systematic review. International Journal Of Surgery. 1 Aug 2017:295-302. Also available: https://doi.org/10.1016/j.ijsu.2017.06.085. PMID: 28689861.

2. Aziz HA, Lunde J, Barraco R, Como JJ, Cooper Z, Hayward T, Hwang F, Lottenberg L, Mentzer C, Mosenthal A, Mukherjee K, Nash J, Robinson B, Staudenmayer K, Wright R, Yon J, Crandall $M$. Evidence-based review of trauma center care and routine palliative care processes for geriatric trauma patients; A collaboration from the American Association for the Surgery of Trauma Patient Assessment Committee, the American Association for the Surgery of Trauma Geriatric Trauma Committee, and the Eastern Association for the Surgery of Trauma Guidelines Committee. Journal Of Trauma And Acute Care Surgery. 1 Apr 2019. 86:737-743. Also available: https://doi.org/10.1097/ta.0000000000002155. PMID: 30531333.
36. Zhang X, Yang J, Chen X, Du L, Li K, Zhou Y. Enhanced recovery after surgery on multiple clinical outcomes: Umbrella review of systematic reviews and meta-analyses. Medicine. 17 Jul 2020. 99. Also available: https://doi.org/10.1097/md.0000000000020983. PMID: 32702839.

37. Sun L, Joshi M, Khan SN, Ashrafian H, Darzi A. Clinical impact of multi-parameter continuous non-invasive monitoring in hospital wards: a systematic review and meta-analysis. Journal of The Royal Society Of Medicine. 2020. Also available: https://doi.org/10.1177/0141076820925436.

3. Bhide A, Chakraborty K. General Principles for Psychotherapeutic Interventions in Children and Adolescents. Indian Journal Of Psychiatry. 1 Jan 2020. 62. Also available: https://dx.doi.org/10.4103\%2Fpsychiatry.IndianJ Psychiatry 811 19. PMID: 32055072.

4. Brooks Paula Beth. Postoperative Delirium in Elderly Patients. Ajn American Journal Of Nursing. Sep 2012. 112:38-52. Also available: 10.1097/01.NAJ.0000418922.53224.36.

5. Buchleitner AM, Martinez-Alonso M, Hernandez M, Sola I, Mauricio D. Perioperative glycaemic control for diabetic patients undergoing surgery. The Cochrane Database Of Systematic Reviews. 2012. 9:CD007315. Also available:

https://doi.org/10.1002/14651858.cd007315.pub 2. PMID: 22972106.

6. Buchleitner AM, Martinez-Alonso M, Hernandez M, Sola I, Mauricio D. Perioperative glycaemic control for diabetic patients undergoing surgery. The Cochrane Database Of Systematic Reviews. 2012. 9:CD007315. https://doi.org/10.1002/14651858.cd007315.pub 2. PMID: 22972106. 
7. Busby J, Purdy S, Hollingworth W. A systematic review of the magnitude and cause of geographic variation in unplanned hospital admission rates and length of stay for ambulatory care sensitive conditions. Bmc Health Services Research. 13 Aug 2015. Also available: https://doi.org/10.1186/s12913-015-0964-3.

8. Castanheira L, Fresco P, MacEdo AF. Guidelines for the management of chronic medication in the perioperative period: Systematic review and formal consensus. Journal Of Clinical Pharmacy And Therapeutics. August 2011. 36:446-467. Also available: https://doi.org/10.1111/j.13652710.2010.01202.x. PMID: 21729111.

9. Cluver C, Novikova N, Koopmans CM, West HM. Planned early delivery versus expectant management for hypertensive disorders from 34 weeks gestation to term. Cochrane Database Of Systematic Reviews. 2017 Jan 15. 1:CD009273. Also available:

https://doi.org/10.1002/14651858.cd009273.pub 2. PMID: 28106904.

10. Conte T, Mitton C, Trenaman LM, Chavoshi N, Siden H. Effect of pediatric palliative care programs on health care resource utilization and costs among children with life-threatening conditions: a systematic review of comparative studies. Cmaj Open. 2015 Jan-Mar. 3:E68-75. Also available: https://doi.org/10.9778/cmajo.20140044. PMID: 25844372.

11. Curley GF, Shehata N, Mazer CD, Hare GMT, Friedrich JO. Transfusion triggers for guiding $\mathrm{RBC}$ transfusion for cardiovascular surgery: A systematic review and meta-analysis. Critical Care Medicine. 27 Aug 2014. Also available: https://doi.org/10.1097/ccm.0000000000000548. PMID: 25167086.

12. Darvall JN, Gregorevic KJ, Story DA, Hubbard RE, Lim, WK. Frailty indexes in perioperative and critical care: A systematic review. Archives Of Gerontology And Geriatrics. 1 Nov 2018. 8896. Also available: https://doi.org/10.1016/j.archger.2018.08.006. PMID: 30153605.
13. Davies Sarah E, Dodd Karen J, Hill Keith D. Does cultural and linguistic diversity affect health-related outcomes for people with stroke at discharge from hospital?. Disability \& Rehabilitation. Apr 2017. 39:736-746. Also available: https://doi.org/10.3109/09638288.2016.1161839. PMID: 27043166.

14. Davis MP, Temel JS, Balboni T, Glare P. A review of the trials which examine early integration of outpatient and home palliative care for patients with serious illnesses. Annals Of Palliative Medicine. 1 Jul 2015. 4:99-121. Also available: https://doi.org/10.3978/j.issn.22245820.2015.04.04. PMID: 26231807.

15. Diab M, Bilkhu R, Soppa G, McGale N, Hirani SP, Newman SP, Jahangiri M. Quality of Life in Relation to Length of Intensive Care Unit Stay After Cardiac Surgery. Journal Of Cardiothoracic And Vascular Anesthesia. 1 Jun 2017. 31:1080-1090. Also available: https://doi.org/10.1053/j.jvca.2016.06.025. PMID: 27692701.

16. Dolatkhah R, Dastgiri S. Blood transfusions for treating acute chest syndrome in people with sickle cell disease. Cochrane Database Of Systematic Reviews. 16 Jan 2020. 2020. Also available:

https://doi.org/10.1002/14651858.cd007843.pub 4. PMID: 31942751.

17. Groves RL. Increasing Light Exposure for the Prevention of Delirium: A Systematic Review. Dimensions Of Critical Care Nursing : Decn. 1 Mar 2019. 38:96-107. Also available: https://doi.org/10.1097/dcc.0000000000000343. PMID: 30702479.

18. Joannidis M, Druml W, Forni LG, Groeneveld AB, Honore P, Oudemans-van Straaten HM, Ronco C, Schetz MR, Woittiez AJ, Critical Care Nephrology Working Group of the European Society of Intensive Care. Prevention of acute kidney injury and protection of renal function in the intensive care unit. Expert opinion of the Working Group for Nephrology, ESICM. Intensive Care Medicine. 2010 Mar. 36:392-411. Also available: $\mathrm{https://doi.org/10.1007/s00134-}$ 017-4832-y. PMID: 28577069. 
19. Krueger K, Griese-Mammen N, Schubert I, Kieble M, Botermann L, Laufs U, Kloft C, Schulz M. In search of a standard when analyzing medication adherence in patients with heart failure using claims data: a systematic review. Heart Failure Reviews. 1 Jan 2018. 23:63-71. Also available: https://doi.org/10.1007/s10741-017-9656-x. PMID: 28993930.

20. Lewis SR, Butler AR, Brammar A, Nicholson A, Smith AF. Perioperative fluid volume optimization following proximal femoral fracture. Cochrane Database Of Systematic Reviews. 14 Mar 2016. 2016. Also available: https://doi.org/10.1002/14651858.cd003004.pub 4. PMID: 26976366.

21. McCurdy BR. Noninvasive positive pressure ventilation for acute respiratory failure patients with chronic obstructive pulmonary disease (COPD): an evidence-based analysis. Ontario Health Technology Assessment Series. 2012. 12:1-102. PMID: 23074436.

22. Ni W, Bao J, Yang D, Xi W, Wang K, Xu Y, Zhang R, Gao Z. Potential of serum procalcitonin in predicting bacterial exacerbation and guiding antibiotic administration in severe COPD exacerbations: a systematic review and meta-analysis. Infectious Diseases. 2019. 51:639-650. Also available: https://doi.org/10.1080/23744235.2019.1644456. PMID: 31355690.

23. Okusanya BO, Oladapo OT. Prophylactic versus selective blood transfusion for sickle cell disease in pregnancy. Cochrane Database Of Systematic Reviews. 22 Dec 2016. Also available: https://doi.org/10.1002/14651858.cd010378.pub 3. PMID: 28005272.

24. Pan J, Peng M, Liao C, Hu X, Wang A, Li X. Relative efficacy and safety of early lactate clearance-guided therapy resuscitation in patients with sepsis: A meta-analysis. Medicine. 1 Feb 2019. 98. Also available: https://doi.org/10.1097/md.0000000000014453. PMID: 30813144.

25. Rattray M, Roberts S, Marshall A, Desbrow B. A systematic review of feeding practices among postoperative patients: is practice in-line with evidenced-based guidelines?. Journal Of Human Nutrition And Dietetics : The Official Journal Of The British Dietetic Association. 1 Apr 2018. 31:151-167. Also available: https://doi.org/10.1111/jhn.12486. PMID: 28589624.
26. Rawlinson A, Kitchingham N, Hart C, McMahon G, Ong SL, Khanna A. Mechanisms of reducing postoperative pain, nausea and vomiting: A systematic review of current techniques. Evidence-Based Medicine. June 2012. 17:75-80. Also available: https://doi.org/10.1136/ebmed-2011-100265. PMID: 22419772.

27. Roberts MB, Glaspey LJ, Mazzarelli A, Jones CW, Kilgannon HJ, Trzeciak S, Roberts BW. Early interventions for the prevention of posttraumatic stress symptoms in survivors of critical illness: A qualitative systematic review. Critical Care Medicine. 2018. 46:1328-13333. Also available: https://doi.org/10.1097/ccm.0000000000003222. PMID: 29794546.

28. Sanson G, Vellone E, Kangasniemi M, Alvaro R, D'Agostino F. Impact of nursing diagnoses on patient and organisational outcomes: a systematic literature review. Journal Of Clinical Nursing. 1 Dec 2017. 26:3764-3783. Also available: https://doi.org/10.1111/jocn.13717. PMID: 28042921.

29. Schuetz P, Chiappa V, Briel M, Greenwald JL. Procalcitonin algorithms for antibiotic therapy decisions: A systematic review of randomized controlled trials and recommendations for clinical algorithms. Archives Of Internal Medicine. 2011 Aug 8. 171:1322-31. Also available:

https://doi.org/10.1001/archinternmed.2011.318. PMID: 21824946.

30. Spiers G, Matthews FE, Moffatt S, Barker RO, Jarvis H, Stow D, Kingston A, Hanratty B. Impact of social care supply on healthcare utilisation by older adults: A systematic review and meta-analysis. Age And Ageing. 1 Jan 2019. 48:57-66. Also available: https://doi.org/10.1093/ageing/afy147.

31. Sun Y, Ye F, Wang J, Ai P, Wei C, Wu A, Xie W. Electroencephalography-Guided Anesthetic Delivery for Preventing Postoperative Delirium in Adults: An Updated Meta-analysis. Anesthesia And Analgesia. 27 Mar 2020. Also available: https://doi.org/10.1213/ane.0000000000004746. PMID: 32224720. 
32. Svenningsen Helle, Langhorn Leanne, Ågård Anne Sophie, Dreyer Pia. Post- ICU symptoms, consequences, and follow-up: an integrative review. Nursing In Critical Care. Jul 2017. 22:212-221. Also available: https://doi.org/10.1111/nicc.12165. PMID: 25688675

33. Valtorta NK, Moore DC, Barron L, Stow D, Hanratty B. Older Adults' Social Relationships and Health Care Utilization: A Systematic Review. American Journal Of Public Health. 1 Apr 2018. 108:e1-e10. Also available: https://doi.org/10.2105/ajph.2017.304256. PMID: 29470115.

\section{Duplicate or Superseded}

1. Buggy A, Moore Z. The impact of the multidisciplinary team in the management of individuals with diabetic foot ulcers: a systematic review. Journal Of Wound Care. 2 Jun 2017. 26:324-339. Also available: https://doi.org/10.12968/jowc.2017.26.6.324. PMID: 28598756.

2. Butler M, Collins R, Drennan J, Halligan P, O'Mathuna DP, Schultz TJ, Sheridan A, Vilis E. Hospital nurse staffing models and patient and staff-related outcomes. The Cochrane Database Of Systematic Reviews. 2011:CD007019. Also available:

https://doi.org/10.1002/14651858.cd007019.pub 2. PMID: 21735407.

3. Coffey A, Leahy-Warren P, Savage E, Hegarty J, Cornally N, Day MR, Sahm L, O'Connor K, O'Doherty J, Liew A, Sezgin D, O'Caoimh R. Interventions to promote early discharge and avoid inappropriate hospital (Re)admission: a systematic review. International Journal Of Environmental Research And Public Health. 2019 Jul 10. 16:2457. Also available: https://dx.doi.org/10.3390\%2Fijerph16142457. PMID: 31295933.

4. Conroy SP, Stevens T, Parker SG, Gladman JRF. A systematic review of comprehensive geriatric assessment to improve outcomes for frail older people being rapidly discharged from acute hospital: 'Interface geriatrics'. Age And Ageing. July 2011. 40:436-443. Also available: https://doi.org/10.1093/ageing/afr060. PMID: 21616954
34. Yee J, Pillai A, Ferris L. Diabetic ankle fractures: A review of the literature and an introduction to the adelaide fracture in the diabetic ankle algorithm and score. Biomed Research International. 2014. Also available: https://dx.doi.org/10.1155\%2F2014\%2F153146. PMID: 24719845.

5. Davies SE, Dodd KJ, Hill KD. Does cultural and linguistic diversity affect health-related outcomes for people with stroke at discharge from hospital?. Disability And Rehabilitation. 1 Apr 2017. 39:736-745. Also available: https://doi.org/10.3109/09638288.2016.1161839. PMID: 27043166.

6. Fox MT, Persaud M, Maimets I, Brooks D, OBrien K, Tregunno D. Effectiveness of early discharge planning in acutely ill or injured hospitalized older adults: a systematic review and meta-analysis. Bmc Geriatrics. 2013. 13:70. Also available: https://doi.org/10.1186/14712318-13-70. PMID: 23829698.

7. Kitts NK, Reeve AR, Tsu L. Care transitions in elderly heart failure patients: Current practices and the pharmacist's role. Consultant Pharmacist. March 2014. 29:179-190. Also available: https://doi.org/10.4140/tcp.n.2014.179. PMID: 24589767.

8. Mabire C, Dwyer A, Garnier A, Pellet J. Effectiveness of nursing discharge planning interventions on health-related outcomes in discharged elderly inpatients: A systematic review. Jbi Database Of Systematic Reviews And Implementation Reports. 2016. 14:217-260. Also available: https://doi.org/10.11124/jbisrir2016-003085. PMID: 27755325. 
9. MacMillan Kathryn Dee L, Rendon Cassandra P, Verma Kanak, Riblet Natalie, Washer David B, Volpe Holmes Alison. Association of Roomingin With Outcomes for Neonatal Abstinence Syndrome: A Systematic Review and Metaanalysis. Jama Pediatrics. Apr 2018. 172:345352. Also available:

https://doi.org/10.1001/jamapediatrics.2017.5195 . PMID: 29404599.

10. Oldham MA, Chahal K, Lee HB. A systematic review of proactive psychiatric consultation on hospital length of stay. General Hospital Psychiatry. 1 Sep 2019:120-126. Also available: https://doi.org/10.1016/j.genhosppsych.2019.08. 001. PMID: 31404826.

11. Oldham Mark A, Chahal Khushminder, Lee Hochang B. A systematic review of proactive psychiatric consultation on hospital length of stay. General Hospital Psychiatry. Sep 2019. 60:120-127. Also available: https://doi.org/10.1016/j.genhosppsych.2019.08. 001. PMID: 31404826.

12. Pollok J, Van Agteren JEM, Esterman AJ, Carson-Chahhoud KV. Psychological therapies for the treatment of depression in chronic obstructive pulmonary disease. Cochrane Database Of Systematic Reviews. 6 Mar 2019. Also available: https://doi.org/10.1002/14651858.CD012347.pu b2.
13. Rotter T, Kinsman L, James E, Machotta A, Willis J, Snow P, Kugler J. The effects of clinical pathways on professional practice, patient outcomes, length of stay, and hospital costs: Cochrane systematic review and metaanalysis. Evaluation \& The Health Professions. 2012 Mar. 35:3-27. Also available: https://doi.org/10.1177/0163278711407313. PMID: 21613244.

14. Tang L, Li K, Wu CJJ. Thirty-day readmission, length of stay and self-management behaviour among patients with acute coronary syndrome and type 2 diabetes mellitus: A scoping review. Journal Of Clinical Nursing. 1 Feb 2020. 29:320329. Also available:

https://doi.org/10.1111/jocn.15087. PMID: 31698508.

15. Walker C, Kappus K, Hall N. Strategies for Improving Patient Throughput in an Acute Care Setting Resulting in Improved Outcomes: A Systematic Review. Nursing Economics. 1 Nov 2016. 34:277-288. PMID: 29975490.

\section{Full Text Not Available or Not Published in English}

1. Ahmed Adnan, Verghese Dhiran, Ali Faisal, Nimmagadda Manojna, Bodapati Rohan, Iqbal Arshad Muhammad. IMPACT OF EARLY DIURETIC ADMINISTRATION ON INHOSPITAL MORTALITY AND LENGTH OF HOSPITAL STAY AMONG PATIENTS WITH ACUTE CONGESTIVE HEART FAILURE: A META-ANALYSIS. Journal Of The American College Of Cardiology (Jacc). Mar 2020. 75:1054-1055

2. BAO Xiuhong, HU Yanning, ZHENG Suxian, FU Lianqi, YAN Sisi. A meta-analysis of fasttrack surgery in perioperative pain management of elderly patients with hip fracture. Nursing Of Integrated Traditional Chinese \& Western Medicine. Jun 2019. 5:28-33. Also available: https://doi.org/10.11997/nitcwm.201906008.
3. Cafarella PA, Effing TW, Barton C, Ahmed D, Frith PA. Management of depression and anxiety in COPD. Revue Du Praticien. Medecine Generale. 2013. 59:144-163. Also available: https://doi.org/10.1183/1025448x.10012112.

4. Campbell ZC, Stevenson JK, Mccaffery KJ, Jansen J, Campbell KL, Lee VWS, Webster AC. Interventions for improving health literacy in people with chronic kidney disease. Cochrane Database Of Systematic Reviews. 2 Feb 2016. Also available: https://doi.org/10.1002/14651858.CD012026.

5. Cawood AL, Walters ER, Smith TR, Stratton RJ. Oral nutritional supplements used in hospital and after discharge reduces complications: A systematic review and meta-analysis...40th European Society for Clinical Nutrition and Metabolism Congress, September 1-4, 2018, Madrid, Spain. Clinical Nutrition. Sep 2018. 37:S305 
6. Epelde F, Iglesias-Lepine ML, Anarte L. Economic crisis: Cost and effectiveness of short stay hospital units. Anales Del Sistema Sanitario De Navarra. 2012. 35:469-475. Also available: https://doi.org/10.23938/assn.0103. PMID:

7. Hsiao-Mei Chen, Tung-Chen Han, Ching-Min Chen. The Effectiveness of Continuing Care Models in Patients With Chronic Diseases: A Systematic Review. Journal Of Nursing. Apr 2014. 61:74-84. Also available: https://doi.org/10.6224/jn.61.2.74. PMID: 24676954.

8. Hyasat K, Singh K. A Systematic Review of Early Hospital Discharge Following Successful Reperfusion of ST Elevation Myocardial Infarction. Heart, Lung \& Circulation. Aug 2019. 28:S283 23296228

9. Mercedes Angela, Fairman Precillia, Hogan Lisa, Thomas Rexi. The Effectiveness of Structured Multidisciplinary Rounding in Acute Care Units on Length of Stay and Satisfaction of Patient and Staff: A Systematic Review...28th Annual Scientific Session, June 2-6, 2017, Baltimore, Maryland. Nursing Research. Mar 2016. 65:E36

10. Verstappen J, van Dronkelaar C, Streppel M, Tieland M, Biolo G, Boirio Y, Rooijackers O, Kondrup J, Weijs P. Impact of dietary protein supplementation on length of hospital stay and mortality in older adults: A systematic review and meta-analysis...European Society for Clinical Nutrition and Metabolism (ESPEN) 40th Congress, September 1-4, 2018, Madrid, Spain. Clinical Nutrition. Sep 2018. 37:S336. Also available: https://doi.org/10.1016/j.clnu.2018.09.003.

11. Yao L, Chang Y, Han C, Yang L, Zhang C, Tian J, Zhang Z. Effect of early activity on delirium in ICU patients: a meta-analysis. Chinese Nursing Research. Aug 2019. 33:2600-2606

5. Leigheb F, Vanhaecht K, Sermeus W, Lodewijckx C, Deneckere S, Boonen S, Boto PA, Mendes RV, Panella M. The effect of care pathways for hip fractures: A systematic overview of secondary studies. European Journal Of Orthopaedic Surgery And Traumatology. 2013. 23:737-745. Also available: https://doi.org/10.1007/s00590-012-1085-x. PMID: 23412217.

6. MacVicar S, Kelly LE. Systematic mixed-study review of nonpharmacological management of neonatal abstinence syndrome. Birth. 1 Sep 2019. 46:428-438. Also available: https://doi.org/10.1111/birt.12427. PMID: 30938466.

3. Cafarella PA, Effing TW, Barton C, Ahmed D, Frith PA. Management of depression and anxiety in COPD. Revue Du Praticien. Medecine Generale. 2013. 59:144-163. Also available: https://doi.org/10.1183/1025448x.10012112.

4. Hebert JS, Payne MW, Wolfe DL, Deathe AB, Devlin M. Comorbidities in amputation: a systematic review of hemiplegia and lower limb amputation. Disability And Rehabilitation. 2012. 34:1943-9. Also available: https://doi.org/10.3109/09638288.2012.665131. PMID: 22424496.
7. Nirantharakumar K, Chen YF, Marshall T, Webber J, Coleman JJ. Clinical decision support systems in the care of inpatients with diabetes in non-critical care setting: Systematic review. Diabetic Medicine. June 2012. 29:698-708. Also available: https://doi.org/10.1111/j.1464- 5491.2011.03540.x. PMID: 22150466.


8. Philp I, Mills KA, Thanvi B, Ghosh K, Long JF. Reducing hospital bed use by frail older people: results from a systematic review of the literature. International Journal Of Integrated Care. 2013. 13:e 048. Also available:

https://dx.doi.org/10.5334\%2Fijic.1148. PMID: 24363636

9. Salamanca-Balen N, Seymour J, Caswell G, Whynes D, Tod A. The costs, resource use and cost-effectiveness of Clinical Nurse Specialistled interventions for patients with palliative care needs: A systematic review of international evidence. Palliative Medicine. 1 Feb 2018. 32:447-465. Also available: https://doi.org/10.1177/0269216317711570. PMID: 28655289.

10. Stephenson MD, Lisy K, Stern CJ, Feyer AM, Fisher L, Aromataris EC. The impact of integrated care for people with chronic conditions on hospital and emergency department utilization: a rapid review. International Journal Of Evidence-Based Healthcare. 1 Mar 2019. 17:14-26. Also available:

https://doi.org/10.1097/xeb.0000000000000151. PMID: 30247173.
11. Walker Colleen. Strategies for Improving Patient Throughput in an Acute Care Setting Resulting in Improved Outcomes: A Systematic Review. Nursing Economic\$. Nov 2016. 34:277-289. PMID: 29975490.

12. Wielenga JM, van den Hoogen A, van Zanten HA, Helder O, Bol B, Blackwood B.

Protocolized versus non-protocolized weaning for reducing the duration of invasive mechanical ventilation in newborn infants. Cochrane Database Of Systematic Reviews. 21 Mar 2016. Also available:

https://doi.org/10.1002/14651858.cd011106.pub 2. PMID: 26998745.

13. Smith TO, Sreekanta A, Walkeden S, Penhale B, Hanson S. Interventions for reducing hospital-associated deconditioning: A systematic review and meta-analysis. Archives Of Gerontology And Geriatrics. 1 Sep 2020. Also available: https://doi.org/10.1016/j.archger.2020.10416. PMID: 32652367. 


\section{Appendix C. Evidence Tables}

Table C-1. Characteristics of systematic reviews on reducing length of hospital stay

\begin{tabular}{|c|c|c|c|c|c|c|c|c|}
\hline $\begin{array}{l}\text { Author } \\
\text { Year }\end{array}$ & Objective & $\begin{array}{l}\text { Primary } \\
\text { Studies: N, } \\
\text { Design } \\
\end{array}$ & $\begin{array}{l}\text { Search } \\
\text { Timeframe }\end{array}$ & $\begin{array}{l}\text { Inclusion/Exclusion } \\
\text { Criteria }\end{array}$ & $\begin{array}{l}\text { Risk of Bias } \\
\text { Assessment }\end{array}$ & $\begin{array}{l}\text { Meta- } \\
\text { Analysis }\end{array}$ & $\begin{array}{l}\text { Qualitative } \\
\text { or Narrative } \\
\text { Synthesis } \\
\end{array}$ & $\begin{array}{l}\text { GRADE or } \\
\text { Similar } \\
\text { Analysis } \\
\end{array}$ \\
\hline $\begin{array}{l}\text { Austin } \\
\text { et al. } \\
2020^{24}\end{array}$ & $\begin{array}{l}\text { Examine which } \\
\text { electronic medical } \\
\text { record } \\
\text { interventions have } \\
\text { improved safety } \\
\text { and quality of } \\
\text { therapeutic } \\
\text { anticoagulation in } \\
\text { an inpatient } \\
\text { hospital setting } \\
\end{array}$ & $\begin{array}{l}27 \text { total studies: } \\
3 \text { RCTs, } \\
4 \text { cohort } \\
\text { studies, } \\
20 \text { pre/post } \\
\text { observational } \\
\text { studies }(\mathrm{N}=\text { not } \\
\text { reported) }\end{array}$ & $\begin{array}{l}\text { Inception to } \\
\text { September } 2018\end{array}$ & $\begin{array}{l}\text { Included: Studies } \\
\text { published in English } \\
\text { with pediatric and adult } \\
\text { inpatients; EMR } \\
\text { compared to routine } \\
\text { care; reporting at least } \\
\text { one outcome of interest }\end{array}$ & $\begin{array}{l}\text { Yes, EPOC for } \\
\text { RCTs and } \\
\text { cohort studies }\end{array}$ & No & Yes & No \\
\hline $\begin{array}{l}\text { Agarwal } \\
\text { et al. } \\
2018^{34}\end{array}$ & $\begin{array}{l}\text { Examine the } \\
\text { effect and quality } \\
\text { of evidence for } \\
\text { hospital-based } \\
\text { HF quality } \\
\text { improvement } \\
\text { interventions on } \\
\text { process of care } \\
\text { measures and } \\
\text { clinical outcomes } \\
\text { among patients } \\
\text { with acute HF }\end{array}$ & $\begin{array}{l}14 \text { RCTs } \\
(\mathrm{N}=96,913) \\
*(\mathrm{~N}=75,664 \text { for } \\
6 \text { US RCTs }) \\
\text { reporting } \\
\text { outcomes of } \\
\text { interest }\end{array}$ & $\begin{array}{l}\text { Inception to } \\
\text { February 6, } 2017\end{array}$ & $\begin{array}{l}\text { Included: RCTs or } \\
\text { quasi-randomized trials } \\
\text { of HF quality } \\
\text { improvement } \\
\text { interventions testing } \\
\text { effect of individual or } \\
\text { combined interventions } \\
\text { (e.g., audit and } \\
\text { feedback reporting } \\
\text { systems, admission and } \\
\text { discharge checklists, } \\
\text { chart case } \\
\text { management, patient } \\
\text { educational or } \\
\text { behavioral change } \\
\text { materials, healthcare } \\
\text { quality training that was } \\
\text { directed at the hospital } \\
\text { system, doctors, nurses } \\
\text { or allied health } \\
\text { professionals or } \\
\text { information } \\
\text { management systems }\end{array}$ & $\begin{array}{l}\text { Yes, Cochrane } \\
\text { ROB }\end{array}$ & $\begin{array}{l}\text { No (due to } \\
\text { substantial } \\
\text { unexplained } \\
\text { heterogeneity, } \\
\text { differences in } \\
\text { presentation of } \\
\text { intervention } \\
\text { effects) }\end{array}$ & Yes & $\begin{array}{l}\text { Yes, GRADE } \\
\text { (For the most } \\
\text { part, } \\
\text { outcomes } \\
\text { from specific } \\
\text { RCTs of } \\
\text { interest for } \\
\text { this report } \\
\text { were not } \\
\text { graded } \\
\text { separately) }\end{array}$ \\
\hline
\end{tabular}




\begin{tabular}{|c|c|c|c|c|c|c|c|c|}
\hline $\begin{array}{l}\text { Author } \\
\text { Year }\end{array}$ & Objective & $\begin{array}{l}\text { Primary } \\
\text { Studies: N, } \\
\text { Design }\end{array}$ & $\begin{array}{l}\text { Search } \\
\text { Timeframe }\end{array}$ & $\begin{array}{l}\text { Inclusion/Exclusion } \\
\text { Criteria }\end{array}$ & $\begin{array}{l}\text { Risk of Bias } \\
\text { Assessment }\end{array}$ & \begin{tabular}{|l|} 
Meta- \\
Analysis
\end{tabular} & $\begin{array}{l}\text { Qualitative } \\
\text { or Narrative } \\
\text { Synthesis }\end{array}$ & $\begin{array}{l}\text { GRADE or } \\
\text { Similar } \\
\text { Analysis }\end{array}$ \\
\hline $\begin{array}{l}\text { Baratloo } \\
\text { et al. } \\
2018^{25}\end{array}$ & $\begin{array}{l}\text { Examine effects } \\
\text { of telemedicine on } \\
\text { treatment times } \\
\text { and clinical } \\
\text { outcomes of acute } \\
\text { stroke care }\end{array}$ & $\begin{array}{l}26 \text { total studies: } \\
2 \text { RCTs, } \\
8 \text { prospective } \\
\text { observational } \\
\text { studies, } \\
16 \text { retrospective } \\
\text { observational } \\
\text { studies } \\
(\mathrm{N}=6,605)\end{array}$ & May 2017 & $\begin{array}{l}\text { Included: Original } \\
\text { prospective and } \\
\text { retrospective studies, } \\
\text { individuals with AIS, } \\
\text { telestroke-based } \\
\text { systems, bedside (face } \\
\text { to face) care as a } \\
\text { comparator, studies } \\
\text { investigating outcomes } \\
\text { of interest } \\
\text { Excluded: Single-arm } \\
\text { studies, studies } \\
\text { reporting irrelevant } \\
\text { outcomes, conference } \\
\text { abstracts }\end{array}$ & $\begin{array}{l}\text { Yes, Cochrane } \\
\text { (RCTs), } \\
\text { Newcastle- } \\
\text { Ottawa scale } \\
\text { (observational } \\
\text { studies) }\end{array}$ & Yes & No & No \\
\hline $\begin{array}{l}\text { Bryant- } \\
\text { Lukosius } \\
\text { et al. } \\
2015^{35}\end{array}$ & $\begin{array}{l}\text { Examine the } \\
\text { clinical } \\
\text { effectiveness and } \\
\text { cost-effectiveness } \\
\text { of clinical nurse } \\
\text { specialists } \\
\text { transitional care }\end{array}$ & $\begin{array}{l}13 \text { RCTS } \\
(\mathrm{N}=2,463)\end{array}$ & $\begin{array}{l}1980 \text { to } \\
\text { July } 31,2013\end{array}$ & $\begin{array}{l}\text { Included: Published and } \\
\text { unpublished RCTs } \\
\text { comparing CNS-led } \\
\text { transitional care to } \\
\text { usual care. Intervention } \\
\text { was delivered by a } \\
\text { master's prepared CNS } \\
\text { Excluded: Studies of } \\
\text { outcomes that could not } \\
\text { be solely attributed to } \\
\text { the CNS; the control } \\
\text { group was exposed to a } \\
\text { CNS; or did not include } \\
\text { a measure of health } \\
\text { system utilization }\end{array}$ & $\begin{array}{l}\text { Yes, Cochrane } \\
\text { ROB }\end{array}$ & Yes & Yes & Yes, GRADE \\
\hline
\end{tabular}




\begin{tabular}{|c|c|c|c|c|c|c|c|c|}
\hline $\begin{array}{l}\text { Author } \\
\text { Year }\end{array}$ & Objective & $\begin{array}{l}\text { Primary } \\
\text { Studies: N, } \\
\text { Design }\end{array}$ & $\begin{array}{l}\text { Search } \\
\text { Timeframe }\end{array}$ & $\begin{array}{l}\text { Inclusion/Exclusion } \\
\text { Criteria }\end{array}$ & $\begin{array}{l}\text { Risk of Bias } \\
\text { Assessment }\end{array}$ & \begin{tabular}{|l|} 
Meta- \\
Analysis
\end{tabular} & $\begin{array}{l}\text { Qualitative } \\
\text { or Narrative } \\
\text { Synthesis } \\
\end{array}$ & $\begin{array}{l}\text { GRADE or } \\
\text { Similar } \\
\text { Analysis }\end{array}$ \\
\hline $\begin{array}{l}\text { Bakker } \\
\text { et al. } \\
2011^{26}\end{array}$ & $\begin{array}{l}\text { Examine } \\
\text { effectiveness of } \\
\text { geriatric care } \\
\text { teams and units }\end{array}$ & $\begin{array}{l}17 \text { total studies; } \\
6 \text { reported LOS: } \\
4 \text { RCTs, } \\
2 \text { observational }\end{array}$ & $\begin{array}{l}1980 \text { - May } \\
2009\end{array}$ & $\begin{array}{l}\text { Included: RCTs and } \\
\text { observational studies; } \\
\text { patients at least } \\
65 \text { years old; } \\
\text { multicomponent } \\
\text { interventions } \\
\text { Excluded: Non-English } \\
\text { studies; single-disease } \\
\text { or single-component } \\
\text { interventions }\end{array}$ & EPOC tool & No & Yes & No \\
\hline $\begin{array}{l}\text { Eagles } \\
\text { et al. } \\
2020^{41}\end{array}$ & $\begin{array}{l}\text { Examine impact } \\
\text { of a geriatric } \\
\text { assessment on } \\
\text { mortality, hospital } \\
\text { length of stay, } \\
\text { discharge } \\
\text { destination, and } \\
\text { delirium incidence } \\
\text { in patients } \\
65 \text { years and } \\
\text { older admitted to } \\
\text { a trauma center }\end{array}$ & $\begin{array}{l}8 \text { retrospective } \\
\text { cohort studies } \\
(\mathrm{N}=122 \text { to } \\
4,534)\end{array}$ & April 26, 2019 & $\begin{array}{l}\text { Included: Peer- } \\
\text { reviewed studies } \\
\text { describing impact of } \\
\text { geriatric trauma } \\
\text { consultation (GTC) in } \\
\text { adults } 65 \text { years and } \\
\text { older admitted to a } \\
\text { trauma center } \\
\text { compared with standard } \\
\text { trauma care alone } \\
\text { Excluded: Case reports, } \\
\text { SRs, and commentaries }\end{array}$ & $\begin{array}{l}\text { Yes, } \\
\text { Newcastle- } \\
\text { Ottawa Quality } \\
\text { Assessment } \\
\text { Scale }\end{array}$ & Yes & Yes & $\begin{array}{l}\text { No formal } \\
\text { analysis. } \\
\text { Authors } \\
\text { reported } \\
\text { strength of } \\
\text { findings are } \\
\text { limited by } \\
\text { study design, } \\
\text { confounding, } \\
\text { meta-analysis } \\
\text { results based } \\
\text { on few } \\
\text { studies. }\end{array}$ \\
\hline $\begin{array}{l}\text { Ellis et al. } \\
2017^{36}\end{array}$ & $\begin{array}{l}\text { Examine } \\
\text { effectiveness and } \\
\text { resource use of } \\
\text { comprehensive } \\
\text { geriatric } \\
\text { assessment } \\
\text { (CGA) for older } \\
\text { adults admitted to } \\
\text { hospital, and to } \\
\text { use these data to } \\
\text { estimate its cost- } \\
\text { effectiveness }\end{array}$ & $\begin{array}{l}29 \text { RCTs } \\
(\mathrm{N}=13,766)\end{array}$ & $\begin{array}{l}\text { Inception to } \\
\text { October 5, } 2016\end{array}$ & $\begin{array}{l}\text { Included: RCTs } \\
\text { comparing inpatient } \\
\text { CGA versus usual care } \\
\text { on a general medical } \\
\text { ward or on a ward for } \\
\text { older people, usually } \\
\text { admitted to hospital for } \\
\text { acute care or for } \\
\text { inpatient rehabilitation } \\
\text { after an acute } \\
\text { admission }\end{array}$ & $\begin{array}{l}\text { Yes, using } \\
\text { guidance for } \\
\text { EPOC reviews }\end{array}$ & Yes & Yes & Yes, GRADE \\
\hline
\end{tabular}




\begin{tabular}{|c|c|c|c|c|c|c|c|c|}
\hline $\begin{array}{l}\text { Author } \\
\text { Year }\end{array}$ & Objective & $\begin{array}{l}\text { Primary } \\
\text { Studies: N, } \\
\text { Design }\end{array}$ & $\begin{array}{l}\text { Search } \\
\text { Timeframe }\end{array}$ & $\begin{array}{l}\text { Inclusion/Exclusion } \\
\text { Criteria }\end{array}$ & $\begin{array}{l}\text { Risk of Bias } \\
\text { Assessment }\end{array}$ & \begin{tabular}{|l|} 
Meta- \\
Analysis
\end{tabular} & $\begin{array}{l}\text { Qualitative } \\
\text { or Narrative } \\
\text { Synthesis } \\
\end{array}$ & $\begin{array}{l}\text { GRADE or } \\
\text { Similar } \\
\text { Analysis }\end{array}$ \\
\hline $\begin{array}{l}\text { Frazer } \\
\text { et al. } \\
2019^{37}\end{array}$ & $\begin{array}{l}\text { Examine } \\
\text { interventions } \\
\text { intended to } \\
\text { improve safety or } \\
\text { quality } \\
\text { anticoagulant } \\
\text { prescribing }\end{array}$ & $\begin{array}{l}19 \text { RCTs } \\
(\mathrm{N}=12,742)\end{array}$ & $\begin{array}{l}\text { Inception to } \\
\text { March 24, } 2018\end{array}$ & $\begin{array}{l}\text { Included: RCTs, non- } \\
\text { RCTs, controlled } \\
\text { before-after, interrupted } \\
\text { time-series in } \\
\text { economically developed } \\
\text { countries assessing } \\
\text { system-level } \\
\text { interventions for any } \\
\text { indication in adult } \\
\text { inpatients aged } 18 \\
\text { years or older } \\
\text { Excluded: Interventions } \\
\text { targeting prophylactic } \\
\text { (low-dose) } \\
\text { anticoagulant use, } \\
\text { evaluating intra- } \\
\text { operative } \\
\text { anticoagulation, } \\
\text { delivered in the } \\
\text { outpatient setting or at } \\
\text { transition to outpatient } \\
\text { care, or compared with } \\
\text { interventions not in } \\
\text { current practice. Cross- } \\
\text { sectional, uncontrolled } \\
\text { cohort, review articles, } \\
\text { unpublished, opinion } \\
\text { pieces, conference } \\
\text { abstracts/proceedings }\end{array}$ & $\begin{array}{l}\text { Yes, Cochrane } \\
\text { EPOC criteria }\end{array}$ & Yes & Yes & No \\
\hline $\begin{array}{l}\text { Gonçalves- } \\
\text { Bradley } \\
\text { et al. } \\
2016^{38}\end{array}$ & $\begin{array}{l}\text { Examine } \\
\text { effectiveness of } \\
\text { planning the } \\
\text { discharge of } \\
\text { individual patients } \\
\text { moving from } \\
\text { hospital }\end{array}$ & $\begin{array}{l}30 \text { RCTs } \\
(\mathrm{N}=11,964)\end{array}$ & $\begin{array}{l}1946 \text { to October } \\
2015\end{array}$ & $\begin{array}{l}\text { Included: RCTs; } \\
\text { participants were } \\
\text { hospital inpatients } \\
\text { Excluded: Studies of } \\
\text { discharge planning part } \\
\text { of a broader package of } \\
\text { inpatient care, did not } \\
\text { describe study design } \\
\text { or report control group } \\
\text { results }\end{array}$ & $\begin{array}{l}\text { Yes, Cochrane } \\
\text { ROB }\end{array}$ & Yes & Yes & $\begin{array}{l}\text { GRADE } \\
\text { (Moderate to } \\
\text { very low) }\end{array}$ \\
\hline
\end{tabular}




\begin{tabular}{|c|c|c|c|c|c|c|c|c|}
\hline $\begin{array}{l}\text { Author } \\
\text { Year }\end{array}$ & Objective & $\begin{array}{l}\text { Primary } \\
\text { Studies: N, } \\
\text { Design }\end{array}$ & $\begin{array}{l}\text { Search } \\
\text { Timeframe }\end{array}$ & $\begin{array}{l}\text { Inclusion/Exclusion } \\
\text { Criteria }\end{array}$ & $\begin{array}{l}\text { Risk of Bias } \\
\text { Assessment }\end{array}$ & \begin{tabular}{|l|} 
Meta- \\
Analysis
\end{tabular} & $\begin{array}{l}\text { Qualitative } \\
\text { or Narrative } \\
\text { Synthesis }\end{array}$ & $\begin{array}{l}\text { GRADE or } \\
\text { Similar } \\
\text { Analysis }\end{array}$ \\
\hline $\begin{array}{l}\text { Gillaizeau } \\
\text { et al. } \\
2013^{27}\end{array}$ & $\begin{array}{l}\text { Examine } \\
\text { effectiveness of } \\
\text { computerized } \\
\text { advice on drug } \\
\text { dosing }\end{array}$ & $\begin{array}{l}42 \text { total studies; } \\
9 \text { reported LOS: } \\
8 \text { RCTs, } \\
1 \text { observational }\end{array}$ & $\begin{array}{l}\text { Through January } \\
2012\end{array}$ & $\begin{array}{l}\text { Included: RCTs and } \\
\text { observational studies; } \\
\text { interventions using } \\
\text { computerized advice to } \\
\text { guide drug dosing } \\
\text { tailored to individual } \\
\text { patient } \\
\text { Excluded: Studies of } \\
\text { equations or algorithms } \\
\text { not supported by a } \\
\text { computerized device; } \\
\text { popups or dosing } \\
\text { advice that was not } \\
\text { patient-specific }\end{array}$ & EPOC tool & Yes & Yes & Very low \\
\hline $\begin{array}{l}\text { Huntley } \\
\text { et al. } \\
2016^{28}\end{array}$ & $\begin{array}{l}\text { Examine } \\
\text { effectiveness and } \\
\text { cost of case } \\
\text { management for } \\
\text { patients with heart } \\
\text { failure }\end{array}$ & $\begin{array}{l}22 \text { total studies; } \\
9 \text { reported LOS: } \\
8 \text { RCTs, } \\
1 \text { observational; } \\
13 \text { reported } \\
\text { readmissions: } \\
12 \text { RCTs, } \\
1 \text { observational }\end{array}$ & $\begin{array}{l}1985 \text { - } \\
\text { November } 2015\end{array}$ & $\begin{array}{l}\text { Included: RCTs and } \\
\text { observational studies; } \\
\text { adult studies only; all } \\
\text { languages }\end{array}$ & $\begin{array}{l}\text { Cochrane risk } \\
\text { of bias tool for } \\
\text { RCTs; EPOC } \\
\text { tool for } \\
\text { observational } \\
\text { studies }\end{array}$ & Yes & Yes & No \\
\hline $\begin{array}{l}\text { Kul et al. } \\
2012^{29}\end{array}$ & $\begin{array}{l}\text { Examine } \\
\text { effectiveness of } \\
\text { clinical pathways } \\
\text { for patients with } \\
\text { heart failure }\end{array}$ & $\begin{array}{l}7 \text { total studies: } \\
3 \text { RCTs, } \\
1 \text { cohort, } \\
3 \text { pre-post }\end{array}$ & $1985-2011$ & $\begin{array}{l}\text { Included: RCTs and } \\
\text { observational studies; } \\
\text { all languages }\end{array}$ & $\begin{array}{l}\text { Jadad tool for } \\
\text { RCTs; } \\
\text { Newcastle- } \\
\text { Ottawa Scale } \\
\text { for } \\
\text { observational } \\
\text { studies }\end{array}$ & Yes & No & No \\
\hline
\end{tabular}




\begin{tabular}{|c|c|c|c|c|c|c|c|c|}
\hline $\begin{array}{l}\text { Author } \\
\text { Year }\end{array}$ & Objective & $\begin{array}{l}\text { Primary } \\
\text { Studies: N, } \\
\text { Design }\end{array}$ & $\begin{array}{l}\text { Search } \\
\text { Timeframe }\end{array}$ & $\begin{array}{l}\text { Inclusion/Exclusion } \\
\text { Criteria }\end{array}$ & $\begin{array}{l}\text { Risk of Bias } \\
\text { Assessment }\end{array}$ & \begin{tabular}{|l} 
Meta- \\
Analysis
\end{tabular} & $\begin{array}{l}\text { Qualitative } \\
\text { or Narrative } \\
\text { Synthesis } \\
\end{array}$ & $\begin{array}{l}\text { GRADE or } \\
\text { Similar } \\
\text { Analysis }\end{array}$ \\
\hline $\begin{array}{l}\text { Mabire } \\
\text { et al. } \\
2017^{15,30}\end{array}$ & $\begin{array}{l}\text { Examine } \\
\text { effectiveness of } \\
\text { nursing discharge } \\
\text { planning } \\
\text { interventions on } \\
\text { health-related } \\
\text { outcomes for } \\
\text { older inpatients } \\
\text { discharged home }\end{array}$ & $\begin{array}{l}13 \text { total studies: } \\
11 \text { RCTs, } 1 \text { pilot } \\
\text { cohort, } 1 \text { pre- } \\
\text { post study } \\
(\mathrm{N}=3,964)\end{array}$ & 2000 to 2015 & $\begin{array}{l}\text { Included: Studies } \\
\text { published in English of } \\
\text { older patients } \\
\text { ( } \geq 65 \text { years) discharged } \\
\text { home from an acute } \\
\text { care or post-acute care } \\
\text { rehabilitation setting, } \\
\text { i.e., skilled nursing } \\
\text { facility. Interventions } \\
\text { had to be provided by } \\
\text { at least one nurse and } \\
\text { involve a multi- } \\
\text { disciplinary and/or } \\
\text { interdisciplinary model } \\
\text { of care }\end{array}$ & $\begin{array}{l}\text { Yes, JBI- } \\
\text { MAStARI } \\
\text { assessment of } \\
\text { methodological } \\
\text { quality }\end{array}$ & Yes & Yes & Yes, GRADE \\
\hline $\begin{array}{l}\text { Patel et al. } \\
2020^{31}\end{array}$ & $\begin{array}{l}\text { Examine } \\
\text { treatment of } \\
\text { geriatric hip } \\
\text { fractures by a } \\
\text { multidisciplinary } \\
\text { hip fracture } \\
\text { service and what } \\
\text { impact this has on } \\
\text { patient outcomes }\end{array}$ & $\begin{array}{l}17 \text { total studies: } \\
9 \text { retrospective } \\
\text { studies, } \\
6 \text { prospective } \\
\text { studies, } 1 \mathrm{RCT}, \\
1 \text { non- } \mathrm{RCT} \\
(\mathrm{N}=146 \text { to } \\
23,973)\end{array}$ & $\begin{array}{l}\text { January 1, } 2012 \\
\text { to November } 12, \\
2017\end{array}$ & $\begin{array}{l}\text { Included: Indexed in the } \\
\text { databases searched, } \\
\text { full-text comparative } \\
\text { studies published in } \\
\text { English that studied at } \\
\text { least one of the four } \\
\text { main outcome } \\
\text { measures of interest }\end{array}$ & $\begin{array}{l}\text { Yes, Oxford } \\
\text { quality-scoring } \\
\text { system (Jadad) } \\
\text { for RCTs and } \\
\text { Newcastle } \\
\text { Ottawa grading } \\
\text { system for non- } \\
\text { RCTs }\end{array}$ & No & Yes & $\begin{array}{l}\text { Tool used not } \\
\text { reported } 16 \\
\text { of } 17 \text { studies } \\
\text { receive an } \\
\text { evidence } \\
\text { grade of } \\
\text { good, } 1 \text { of } 17 \\
\text { received an } \\
\text { evidence } \\
\text { grade of fair }\end{array}$ \\
\hline
\end{tabular}




\begin{tabular}{|c|c|c|c|c|c|c|c|c|}
\hline $\begin{array}{l}\text { Author } \\
\text { Year }\end{array}$ & Objective & $\begin{array}{l}\text { Primary } \\
\text { Studies: N, } \\
\text { Design }\end{array}$ & $\begin{array}{l}\text { Search } \\
\text { Timeframe }\end{array}$ & $\begin{array}{l}\text { Inclusion/Exclusion } \\
\text { Criteria }\end{array}$ & $\begin{array}{l}\text { Risk of Bias } \\
\text { Assessment }\end{array}$ & \begin{tabular}{|l|} 
Meta- \\
Analysis
\end{tabular} & $\begin{array}{l}\text { Qualitative } \\
\text { or Narrative } \\
\text { Synthesis } \\
\end{array}$ & $\begin{array}{l}\text { GRADE or } \\
\text { Similar } \\
\text { Analysis }\end{array}$ \\
\hline $\begin{array}{l}\text { Pannick } \\
\text { et al. } \\
2015^{32}\end{array}$ & $\begin{array}{l}\text { Examine the } \\
\text { range of objective } \\
\text { patient outcomes } \\
\text { used in studies of } \\
\text { general medical } \\
\text { ward } \\
\text { interdisciplinary } \\
\text { team care, and to } \\
\text { evaluate the } \\
\text { performance of } \\
\text { interdisciplinary } \\
\text { interventions } \\
\text { against them }\end{array}$ & $\begin{array}{l}30 \text { total studies: } \\
8 \text { RCTs, } \\
9 \text { cluster-RCTs, } \\
8 \text { non-RCT } \\
\text { cluster, } \\
4 \text { before-after, } \\
1 \text { interrupted } \\
\text { time series } \\
(\mathrm{N}=66,548)\end{array}$ & $\begin{array}{l}\text { January 1, } 1998 \\
\text { January 29, } \\
2014\end{array}$ & $\begin{array}{l}\text { Included: Primary } \\
\text { reports of inter- } \\
\text { disciplinary team care } \\
\text { interventions in adult } \\
\text { general medical wards } \\
\text { using an objective } \\
\text { patient outcome } \\
\text { measure } \\
\text { Excluded: Patients } \\
\text { <18 years in intensive } \\
\text { care unit, operating } \\
\text { rooms, stroke units, } \\
\text { coronary care, } \\
\text { pharmacotherapy; } \\
\text { interventions relying } \\
\text { solely on a staff } \\
\text { member taking } \\
\text { dedicated coordinating } \\
\text { or facilitating role (e.g., } \\
\text { case management); } \\
\text { interventions targeting } \\
\text { continuation of care by } \\
\text { a similar group during } \\
\text { the following shift (e.g., } \\
\text { handoff processes) }\end{array}$ & $\begin{array}{l}\text { Yes, Cochrane } \\
\text { ROB }\end{array}$ & Yes & Yes & No \\
\hline $\begin{array}{l}\text { Van Craen } \\
\text { et al. } \\
2010^{39}\end{array}$ & $\begin{array}{l}\text { Examine } \\
\text { effectiveness of } \\
\text { geriatric } \\
\text { evaluation units }\end{array}$ & 7 RCTs & $\begin{array}{l}\text { Through October } \\
2007\end{array}$ & $\begin{array}{l}\text { Included: RCTs and } \\
\text { cohort studies; patients } \\
\text { at least } 65 \text { years old; } \\
\text { published in English, } \\
\text { French, or Dutch } \\
\text { Excluded: Studies of } \\
\text { single-disease } \\
\text { management programs } \\
\text { and geriatric } \\
\text { consultation services }\end{array}$ & $\begin{array}{l}\text { Delphi list for } \\
\text { RCTs }\end{array}$ & Yes & No & No \\
\hline
\end{tabular}




\begin{tabular}{|c|c|c|c|c|c|c|c|c|}
\hline $\begin{array}{l}\text { Author } \\
\text { Year }\end{array}$ & Objective & $\begin{array}{l}\text { Primary } \\
\text { Studies: N, } \\
\text { Design }\end{array}$ & $\begin{array}{l}\text { Search } \\
\text { Timeframe }\end{array}$ & $\begin{array}{l}\text { Inclusion/Exclusion } \\
\text { Criteria }\end{array}$ & $\begin{array}{l}\text { Risk of Bias } \\
\text { Assessment }\end{array}$ & \begin{tabular}{|l|} 
Meta- \\
Analysis
\end{tabular} & $\begin{array}{l}\text { Qualitative } \\
\text { or Narrative } \\
\text { Synthesis } \\
\end{array}$ & $\begin{array}{l}\text { GRADE or } \\
\text { Similar } \\
\text { Analysis }\end{array}$ \\
\hline $\begin{array}{l}\text { White et al. } \\
2011^{33}\end{array}$ & $\begin{array}{l}\text { Examine the } \\
\text { effectiveness of } \\
\text { hospitalists on the } \\
\text { quality of inpatient } \\
\text { care }\end{array}$ & $\begin{array}{l}65 \text { total studies; } \\
1 \mathrm{RCT}, 8 \text { non- } \\
\text { randomized } \\
\text { controlled trials, } \\
1 \text { interrupted } \\
\text { time series, } \\
37 \text { cohort, } \\
18 \text { pre-post }\end{array}$ & $\begin{array}{l}1996 \text { - } \\
\text { December } 2010\end{array}$ & $\begin{array}{l}\text { Included: All study } \\
\text { designs, ages, } \\
\text { languages }\end{array}$ & $\begin{array}{l}\text { Modified Downs } \\
\text { and Black } \\
\text { checklist, } \\
32 \text { items }\end{array}$ & No & Yes & No \\
\hline $\begin{array}{l}\text { Zhu et al. } \\
2015^{12}\end{array}$ & $\begin{array}{l}\text { Examine } \\
\text { effectiveness of } \\
\text { nurse-led early } \\
\text { discharge } \\
\text { planning program } \\
\text { (DPP) to standard } \\
\text { care for in- } \\
\text { patients with } \\
\text { chronic disease or } \\
\text { rehabilitation } \\
\text { needs }\end{array}$ & $\begin{array}{l}10 \text { RCTs } \\
(\mathrm{N}=3,438)\end{array}$ & $\begin{array}{l}1946 \text { to } \\
\text { March 29, } 2014\end{array}$ & $\begin{array}{l}\text { Included: RCTs; } \\
\text { general hospital setting; } \\
\text { include at least one } \\
\text { primary or secondary } \\
\text { outcome } \\
\text { Excluded: Non-English } \\
\text { studies, assessing } \\
\text { patients with acute, } \\
\text { critical illness, or social } \\
\text { admissions; programs } \\
\text { was directed by non- } \\
\text { nursing staff; assessing } \\
\text { post-discharge care of } \\
\text { patients transferred to } \\
\text { nursing home or long- } \\
\text { term care facility; } \\
\text { intervention initiated at } \\
\text { discharge; post- } \\
\text { discharge care }\end{array}$ & $\begin{array}{l}\text { Yes, Cochrane } \\
\text { ROB }\end{array}$ & Yes & Yes & No \\
\hline
\end{tabular}




\begin{tabular}{|c|c|c|c|c|c|c|c|c|}
\hline $\begin{array}{l}\text { Author } \\
\text { Year }\end{array}$ & Objective & $\begin{array}{l}\text { Primary } \\
\text { Studies: N, } \\
\text { Design }\end{array}$ & $\begin{array}{l}\text { Search } \\
\text { Timeframe }\end{array}$ & $\begin{array}{l}\text { Inclusion/Exclusion } \\
\text { Criteria }\end{array}$ & $\begin{array}{l}\text { Risk of Bias } \\
\text { Assessment }\end{array}$ & \begin{tabular}{|l|} 
Meta- \\
Analysis
\end{tabular} & $\begin{array}{l}\text { Qualitative } \\
\text { or Narrative } \\
\text { Synthesis } \\
\end{array}$ & $\begin{array}{l}\text { GRADE or } \\
\text { Similar } \\
\text { Analysis }\end{array}$ \\
\hline $\begin{array}{l}\text { Zhang } \\
\text { et al. } \\
2013^{40}\end{array}$ & $\begin{array}{l}\text { Examine } \\
\text { effectiveness of } \\
\text { interventions to } \\
\text { prevent } \\
\text { postoperative } \\
\text { delirium in elderly } \\
\text { patients }\end{array}$ & $\begin{array}{l}38 \text { total RCTs; } \\
10 \text { studies } \\
\text { reported LOS, } \\
\text { only } 2 \text { used a } \\
\text { systemic } \\
\text { intervention } \\
\text { (others were } \\
\text { pharmacologic) }\end{array}$ & $\begin{array}{l}\text { Through July } \\
2012\end{array}$ & $\begin{array}{l}\text { Included: RCTs only; } \\
\text { adult patients } \\
\text { Excluded: Non-English } \\
\text { studies; patients with } \\
\text { delirium prior to } \\
\text { surgery; non-surgical } \\
\text { patients; patients with } \\
\text { alcohol withdrawal } \\
\text { syndrome; studies of } \\
\text { homogenous } \\
\text { populations of patients } \\
\text { with central nervous } \\
\text { diseases or mental } \\
\text { disorders }\end{array}$ & $\begin{array}{l}\text { Modified Jadad } \\
\text { tool }\end{array}$ & $\begin{array}{l}\text { Not for the } \\
2 \text { studies of } \\
\text { systemic } \\
\text { interventions } \\
\text { reporting LOS; } \\
\text { meta-analysis } \\
\text { performed for } \\
\text { all studies } \\
\text { reporting LOS }\end{array}$ & Yes & No \\
\hline
\end{tabular}

AIS = acute ischemic stroke; CGA = comprehensive geriatric assessment; CNS = clinical nurse specialists; EMR = electronic medical record;

$\mathrm{EPOC}=$ effective practice and organization of care; GRADE = Grading of Recommendations Assessment, Development and Evaluation; GTC = geriatric trauma consultation; $\mathrm{HF}=$ heart failure; JBI-MAStARI = Joanna Briggs Institute Meta-analysis Statistics Assessment and Review Instrument; LOS = length of stay; RCT = randomized controlled trial; $\mathrm{ROB}=$ risk of bias; US = United States 
Table C-2. Hospital and patient characteristics of systematic reviews on reducing length of hospital stay

\begin{tabular}{|c|c|c|c|c|c|c|c|c|c|}
\hline $\begin{array}{l}\text { Author } \\
\text { Year }\end{array}$ & $\begin{array}{l}\text { Patient } \\
\text { Age } \\
\text { Cohort }\end{array}$ & $\begin{array}{l}\text { Location, } \\
\text { No. of } \\
\text { Studies }\end{array}$ & $\begin{array}{l}\text { Bed Size, } \\
\text { No. of } \\
\text { Studies }\end{array}$ & $\begin{array}{l}\text { Type of } \\
\text { Hospital, No. } \\
\text { of Studies }\end{array}$ & $\begin{array}{l}\text { Health } \\
\text { System } \\
\text { Affiliation, } \\
\text { No. of } \\
\text { Studies }\end{array}$ & $\begin{array}{l}\text { Age, No. of } \\
\text { Studies }\end{array}$ & $\begin{array}{l}\text { Primary Dx \& } \\
\text { Comorbidity, } \\
\text { No. of Studies }\end{array}$ & $\begin{array}{l}\text { Medical } \\
\text { Insurance, } \\
\text { No. of } \\
\text { Studies }\end{array}$ & $\begin{array}{l}\text { Vulnerabilityl } \\
\text { Social Isolation } \\
\text { Measures, } \\
\text { No. of Studies }\end{array}$ \\
\hline $\begin{array}{l}\text { Austin } \\
\text { et al. } \\
2020^{24}\end{array}$ & Adults & Not reported & Not reported & Not reported & Not reported & $>18$ years & $\begin{array}{l}\text { Types of } \\
\text { anticoagulants } \\
\text { assessed: } \\
\text { Unfractionated } \\
\text { heparin: } 9 \\
\text { Vitamin K } \\
\text { antagonists: } 8 \\
\text { Combination of } \\
\text { anticoagulants: } \\
8 \text { studies } \\
\text { Low molecular } \\
\text { weight heparins: } 2\end{array}$ & Not reported & Not reported \\
\hline $\begin{array}{l}\text { Agarwal } \\
\text { et al. } \\
2018^{34}\end{array}$ & Adults & Urban, rural & Not reported & $\begin{array}{l}\text { Academic } \\
\text { centers: } 2 \\
\text { Community } \\
\text { hospital: } 2\end{array}$ & Not reported & $\begin{array}{l}67.5 \text { to } \\
79.3 \text { years }\end{array}$ & Heart failure & Not reported & Not reported \\
\hline $\begin{array}{l}\text { Baratloo } \\
\text { et al. } \\
2018^{25}\end{array}$ & Adult & $\begin{array}{l}\text { Rural and } \\
\text { remote } \\
\text { areas }\end{array}$ & Not reported & Not reported & Not reported & $\begin{array}{l}\text { Mean range: } \\
60.1 \text { to } \\
80 \text { years }\end{array}$ & $\begin{array}{l}\text { Tissue } \\
\text { plasminogen } \\
\text { activator treated } \\
\text { patients with } \\
\text { acute ischemic } \\
\text { stroke }\end{array}$ & Not reported & Not reported \\
\hline
\end{tabular}




\begin{tabular}{|c|c|c|c|c|c|c|c|c|c|}
\hline $\begin{array}{l}\text { Author } \\
\text { Year }\end{array}$ & $\begin{array}{l}\text { Patient } \\
\text { Age } \\
\text { Cohort }\end{array}$ & $\begin{array}{l}\text { Location, } \\
\text { No. of } \\
\text { Studies }\end{array}$ & $\begin{array}{l}\text { Bed Size, } \\
\text { No. of } \\
\text { Studies }\end{array}$ & $\begin{array}{l}\text { Type of } \\
\text { Hospital, No. } \\
\text { of Studies }\end{array}$ & \begin{tabular}{|l|} 
Health \\
System \\
Affiliation, \\
No. of \\
Studies \\
\end{tabular} & $\begin{array}{l}\text { Age, No. of } \\
\text { Studies }\end{array}$ & $\begin{array}{l}\text { Primary Dx \& } \\
\text { Comorbidity, } \\
\text { No. of Studies }\end{array}$ & \begin{tabular}{|l|} 
Medical \\
Insurance, \\
No. of \\
Studies
\end{tabular} & $\begin{array}{l}\text { Vulnerabilityl } \\
\text { Social Isolation } \\
\text { Measures, } \\
\text { No. of Studies }\end{array}$ \\
\hline $\begin{array}{l}\text { Bryant- } \\
\text { Lukosius } \\
\text { et al. } \\
2015^{35}\end{array}$ & $\begin{array}{l}\text { Adults } \\
\text { and } \\
\text { infants }\end{array}$ & $\begin{array}{l}\text { Urban and } \\
\text { rural }\end{array}$ & $\begin{array}{l}\text { Few studies } \\
\text { reported bed } \\
\text { size } \\
500 \text { to } \\
550 \text { beds: } 2\end{array}$ & $\begin{array}{l}\text { Academic } \\
\text { medical } \\
\text { centers, } \\
\text { community } \\
\text { hospitals, non- } \\
\text { profit acute care } \\
\text { teaching } \\
\text { hospital }\end{array}$ & $\begin{array}{l}\text { Systems in } \\
\text { Pennsylvania } \\
\text { and Vermont }\end{array}$ & $\begin{array}{l}\text { Patients with } \\
\text { heart failure: } \\
\text { mean range: } \\
70.7 \text { to } \\
76 \text { years } \\
\text { Elderly } \\
\text { hospitalized } \\
\text { patients: } \\
\text { mean range: } \\
74.4 \text { to } \\
80.3 \text { years } \\
\text { High-risk } \\
\text { pregnant } \\
\text { women and } \\
\text { infants: } \\
\text { mean range: } \\
23.5 \text { to } 28.5\end{array}$ & $\begin{array}{l}\text { Patients with } \\
\text { heart failure: } 3 \\
\text { Elderly } \\
\text { hospitalized } \\
\text { patients: } 5 \\
\text { High-risk pregnant } \\
\text { women and } \\
\text { infants: } 3\end{array}$ & $\begin{array}{l}\text { Patients with } \\
\text { heart failure: } \\
\text { authors } \\
\text { reported no } \\
\text { baseline group } \\
\text { differences in } \\
\text { health } \\
\text { resource use } \\
\text { or costs } \\
\text { Elderly } \\
\text { hospitalized } \\
\text { patients: } \\
97.5 \% \\
\text { received } \\
\text { Medicare and } \\
7.5 \% \text { received } \\
\text { Medicaid } \\
\text { (1 RCT) } \\
\text { High-risk } \\
\text { pregnant } \\
\text { women and } \\
\text { infants: } \\
65 \% \text { Medicaid } \\
\text { (1 RCT), } \\
36.5 \% \\
\text { Medicaid } \\
\text { (1 RCT), } \\
65 \% \text { public } \\
\text { health } \\
\text { insurance } \\
\text { (1 RCT) }\end{array}$ & $\begin{array}{l}\text { Patients with } \\
\text { heart failure: } \\
1 \mathrm{RCT} \text { : } \\
43.2 \%<\$ 15,000 \\
\text { annual income; } \\
41.8 \% \\
\$ 15-50,000 ; \\
7.7 \%>\$ 50,000 \\
1 \mathrm{RCT}: \\
33.1 \%<\$ 10,000 \\
\text { annual income; } \\
26.8 \% \\
\$ 10,000 \text { to } \\
\$ 19,999 ; \\
15.9 \% \geq \$ 20,000 \\
\text { Elderly } \\
\text { hospitalized } \\
\text { patients: } \\
1 \mathrm{RCT}: \\
35 \%<\$ 10,000 \\
\text { annual income } \\
1 \mathrm{RCT}: 64 \% \\
\text { (intervention) } \\
\text { and } 46 \% \\
\text { (control) } \\
<\$ 20,000 \text { annual } \\
\text { income; } 36 \% \\
\text { (intervention) } \\
\text { and } 46 \% \\
\text { (control) } \\
>\$ 20,000 \text { annual } \\
\text { income } \\
1 \mathrm{RCT}: \\
72 \%<\$ 19,000 \\
\text { annual income; } \\
28 \% \geq \$ 20,000\end{array}$ \\
\hline
\end{tabular}




\begin{tabular}{|c|c|c|c|c|c|c|c|c|c|}
\hline $\begin{array}{l}\text { Author } \\
\text { Year }\end{array}$ & $\begin{array}{l}\text { Patient } \\
\text { Age } \\
\text { Cohort }\end{array}$ & $\begin{array}{l}\text { Location, } \\
\text { No. of } \\
\text { Studies }\end{array}$ & $\begin{array}{l}\text { Bed Size, } \\
\text { No. of } \\
\text { Studies }\end{array}$ & $\begin{array}{l}\text { Type of } \\
\text { Hospital, No. } \\
\text { of Studies }\end{array}$ & $\begin{array}{l}\text { Health } \\
\text { System } \\
\text { Affiliation, } \\
\text { No. of } \\
\text { Studies } \\
\end{array}$ & $\begin{array}{l}\text { Age, No. of } \\
\text { Studies }\end{array}$ & $\begin{array}{l}\text { Primary Dx \& } \\
\text { Comorbidity, } \\
\text { No. of Studies }\end{array}$ & \begin{tabular}{|l|} 
Medical \\
Insurance, \\
No. of \\
Studies
\end{tabular} & $\begin{array}{l}\text { Vulnerabilityl } \\
\text { Social Isolation } \\
\text { Measures, } \\
\text { No. of Studies }\end{array}$ \\
\hline & & & & & & & & & $\begin{array}{l}\text { High-risk } \\
\text { pregnant women } \\
\text { and infants: } \\
1 \mathrm{RCT} \text { : } \\
68 \%<\$ 9999 ; \\
21 \% \$ 10,000 \text { to } \\
\$ 49,000, \\
11 \%>\$ 50,000 \\
1 \mathrm{RCT} \text { : } \\
31 \%<\$ 9999 \\
\text { annual income; } \\
25.5 \% \$ 10,000 \\
\text { to } \$ 24,999 ; \\
43.5 \% \geq \$ 25,000 \\
1 \mathrm{RCT}: \\
62 \% \text { below } \\
\text { poverty-level } \\
\text { income }\end{array}$ \\
\hline $\begin{array}{l}\text { Bakker } \\
\text { et al. } \\
2011^{26}\end{array}$ & Adult & Not reported & Not reported & $\begin{array}{l}\text { AMC: } 2 \\
\text { Community: } 2 \\
\text { VA: } 1 \\
\text { Not reported: } 1\end{array}$ & Not reported & $65+$ years & Frail elderly & Not reported & Not reported \\
\hline $\begin{array}{l}\text { Eagles } \\
\text { et al. } \\
2020^{41}\end{array}$ & Adults & Not reported & Not reported & $\begin{array}{l}\text { Level } 2 \text { trauma } \\
\text { center: } 2 \text { (US) } \\
\text { Level } 1 \text { trauma } \\
\text { center: } 5 \text { (US), } \\
1 \text { (Canada) } \\
\end{array}$ & Not reported & $\begin{array}{l}\text { Range: } \\
60 \text { to } \\
70 \text { years }\end{array}$ & $\begin{array}{l}\text { Older adults } \\
\text { admitted to } \\
\text { trauma center }\end{array}$ & Not reported & Not reported \\
\hline $\begin{array}{l}\text { Ellis et al. } \\
2017^{36}\end{array}$ & Adults & $\begin{array}{l}\text { Mostly } \\
\text { urban }\end{array}$ & $\begin{array}{l}\text { Few studies } \\
\text { reported bed } \\
\text { size. } \\
60 \text { beds: } 1 \\
1500 \text { beds: } 1\end{array}$ & $\begin{array}{l}\text { University/ } \\
\text { teaching; VA; } \\
\text { Community; } \\
\text { Multi-center }\end{array}$ & Yes & $\begin{array}{l}\text { Mean range: } \\
74 \text { to } \\
85 \text { years }\end{array}$ & $\begin{array}{l}\text { Frail or at-risk } \\
\text { participants: } 11 \\
\text { Older participants: } \\
11\end{array}$ & Not reported & Not reported \\
\hline
\end{tabular}




\begin{tabular}{|c|c|c|c|c|c|c|c|c|c|}
\hline $\begin{array}{l}\text { Author } \\
\text { Year }\end{array}$ & $\begin{array}{l}\text { Patient } \\
\text { Age } \\
\text { Cohort }\end{array}$ & $\begin{array}{l}\text { Location, } \\
\text { No. of } \\
\text { Studies }\end{array}$ & $\begin{array}{l}\text { Bed Size, } \\
\text { No. of } \\
\text { Studies }\end{array}$ & $\begin{array}{l}\text { Type of } \\
\text { Hospital, No. } \\
\text { of Studies }\end{array}$ & \begin{tabular}{|l|} 
Health \\
System \\
Affiliation, \\
No. of \\
Studies \\
\end{tabular} & $\begin{array}{l}\text { Age, No. of } \\
\text { Studies }\end{array}$ & \begin{tabular}{|l|} 
Primary Dx \& \\
Comorbidity, \\
No. of Studies
\end{tabular} & \begin{tabular}{|l} 
Medical \\
Insurance, \\
No. of \\
Studies
\end{tabular} & $\begin{array}{l}\text { Vulnerabilityl } \\
\text { Social Isolation } \\
\text { Measures, } \\
\text { No. of Studies }\end{array}$ \\
\hline $\begin{array}{l}\text { Frazer } \\
\text { et al. } \\
2019^{37}\end{array}$ & Adults & Not reported & Not reported & $\begin{array}{l}\text { Single hospital: } \\
10 \\
\text { Multiple } \\
\text { centers: } 9\end{array}$ & Not reported & $\begin{array}{l}\text { Mean range: } \\
46 \text { to } \\
77 \text { years }\end{array}$ & $\begin{array}{l}\text { History of AF, } \\
\text { ACS, VTE, } \\
\text { stroke/TIA, valve } \\
\text { replacement, } \\
\text { severe heart } \\
\text { failure, PVD, } \\
\text { ARDS, bridge to } \\
\text { lung transplant, } \\
\text { valve disease, } \\
\text { systemic arterial } \\
\text { embolism, left } \\
\text { ventricular } \\
\text { thrombus, cardiac } \\
\text { prophylaxis }\end{array}$ & Not reported & Not reported \\
\hline $\begin{array}{l}\text { Gonçalves- } \\
\text { Bradley } \\
\text { et al. } \\
2016^{38}\end{array}$ & Adult & Urban, rural & $\begin{array}{l}\text { Few studies } \\
\text { reported bed } \\
\text { size } \\
\text { Minimum bed } \\
\text { size reported: } \\
100 \text { beds }\end{array}$ & $\begin{array}{l}\text { US studies: } \\
\text { Academic/ } \\
\text { teaching: } 9 \\
\text { VA: } 2 \\
\text { Safety-net: } 2\end{array}$ & $\begin{array}{l}\text { Most reported } \\
\text { health system } \\
\text { affiliation }\end{array}$ & $\begin{array}{l}75 \text { years: } 10 \\
70 \text { to } \\
75 \text { years: } 7 \\
<70 \text { years: } \\
13\end{array}$ & $\begin{array}{l}\text { Older participant: } \\
21 \\
\text { Mix of medical } \\
\text { and surgical } \\
\text { conditions } \\
\text { including heart } \\
\text { failure: } 5 \\
\text { Psychiatric } \\
\text { hospital or } \\
\text { general ward: } 2 \\
\text { Admitted following } \\
\text { fall: } 2 \\
\text { Note: some trials } \\
\text { included multiple } \\
\text { population types }\end{array}$ & Not reported & $\begin{array}{l}\text { Language and } \\
\text { health literacy: } 4 \\
\text { *Mixed evidence } \\
\text { for non-English } \\
\text { speakers, and } \\
\text { evidence does } \\
\text { not seem to } \\
\text { support an } \\
\text { increased or } \\
\text { decreased effect } \\
\text { of discharge } \\
\text { planning for } \\
\text { patients with low } \\
\text { health literacy. }\end{array}$ \\
\hline $\begin{array}{l}\text { Gillaizeau } \\
\text { et al. } \\
2013^{27}\end{array}$ & Adult & $\begin{array}{l}4 \text { urban, } \\
6 \text { not } \\
\text { reported }\end{array}$ & $\begin{array}{l}4 \text { studies } \\
\text { reported: } \\
\text { range } 288 \text { to } \\
1400\end{array}$ & $\begin{array}{l}\text { AMC: } 4 \\
\text { VA: } 2 \\
\text { Community: } 3\end{array}$ & Not reported & Not reported & $\begin{array}{l}\text { Mix includes } \\
\text { diabetes, COPD, } \\
\text { renal disease, etc. }\end{array}$ & Not reported & Not reported \\
\hline
\end{tabular}




\begin{tabular}{|c|c|c|c|c|c|c|c|c|c|}
\hline $\begin{array}{l}\text { Author } \\
\text { Year }\end{array}$ & $\begin{array}{l}\text { Patient } \\
\text { Age } \\
\text { Cohort }\end{array}$ & $\begin{array}{l}\text { Location, } \\
\text { No. of } \\
\text { Studies }\end{array}$ & $\begin{array}{l}\text { Bed Size, } \\
\text { No. of } \\
\text { Studies }\end{array}$ & $\begin{array}{l}\text { Type of } \\
\text { Hospital, No. } \\
\text { of Studies }\end{array}$ & \begin{tabular}{|l} 
Health \\
System \\
Affiliation, \\
No. of \\
Studies \\
\end{tabular} & $\begin{array}{l}\text { Age, No. of } \\
\text { Studies }\end{array}$ & $\begin{array}{l}\text { Primary Dx \& } \\
\text { Comorbidity, } \\
\text { No. of Studies }\end{array}$ & \begin{tabular}{|l} 
Medical \\
Insurance, \\
No. of \\
Studies
\end{tabular} & $\begin{array}{l}\text { Vulnerability/ } \\
\text { Social Isolation } \\
\text { Measures, } \\
\text { No. of Studies }\end{array}$ \\
\hline $\begin{array}{l}\text { Huntley } \\
\text { et al. } \\
2016^{28}\end{array}$ & Adult & $\begin{array}{l}\text { For LOS: } \\
\text { Urban: } 5 \\
\text { Not } \\
\text { reported: } 4\end{array}$ & Not reported & $\begin{array}{l}\text { For LOS: } \\
\text { AMC:2 } \\
\text { Community: } 5 \\
\text { Not reported: } 2\end{array}$ & $\begin{array}{l}\text { For LOS: } \\
\text { Yes: } 2 \\
\text { Not reported: } 7\end{array}$ & $65+$ years & $\begin{array}{l}\text { Congestive heart } \\
\text { failure }\end{array}$ & Not reported & $\begin{array}{l}3 \text { studies have } \\
>20 \% \text { of patients } \\
\text { with first } \\
\text { language other } \\
\text { than English; } \\
\text { in } 2 \text { studies, } \\
>50 \% \text { of patients } \\
\text { are Black, other } \\
\text { non-white, or } \\
\text { Hispanic }\end{array}$ \\
\hline $\begin{array}{l}\text { Kul et al. } \\
2012^{29}\end{array}$ & Adult & $\begin{array}{l}1 \text { urban, } \\
1 \text { suburban, } \\
1 \text { rural, } \\
4 \text { not } \\
\text { reported }\end{array}$ & Not reported & Not reported & Not reported & $\begin{array}{l}\text { Mean: } \\
>65 \text { years }\end{array}$ & $\begin{array}{l}\text { Congestive heart } \\
\text { failure }\end{array}$ & Not reported & Not reported \\
\hline $\begin{array}{l}\text { Mabire } \\
\text { et al } \\
2017^{15,30}\end{array}$ & Adults & Not reported & Not reported & $\begin{array}{l}\text { University } \\
\text { hospitals: } 11 \\
\text { City hospitals: } 2\end{array}$ & Not reported & $\begin{array}{l}\text { Median: } \\
77 \text { years }\end{array}$ & $\begin{array}{l}\text { Older patients: } \\
\text { With severe } \\
\text { comorbidities: } 1 \\
\text { With moderate } \\
\text { comorbidities: } 5 \\
\text { With low } \\
\text { morbidities: } 5\end{array}$ & Not reported & Not reported \\
\hline $\begin{array}{l}\text { Patel et al. } \\
2020^{31}\end{array}$ & Adults & Not reported & Not reported & Not reported & Not reported & $>60$ years & $\begin{array}{l}\text { Older patients } \\
\text { with hip fracture }\end{array}$ & Not reported & Not reported \\
\hline $\begin{array}{l}\text { Pannick } \\
\text { et al. } \\
2015^{32}\end{array}$ & Adults & Not reported & Not reported & $\begin{array}{l}\text { Safety-net } \\
\text { hospitals, large } \\
\text { academic } \\
\text { facilities }\end{array}$ & Yes & $\begin{array}{l}\text { Mean: } \\
63 \text { years }\end{array}$ & $\begin{array}{l}\text { Variety of primary } \\
\text { diagnoses: } \\
\text { delirium, } \\
\text { community- } \\
\text { acquired } \\
\text { pneumonia, acute } \\
\text { stroke, advanced } \\
\text { liver disease, } \\
\text { patients taking } \\
\text { anticoagulant } \\
\text { medication }\end{array}$ & Not reported & Not reported \\
\hline
\end{tabular}




\begin{tabular}{|c|c|c|c|c|c|c|c|c|c|}
\hline $\begin{array}{l}\text { Author } \\
\text { Year }\end{array}$ & $\begin{array}{l}\text { Patient } \\
\text { Age } \\
\text { Cohort }\end{array}$ & $\begin{array}{l}\text { Location, } \\
\text { No. of } \\
\text { Studies }\end{array}$ & $\begin{array}{l}\text { Bed Size, } \\
\text { No. of } \\
\text { Studies }\end{array}$ & $\begin{array}{l}\text { Type of } \\
\text { Hospital, No. } \\
\text { of Studies }\end{array}$ & \begin{tabular}{|l|} 
Health \\
System \\
Affiliation, \\
No. of \\
Studies \\
\end{tabular} & $\begin{array}{l}\text { Age, No. of } \\
\text { Studies }\end{array}$ & $\begin{array}{l}\text { Primary Dx \& } \\
\text { Comorbidity, } \\
\text { No. of Studies }\end{array}$ & \begin{tabular}{|l} 
Medical \\
Insurance, \\
No. of \\
Studies
\end{tabular} & $\begin{array}{l}\text { Vulnerabilityl } \\
\text { Social Isolation } \\
\text { Measures, } \\
\text { No. of Studies }\end{array}$ \\
\hline $\begin{array}{l}\text { Van Craen } \\
\text { et al. } \\
2010^{39}\end{array}$ & Adult & Not reported & Not reported & $\begin{array}{l}\text { AMC: } 2 \\
\text { Community: } 1 \\
\text { VA: } 2 \\
\text { Not reported: } 2 \\
\end{array}$ & Not reported & $65+$ years & Frail elderly & Not reported & Not reported \\
\hline $\begin{array}{l}\text { White et al. } \\
2011^{33}\end{array}$ & $\begin{array}{l}\text { Adult only: } \\
25 \text { studies } \\
\text { Pediatric } \\
\text { only: } \\
10 \text { studies } \\
\text { All ages: } \\
30 \text { studies }\end{array}$ & Not reported & Not reported & $\begin{array}{l}\text { AMC: } 54 \\
\text { Community: } 11\end{array}$ & Not reported & All ages & $\begin{array}{l}\text { Mix includes heart } \\
\text { failure, COPD, } \\
\text { psychiatric illness, } \\
\text { substance use } \\
\text { disorder, etc. }\end{array}$ & Not reported & Not reported \\
\hline $\begin{array}{l}\text { Zhu et al. } \\
2015^{12}\end{array}$ & Adults & Not reported & Not reported & Not reported & Not reported & $\begin{array}{l}\text { Mean range: } \\
36.4 \text { to } \\
94 \text { years }\end{array}$ & $\begin{array}{l}\text { Older hospitalized } \\
\text { adults: } 5 \\
\text { Decompensated } \\
\text { HF: } 1 \\
\text { Hip fracture } \\
\text { patients: } 1 \\
\text { Rehab patients: } 1 \\
\text { CHD: } 1 \\
\text { Hospitalized } \\
\text { psychiatric } \\
\text { patients: } 1 \\
\end{array}$ & Medicare: 1 & Not reported \\
\hline $\begin{array}{l}\text { Zhang } \\
\text { et al. } \\
2013^{40}\end{array}$ & Adult & Not reported & Not reported & Not reported & Not reported & $\begin{array}{l}\text { Mean age: } \\
80+\text { years }\end{array}$ & $\begin{array}{l}\text { Frail elderly } \\
\text { undergoing } \\
\text { orthopedic } \\
\text { surgery }\end{array}$ & Not reported & Not reported \\
\hline
\end{tabular}

$\mathrm{ACS}=$ acute coronary syndrome; $\mathrm{AF}=$ atrial fibrillation; $\mathrm{AMC}=$ academic medical center; $\mathrm{ARDS}=$ acute respiratory distress syndrome; CHD = congenital heart disease;

$\mathrm{COPD}=$ chronic obstructive pulmonary disease; $\mathrm{PVD}=$ peripheral vascular disease; $\mathrm{RCT}=$ randomized controlled trial; TIA = transient ischemic attack; $\mathrm{VA}=\mathrm{Veteran}$ Affairs; $\mathrm{VTE}=$ venous thromboembolism 
Table C-3. Interventions to reduce length of hospital stay

\begin{tabular}{|c|c|c|c|c|c|}
\hline $\begin{array}{l}\text { Author } \\
\text { Year }\end{array}$ & $\begin{array}{l}\text { Type of } \\
\text { Intervention }\end{array}$ & $\begin{array}{l}\text { Description of } \\
\text { Intervention }\end{array}$ & Comparator & Resources & \begin{tabular}{|l|} 
Implementation \\
Features
\end{tabular} \\
\hline $\begin{array}{l}\text { Austin } \\
\text { et al. } \\
2020^{24}\end{array}$ & $\begin{array}{l}\text { Computerized } \\
\text { physician order } \\
\text { entry (CPOE): } 4 \\
\text { Clinical decision } \\
\text { support system } \\
\text { (CDSS): } 21 \\
\text { Dashboard } \\
\text { utilization: } 1 \\
\text { EMR } \\
\text { implementation } \\
\text { in general: } 1\end{array}$ & $\begin{array}{l}\text { CPOE: Providers used } \\
\text { computer assistance to } \\
\text { directly enter medication } \\
\text { orders from a computer } \\
\text { or mobile device. } \\
2 \text { studies focused on } \\
\text { discharge reconciliation } \\
\text { process (warfarin } \\
\text { prescribing), } 1 \text { study } \\
\text { assessed impact of } \\
\text { CPOE on medication } \\
\text { errors and preventable } \\
\text { adverse events, and } \\
1 \text { study assessed } \\
\text { appropriateness of } \\
\text { CPOE on pathology } \\
\text { information. } \\
\text { CDSS: Majority of } \\
\text { methods assessed } \\
\text { impact of CDSS alerts } \\
\text { (14 studies). Additional } \\
\text { strategies or functionality } \\
\text { of the EMR utilized were } \\
\text { classified according to } \\
\text { type of CDSS. }\end{array}$ & Routine care & Providers & Not reported \\
\hline $\begin{array}{l}\text { Agarwal } \\
\text { et al. } \\
2018^{34}\end{array}$ & $\begin{array}{l}\text { Clinical } \\
\text { pathway: } \\
\text { Multi- } \\
\text { component } \\
\text { interventions } \\
\text { (5 RCTs) } \\
\text { Education at } \\
\text { discharge } \\
\text { (1 RCT) }\end{array}$ & $\begin{array}{l}5 \text { RCTs assessed a } \\
\text { variety of multi- } \\
\text { component interventions: } \\
\text { In } 2 \text { trials these were } \\
\text { quality improvement } \\
\text { initiatives including } \\
\text { inpatient critical pathway } \\
\text { for HF management, } \\
\text { standardized admissions } \\
\text { orders, staff and patient } \\
\text { HF education, home } \\
\text { care pathway for after } \\
\text { hospital discharge, and } \\
\text { tailored performance } \\
\text { reports; } 3 \text { other trials } \\
\text { assessed multi- } \\
\text { component interventions } \\
\text { including components } \\
\text { such as use of case } \\
\text { manager, HF education, } \\
\text { medication review, and } \\
\text { telephone surveillance } \\
\text { post-discharge; } 1 \text { RCT } \\
\text { assessed } 1 \text { hour } \\
\text { educational session at } \\
\text { discharge. }\end{array}$ & Usual care & $\begin{array}{l}1 \text { intervention } \\
\text { included } \\
\text { experienced } \\
\text { consulting form } \\
\text { assisted in } \\
\text { implementation } \\
\text { of the pathways } \\
\text { and other } \\
\text { pathway } \\
\text { components }\end{array}$ & Not reported \\
\hline
\end{tabular}




\begin{tabular}{|c|c|c|c|c|c|}
\hline $\begin{array}{l}\text { Author } \\
\text { Year }\end{array}$ & \begin{tabular}{|l|} 
Type of \\
Intervention
\end{tabular} & $\begin{array}{l}\text { Description of } \\
\text { Intervention }\end{array}$ & Comparator & Resources & \begin{tabular}{|l|} 
Implementation \\
Features
\end{tabular} \\
\hline $\begin{array}{l}\text { Baratloo } \\
\text { et al. } \\
2018^{25}\end{array}$ & $\begin{array}{l}\text { Telestroke- } \\
\text { based systems }\end{array}$ & $\begin{array}{l}\text { Telephone, } \\
\text { videoconferencing, or } \\
\text { tele radiology used to } \\
\text { deliver intervention. }\end{array}$ & $\begin{array}{l}\text { Bedside (face } \\
\text { to face) acute } \\
\text { stroke care at } \\
\text { comprehensive } \\
\text { stroke center } \\
\text { with } 24 \text { hour } \\
\text { access to } \\
\text { thrombolysis } \\
\text { and specialized } \\
\text { stroke expertise }\end{array}$ & Not reported & Not reported \\
\hline $\begin{array}{l}\text { Bryant- } \\
\text { Lukosius } \\
\text { et al. } \\
2015^{35}\end{array}$ & $\begin{array}{l}\text { Clinical nurse } \\
\text { specialists } \\
\text { (CNS) } \\
\text { transitional care }\end{array}$ & $\begin{array}{l}\text { Early discharge } \\
\text { interventions: } 3 \text { studies } \\
\text { of patients with heart } \\
\text { failure, CNSs visited } \\
\text { patients while in hospital, } \\
\text { had regular post- } \\
\text { discharge contact via } \\
\text { telephone, home visits, } \\
\text { or home and heart failure } \\
\text { clinic. } \\
\text { Early discharge } \\
\text { interventions: } 3 \text { studies } \\
\text { of high-risk pregnant } \\
\text { women and infants, } \\
\text { CNSs provided direct } \\
\text { care to hospitalized } \\
\text { women and infants, } \\
\text { assessed their suitability } \\
\text { for early discharge and } \\
\text { provided post-discharge } \\
\text { care via home visits, } \\
\text { telephone calls, and on- } \\
\text { call services over several } \\
\text { weeks. } \\
\text { Post-discharge } \\
\text { intervention: } 5 \text { studies of } \\
\text { elderly hospitalized } \\
\text { patients, CNSs and/or } \\
\text { nurse practitioners } \\
\text { visited patients in } \\
\text { hospital to prepare } \\
\text { individualized discharge } \\
\text { plans and provide } \\
\text { regular post-discharge } \\
\text { follow-up home visits or } \\
\text { telephone calls. Patients } \\
\text { had telephone access to } \\
\text { CNS as needed. }\end{array}$ & Usual care & $\begin{array}{l}\text { Master's } \\
\text { prepared CNS, } \\
\text { nurse } \\
\text { practitioner }\end{array}$ & Not reported \\
\hline $\begin{array}{l}\text { Bakker } \\
\text { et al. } \\
2011^{26}\end{array}$ & $\begin{array}{l}\text { Geriatric } \\
\text { specialty teams } \\
\text { or units }\end{array}$ & $\begin{array}{l}3 \text { studies used } \\
\text { multidisciplinary } \\
\text { geriatrics team to consult } \\
\text { on patient management; } \\
3 \text { studies had separate } \\
\text { geriatric unit. }\end{array}$ & Usual care & Not reported & Not reported \\
\hline
\end{tabular}




\begin{tabular}{|c|c|c|c|c|c|}
\hline $\begin{array}{l}\text { Author } \\
\text { Year }\end{array}$ & $\begin{array}{l}\text { Type of } \\
\text { Intervention }\end{array}$ & $\begin{array}{l}\text { Description of } \\
\text { Intervention }\end{array}$ & Comparator & Resources & $\begin{array}{l}\text { Implementation } \\
\text { Features }\end{array}$ \\
\hline $\begin{array}{l}\text { Eagles } \\
\text { et al. } \\
2020^{41}\end{array}$ & $\begin{array}{l}\text { Geriatric trauma } \\
\text { consultation }\end{array}$ & $\begin{array}{l}\text { Mandatory element in all } \\
\text { studies was an } \\
\text { assessment by a } \\
\text { geriatrician. Some } \\
\text { studies reported } \\
\text { participation in } \\
\text { multidisciplinary rounds } \\
\text { ( } 3 \text { studies) or compliance } \\
\text { of trauma team to } \\
\text { geriatric } \\
\text { recommendations } \\
\text { ( } 2 \text { studies). }\end{array}$ & $\begin{array}{l}\text { Standard } \\
\text { trauma care }\end{array}$ & $\begin{array}{l}\text { Geriatrician, } \\
\text { advanced } \\
\text { practice nurse } \\
\text { ( } 2 \text { studies), } \\
\text { resident/fellows } \\
\text { ( } 2 \text { studies) }\end{array}$ & Not reported \\
\hline $\begin{array}{l}\text { Ellis et al. } \\
2017^{36}\end{array}$ & $\begin{array}{l}\text { Comprehensive } \\
\text { geriatric } \\
\text { assessment }\end{array}$ & $\begin{array}{l}\text { Most common } \\
\text { components included } \\
\text { tailored treatment plans } \\
\text { to the individual. } \\
12 \text { studies held multi- } \\
\text { disciplinary team } \\
\text { meetings; } 11 \text { studies } \\
\text { included clinical } \\
\text { leadership; } 11 \text { studies } \\
\text { included specialty } \\
\text { knowledge, experience, } \\
\text { and competence; and } \\
10 \text { studies involved } \\
\text { participants and carers in } \\
\text { goal setting. }\end{array}$ & Usual care & $\begin{array}{l}\text { Consultant } \\
\text { geriatricians, } \\
\text { healthcare } \\
\text { assistants, junior } \\
\text { doctors, nurses, } \\
\text { occupational } \\
\text { therapists, } \\
\text { pharmacists, } \\
\text { physiotherapists, } \\
\text { psychiatric } \\
\text { nurses, social } \\
\text { workers, therapy } \\
\text { assistants }\end{array}$ & $\begin{array}{l}\text { Delivered in a } \\
\text { dedicated geriatric } \\
\text { ward ( } 20 \text { studies); } \\
\text { mobile team on a } \\
\text { general medical } \\
\text { ward (8 studies) }\end{array}$ \\
\hline
\end{tabular}




\begin{tabular}{|c|c|c|c|c|c|}
\hline $\begin{array}{l}\text { Author } \\
\text { Year }\end{array}$ & \begin{tabular}{|l|} 
Type of \\
Intervention
\end{tabular} & $\begin{array}{l}\text { Description of } \\
\text { Intervention }\end{array}$ & Comparator & Resources & \begin{tabular}{|l|} 
Implementation \\
Features
\end{tabular} \\
\hline $\begin{array}{l}\text { Frazer } \\
\text { et al. } \\
2019^{37}\end{array}$ & $\begin{array}{l}\text { Anticoagulation } \\
\text { consultation } \\
\text { services } \\
\text { Decision } \\
\text { supported } \\
\text { warfarin dosing } \\
\text { Heparin } \\
\text { monitoring } \\
\text { systems } \\
\text { Other CDSS } \\
\text { Systematic } \\
\text { education and } \\
\text { feedback } \\
\text { programs }\end{array}$ & $\begin{array}{l}\text { Anticoagulation } \\
\text { consultation services: } \\
\text { Pharmacist-led } \\
\text { anticoagulation service } \\
\text { Decision supported } \\
\text { warfarin dosing: } \\
\text { Computer dosing- } \\
\text { algorithm, linear } \\
\text { regression dosing } \\
\text { algorithm, genotype and } \\
\text { clinical information } \\
\text { dosing algorithm, } \\
\text { mathematical formula } \\
\text { dosing algorithm } \\
\text { Heparin monitoring } \\
\text { systems: Point of care } \\
\text { coagulation monitoring, } \\
\text { thromboelastography, } \\
\text { heparin assay } \\
\text { Other CDSs: } \\
\text { Computerized electronic } \\
\text { alert system requiring } \\
\text { active response or with } \\
\text { hard-stop alert, computer } \\
\text { based decision support } \\
\text { system } \\
\text { Systematic education } \\
\text { and feedback programs: } \\
\text { Multifaceted safety } \\
\text { program, enhanced } \\
\text { feedback intervention } \\
\end{array}$ & $\begin{array}{l}\text { Physician-led } \\
\text { anticoagulation } \\
\text { service, usual } \\
\text { physician care, } \\
\text { standard } \\
\text { physician-led } \\
\text { dose } \\
\text { adjustment, } \\
\text { clinical } \\
\text { information } \\
\text { dosing } \\
\text { algorithm, } \\
\text { standard } \\
\text { activated partial } \\
\text { thromboplastin } \\
\text { time monitoring, } \\
\text { computerized } \\
\text { alert system, } \\
\text { written } \\
\text { feedback } \\
\text { intervention }\end{array}$ & $\begin{array}{l}\text { Pharmacist, } \\
\text { physician }\end{array}$ & Not reported \\
\hline $\begin{array}{l}\text { Gonçalves- } \\
\text { Bradley } \\
\text { et al. } \\
2016^{38}\end{array}$ & $\begin{array}{l}\text { Discharge } \\
\text { planning }\end{array}$ & $\begin{array}{l}\text { Studies included } \\
\text { assessment, planning, } \\
\text { implementation and } \\
\text { monitoring (e.g., } \\
\text { telephone, PCP } \\
\text { appointments) phases. } \\
7 \text { studies evaluated a } \\
\text { pharmacy discharge plan } \\
\text { implemented by a } \\
\text { hospital pharmacy. } \\
12 \text { studies provided post- } \\
\text { discharge phone call, } \\
\text { four a visit, two a phone } \\
\text { call and visit. Most } \\
\text { studies included a } \\
\text { patient education } \\
\text { component and } 7 \text { studies } \\
\text { reported place of } \\
\text { discharge (e.g., home } \\
\text { residential care). }\end{array}$ & $\begin{array}{l}\text { Standard care } \\
\text { with no } \\
\text { individualized } \\
\text { discharge plan }\end{array}$ & $\begin{array}{l}\text { Healthcare } \\
\text { professional } \\
\text { coordinated plan }\end{array}$ & $\begin{array}{l}\text { Implemented from } \\
\text { admission to three } \\
\text { days prior to } \\
\text { discharge }\end{array}$ \\
\hline
\end{tabular}




\begin{tabular}{|c|c|c|c|c|c|}
\hline $\begin{array}{l}\text { Author } \\
\text { Year }\end{array}$ & $\begin{array}{l}\text { Type of } \\
\text { Intervention }\end{array}$ & $\begin{array}{l}\text { Description of } \\
\text { Intervention }\end{array}$ & Comparator & Resources & $\begin{array}{l}\text { Implementation } \\
\text { Features }\end{array}$ \\
\hline $\begin{array}{l}\text { Gillaizeau } \\
\text { et al. } \\
2013^{27}\end{array}$ & $\begin{array}{l}\text { Computerized } \\
\text { decision } \\
\text { support }\end{array}$ & $\begin{array}{l}\text { All studies used real-time } \\
\text { computer support to } \\
\text { guide drug dosing; drugs } \\
\text { included: theophylline } \\
\text { ( } 3 \text { studies), } \\
\text { aminoglycoside } \\
\text { ( } 2 \text { studies), oral } \\
\text { anticoagulants } \\
\text { ( } 2 \text { studies), insulin } \\
\text { (1 study), cyclosporine } \\
\text { (1 study); } 3 \text { studies } \\
\text { supported computerized } \\
\text { physician order entry. }\end{array}$ & Usual care & Not reported & Not reported \\
\hline $\begin{array}{l}\text { Huntley } \\
\text { et al. } \\
2016^{28}\end{array}$ & $\begin{array}{l}\text { Case } \\
\text { management }\end{array}$ & $\begin{array}{l}\text { Studies included various } \\
\text { strategies, usually } \\
\text { directed by a nurse case } \\
\text { manager, including: } \\
\text { medication review, family } \\
\text { conferencing, education, } \\
\text { home environment } \\
\text { assessment, referral to } \\
\text { other services or medical } \\
\text { specialties. }\end{array}$ & Usual care & Case managers & Not reported \\
\hline $\begin{array}{l}\text { Kul et al. } \\
2012^{29}\end{array}$ & $\begin{array}{l}\text { Clinical } \\
\text { pathways }\end{array}$ & $\begin{array}{l}\text { Descriptions of each } \\
\text { study not given. All } \\
\text { studies had to include } \\
\text { pathways that met the } \\
\text { definition of a pathway } \\
\text { according to the } \\
\text { European Pathway } \\
\text { Association. }\end{array}$ & Usual care & Not reported & Not reported \\
\hline $\begin{array}{l}\text { Mabire } \\
\text { et al } \\
2017^{15,30}\end{array}$ & $\begin{array}{l}\text { Nursing } \\
\text { discharge } \\
\text { planning } \\
\text { interventions }\end{array}$ & $\begin{array}{l}\text { All interventions } \\
\text { comprised nurse } \\
\text { assessment and follow- } \\
\text { up. Some interventions } \\
\text { continued post-discharge } \\
\text { in the home setting (i.e. } \\
\text { telephone contact, visits, } \\
\text { combination); number of } \\
\text { contacts varied widely } \\
\text { ( } 2 \text { to } 10+\text { ) and timing } \\
\text { varied. Follow-up } \\
\text { contacts were within } \\
24 \text { hours post discharge, } \\
\text { others persisted up to } \\
9 \text { months. } 5 \text { studies } \\
\text { included geriatric } \\
\text { assessment; } 6 \text { studies } \\
\text { considered discharge } \\
\text { preparation interventions } \\
\text { as either effective } \\
\text { communication/ } \\
\text { information regarding the } \\
\text { discharge care plan; } \\
1 \text { study examined patient } \\
\text { participation. }\end{array}$ & Usual care & $\begin{array}{l}\text { Registered } \\
\text { nurses and } \\
\text { cardiac nurses } \\
\text { (4 studies); } \\
\text { Case managers } \\
\text { (3 studies); } \\
\text { Advance practice } \\
\text { nurses } \\
\text { (2 studies); } \\
\text { Community } \\
\text { nurse (1 study) }\end{array}$ & Not reported \\
\hline
\end{tabular}




\begin{tabular}{|c|c|c|c|c|c|}
\hline \begin{tabular}{|l|} 
Author \\
Year
\end{tabular} & $\begin{array}{l}\text { Type of } \\
\text { Intervention }\end{array}$ & \begin{tabular}{|l|} 
Description of \\
Intervention
\end{tabular} & Comparator & Resources & $\begin{array}{l}\text { Implementation } \\
\text { Features }\end{array}$ \\
\hline $\begin{array}{l}\text { Patel et al. } \\
2020^{31}\end{array}$ & $\begin{array}{l}\text { Orthopedic-led } \\
\text { care } \\
\text { (13 studies) } \\
\text { Geriatrics-led } \\
\text { care ( } 4 \text { studies) }\end{array}$ & $\begin{array}{l}\text { Interventions included } \\
\text { co-management } \\
\text { between orthopedic } \\
\text { service and } \\
\text { geriatrics/medicine } \\
\text { service. Example of } \\
\text { components include } \\
\text { prompt admission with } \\
\text { surgical optimization, } \\
\text { fast-tracking hip } \\
\text { fractures from ED to } \\
\text { inpatient unit, surgeon } \\
\text { availability, case } \\
\text { management evaluation } \\
\text { of patient's social } \\
\text { dynamics/needs and } \\
\text { anticipate discharge } \\
\text { needs starting day of } \\
\text { admission, brief } \\
\text { meeting/discussion } \\
\text { between management } \\
\text { team, continued medical } \\
\text { optimization (i.e. } \\
\text { coordinating } \\
\text { postoperative follow-up } \\
\text { for comorbidities). }\end{array}$ & $\begin{array}{l}\text { Coordinated } \\
\text { ortho-geriatrics } \\
\text { care model } \\
\text { (13 studies) or } \\
\text { orthopedic-led } \\
\text { care model } \\
\text { (4 studies) }\end{array}$ & Not reported & Not reported \\
\hline
\end{tabular}




\begin{tabular}{|c|c|c|c|c|c|}
\hline $\begin{array}{l}\text { Author } \\
\text { Year }\end{array}$ & $\begin{array}{l}\text { Type of } \\
\text { Intervention }\end{array}$ & $\begin{array}{l}\text { Description of } \\
\text { Intervention }\end{array}$ & Comparator & Resources & $\begin{array}{l}\text { Implementation } \\
\text { Features }\end{array}$ \\
\hline $\begin{array}{l}\text { Pannick } \\
\text { et al. } \\
2015^{32}\end{array}$ & $\begin{array}{l}\text { Interdisciplinary } \\
\text { team care } \\
8 \text { studies } \\
\text { involved low- } \\
\text { intensity } \\
\text { interventions } \\
\text { and remainder } \\
\text { were of medium } \\
\text { or high intensity }\end{array}$ & $\begin{array}{l}\text { Interdisciplinary team } \\
\text { care with altered } \\
\text { composition: } 15 \text { studies } \\
\text { required additional } \\
\text { specialists or } \\
\text { professionals to provide } \\
\text { advice. Consultants } \\
\text { specialized in geriatrics, } \\
\text { infectious diseases, } \\
\text { intravenous therapy, } \\
\text { stroke, } \\
\text { pharmacotherapy, or } \\
\text { psychiatry. } 4 \text { studies } \\
\text { assessed effect of } \\
\text { embedding additional } \\
\text { health care professionals } \\
\text { in rounding teams, } \\
\text { incorporating } \\
\text { pharmacists, medical } \\
\text { librarians, supervising } \\
\text { medical subspecialists. } \\
\text { Interdisciplinary team } \\
\text { care addressing team } \\
\text { practice: } 10 \text { studies } \\
\text { addressed the logistics } \\
\text { of when, where, and how } \\
\text { team members would } \\
\text { work together. } 2 \text { studies } \\
\text { assessed team } \\
\text { localization, with medical } \\
\text { and nursing staff co- } \\
\text { positioned in same } \\
\text { geographic area in } \\
\text { hospital. } 1 \text { study } \\
\text { described teamwork and } \\
\text { communication program. }\end{array}$ & $\begin{array}{l}\text { Usual, routine, } \\
\text { or standard } \\
\text { care }\end{array}$ & $\begin{array}{l}\text { Interdisciplinary } \\
\text { teams including } \\
\text { specialists and } \\
\text { subspecialists, } \\
\text { physicians, } \\
\text { nurses, } \\
\text { pharmacists, } \\
\text { medical } \\
\text { librarians }\end{array}$ & Not reported \\
\hline $\begin{array}{l}\text { Van Craen } \\
\text { et al. } \\
2010^{39}\end{array}$ & $\begin{array}{l}\text { Geriatric } \\
\text { evaluation unit }\end{array}$ & $\begin{array}{l}\text { Geriatric units included } \\
\text { many or most of the } \\
\text { following: } \\
\text { Assessment of medical, } \\
\text { functional, nutritional } \\
\text { cognitive, and psychiatric } \\
\text { status, social situation, } \\
\text { and quality of life } \\
\text { Development of } \\
\text { individual care plans } \\
\text { Initiation of early } \\
\text { discharge planning } \\
\text { Ensuring rehabilitation } \\
\text { services were available } \\
\text { Arranging post-discharge } \\
\text { follow-up plan }\end{array}$ & Usual care & $\begin{array}{l}\text { Interdisciplinary } \\
\text { teams including } \\
\text { physicians, } \\
\text { nurses, and/or } \\
\text { social workers, } \\
\text { dieticians, } \\
\text { psychologists, } \\
\text { physical/ } \\
\text { occupational } \\
\text { therapists }\end{array}$ & $\begin{array}{l}5 \text { studies admitted } \\
\text { patients directly to } \\
\text { geriatric unit from } \\
\text { home or } \\
\text { emergency } \\
\text { department; } \\
2 \text { studies admitted } \\
\text { patients from other } \\
\text { hospitals } \\
4 \text { studies } \\
\text { specifically } \\
\text { targeted frail } \\
\text { patients, while } \\
3 \text { studies included } \\
\text { all elderly patients } \\
\text { Patient } \\
\text { management } \\
\text { teams met daily } \\
\text { (2 studies), } \\
\text { twice weekly } \\
\text { (2 studies), or } \\
\text { weekly (3 studies) }\end{array}$ \\
\hline
\end{tabular}




\begin{tabular}{|c|c|c|c|c|c|}
\hline $\begin{array}{l}\text { Author } \\
\text { Year }\end{array}$ & $\begin{array}{l}\text { Type of } \\
\text { Intervention }\end{array}$ & \begin{tabular}{|l|} 
Description of \\
Intervention
\end{tabular} & Comparator & Resources & $\begin{array}{l}\text { Implementation } \\
\text { Features }\end{array}$ \\
\hline $\begin{array}{l}\text { White et al. } \\
2011^{33}\end{array}$ & $\begin{array}{l}\text { Hospitalist } \\
\text { service }\end{array}$ & $\begin{array}{l}\text { All studies used } \\
\text { hospitalist physician } \\
\text { structures. }\end{array}$ & $\begin{array}{l}\text { Traditional } \\
\text { attending } \\
\text { physician } \\
\text { structures } \\
\end{array}$ & Not reported & Not reported \\
\hline $\begin{array}{l}\text { Zhu et al. } \\
2015^{12}\end{array}$ & $\begin{array}{l}\text { Nurse-led early } \\
\text { discharge } \\
\text { planning }\end{array}$ & $\begin{array}{l}\text { Interventions included } \\
\text { telephone-based } \\
\text { programs, } \\
\text { biopsychosocial } \\
\text { assessment and } \\
\text { individualized plans to } \\
\text { address transitional care } \\
\text { needs, comprehensive } \\
\text { program for a specific } \\
\text { condition of interest (i.e. } \\
\text { decompensated heart } \\
\text { failure) providing easy } \\
\text { availability for consults } \\
\text { and close follow-up at } \\
\text { clinic. Nurse advocates } \\
\text { work with patients during } \\
\text { stay to arrange follow-up } \\
\text { appointments, confirm } \\
\text { medication } \\
\text { reconciliation; discharge } \\
\text { planning needs } \\
\text { assessment, } \\
\text { individualized nursing } \\
\text { instruction, monitoring } \\
\text { services, coordinated } \\
\text { resources, arranging } \\
\text { referrals and home or } \\
\text { nursing visits (e.g., within } \\
\text { first } 48 \text { hours of } \\
\text { admission). }\end{array}$ & Usual care & $\begin{array}{l}\text { Nurse, nurse } \\
\text { case manager, } \\
\text { volunteers } \\
\text { supported by } \\
\text { social workers }\end{array}$ & $\begin{array}{l}\text { Nurse-led with or } \\
\text { without additional } \\
\text { support from } \\
\text { hospital staff, } \\
\text { family member or } \\
\text { caregiver, or } \\
\text { volunteers } \\
\text { supported by social } \\
\text { workers }\end{array}$ \\
\hline $\begin{array}{l}\text { Zhang } \\
\text { et al. } \\
2013^{40}\end{array}$ & $\begin{array}{l}\text { Multicomponent } \\
\text { interventions }\end{array}$ & $\begin{array}{l}1 \text { study used geriatrics } \\
\text { consultation service, and } \\
\text { implementation of } \\
\text { targeted } \\
\text { recommendations; } \\
1 \text { study used staff } \\
\text { education, team-based } \\
\text { approach, individual care } \\
\text { planning. }\end{array}$ & Usual care & Not reported & Not reported \\
\hline
\end{tabular}

CDSS = clinical decision support system; $\mathrm{CPOE}=$ computerized physician order entry; EMR = electronic medical record; $\mathrm{HF}=$ heart failure; $\mathrm{RCT}=$ randomized controlled trial 
Table C-4. Outcomes of interventions to reduce length of hospital stay

\begin{tabular}{|c|c|c|c|c|c|c|c|}
\hline $\begin{array}{l}\text { Author } \\
\text { Year }\end{array}$ & Length of Stay & $\begin{array}{l}\text { Patient } \\
\text { Functional } \\
\text { Return }\end{array}$ & Readmissions & Patient Harms & $\begin{array}{l}\text { Patient/Family } \\
\text { Experience }\end{array}$ & $\begin{array}{l}\text { Clinician/Staff } \\
\text { Satisfaction }\end{array}$ & Resource Use \\
\hline $\begin{array}{l}\text { Austin } \\
\text { et al. } \\
2020^{24}\end{array}$ & $\begin{array}{l}\text { CDSS (heparin-induced } \\
\text { thrombocytopenia alerts } \\
\text { ( } 1 \text { US RCT, } n=2086 \text { ) } \\
\text { Median LOS: } 49.7 \% \text { vs. } \\
50.3 \%, p=0.94, \text { no } \\
\text { difference } \\
\text { CDSS (order sets) } \\
\text { (1 US retrospective } \\
\text { study, n=5,879) } \\
\text { Median LOS (hours): } \\
68.3 \text { hours vs. } \\
68.9 \text { hours, } p=0.2615, \\
\text { no difference } \\
\text { CDSS (general acute } \\
\text { myocardial infarction } \\
\text { order set) } \\
\text { (1 US retrospective } \\
\text { study, n=5,879) } \\
\text { No significant difference } \\
\text { in reduction of LOS } \\
\text { Multiple CDSS/CPOE } \\
\text { interventions } \\
\text { (1 US pre-post study, } \\
n=190) \\
\text { No significant } \\
\text { improvement in LOS } \\
\text { (study reported LOS } \\
\text { days differently for } \\
\text { intervention and } \\
\text { comparator, i.e., mean } \\
\text { vs. median) }\end{array}$ & Not reported & $\begin{array}{l}\frac{\text { All-cause }}{\text { hospitalization after }} \\
\underline{30 \text { days }} \\
\text { (1 US retrospective } \\
\text { study, } n=5,879) \\
16.3 \% \text { vs. } 17.1 \%, \\
p=0.4398, \text { no } \\
\text { difference }\end{array}$ & 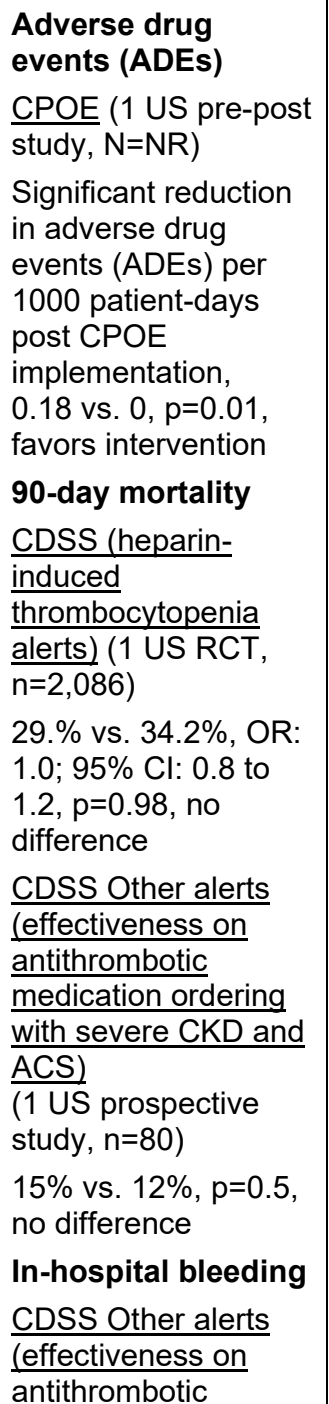 & Not reported & $\begin{array}{l}\frac{\text { User satisfaction }}{\text { scale of } 1 \text { to } 5} \\
\frac{\text { (how user }}{\text { friendly } \&} \\
\frac{\text { accessible is }}{\text { new warfarin }} \\
\frac{\text { order) }(1 \text { study, }}{\mathrm{n}=28)} \\
1=4 \% ; 2=7 \% ; \\
3=29 \% ; 4=54 \% \text {; } \\
5=7 \% \\
\text { User } \\
\text { acceptance/ } \\
\text { satisfaction } \\
\text { survey (1 study, } \\
87 \text { of } 207 \\
\text { responded) } \\
58 \% \text { viewed safe } \\
\text { transitions } \\
\text { anticoagulation } \\
\text { report (STAR), of } \\
\text { these, } 67 \% \\
\text { found it helpful, } \\
58 \% \text { improved } \\
\text { workflow, } 77 \% \\
\text { improved patient } \\
\text { safety } \\
\text { Pharmacist } \\
\text { survey (1 study, } \\
56 \text { of } 96 \\
\text { responded) } \\
80 \% \text { reported it } \\
\text { improved } \\
\text { documentation of } \\
\text { Heparin-induced } \\
\text { thrombocyte- } \\
\text { penia }\end{array}$ & Not reported \\
\hline
\end{tabular}




\begin{tabular}{|c|c|c|c|c|c|c|c|}
\hline $\begin{array}{l}\text { Author } \\
\text { Year }\end{array}$ & Length of Stay & $\begin{array}{l}\text { Patient } \\
\text { Functional } \\
\text { Return }\end{array}$ & Readmissions & Patient Harms & $\begin{array}{l}\text { Patient/Family } \\
\text { Experience }\end{array}$ & $\begin{array}{l}\text { Clinician/Staff } \\
\text { Satisfaction }\end{array}$ & Resource Use \\
\hline & & & & $\begin{array}{l}\text { medication ordering } \\
\text { with severe CKD and } \\
\text { ACS) } \\
(1 \text { US prospective } \\
\text { study, } n=80) \\
21 \% \text { vs. } 9 \%, p=0.12, \\
\text { no difference } \\
\text { Reduction in } \\
\text { inpatient mortality } \\
\text { CDSS (general acute } \\
\text { myocardial infarction } \\
\text { order set) } \\
(1 \text { US retrospective } \\
\text { study, } n=5,879) \\
6.5 \% \text { vs. } 3.5 \%, \\
\text { p<0.0001, favors } \\
\text { intervention } \\
\text { Multiple CDSS/CPOE } \\
\text { interventions } \\
11 \text { US pre-post study } \\
\text { (n=190) found no } \\
\text { significant } \\
\text { improvement in } \\
\text { mortality (study } \\
\text { reported data } \\
\text { differently for } \\
\text { intervention and } \\
\text { comparator groups, } \\
\text { i.e. mean vs. median) } \\
\text { EMR (patients with } \\
\text { NSTEMI) } \\
\text { Mortality } \\
(1 \text { US retrospective } \\
\text { study, } n=N R \text { ) } \\
\text { OR: } 0.82 ; 95 \% \text { Cl: } \\
0.69 \text { to } 0.97, \text { favors } \\
\text { intervention } \\
\text { Major bleeding } \\
\text { (1 US retrospective }\end{array}$ & & $\begin{array}{l}\frac{\text { Overall }}{\text { satisfaction }} \\
\text { (1 study, 7-point } \\
\text { Likert scale, } \\
\text { n=NR) } \\
\text { Development } \\
\text { phase: Median: } \\
2 \text { (Agree), IQR: } \\
2 \text { to } 4 \\
\text { Validation phase: } \\
\text { Median: } \\
3 \text { (Somewhat } \\
\text { agree), IQR: } 2 \text { to } \\
4 \text { (p=0.29), } \\
\text { inconclusive }\end{array}$ & \\
\hline
\end{tabular}




\begin{tabular}{|c|c|c|c|c|c|c|c|}
\hline $\begin{array}{l}\text { Author } \\
\text { Year }\end{array}$ & Length of Stay & $\begin{array}{l}\text { Patient } \\
\text { Functional } \\
\text { Return }\end{array}$ & Readmissions & Patient Harms & $\begin{array}{l}\text { Patient/Family } \\
\text { Experience }\end{array}$ & $\begin{array}{l}\text { Clinician/Staff } \\
\text { Satisfaction }\end{array}$ & Resource Use \\
\hline & & & & $\begin{array}{l}\text { study): OR: } 0.78 \text {; } \\
95 \% \text { Cl: } 0.67 \text { to } 0.91 \text {, } \\
\text { favors intervention if } \\
\text { admitted to a fully } \\
\text { implemented EMR } \\
\text { site } \\
\text { A slightly lower risk of } \\
\text { bleeding in partially } \\
\text { implemented sites } \\
\text { (OR: } 0.81 ; 95 \% \mathrm{Cl} \text { : } \\
0.70 \text { to } 0.94 \text { ), favors } \\
\text { intervention } \\
\text { Authors report no } \\
\text { significant difference } \\
\text { in adjusted risk of } \\
\text { mortality or major } \\
\text { bleeding for patients } \\
\text { admitted with STEMI } \\
\text { in } 1 \text { US retrospective } \\
\text { study }\end{array}$ & & & \\
\hline
\end{tabular}




\begin{tabular}{|c|c|c|c|c|c|c|c|}
\hline $\begin{array}{l}\text { Author } \\
\text { Year }\end{array}$ & Length of Stay & \begin{tabular}{|l|} 
Patient \\
Functional \\
Return \\
\end{tabular} & Readmissions & Patient Harms & $\begin{array}{l}\text { Patient/Family } \\
\text { Experience }\end{array}$ & $\begin{array}{l}\text { Clinician/Staff } \\
\text { Satisfaction }\end{array}$ & Resource Use \\
\hline $\begin{array}{l}\text { Agarwal } \\
\text { et al. } \\
2018^{34} \\
\text { *Note: } \\
\text { Laramee } \\
2003 \text { and } \\
\text { Rich } 1995 \\
\text { are also } \\
\text { reported in } \\
\text { Goncalves- } \\
\text { Bradley } \\
\text { et al. } \\
2016^{38} \text { and } \\
\text { Bryant- } \\
\text { Lukosius } \\
\text { et al. } \\
2015^{35}\end{array}$ & $\begin{array}{l}1 \mathrm{RCT}(\mathrm{n}=2906) \text {, } \\
\text { compared to usual care, } \\
\text { intervention was } \\
\text { associated with a } \\
-1.1 \text { days; } 95 \% \mathrm{Cl} \text { : } \\
-2.9 \text { to } 0.7 \text { change in } \\
\text { LOS, favors intervention }\end{array}$ & $\begin{array}{l}1 \mathrm{RCT} \text { found } \\
\text { that compared to } \\
\text { usual care, the } \\
\text { intervention was } \\
\text { not associated } \\
\text { with a } \\
\text { statistically } \\
\text { significant } \\
\text { change in } \mathrm{NYHA} \\
\text { class: } 0 ; 95 \% \mathrm{Cl} \text { : } \\
-0.4 \text { to } 0.3, \\
p=0.88, \text { no } \\
\text { difference }\end{array}$ & $\begin{array}{l}\frac{\text { Hospital }}{\text { readmission }} \\
\frac{\text { (up to } 90 \text { days after }}{\text { discharge) (3 RCTs }} \\
\text { [2 of } 3 \text { US], n=706 } \\
2 \text { studies } \\
\text { (419 combined } \\
\text { patients) reported } \\
\text { intervention was } \\
\text { associated with } \\
\text { decreased hospital } \\
\text { readmissions up to } \\
90 \text { days after } \\
\text { discharge } \\
37 \% \text { (intervention) } \\
\text { vs. } \\
67 \% \text { (comparator), } \\
p=-0.02, \text { favors } \\
\text { intervention } \\
7 \% \text { (intervention) vs. } \\
19 \% \text { (comparator), } \\
\text { absolute risk } \\
\text { reduction: } 12 \%, \\
p=0.04, \text { favors } \\
\text { intervention } \\
1 \text { study ( } n=287 \text { ), } \\
\text { found no difference } \\
37 \% \text { (intervention) } \\
\text { vs. } \\
37 \% \text { (comparator), } \\
p>0.99\end{array}$ & $\begin{array}{l}\frac{\text { In-hospital mortality }}{2 \mathrm{RCT}(\mathrm{n}=74,735)} \\
\text { reported in-hospital } \\
\text { mortality; neither } \\
\text { study found a } \\
\text { statistically significant } \\
\text { change in in-hospital } \\
\text { mortality } \\
\text { All-cause mortality } \\
\text { (30 days) } 1 \mathrm{RCT} \\
\text { (Sales } 2013) \text { found } \\
\text { no statistically } \\
\text { significant change in } \\
\text { mortality: Absolute } \\
\text { risk reduction } 0.4 \% \\
\text { ( } p=1.00)\end{array}$ & $\begin{array}{l}3 \text { RCTs reported } \\
\text { on QOL ( } n=3,411 \text { ) } \\
1 \text { RCT found } \\
\text { intervention } \\
\text { improved QOL, } \\
\text { while } 2 \text { RCTs } \\
\text { found no } \\
\text { statistically } \\
\text { significant change } \\
\text { Ladder of Life: } \\
-0.3 ; 95 \% \text { Cl: } \\
-1.6 \text { to } 1.0 \text { higher } \\
\text { scores reflect } \\
\text { better quality of } \\
\text { life } \\
\text { Minnesota Living } \\
\text { with Heart Failure } \\
\text { Questionnaire: } \\
p=0.049 \\
\frac{\text { Chronic Heart }}{\text { Failure }} \\
\frac{\text { Questionnaire }}{\text { (CFHQ): }} \\
\text { Mean: } 22.1 \\
\text { (intervention) vs. } \\
11.3 \\
\text { (comparator), } \\
p=0.001\end{array}$ & Not reported & Not reported \\
\hline
\end{tabular}




\begin{tabular}{|c|c|c|c|c|c|c|c|}
\hline $\begin{array}{l}\text { Author } \\
\text { Year }\end{array}$ & Length of Stay & \begin{tabular}{|l|} 
Patient \\
Functional \\
Return \\
\end{tabular} & Readmissions & Patient Harms & $\begin{array}{l}\text { Patient/Family } \\
\text { Experience }\end{array}$ & $\begin{array}{l}\text { Clinician/Staff } \\
\text { Satisfaction }\end{array}$ & Resource Use \\
\hline $\begin{array}{l}\text { Baratloo } \\
\text { et al. } \\
2018^{25}\end{array}$ & $\begin{array}{l}9 \text { trials }(6 \text { of } 9 \text { US), } \\
n=2,850 \\
\text { MD: }-0.55 \text { days; } \\
95 \% \mathrm{Cl}:-1.02 \text { to }-0.07, \\
p=0.02, I^{2}=38 \%, \text { favors } \\
\text { intervention }\end{array}$ & Not reported & Not reported & $\begin{array}{l}\text { In-hospital mortality } \\
\text { (18 trials }[10 \text { of } \\
18 \text { US], } n=4,907) \\
\text { OR: } 1.21 ; 95 \% \mathrm{Cl}: \\
0.98 \text { to } 1.49, p=0.08, \\
\mathrm{I}^{2}=0 \%, \text { no difference } \\
\frac{\text { Symptomatic }}{\underline{\text { Intracranial }}} \\
\frac{\text { Hemorrhage }}{(21 \text { trials }[10 \text { of }} \\
21 \text { US], n=4,022) } \\
\text { OR: } 1.10 ; 95 \% \mathrm{Cl}: \\
0.79 \text { to } 1.53, p=0.58, \\
\mathrm{I}^{2}=0 \%, \text { no difference }\end{array}$ & Not reported & Not reported & Not reported \\
\hline $\begin{array}{l}\text { Bryant- } \\
\text { Lukosius } \\
\text { et al. } \\
2015^{35} \\
\text { *Some } \\
\text { studies in } \\
\text { this SR } \\
\text { overlap } \\
\text { with } \\
\text { Goncalves- } \\
\text { Bradley } \\
\text { et al. } \\
2016^{38} \\
\text { Zhu et al. } \\
2015^{12} \text {, } \\
\text { and Mabire } \\
\text { et al. } \\
2017^{30} \\
\text { data } \\
\text { reported } \\
\text { here is not } \\
\text { reported by } \\
\text { the other } \\
\text { SRs. }\end{array}$ & $\begin{array}{l}\text { Elderly hospitalized } \\
\frac{\text { patients (3 US RCTs, }}{n=396)} \\
\text { MD: }-0.69 \text { days; } \\
95 \% \text { Cl: }-1.95 \text { to } 0.56, \\
p=0.28, \text { no difference } \\
\text { (SOE: Low) } \\
\text { Very-low birth weight } \\
\frac{\text { infants (1 US RCT, }}{n=79)} \\
\text { MD: }-11.2 \text { days; } \\
95 \% \text { Cl: }-17.8 \text { to }-4.6, \\
p<0.05, \text { favors } \\
\text { intervention } \\
\text { (SOE: Low) } \\
\frac{\text { Infants }(1 \text { US RCT, }}{n=93)} \\
\text { MD: }-2.7 \text { days; } \\
95 \% \text { Cl: }-6.67 \text { to } 1.27, \\
p=0.45, \text { no difference } \\
\text { (SOE: Low) } \\
\frac{\text { Maternal post-partum }}{\text { (high-risk pregnant }}\end{array}$ & Not reported & $\begin{array}{l}\frac{\text { Re-hospitalization }}{\text { more than once for }} \\
\frac{\text { any reason at }}{90 \text { days and }} \\
\underline{52 \text { weeks patients }} \\
\frac{\text { with heart failure }}{\text { (2 US RCTs, } \mathrm{n}=495)} \\
\text { RR: } 0.81 ; 95 \% \mathrm{Cl}: \\
0.57 \text { to } 1.13, \\
\mathrm{p}=0.21, \text { no } \\
\text { difference } \\
\text { (SOE: Low) } \\
\text { Maternal re- } \\
\text { hospitalizations } \\
\text { high-risk pregnant } \\
\text { women (1 US RCT, } \\
\text { n=122) } \\
\text { RR: } 0.14 ; 95 \% \text { CI: } \\
0.01 \text { to } 2.71, \\
\text { p=0.19, no } \\
\text { difference } \\
\text { (SOE: Low) } \\
\text { Maternal re- } \\
\text { hospitalizations }\end{array}$ & $\begin{array}{l}\text { Mortality at } 6 \text { months } \\
\text { and } 52 \text { weeks of } \\
\text { follow-up patients } \\
\text { with heart failure } \\
\text { (2 RCTs [1 of } 2 \text { US], } \\
\text { n=345) } \\
\text { RR: } 0.76 ; 95 \% \mathrm{Cl}: \\
0.41 \text { to } 1.42, p=0.40, \\
\text { no difference } \\
\text { (SOE: Low) } \\
\text { Mortality during index } \\
\text { hospitalization and } 6 \\
\text { and } 8 \text { weeks post- } \\
\text { discharge elderly } \\
\text { hospitalized patients } \\
\text { (2 US RCTs, } n=443 \text { ) } \\
\text { RR: } 1.05 ; 95 \% \text { Cl: } \\
0.48 \text { to } 2.28, p=0.90, \\
\text { no difference } \\
\text { (SOE: Low) }\end{array}$ & 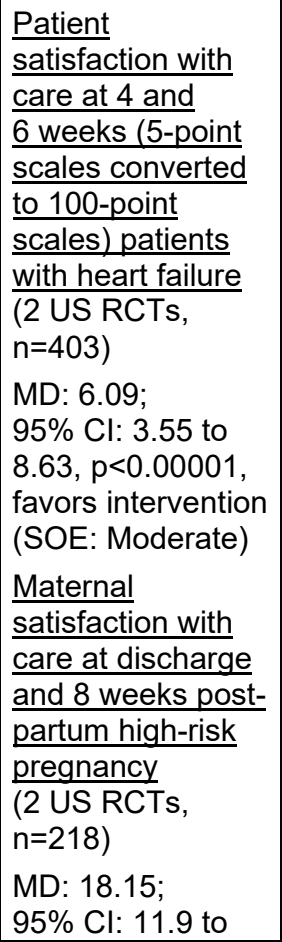 & Not reported & $\begin{array}{l}\text { Authors } \\
\text { reported that } \\
\text { none of the } \\
\text { studies } \\
\text { assessed costs } \\
\text { and outcomes } \\
\text { jointly. There } \\
\text { was no instance } \\
\text { when resource } \\
\text { use or costs } \\
\text { were higher } \\
\text { with CNS care } \\
\text { but often } \\
\text { instances when } \\
\text { the CNS } \\
\text { reduced } \\
\text { resource use } \\
\text { and costs, } \\
\text { despite the fact } \\
\text { that the CNS } \\
\text { was an 'add-on' } \\
\text { cost. }\end{array}$ \\
\hline
\end{tabular}




\begin{tabular}{|c|c|c|c|c|c|c|c|}
\hline $\begin{array}{l}\text { Author } \\
\text { Year }\end{array}$ & Length of Stay & \begin{tabular}{|l|} 
Patient \\
Functional \\
Return \\
\end{tabular} & Readmissions & Patient Harms & $\begin{array}{l}\text { Patient/Family } \\
\text { Experience }\end{array}$ & $\begin{array}{l}\text { Clinician/Staff } \\
\text { Satisfaction }\end{array}$ & Resource Use \\
\hline & $\begin{array}{l}\frac{\text { women) ( } 2 \text { US RCTs, }}{\mathrm{n}=215)} \\
\text { MD: }-1.19 \text { days; } \\
95 \% \mathrm{Cl}:-1.55 \text { to } \\
-0.83, \mathrm{p}<0.00001, \\
\text { favors intervention } \\
\text { (reduces maternal post- } \\
\text { partum LOS) } \\
\text { (SOE: Moderate) }\end{array}$ & & $\begin{array}{l}\text { before delivery high- } \\
\text { risk pregnant } \\
\frac{\text { women }(1 \mathrm{US} R C T}{\mathrm{n}=55)} \\
\mathrm{RR}: 0.7 ; 95 \% \mathrm{Cl}: \\
0.33 \text { to } 1.47, \\
\mathrm{p}=0.34, \text { no } \\
\text { difference } \\
\text { (SOE: Low) } \\
\text { Infant re- } \\
\text { hospitalizations at } 2 \\
\text { and 8 weeks post- } \\
\text { discharge } \\
\text { (2 US RCTs, n=202) } \\
\text { RR: } 0.56 ; 95 \% \mathrm{Cl}: \\
0.21 \text { to } 1.44, \\
\mathrm{p}=0.23, \text { no } \\
\text { difference } \\
\text { (SOE: Low) }\end{array}$ & & $\begin{array}{l}24.4, p<0.00001, \\
\text { favors intervention } \\
\text { (SOE: Low) } \\
\text { Authors noted } \\
\text { considerable } \\
\text { heterogeneity for } \\
\text { this outcome. }\end{array}$ & & \\
\hline $\begin{array}{l}\text { Bakker } \\
\text { et al. } \\
2011^{26}\end{array}$ & $\begin{array}{l}6 \text { studies, } \\
\text { n=1660 patients } \\
3 \text { studies found no } \\
\text { difference; } 3 \text { studies did } \\
\text { not provide statistical } \\
\text { analysis of results }\end{array}$ & $\begin{array}{l}\underline{\text { Multiple function }} \\
\underline{\text { measures }} \\
\text { (4 studies, } \\
n=833) \\
\text { Most measures } \\
\text { found no } \\
\text { difference; } \\
1 \text { study favors } \\
\text { intervention for } \\
\text { Self Rating } \\
\text { Depression } \\
\text { Scale; } 1 \text { study } \\
\text { favors inter- } \\
\text { vention for Mini- } \\
\text { Mental State } \\
\text { Examination }\end{array}$ & $\begin{array}{l}2 \text { studies, } \\
\mathrm{n}=252 \text { patients } \\
1 \text { study favors } \\
\text { intervention; } \\
1 \text { study did not } \\
\text { provide statistical } \\
\text { analysis of results }\end{array}$ & $\begin{array}{l}\text { Mortality } \\
1 \text { study ( } \mathrm{N}=197) \\
\text { found no difference } \\
\text { Complications } \\
\text { (type not specified): } \\
1 \text { study ( } \mathrm{N}=695) \\
\text { found no difference }\end{array}$ & Not reported & Not reported & $\begin{array}{l}1 \text { study found } \\
\text { reduced costs }\end{array}$ \\
\hline
\end{tabular}




\begin{tabular}{|c|c|c|c|c|c|c|c|}
\hline $\begin{array}{l}\text { Author } \\
\text { Year }\end{array}$ & Length of Stay & $\begin{array}{l}\text { Patient } \\
\text { Functional } \\
\text { Return }\end{array}$ & Readmissions & Patient Harms & $\begin{array}{l}\text { Patient/Family } \\
\text { Experience }\end{array}$ & $\begin{array}{l}\text { Clinician/Staff } \\
\text { Satisfaction }\end{array}$ & Resource Use \\
\hline $\begin{array}{l}\text { Eagles } \\
\text { et al. } \\
2020^{41}\end{array}$ & $\begin{array}{l}2 \text { US retrospective } \\
\text { cohort studies, } n=5,414 \\
\text { MD: }-1.11 \text { days; } \\
95 \% \text { Cl: }-1.43 \text { to } \\
-0.79, I^{2}=0 \% \text {, favors } \\
\text { intervention (post } \\
\text { implementation) }\end{array}$ & Not reported & Not reported & 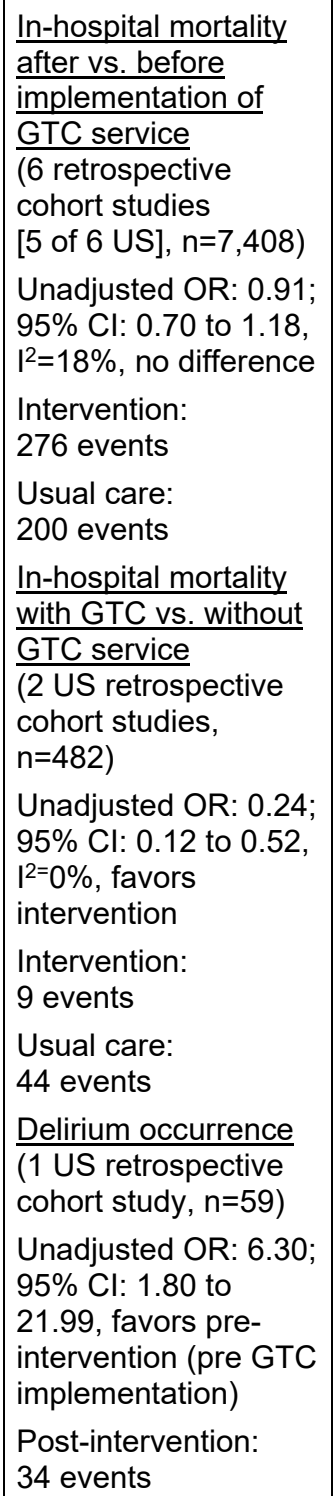 & Not reported & Not reported & Not reported \\
\hline
\end{tabular}




\begin{tabular}{|c|c|c|c|c|c|c|c|}
\hline $\begin{array}{l}\text { Author } \\
\text { Year }\end{array}$ & Length of Stay & \begin{tabular}{|l|} 
Patient \\
Functional \\
Return
\end{tabular} & Readmissions & Patient Harms & $\begin{array}{l}\text { Patient/Family } \\
\text { Experience }\end{array}$ & $\begin{array}{l}\text { Clinician/Staff } \\
\text { Satisfaction }\end{array}$ & Resource Use \\
\hline & & & & $\begin{array}{l}\text { Pre-intervention: } \\
6 \text { events }\end{array}$ & & & \\
\hline $\begin{array}{l}\text { Ellis et al. } \\
2017^{36}\end{array}$ & $\begin{array}{l}17 \text { trials reported LOS } \\
\text { ( } n=5303 \text { ) } \\
\text { Geriatric assessment } \\
\text { group: Mean LOS } \\
\text { ranged from } 1.63 \text { to } \\
40.7 \text { days } \\
\text { Control group: Mean } \\
\text { LOS ranged from } 1.8 \text { to } \\
42.8 \text { days } \\
\text { Authors did not retain } \\
\text { meta-analysis due to } \\
\text { high levels of } \\
\text { heterogeneity. Trials } \\
\text { showed inconsistency. }\end{array}$ & Not reported & $\begin{array}{l}\text { Note: }<50 \% \text { of } \\
\text { studies reporting } \\
\text { readmissions were } \\
\text { US based, therefore } \\
\text { data is not reported }\end{array}$ & $\begin{array}{l}\text { Mortality at discharge } \\
\text { (11 RCTs [7 of } \\
11 \text { US], n=4346) } \\
\text { RR: } 1.04 ; 95 \% \mathrm{Cl}: \\
0.82 \text { to } 1.32, I^{2}=16 \%, \\
\text { no difference } \\
\text { (SOE: high-certainty } \\
\text { evidence) } \\
\text { Intervention: } \\
130 \text { events } \\
\text { Usual care: } \\
138 \text { events } \\
\text { Mortality at } 3 \text { to } \\
12 \text { months' follow-up } \\
\text { (21 RCTs [12 of } \\
21 \text { US, n=10,023) } \\
\text { RR: } 1.00 ; 95 \% \text { Cl: } \\
0.93 \text { to } 1.07, I^{2}=0 \%, \\
\text { no difference } \\
\text { (SOE: high-certainty } \\
\text { evidence) } \\
\text { Intervention: } \\
1195 \text { events } \\
\text { Usual care: } \\
1089 \text { events }\end{array}$ & Not reported & Not reported & $\begin{array}{l}\text { Note: Summary } \\
\text { of costs } \\
\text { reported in } \\
\text { non-US } \\
\text { currency. } \\
\text { Therefore, cost } \\
\text { data not } \\
\text { reported here. }\end{array}$ \\
\hline
\end{tabular}




\begin{tabular}{|c|c|c|c|c|c|c|c|}
\hline $\begin{array}{l}\text { Author } \\
\text { Year }\end{array}$ & Length of Stay & \begin{tabular}{|l|} 
Patient \\
Functional \\
Return \\
\end{tabular} & Readmissions & Patient Harms & $\begin{array}{l}\text { Patient/Family } \\
\text { Experience }\end{array}$ & $\begin{array}{l}\text { Clinician/Staff } \\
\text { Satisfaction }\end{array}$ & Resource Use \\
\hline $\begin{array}{l}\text { Frazer } \\
\text { et al. } \\
2019^{37}\end{array}$ & $\begin{array}{l}\frac{\text { Anticoagulation }}{\text { consultation service }} \\
\frac{\text { (physician-led) }}{(1 \text { US RCT, } n=101)} \\
\text { Mean (days): } 12.9 \text { vs. } \\
13.4, p \geq 0.2, n o \\
\text { difference } \\
\text { Decision supported } \\
\text { warfarin dosing } \\
\text { (1 RCT, } n=75) \\
\text { Mean (days): } 13 \text { vs. } 20, \\
p=0.01, \text { favors } \\
\text { intervention }\end{array}$ & Not reported & $\begin{array}{l}\frac{\% \text { Unplanned }}{\text { readmission }} \\
\text { (1 US RCT, } n=101) \\
19 \% \text { vs. } 29 \%\end{array}$ & 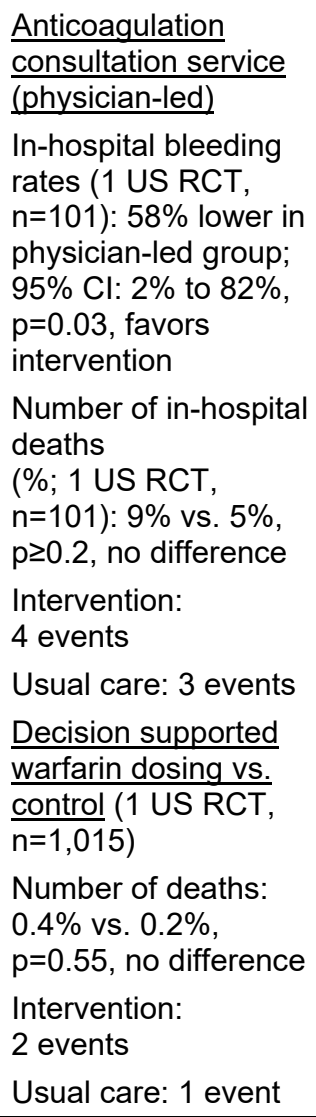 & Not reported & Not reported & $\begin{array}{l}\frac{\text { Costs of }}{\text { protocol (per }} \\
\text { patient per day) } \\
1 \text { US study } \\
(n=268): \$ 31.46 \\
\text { vs. } \$ 27.10\end{array}$ \\
\hline $\begin{array}{l}\text { Gonçalves- } \\
\text { Bradley } \\
\text { et al. } \\
2016^{38}\end{array}$ & $\begin{array}{l}\frac{\text { Older patients with }}{\text { medical condition }} \\
\frac{(12 \text { trials }[6 \text { of } 12 \text { US], }}{n=2,193)} \\
\text { MD: }-0.73 \text { days; } \\
95 \% \text { Cl: }-1.33 \text { to }-0.12 \text {, } \\
I^{2}=9.44 \%, \text { favors } \\
\text { intervention }\end{array}$ & Not reported & $\begin{array}{l}\frac{\text { Unscheduled }}{\text { readmission within }} \\
\frac{3 \text { months for }}{\text { patients with }} \\
\frac{\text { medical condition }}{(15 \text { trials }[9 \text { of }} \\
15 \text { US], } n=4,743) \\
\text { RR: } 0.87 ; 95 \% \mathrm{Cl}: \\
0.79 \text { to } 0.97, \\
\mathrm{I}^{2}=28.26 \%, \text { favors }\end{array}$ & $\begin{array}{l}\text { Note: }<50 \% \text { of } \\
\text { studies reporting } \\
\text { harms were US } \\
\text { based, therefore data } \\
\text { is not reported }\end{array}$ & $\begin{array}{l}\text { May lead to } \\
\text { increased } \\
\text { satisfaction for } \\
\text { patients and } \\
\text { healthcare } \\
\text { professionals. } \\
\text { Satisfaction was } \\
\text { measured in } \\
\text { different ways and } \\
\text { findings were }\end{array}$ & $\begin{array}{l}\text { May lead to } \\
\text { increased } \\
\text { satisfaction for } \\
\text { patients and } \\
\text { healthcare } \\
\text { professionals } \\
\text { (low certainty } \\
\text { evidence, } \\
\text { six trials but not } \\
\text { specified, n=NR) }\end{array}$ & $\begin{array}{l}\text { A lower } \\
\text { readmission } \\
\text { rate for those } \\
\text { receiving } \\
\text { discharge } \\
\text { planning may } \\
\text { be associated } \\
\text { with lower } \\
\text { health service } \\
\text { costs in the }\end{array}$ \\
\hline
\end{tabular}




\begin{tabular}{|c|c|c|c|c|c|c|c|}
\hline $\begin{array}{l}\text { Author } \\
\text { Year }\end{array}$ & Length of Stay & $\begin{array}{l}\text { Patient } \\
\text { Functional } \\
\text { Return }\end{array}$ & Readmissions & Patient Harms & $\begin{array}{l}\text { Patient/Family } \\
\text { Experience }\end{array}$ & $\begin{array}{l}\text { Clinician/Staff } \\
\text { Satisfaction }\end{array}$ & Resource Use \\
\hline & $\begin{array}{l}\text { (SOE: moderate } \\
\text { certainty of evidence) } \\
\text { Older surgical patients } \\
\text { ( } 2 \text { trials [1 of } 2 \text { US], } \\
n=184) \\
\text { MD: }-0.06 ; 95 \% \mathrm{Cl} \text { : } \\
-1.23 \text { to } 1.11, \mathrm{I}^{2}=0 \% \text {, no } \\
\text { difference }\end{array}$ & & $\begin{array}{l}\text { intervention } \\
\text { (SOE: moderate } \\
\text { certainty of } \\
\text { evidence) } \\
\text { Intervention: } \\
525 \text { events } \\
\text { Usual care: } \\
605 \text { events } \\
\text { *Lin } 2009 \text { and } \\
\text { Jack } 2009 \text { (US) also } \\
\text { included in Zhu SR } \\
\text { meta-analysis for } \\
\text { readmissions }\end{array}$ & & $\begin{array}{l}\text { inconsistent } \\
\text { across studies } \\
\text { (low certainty } \\
\text { evidence, } \\
\text { six trials but not } \\
\text { specified, n=NR). }\end{array}$ & & $\begin{array}{l}\text { short term. } \\
\text { Differences in } \\
\text { use of primary } \\
\text { care varied. } \\
\text { (SOE: very low } \\
\text { certainty } \\
\text { evidence, } \\
\text { five trials but } \\
\text { not specified, } \\
\text { n=NR). } \\
\text { Findings were } \\
\text { inconsistent. } \\
\text { Healthcare } \\
\text { resources that } \\
\text { were assessed } \\
\text { varied among } \\
\text { studies, } \\
\text { e.g., primary } \\
\text { care visits, } \\
\text { readmission, } \\
\text { length of stay, } \\
\text { laboratory } \\
\text { services, } \\
\text { medication, } \\
\text { diagnostic } \\
\text { imaging. The } \\
\text { charges used to } \\
\text { cost the } \\
\text { healthcare } \\
\text { resources also } \\
\text { varied. }\end{array}$ \\
\hline $\begin{array}{l}\text { Gillaizeau } \\
\text { et al. } \\
2013^{27}\end{array}$ & $\begin{array}{l}9 \text { studies, } \\
n=18507 \text { patients } \\
\text { SMD: }-0.15 \text { days; } \\
95 \% \mathrm{Cl}:-0.33 \text { to } 0.02 \text {, } \\
\mathrm{I}^{2}=57 \%, \text { no difference, } \\
\text { but leans towards } \\
\text { favoring intervention }\end{array}$ & Not reported & Not reported & Not reported & Not reported & Not reported & $\begin{array}{l}1 \text { study found } \\
\text { reduced costs } \\
\text { of } \$ 7,103 \text { per } \\
\text { patient vs. } \\
\$ 13,759 ; \\
1 \text { study found } \\
\text { no difference }\end{array}$ \\
\hline
\end{tabular}




\begin{tabular}{|c|c|c|c|c|c|c|c|}
\hline $\begin{array}{l}\text { Author } \\
\text { Year }\end{array}$ & Length of Stay & \begin{tabular}{|l} 
Patient \\
Functional \\
Return \\
\end{tabular} & Readmissions & Patient Harms & $\begin{array}{l}\text { Patient/Family } \\
\text { Experience }\end{array}$ & $\begin{array}{l}\text { Clinician/Staff } \\
\text { Satisfaction }\end{array}$ & Resource Use \\
\hline $\begin{array}{l}\text { Huntley } \\
\text { et al. } \\
2016^{28}\end{array}$ & $\begin{array}{l}9 \text { studies, } \\
\mathrm{n}=1765 \text { patients } \\
\text { Mean reduction: } \\
1.28 \text { days; } 95 \% \mathrm{Cl}: 0.52 \\
\text { to } 2.04, \mathrm{I}^{2}=63 \% \text {, favors } \\
\text { intervention } \\
\text { Subgroup analysis, } \\
\text { excluding studies at } \\
\text { high risk of bias: Mean } \\
\text { reduction: } 1.76 \text { days; } \\
95 \% \mathrm{Cl}: 1.23 \text { to } 2.29, \\
\mathrm{I}^{2}=14 \%, \text { favors } \\
\text { intervention }\end{array}$ & Not reported & $\begin{array}{l}13 \text { studies, } \\
\text { n=3346 patients } \\
\text { RR: } 0.74 ; 95 \% \mathrm{Cl} \text { : } \\
0.60 \text { to } 0.92, \\
I^{2}=69 \%, \text { favors } \\
\text { intervention } \\
\text { Subgroup analysis, } \\
\text { excluding studies at } \\
\text { high risk of bias } \\
\text { RR: } 0.77 ; 95 \% \mathrm{Cl}: \\
0.61 \text { to } 0.96, \\
I^{2}=68 \%, \text { favors } \\
\text { intervention }\end{array}$ & Not reported & Not reported & Not reported & $\begin{array}{l}1 \text { study found } \\
\text { reduced costs } \\
\text { but details not } \\
\text { reported; } \\
1 \text { study found } \\
\text { hospital saved } \\
\$ 227 \text { per } \\
\text { Medicare } \\
\text { patient; } \\
1 \text { study found } \\
\text { overall savings } \\
\text { after } 18 \text { months } \\
\text { of } \$ 1.6 \text { million; } \\
6 \text { studies found } \\
\text { no difference in } \\
\text { costs }\end{array}$ \\
\hline $\begin{array}{l}\text { Kul et al. } \\
2012^{29}\end{array}$ & $\begin{array}{l}5 \text { studies, } \\
\mathrm{n}=2095 \text { patients } \\
\text { Mean reduction: } \\
1.89 \text { days; } 95 \% \mathrm{Cl}: 1.33 \\
\text { to } 2.44, \mathrm{I}^{2}=42 \% \text {, favors } \\
\text { intervention }\end{array}$ & Not reported & $\begin{array}{l}5 \text { studies, } \\
\mathrm{N}=3006 \text { patients } \\
\mathrm{RR}: 0.81 ; 95 \% \mathrm{Cl} \text { : } \\
0.66 \text { to } 0.99, \\
\mathrm{I}^{2}=16 \% \text {, favors } \\
\text { intervention }\end{array}$ & $\begin{array}{l}\text { Hospital Mortality } \\
\text { (5 studies, } N=2343 \\
\text { patients) } \\
\text { RR: } 0.45 ; 0.21 \text { to } \\
0.94, I^{2}=73 \% \text {, favors } \\
\text { intervention }\end{array}$ & Not reported & Not reported & $\begin{array}{l}3 \text { studies found } \\
\text { no difference in } \\
\text { costs }\end{array}$ \\
\hline
\end{tabular}




\begin{tabular}{|c|c|c|c|c|c|c|c|}
\hline $\begin{array}{l}\text { Author } \\
\text { Year }\end{array}$ & Length of Stay & $\begin{array}{l}\text { Patient } \\
\text { Functional } \\
\text { Return }\end{array}$ & Readmissions & Patient Harms & \begin{tabular}{|l} 
Patient/Family \\
Experience
\end{tabular} & $\begin{array}{l}\text { Clinician/Staff } \\
\text { Satisfaction }\end{array}$ & Resource Use \\
\hline $\begin{array}{l}\text { Mabire } \\
\text { et al } \\
2017^{15,30}\end{array}$ & $\begin{array}{l}\frac{\text { Initial (index) }}{\text { hospitalization }} \\
\text { (6 studies, [3 of } 6 \text { US] } \\
\text { n=2,370) } \\
\text { WMD: } 0.29 \text { days; } \\
95 \% \text { Cl: } 0.24 \text { to } 0.35, \\
\left.\right|^{2}=0 \% \text {, intervention } \\
\text { increases LOS } \\
\text { (SOE: Low) }\end{array}$ & Not reported & $\begin{array}{l}\text { Readmission rates } \\
\text { (3 US RCTs/pre- } \\
\text { post studies, } n=465) \\
\text { OR: } 0.57 ; 95 \% \mathrm{Cl}: \\
0.40 \text { to } 0.81, \\
\mathrm{p}=0.01, \mathrm{I}^{2}=0 \%, \\
\text { favors intervention } \\
\text { Intervention: } \\
84 \text { events } \\
\text { Usual care: } \\
131 \text { events } \\
\text { Readmission rates } \\
\text { (transitional care } \\
\text { intervention) } \\
(4 \text { RCTs [3 of } \\
4 \text { US], n=1,030) } \\
\text { OR: } 0.70 ; 95 \% \mathrm{Cl}: \\
0.38 \text { to } 1.27, \\
\mathrm{I}^{2}=69.2 \%, \text { no } \\
\text { difference } \\
\text { Intervention: } \\
117 \text { events } \\
\text { Usual care: } \\
157 \text { events }\end{array}$ & Not reported & $\begin{array}{l}\text { Note: }<50 \% \text { of } \\
\text { studies reporting } \\
\text { QoL were US } \\
\text { based, therefore } \\
\text { data is not } \\
\text { reported }\end{array}$ & Not reported & Not reported \\
\hline
\end{tabular}




\begin{tabular}{|c|c|c|c|c|c|c|c|}
\hline $\begin{array}{l}\text { Author } \\
\text { Year }\end{array}$ & Length of Stay & $\begin{array}{l}\text { Patient } \\
\text { Functional } \\
\text { Return }\end{array}$ & Readmissions & Patient Harms & $\begin{array}{l}\text { Patient/Family } \\
\text { Experience }\end{array}$ & $\begin{array}{l}\text { Clinician/Staff } \\
\text { Satisfaction }\end{array}$ & Resource Use \\
\hline $\begin{array}{l}\text { Patel et al. } \\
2020^{31}\end{array}$ & $\begin{array}{l}10 \text { studies showed a } \\
\text { notable decrease in } \\
\text { hospital length of stay } \\
\text { when patients were } \\
\text { admitted to either an } \\
\text { ortho-geriatrics unit or a } \\
\text { geriatrics unit compared } \\
\text { with being admitted to } \\
\text { an orthopedic unit. } \\
2 \text { studies found no } \\
\text { notable difference or } \\
\text { improvement with no } \\
\text { statistical significance. } \\
1 \text { study found a notable } \\
\text { increase. }\end{array}$ & Not reported & $\begin{array}{l}3 \text { studies showed no } \\
\text { notable difference in } \\
\text { readmission rates } \\
\text { when hip fracture } \\
\text { patients were } \\
\text { admitted to an } \\
\text { ortho-geriatrics unit } \\
\text { or geriatrics unit } \\
\text { versus being } \\
\text { admitted to an } \\
\text { orthopedic unit. } \\
1 \text { study showed a } \\
\text { notable increase in } \\
\text { readmission rates } \\
\text { when patients were } \\
\text { admitted to an } \\
\text { orthopedic unit; } \\
1 \text { study showed a } \\
\text { notable decrease in } \\
\text { readmission rates } \\
\text { when patients were } \\
\text { admitted to a } \\
\text { geriatrics unit. }\end{array}$ & $\begin{array}{l}\frac{\text { Post-operative }}{\text { mortality (in-hospital }} \\
\underline{\text { mortality and 1 year }} \\
\text { mortality rates) } \\
\text { Five studies showed } \\
\text { a notable decrease in } \\
\text { postoperative } \\
\text { mortality rates when } \\
\text { hip fracture patients } \\
\text { were admitted to an } \\
\text { orthogeriatrics unit or } \\
\text { a geriatrics unit. } \\
11 \text { studies showed no } \\
\text { notable difference in } \\
\text { mortality rates. }\end{array}$ & Not reported & Not reported & Not reported \\
\hline
\end{tabular}




\begin{tabular}{|c|c|c|c|c|c|c|c|}
\hline $\begin{array}{l}\text { Author } \\
\text { Year }\end{array}$ & Length of Stay & \begin{tabular}{|l|} 
Patient \\
Functional \\
Return
\end{tabular} & Readmissions & Patient Harms & $\begin{array}{l}\text { Patient/Family } \\
\text { Experience }\end{array}$ & $\begin{array}{l}\text { Clinician/Staff } \\
\text { Satisfaction }\end{array}$ & Resource Use \\
\hline $\begin{array}{l}\text { Pannick } \\
\text { et al. } \\
2015^{32}\end{array}$ & $\begin{array}{l}\frac{\text { Interventions altering }}{\text { interdisciplinary team }} \\
\text { composition (ITC-C) } \\
\text { (6 studies [4 of } 6 \text { US], } \\
\text { n=NR, mixed patient } \\
\text { population - geriatric, } \\
\text { liver transplant, } \\
\text { psychiatric, delirium, } \\
\text { infectious diseases) } \\
\text { WMD: } 0.087 \text { days; } \\
95 \% \text { Cl: }-0.083 \text { to } \\
0.257, \text { no difference } \\
\text { Interventions altering } \\
\text { interdisciplinary team } \\
\text { practice (ITC-P) } \\
\text { (7 studies [6 of } 7 \text { US], } \\
\text { n=NR, most studies did } \\
\text { not specify patient } \\
\text { population, } 1 \text { study } \\
\text { include geriatric patients } \\
\text { and } 1 \text { study's setting VA } \\
\text { hospital) } \\
\text { WMD: } 0.001 \text { days; } \\
95 \% \text { Cl: }-0.035 \text { to } \\
0.037, \text { no difference }\end{array}$ & Not reported & $\begin{array}{l}\text { Early readmissions } \\
\text { ITC-C } \\
\text { (3 US studies, } \\
\text { n=NR, mixed patient } \\
\text { population - } \\
\text { infectious diseases, } \\
\text { pneumonia, or not } \\
\text { specified) } \\
\text { RR: } 1.341 ; 95 \% \mathrm{Cl}: \\
1.120 \text { to } 1.607, \\
\text { ITC-C tended to } \\
\text { increase early } \\
\text { readmissions } \\
\text { (authors noted there } \\
\text { were important } \\
\text { confounding factors, } \\
\text { factors not } \\
\text { specified) } \\
\text { ITC-P (5 US studies, } \\
\text { n=NR, mixed patient } \\
\text { population - } \\
\text { geriatric, VA } \\
\text { hospital, or not } \\
\text { specified) } \\
\text { RR: } 0.995 \text {; } 95 \% \text { Cl: } \\
0.912 \text { to } 1.085, \text { no } \\
\text { difference (ITC-P } \\
\text { did not significantly } \\
\text { reduce early } \\
\text { readmissions) }\end{array}$ & $\begin{array}{l}\text { Early mortality } \\
\text { ITC-C (7 studies } \\
\text { [4 of } 7 \text { US], n=NR, } \\
\text { mixed patient } \\
\text { population }- \text { delirium, } \\
\text { infectious diseases) } \\
\text { RR: } 0.925 ; 95 \% \mathrm{Cl} \text { : } \\
0.816 \text { to } 1.049, \mathrm{no} \\
\text { difference } \\
\text { ITC-P (2 studies } \\
\text { [1 of } 2 \text { US], n=NR, } \\
\text { population not } \\
\text { specified) } \\
\text { RR: } 0.665 ; 95 \% \mathrm{Cl}: \\
0.449 \text { to } 0.986, \\
\text { ITC-P tended to } \\
\text { reduce early mortality }\end{array}$ & Not reported & Not reported & Not reported \\
\hline
\end{tabular}




\begin{tabular}{|c|c|c|c|c|c|c|c|}
\hline $\begin{array}{l}\text { Author } \\
\text { Year }\end{array}$ & Length of Stay & \begin{tabular}{|l|} 
Patient \\
Functional \\
Return \\
\end{tabular} & Readmissions & Patient Harms & $\begin{array}{l}\text { Patient/Family } \\
\text { Experience }\end{array}$ & $\begin{array}{l}\text { Clinician/Staff } \\
\text { Satisfaction }\end{array}$ & Resource Use \\
\hline $\begin{array}{l}\text { Van Craen } \\
\text { et al. } \\
2010^{39}\end{array}$ & $\begin{array}{l}7 \text { studies, } \\
\mathrm{n}=4759 \text { patients } \\
\text { Mean reduction } \\
\text { measured by Hedges } \mathrm{g} \\
0.07 \text { days; } 95 \% \mathrm{Cl} \text { : } \\
-0.11 \text { to } 0.26, \text { no } \\
\text { difference }\end{array}$ & $\begin{array}{l}\frac{\text { Functional }}{\text { decline at }} \\
\frac{\text { discharge }}{(2 \text { studies, }} \\
n=2182) \\
\text { RR: } 0.87 ; \\
95 \% \text { Cl: } 0.77 \text { to } \\
0.99, \text { favors } \\
\text { intervention } \\
\underline{\text { Functional }} \\
\underline{\text { decline at }} \\
12 \text { months } \\
(2 \text { studies, } \\
n=1654) \\
\text { RR: } 0.84 ; \\
95 \% \text { Cl: } 0.69 \text { to } \\
1.03, \text { no } \\
\text { difference }\end{array}$ & $\begin{array}{l}2 \text { studies, } \\
\mathrm{n}=668 \text { patients } \\
\mathrm{RR}: 0.85 ; 95 \% \mathrm{Cl} \text { : } \\
0.65 \text { to } 1.11, \text { no } \\
\text { difference }\end{array}$ & $\begin{array}{l}\frac{\text { Hospital Mortality at }}{12 \text { months }}(6 \text { studies, } \\
\mathrm{n}=4108) \\
\mathrm{RR}: 0.97 ; 95 \% \mathrm{Cl}: \\
0.88 \text { to } 1.08, \text { no } \\
\text { difference }\end{array}$ & Not reported & Not reported & Not reported \\
\hline $\begin{array}{l}\text { White et al. } \\
2011^{33}\end{array}$ & $\begin{array}{l}40 \text { studies favor } \\
\text { intervention with } \\
\text { reduction in LOS; } \\
13 \text { studies found no } \\
\text { difference; } 5 \text { studies } \\
\text { found longer LOS }\end{array}$ & Not reported & $\begin{array}{l}6 \text { studies favor } \\
\text { intervention with } \\
\text { reduction in } \\
\text { readmissions; } \\
34 \text { studies found no } \\
\text { difference; } \\
3 \text { studies found } \\
\text { readmissions } \\
\text { increased }\end{array}$ & $\begin{array}{l}\text { Mortality } \\
8 \text { studies favor } \\
\text { intervention with } \\
\text { reduction in mortality; } \\
29 \text { studies found no } \\
\text { difference } \\
\text { Complications } \\
\text { (type not specified) } \\
2 \text { studies favor } \\
\text { intervention with } \\
\text { reduction in } \\
\text { complications; } \\
5 \text { studies found no } \\
\text { difference; } \\
1 \text { study found } \\
\text { complications } \\
\text { increased }\end{array}$ & $\begin{array}{l}\text { Patient } \\
\text { satisfaction } \\
1 \text { study favors } \\
\text { intervention with } \\
\text { improved } \\
\text { satisfaction; } \\
7 \text { studies found no } \\
\text { difference }\end{array}$ & Not reported & $\begin{array}{l}30 \text { studies } \\
\text { found reduced } \\
\text { costs or } \\
\text { charges; } \\
10 \text { studies } \\
\text { found no } \\
\text { difference; } \\
3 \text { studies found } \\
\text { higher costs or } \\
\text { charges }\end{array}$ \\
\hline
\end{tabular}




\begin{tabular}{|c|c|c|c|c|c|c|c|}
\hline $\begin{array}{l}\text { Author } \\
\text { Year }\end{array}$ & Length of Stay & $\begin{array}{l}\text { Patient } \\
\text { Functional } \\
\text { Return }\end{array}$ & Readmissions & Patient Harms & $\begin{array}{l}\text { Patient/Family } \\
\text { Experience }\end{array}$ & $\begin{array}{l}\text { Clinician/Staff } \\
\text { Satisfaction }\end{array}$ & Resource Use \\
\hline $\begin{array}{l}\text { Zhu et al. } \\
2015^{12}\end{array}$ & $\begin{array}{l}5 \text { trials ( } 4 \text { of } 5 \text { US), } \\
n=1,912 \\
\text { SMD: } 0.03 \text { days; } \\
95 \% \mathrm{Cl}:-0.06 \text { to } 0.12 \text {, } \\
p=0.540, l^{2}=0 \%, \text { no } \\
\text { difference }\end{array}$ & Not reported & 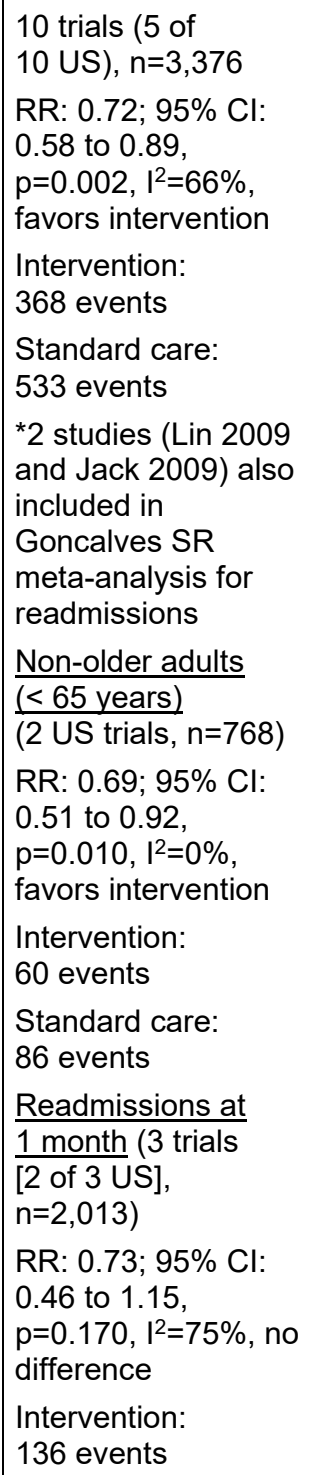 & $\begin{array}{l}\text { All-cause mortality } \\
\text { (index admission to } \\
\text { within } 30 \text { days) } \\
\text { (5 trials [3 of } 5 \text { US], } \\
n=2,729) \\
\text { RR: } 0.70 ; 95 \% \text { Cl: } \\
0.52 \text { to } 0.95, \\
p=0.020, I^{2}=0 \%, \\
\text { favors intervention } \\
\text { Intervention: } \\
59 \text { events } \\
\text { Standard care: } \\
87 \text { events }\end{array}$ & $\begin{array}{l}1 \text { US RCT } \\
\text { ( } n=363 \text { ): used } \\
\text { mean scores and } \\
\text { found little change } \\
\text { over time and } \\
\text { good rates of } \\
\text { satisfaction with } \\
\text { care in both } \\
\text { nurse-led early } \\
\text { DPP and control } \\
\text { groups }\end{array}$ & Not reported & $\begin{array}{l}\text { Total cost } \\
1 \text { US RCT } \\
\text { measured total } \\
\text { Medicare } \\
\text { reimburse- } \\
\text { ments for health } \\
\text { services at } \\
24 \text { weeks } \\
\text { Intervention } \\
\$ 0.6 \text { million vs. } \\
\text { standard care } \\
\$ 1.2 \text { million, } \\
\text { p<0.001, favors } \\
\text { intervention }\end{array}$ \\
\hline
\end{tabular}




\begin{tabular}{|c|c|c|c|c|c|c|c|}
\hline $\begin{array}{l}\text { Author } \\
\text { Year }\end{array}$ & Length of Stay & $\begin{array}{l}\text { Patient } \\
\text { Functional } \\
\text { Return }\end{array}$ & Readmissions & Patient Harms & $\begin{array}{l}\text { Patient/Family } \\
\text { Experience }\end{array}$ & $\begin{array}{l}\text { Clinician/Staff } \\
\text { Satisfaction }\end{array}$ & Resource Use \\
\hline & & & $\begin{array}{l}\text { Standard care: } \\
171 \text { events } \\
\text { Readmissions at } \\
6 \text { months } \\
\text { (2 US trials, } n=393) \\
\text { RR: } 0.48 ; 95 \% \mathrm{Cl} \text { : } \\
0.37 \text { to } 0.63, \\
p<0.001, \mathrm{I}^{2}=0 \%, \\
\text { favors intervention } \\
\text { Intervention: } \\
50 \text { events } \\
\text { Standard care: } \\
109 \text { events }\end{array}$ & & & & \\
\hline $\begin{array}{l}\text { Zhang } \\
\text { et al. } \\
2013^{40}\end{array}$ & $\begin{array}{l}2 \text { studies, } \\
\mathrm{n}=325 \text { patients } \\
\text { Study of geriatrics } \\
\text { consultation service } \\
\text { found no difference: } \\
\text { Mean LOS } 5 \text { days in } \\
\text { both groups } \\
\text { Study of staff education, } \\
\text { team approach, care } \\
\text { planning favors } \\
\text { intervention: Mean LOS } \\
28 \text { vs. } 38 \text { days }\end{array}$ & Not reported & Not reported & Not reported & Not reported & Not reported & Not reported \\
\hline
\end{tabular}

$\mathrm{ACS}=$ acute coronary syndrome; $\mathrm{CDSS}=$ clinical decision support system; $\mathrm{CI}=$ confidence interval; $\mathrm{CKD}=$ chronic kidney disease; $\mathrm{CNS}=$ clinical nurse specialists; $\mathrm{CPOE}=$ computerized physician order entry; $\mathrm{EMR}=$ electronic medical record; $\mathrm{GTC}=$ geriatric trauma consultation; $\mathrm{HF}$ = heart failure; $\mathrm{IQR}=$ interquartile range;

$\mathrm{LOS}=$ length of stay; $\mathrm{MD}=$ mean difference; $\mathrm{NR}=$ not reported; NSTEMI = non-ST-elevation myocardial infarction; NYHA = New York Heart Association; OR = odds ratio; $\mathrm{QoL}=$ quality of life; $\mathrm{RCT}=$ randomized controlled trial; $\mathrm{RR}=$ risk ratio; $\mathrm{SMD}=$ standardized mean difference; $\mathrm{SOE}=$ strength of evidence; STEMI = ST-elevation myocardial infarction; US = United States; WMD = weighted mean difference 
Table C-5. Risk of bias assessment reported in systematic reviews

\begin{tabular}{|c|c|c|c|c|c|}
\hline $\begin{array}{l}\text { Author } \\
\text { Year }\end{array}$ & Intervention & Comparator & $\begin{array}{l}\text { Primary } \\
\text { Studies: N, } \\
\text { Design }\end{array}$ & $\begin{array}{l}\text { Risk of Bias } \\
\text { Assessment } \\
\text { Tool }\end{array}$ & Detailed Risk of Bias Data \\
\hline $\begin{array}{l}\text { Austin et al. } \\
2020^{24}\end{array}$ & $\begin{array}{l}\text { Anticoagulant } \\
\text { prescribing }\end{array}$ & Routine care & $\begin{array}{l}27 \text { total studies: } \\
3 \text { RCTs, } 4 \text { cohort } \\
\text { studies, } \\
20 \text { pre/post } \\
\text { observational } \\
\text { studies ( } n=\text { not } \\
\text { reported) }\end{array}$ & $\begin{array}{l}\text { EPOC for RCTs } \\
\text { and cohort } \\
\text { studies }\end{array}$ & $\begin{array}{l}\text { RCTs: Low ROB due to } \\
\text { allocation sequence and } \\
\text { concealment, baseline } \\
\text { comparability of } \\
\text { characteristics, and } \\
\text { selective outcome reporting. } \\
\text { Either unclear or high ROB } \\
\text { for potential of inadequately } \\
\text { addressing incomplete } \\
\text { outcome data or protecting } \\
\text { against contamination. } \\
\text { Cohort studies: Mostly at } \\
\text { high or unclear ROB for } \\
\text { adequate allocation } \\
\text { sequence or concealment, } \\
\text { potential of not adequately } \\
\text { addressing incomplete } \\
\text { outcome data, protecting } \\
\text { against contamination or } \\
\text { knowledge of the allocated } \\
\text { intervention. Low ROB for } \\
\text { selective outcome reporting. }\end{array}$ \\
\hline $\begin{array}{l}\text { Agarwal } \\
\text { et al. } 2018^{34}\end{array}$ & $\begin{array}{l}\text { Quality } \\
\text { improvement } \\
\text { (multi- } \\
\text { component } \\
\text { interventions) }\end{array}$ & Usual care & $\begin{array}{l}14 \text { RCTs } \\
(n=96,913) \\
*(N=75,664 \text { for } \\
6 \text { US RCTs }) \\
\text { reporting } \\
\text { outcomes of } \\
\text { interest }\end{array}$ & Cochrane ROB & $\begin{array}{l}\text { Randomization: Low ROB } \\
\text { (all } 6 \text { US RCTs) } \\
\text { Adequate allocation } \\
\text { concealment: Low ROB } \\
\text { (3 US RCTs) } \\
\text { Adequate blinding of } \\
\text { outcome assessors: Low } \\
\text { ROB (2 US RCTs) } \\
\text { Attrition bias: Low ROB } \\
\text { (4 US RCTs) } \\
\text { Selective outcome } \\
\text { reporting: High ROB } \\
\text { (1 US RCT) }\end{array}$ \\
\hline $\begin{array}{l}\text { Baratloo } \\
\text { et al. } 2018^{25}\end{array}$ & $\begin{array}{l}\text { Telestroke- } \\
\text { based systems }\end{array}$ & $\begin{array}{l}\text { Bedside } \\
\text { (face-to-face) }\end{array}$ & $\begin{array}{l}26 \text { total studies: } \\
2 \text { RCTs, } \\
8 \text { prospective } \\
\text { observational } \\
\text { studies, } \\
16 \text { retrospective } \\
\text { observational } \\
\text { studies } \\
(\mathrm{N}=6,605)\end{array}$ & $\begin{array}{l}\text { Cochrane } \\
\text { (RCTs), } \\
\text { Newcastle- } \\
\text { Ottawa scale } \\
\text { (observational } \\
\text { studies) }\end{array}$ & $\begin{array}{l}\text { RCTs: Low ROB for random } \\
\text { sequence generation, } \\
\text { incomplete outcome data, } \\
\text { selective reporting. High } \\
\text { ROB due to lack of blinding } \\
\text { participants and personnel, } \\
1 \text { RCT reported blinding } \\
\text { outcome evaluators. } \\
\text { Observational studies: Low } \\
\text { ROB (mean of } 8 \text { out of } \\
9 \text { points on Newcastle- } \\
\text { Ottawa scale) }\end{array}$ \\
\hline
\end{tabular}




\begin{tabular}{|c|c|c|c|c|c|}
\hline $\begin{array}{l}\text { Author } \\
\text { Year }\end{array}$ & Intervention & Comparator & $\begin{array}{l}\text { Primary } \\
\text { Studies: N, } \\
\text { Design }\end{array}$ & $\begin{array}{l}\text { Risk of Bias } \\
\text { Assessment } \\
\text { Tool } \\
\end{array}$ & Detailed Risk of Bias Data \\
\hline $\begin{array}{l}\text { Bryant- } \\
\text { Lukosius } \\
\text { et al. } 2015^{35}\end{array}$ & $\begin{array}{l}\text { Clinical nurse } \\
\text { specialists } \\
\text { transitional care }\end{array}$ & Usual care & $\begin{array}{l}13 \text { RCTS } \\
(n=2,463)\end{array}$ & Cochrane ROB & $\begin{array}{l}\text { Low ROB ( } 3 \text { RCTs), } \\
\text { moderate ROB }(n=8) \text { and } \\
\text { high ROB }(n=2) \\
16 \text {-item Quality of Health } \\
\text { Economic Studies for } \\
\text { economic analyses }\end{array}$ \\
\hline $\begin{array}{l}\text { Bakker } \\
\text { et al. } 2011^{26}\end{array}$ & $\begin{array}{l}\text { Geriatric } \\
\text { specialty teams } \\
\text { or units }\end{array}$ & Usual care & $\begin{array}{l}17 \text { total studies; } \\
6 \text { reported LOS: } \\
4 \text { RCTs, } \\
2 \text { observational } \\
\end{array}$ & EPOC tool & $\begin{array}{l}\text { Most studies high risk of } \\
\text { bias }\end{array}$ \\
\hline $\begin{array}{l}\text { Eagles } \\
\text { et al. } 2020^{41}\end{array}$ & $\begin{array}{l}\text { Geriatric trauma } \\
\text { consultation }\end{array}$ & $\begin{array}{l}\text { Standard } \\
\text { trauma care }\end{array}$ & $\begin{array}{l}8 \text { retrospective } \\
\text { cohort studies } \\
(n=122 \text { to } 4,534)\end{array}$ & $\begin{array}{l}\text { Newcastle- } \\
\text { Ottawa Quality } \\
\text { Assessment } \\
\text { Scale }\end{array}$ & $\begin{array}{l}\text { Main threat to study quality } \\
\text { was a lack of controlling for } \\
\text { study variables. } 3 \text { studies } \\
\text { controlled for at least } \\
\text { two factors in their analyses. } \\
\text { Moderate to high ROB due } \\
\text { to selection, comparability, } \\
\text { and outcomes. }\end{array}$ \\
\hline $\begin{array}{l}\text { Ellis et al. } \\
2017^{36}\end{array}$ & $\begin{array}{l}\text { Comprehensive } \\
\text { geriatric } \\
\text { assessment }\end{array}$ & Usual care & $\begin{array}{l}29 \text { RCTs } \\
(n=13,766)\end{array}$ & $\begin{array}{l}\text { Used guidance } \\
\text { for EPOC } \\
\text { reviews }\end{array}$ & $\begin{array}{l}\text { Random sequence } \\
\text { generation: Low or unclear } \\
\text { ROB (26 RCTs) } \\
\text { Allocation concealment: } \\
\text { High ROB (1 RCT) } \\
\text { Blinding of participant or } \\
\text { researchers: High ROB } \\
\text { (all RCTs) } \\
\text { Blinding of outcome } \\
\text { assessors: Low ROB } \\
\text { (most RCTs) } \\
\text { Attrition bias: High ROB } \\
\text { ( } 3 \text { RCTs), low ROB } \\
\text { (6 RCTs), unclear ROB } \\
\text { (18 RCTs) } \\
\text { Selective reporting due to } \\
\text { not publishing a protocol: } \\
\text { Unclear ROB (25 RCTs) } \\
\text { Other potential sources of } \\
\text { bias: Unclear ROB } \\
\text { (21 RCTs) } \\
\text { Uncertainty about whether } \\
\text { the study adequately } \\
\text { protected against } \\
\text { contamination (i.e. received } \\
\text { the intervention): High ROB } \\
\text { (6 RCTs) }\end{array}$ \\
\hline
\end{tabular}




\begin{tabular}{|c|c|c|c|c|c|}
\hline $\begin{array}{l}\text { Author } \\
\text { Year }\end{array}$ & Intervention & Comparator & $\begin{array}{l}\text { Primary } \\
\text { Studies: N, } \\
\text { Design } \\
\end{array}$ & $\begin{array}{l}\text { Risk of Bias } \\
\text { Assessment } \\
\text { Tool }\end{array}$ & Detailed Risk of Bias Data \\
\hline $\begin{array}{l}\text { Frazer } \\
\text { et al. } 2019^{37}\end{array}$ & $\begin{array}{l}\text { Anticoagulant } \\
\text { prescribing }\end{array}$ & $\begin{array}{l}\text { Physician-led } \\
\text { usual care }\end{array}$ & $\begin{array}{l}19 \text { RCTs } \\
(n=12,742)\end{array}$ & $\begin{array}{l}\text { Cochrane EPOC } \\
\text { criteria }\end{array}$ & $\begin{array}{l}\text { High ROB due to } \\
\text { randomization not clearly } \\
\text { defined ( } 8 \text { RCTs) or } \\
\text { suboptimal (10 RCTs), lack } \\
\text { of clarity surrounding } \\
\text { allocation concealment } \\
\text { (7 RCTs). } 3 \text { RCTs blinded } \\
\text { outcome assessors; } 4 \text { RCTs } \\
\text { describe independent } \\
\text { review of subjective results, } \\
\text { verification of data } \\
\text { collection. } \\
1 \text { RCT funded by } \\
\text { manufacturing company. }\end{array}$ \\
\hline $\begin{array}{l}\text { Gonçalves- } \\
\text { Bradley } \\
\text { et al. } 2016^{38}\end{array}$ & $\begin{array}{l}\text { Discharge } \\
\text { planning }\end{array}$ & $\begin{array}{l}\text { Standard } \\
\text { care with no } \\
\text { individualized } \\
\text { discharge } \\
\text { plan }\end{array}$ & $\begin{array}{l}30 \text { RCTs } \\
(n=11,964)\end{array}$ & Cochrane ROB & $\begin{array}{l}\text { Most trials low risk of Bias: } \\
18 \text { RCTs reported adequate } \\
\text { allocation concealment, } \\
28 \text { RCTs collected data at } \\
\text { baseline, } 21 \text { RCTs } \\
\text { measured primary outcomes } \\
\text { (LOS, readmissions) }\end{array}$ \\
\hline $\begin{array}{l}\text { Gillaizeau } \\
\text { et al. } 2013^{27}\end{array}$ & $\begin{array}{l}\text { Computerized } \\
\text { decision } \\
\text { support }\end{array}$ & Usual care & $\begin{array}{l}42 \text { total studies; } \\
9 \text { reported LOS: } \\
8 \text { RCTs, } \\
1 \text { observational }\end{array}$ & EPOC tool & $\begin{array}{l}\text { Studies varied in quality but } \\
\text { GRADE was not lowered } \\
\text { due to risk of bias }\end{array}$ \\
\hline $\begin{array}{l}\text { Huntley } \\
\text { et al. } 2016^{28}\end{array}$ & $\begin{array}{l}\text { Case } \\
\text { management }\end{array}$ & Usual care & $\begin{array}{l}22 \text { total studies; } \\
9 \text { reported LOS: } \\
8 \text { RCTs, } \\
1 \text { observational; } \\
13 \text { reported } \\
\text { readmissions: } \\
12 \text { RCTs, } \\
1 \text { observational }\end{array}$ & $\begin{array}{l}\text { Cochrane risk of } \\
\text { bias tool for } \\
\text { RCTs; } \\
\text { EPOC tool for } \\
\text { observational } \\
\text { studies }\end{array}$ & $\begin{array}{l}\text { Most RCTs low risk of bias; } \\
\text { most observational studies } \\
\text { high risk of bias }\end{array}$ \\
\hline $\begin{array}{l}\text { Kul et al. } \\
2012^{29}\end{array}$ & $\begin{array}{l}\text { Clinical } \\
\text { pathways }\end{array}$ & Usual care & $\begin{array}{l}7 \text { total studies: } \\
3 \text { RCTs, } \\
1 \text { cohort, } \\
3 \text { pre-post }\end{array}$ & $\begin{array}{l}\text { Jadad tool for } \\
\text { RCTs; } \\
\text { Newcastle- } \\
\text { Ottawa Scale for } \\
\text { observational } \\
\text { studies }\end{array}$ & $\begin{array}{l}\text { Sensitivity analyses } \\
\text { performed for each outcome } \\
\text { after removing respective } \\
\text { study with highest risk of } \\
\text { bias }\end{array}$ \\
\hline
\end{tabular}




\begin{tabular}{|c|c|c|c|c|c|}
\hline $\begin{array}{l}\text { Author } \\
\text { Year }\end{array}$ & Intervention & Comparator & \begin{tabular}{|l} 
Primary \\
Studies: N, \\
Design
\end{tabular} & $\begin{array}{l}\text { Risk of Bias } \\
\text { Assessment } \\
\text { Tool }\end{array}$ & Detailed Risk of Bias Data \\
\hline $\begin{array}{l}\text { Mabire et al } \\
2017^{15,30}\end{array}$ & $\begin{array}{l}\text { Nursing } \\
\text { discharge } \\
\text { planning } \\
\text { interventions }\end{array}$ & Usual care & $\begin{array}{l}13 \text { total studies: } \\
11 \text { RCTs, } \\
1 \text { pilot cohort, } \\
1 \text { pre-post study } \\
(\mathrm{n}=3,964)\end{array}$ & $\begin{array}{l}\text { Yes, JBI- } \\
\text { MAStARI } \\
\text { assessment of } \\
\text { methodological } \\
\text { quality }\end{array}$ & $\begin{array}{l}12 \text { studies considered truly } \\
\text { random; } 7 \text { studies met } \\
\text { applicable criteria for } \\
\text { blinding of participants. } \\
11 \text { studies clearly described } \\
\text { blinded allocation. } \\
12 \text { studies described } \\
\text { outcomes for subjects who } \\
\text { withdrew. } 9 \text { studies reported } \\
\text { blinded assessment } \\
\text { procedures and } 4 \text { studies } \\
\text { were unclear. } 12 \text { studies } \\
\text { demonstrated group } \\
\text { equivalency at baseline. } \\
10 \text { studies adequately } \\
\text { described both intervention } \\
\text { and control groups. All } \\
\text { studies met criteria for } \\
\text { consistent and clear } \\
\text { measurement of outcomes } \\
\text { across groups and analyzed } \\
\text { appropriately. }\end{array}$ \\
\hline $\begin{array}{l}\text { Patel et al. } \\
2020^{31}\end{array}$ & $\begin{array}{l}\text { Orthopedic-led } \\
\text { care } \\
(13 \text { studies }) \\
\text { Geriatrics-led } \\
\text { care (4 studies) }\end{array}$ & $\begin{array}{l}\text { Ortho- } \\
\text { geriatrics co- } \\
\text { management } \\
\text { or orthopedic } \\
\text { care led } \\
\text { model }\end{array}$ & $\begin{array}{l}17 \text { total studies: } \\
9 \text { retrospective } \\
\text { studies, } \\
6 \text { prospective } \\
\text { studies, } 1 \mathrm{RCT}, \\
1 \text { non-RCT } \\
(\mathrm{n}=146 \text { to } \\
23,973)\end{array}$ & $\begin{array}{l}\text { Oxford quality- } \\
\text { scoring system } \\
\text { (Jadad) for RCTs } \\
\text { and Newcastle } \\
\text { Ottawa grading } \\
\text { system for non- } \\
\text { RCTs }\end{array}$ & \\
\hline $\begin{array}{l}\text { Pannick } \\
\text { et al. } 2015^{32}\end{array}$ & $\begin{array}{l}\text { Interdisciplinary } \\
\text { team care }\end{array}$ & $\begin{array}{l}\text { Usual, } \\
\text { routine, or } \\
\text { standard care }\end{array}$ & $\begin{array}{l}30 \text { total studies: } \\
8 \text { RCTs, } \\
9 \text { cluster-RCTs, } \\
8 \text { non-RCT } \\
\text { cluster, } \\
4 \text { before-after, } \\
1 \text { interrupted } \\
\text { time series } \\
(\mathrm{n}=66,548) \\
\end{array}$ & Cochrane ROB & $\begin{array}{l}\text { No study had a low risk of } \\
\text { bias, medium ROB } \\
\text { ( } 7 \text { studies), high ROB } \\
\text { (23 studies) }\end{array}$ \\
\hline $\begin{array}{l}\text { Van Craen } \\
\text { et al. } 2010^{39} \\
\end{array}$ & $\begin{array}{l}\text { Geriatric } \\
\text { evaluation unit }\end{array}$ & Usual care & 7 RCTs & $\begin{array}{l}\text { Delphi list for } \\
\text { RCTs }\end{array}$ & Most studies low risk of bias \\
\hline $\begin{array}{l}\text { White et al. } \\
2011^{33}\end{array}$ & $\begin{array}{l}\text { Hospitalist } \\
\text { service }\end{array}$ & $\begin{array}{l}\text { Traditional } \\
\text { attending } \\
\text { physician } \\
\text { structures }\end{array}$ & $\begin{array}{l}65 \text { total studies: } \\
1 \text { RCT, } 8 \text { non- } \\
\text { randomized } \\
\text { controlled trials, } \\
1 \text { interrupted } \\
\text { time series, } \\
37 \text { cohort, } \\
18 \text { pre-post } \\
\end{array}$ & $\begin{array}{l}\text { Modified Downs } \\
\text { and Black } \\
\text { checklist, } \\
32 \text { items }\end{array}$ & $\begin{array}{l}\text { Mean score across studies: } \\
15 \text {; range: } 5-26\end{array}$ \\
\hline
\end{tabular}




\begin{tabular}{|c|c|c|c|c|c|}
\hline $\begin{array}{l}\text { Author } \\
\text { Year }\end{array}$ & Intervention & Comparator & $\begin{array}{l}\text { Primary } \\
\text { Studies: N, } \\
\text { Design } \\
\end{array}$ & $\begin{array}{l}\text { Risk of Bias } \\
\text { Assessment } \\
\text { Tool } \\
\end{array}$ & Detailed Risk of Bias Data \\
\hline $\begin{array}{l}\text { Zhu et al. } \\
2015^{12}\end{array}$ & $\begin{array}{l}\text { Nurse-led early } \\
\text { discharge } \\
\text { planning }\end{array}$ & Usual care & $\begin{array}{l}10 \text { RCTs } \\
(n=3,438)\end{array}$ & $\begin{array}{l}\text { Yes, Cochrane } \\
\text { ROB }\end{array}$ & $\begin{array}{l}\text { Sequence generation, } \\
\text { selection bias due to failures } \\
\text { of allocation concealment: } \\
\text { Low ROB } \\
\text { Performance bias related to } \\
\text { blinding of participants and } \\
\text { personnel: Low ROB } \\
\text { (4 RCTs), unclear ROB } \\
\text { (5 RCTs), high ROB } \\
\text { (1 RCT) } \\
\text { Detection bias: Low ROB } \\
\text { (2 RCTs) } \\
\text { Attrition: Low ROB (8 RCTs) } \\
\text { Selective reporting: Low } \\
\text { ROB (4 RCTs), high ROB } \\
\text { (1 RCTs), unclear ROB } \\
\text { (5 RCTs) }\end{array}$ \\
\hline $\begin{array}{l}\text { Zhang et al. } \\
2013^{40}\end{array}$ & $\begin{array}{l}\text { Multicomponent } \\
\text { interventions }\end{array}$ & Usual care & $\begin{array}{l}38 \text { total RCTs; } \\
10 \text { studies } \\
\text { reported LOS, } \\
\text { only } 2 \text { used a } \\
\text { systemic } \\
\text { intervention } \\
\text { (others were } \\
\text { pharmacologic) }\end{array}$ & $\begin{array}{l}\text { Modified Jadad } \\
\text { tool }\end{array}$ & Both studies scored 9/12 \\
\hline
\end{tabular}

EPOC = effective practice and organization of care; GRADE = Grading of Recommendations Assessment, Development and Evaluation; JBI-MAStARI = Joanna Briggs Institute Meta-analysis Statistics Assessment and Review Instrument; $\mathrm{LOS}=$ length of stay; $\mathrm{RCT}=$ randomized controlled trial; $\mathrm{ROB}=$ risk of bias; $\mathrm{US}=$ United States 
Table C-6. Strength of evidence for quantitative findings not assessed for systematic review authors

\begin{tabular}{|c|c|c|c|c|c|c|c|c|}
\hline $\begin{array}{l}\text { Outcome } \\
\text { (Strength of } \\
\text { Evidence } \\
\text { Grade) } \\
\end{array}$ & $\begin{array}{l}\text { Author } \\
\text { Study Design: No } \\
\text { Studies (N) }\end{array}$ & Study Limitations & Directness & Consistency & Precision & $\begin{array}{l}\text { Reporting } \\
\text { Bias }\end{array}$ & \begin{tabular}{|l} 
Other \\
Issues
\end{tabular} & Finding \\
\hline $\begin{array}{l}\text { LOS } \\
\text { (Low) }\end{array}$ & $\begin{array}{l}\text { Eagles et al. } 2020^{41} \\
2 \text { US retrospective } \\
\text { cohort studies } \\
(n=5,414)\end{array}$ & $\begin{array}{l}\text { Medium } \\
\text { (1 study scored all points } \\
\text { for selection, comparability, } \\
\text { and outcome domains. } \\
1 \text { study scored all points for } \\
\text { only the selection and } \\
\text { outcome domains.) }\end{array}$ & Direct & Consistent & $\begin{array}{l}\text { Imprecise } \\
\text { (wide CI) }\end{array}$ & Undetected & None & $\begin{array}{l}\text { Geriatric trauma } \\
\text { consultation vs. standard } \\
\text { trauma care } \\
\text { MD: }-1.11 \text { days; } 95 \% \mathrm{Cl} \text { : } \\
-1.43 \text { to }-0.79, I^{2}=0 \% \\
\text { favors intervention }\end{array}$ \\
\hline $\begin{array}{l}\begin{array}{l}\text { LOS } \\
\text { (Low) }\end{array} \\
\end{array}$ & $\begin{array}{l}\text { Baratloo et al. } 2018^{25} \\
6 \text { retrospective } \\
\text { controlled studies, } \\
2 \text { prospective } \\
\text { controlled studies, } \\
1 \text { RCT (6 of } 9 \text { US) } \\
(n=2,850)\end{array}$ & $\begin{array}{l}\text { Medium } \\
\text { (Retrospective and } \\
\text { prospective studies low } \\
\text { ROB on Newottowa scale. } \\
\text { RCT low ROB for random } \\
\text { sequence generation, } \\
\text { incomplete outcome data, } \\
\text { selective reporting, but } \\
\text { high ROB for blinding } \\
\text { participants and } \\
\text { personnel.) }\end{array}$ & Direct & Consistent & $\begin{array}{l}\text { Imprecise } \\
\text { (wide } \mathrm{Cl} \text { ) }\end{array}$ & Undetected & None & $\begin{array}{l}\text { Telestroke-based } \\
\text { systems vs. bedside } \\
\text { (face-to-face) } \\
\text { MD: }-0.55 \text { days; } 95 \% \mathrm{Cl} \text { : } \\
-1.02 \text { to }-0.07, p=0.02, \\
I^{2}=38 \%, \text { favors } \\
\text { intervention }\end{array}$ \\
\hline $\begin{array}{l}\text { LOS } \\
\text { (Low) }\end{array}$ & $\begin{array}{l}\text { Gonçalves-Bradley } \\
\text { et al. } 2016^{38} \\
2 \text { RCTs ( } 1 \text { of } 2 \text { US) } \\
\text { ( } n=184)\end{array}$ & $\begin{array}{l}\text { Medium } \\
\text { (Both RCTs unclear ROB } \\
\text { for random sequence } \\
\text { generation, allocation } \\
\text { concealment, and selective } \\
\text { reporting. Low ROB for } \\
\text { attrition and baseline data. } \\
1 \text { RCT unclear ROB and } \\
1 \text { RCT low ROB for } \\
\text { blinding.) } \\
\end{array}$ & Direct & Consistent & $\begin{array}{l}\text { Imprecise } \\
\text { (wide Cl) }\end{array}$ & Undetected & None & $\begin{array}{l}\text { Discharge planning vs. } \\
\text { standard care (older } \\
\text { surgical patients) } \\
\text { MD: }-0.06 ; 95 \% \mathrm{Cl}: \\
-1.23 \text { to } 1.11, \mathrm{I}^{2}=0 \% \text {, no } \\
\text { difference }\end{array}$ \\
\hline $\begin{array}{l}\text { LOS } \\
\text { (Moderate) }\end{array}$ & $\begin{array}{l}\text { Huntley et al. } 2016^{28} \\
8 \text { RCTs, } \\
1 \text { non-randomized } \\
\text { controlled study } \\
(6 \text { of } 9 \text { US) }(n=1,765)\end{array}$ & Low & Direct & $\begin{array}{l}\text { Inconsistent } \\
(>50 \% \\
\text { heterogeneity })\end{array}$ & Precise & Undetected & None & $\begin{array}{l}\text { Case management vs. } \\
\text { usual care } \\
\text { Mean reduction: } \\
1.28 \text { days; } 95 \% \mathrm{Cl} \text { : } \\
0.52 \text { to } 2.04, \mathrm{I}^{2}=63 \% \text {, } \\
\text { favors intervention }\end{array}$ \\
\hline
\end{tabular}




\begin{tabular}{|c|c|c|c|c|c|c|c|c|}
\hline $\begin{array}{l}\text { Outcome } \\
\text { (Strength of } \\
\text { Evidence } \\
\text { Grade) }\end{array}$ & $\begin{array}{l}\text { Author } \\
\text { Study Design: No } \\
\text { Studies (N) }\end{array}$ & Study Limitations & Directness & Consistency & Precision & $\begin{array}{l}\text { Reporting } \\
\text { Bias }\end{array}$ & $\begin{array}{l}\text { Other } \\
\text { Issues }\end{array}$ & Finding \\
\hline $\begin{array}{l}\text { LOS } \\
\text { (Low) }\end{array}$ & $\begin{array}{l}\text { Pannick et al. } 2015^{32} \\
2 \text { RCTs, } 2 \text { non-RCT } \\
\text { cluster studies, } \\
2 \text { before/after studies } \\
\text { ( } 4 \text { of } 6 \text { US) (n=NR) }\end{array}$ & $\begin{array}{l}\text { High } \\
\text { ( } 2 \text { studies medium ROB, } \\
4 \text { studies high } \mathrm{ROB} \text { ) }\end{array}$ & Direct & Consistent & $\begin{array}{l}\text { Imprecise } \\
\text { (wide } \mathrm{Cl} \text { ) }\end{array}$ & Undetected & None & $\begin{array}{l}\text { Altering interdisciplinary } \\
\text { team composition vs. } \\
\text { usual care } \\
\text { WMD: } 0.087 \text { days; } \\
95 \% \mathrm{Cl}:-0.083 \text { to } 0.257 \text {, } \\
\text { no difference }\end{array}$ \\
\hline $\begin{array}{l}\text { LOS } \\
\text { (Low) }\end{array}$ & $\begin{array}{l}\text { Pannick et al. } 2015^{32} \\
2 \text { cluster RCTs, } \\
3 \text { non RCT cluster } \\
\text { studies, } \\
2 \text { interrupted time } \\
\text { series ( } 6 \text { of } 7 \text { US) } \\
(n=N R)\end{array}$ & $\begin{array}{l}\text { High } \\
\text { ( } 2 \text { studies medium ROB, } \\
5 \text { studies high } R O B \text { ) }\end{array}$ & Direct & Consistent & Precise & Undetected & None & $\begin{array}{l}\text { Altering interdisciplinary } \\
\text { team practice vs. usual } \\
\text { care } \\
\text { WMD: } 0.001 \text { days; } \\
95 \% \mathrm{Cl}:-0.035 \text { to } 0.037 \text {, } \\
\text { no difference }\end{array}$ \\
\hline $\begin{array}{l}\text { LOS } \\
\text { (Moderate) }\end{array}$ & $\begin{array}{l}\text { Zhu et al. } 2015^{12} \\
5 \text { RCTs ( } 4 \text { of } 5 \text { US) } \\
(n=1,912)\end{array}$ & $\begin{array}{l}\text { Medium } \\
\text { (All studies low ROB for } \\
\text { random sequence } \\
\text { generation, allocation } \\
\text { concealment, attrition bias. } \\
2 \text { studies each unclear } \\
\text { ROB and low ROB for } \\
\text { blinding, and } 1 \text { high ROB } \\
\text { for blinding.) }\end{array}$ & Direct & Consistent & Precise & Undetected & None & $\begin{array}{l}\text { Nurse-led early } \\
\text { discharge planning vs. } \\
\text { usual care } \\
\text { SMD: } 0.03 \text { days; } \\
95 \% \mathrm{Cl}:-0.06 \text { to } 0.12 \text {, } \\
p=0.540, I^{2}=0 \%, \text { no } \\
\text { difference }\end{array}$ \\
\hline $\begin{array}{l}\text { LOS } \\
\text { (Very Low) }\end{array}$ & $\begin{array}{l}\text { Gillaizeau et al. } \\
2013^{27} \\
8 \text { RCTs, } 1 \text { alternating } \\
\text { time series study } \\
\text { ( } 7 \text { of } 9 \text { US) } \\
(n=18,507)\end{array}$ & High & Direct & $\begin{array}{l}\text { Inconsistent } \\
(>50 \% \\
\text { heterogeneity })\end{array}$ & Imprecise & Undetected & None & $\begin{array}{l}\text { Computerized decision } \\
\text { support vs. usual care } \\
\text { SMD: }-0.15 ; 95 \% \mathrm{Cl} \text { : } \\
-0.33 \text { to } 0.02, \mathrm{I}^{2}=57 \% \text {, no } \\
\text { difference in reduction of } \\
\text { LOS, but leans towards } \\
\text { favoring intervention }\end{array}$ \\
\hline $\begin{array}{l}\text { LOS } \\
\text { (Low) }\end{array}$ & $\begin{array}{l}\text { Kul et al. } 2012^{29} \\
1 \text { RCT, } 1 \text { interrupted } \\
\text { times series, } \\
3 \text { non-randomized } \\
\text { controlled studies } \\
(3 \text { of } 5 \text { US) }(n=2,095)\end{array}$ & High & Direct & Consistent & Precise & Undetected & None & $\begin{array}{l}\text { Clinical pathways vs. } \\
\text { usual care } \\
\text { Mean reduction: } \\
1.89 \text { days; } 95 \% \mathrm{Cl}: 1.33 \\
\text { to } 2.44, \mathrm{I}^{2}=42 \% \text {, favors } \\
\text { intervention }\end{array}$ \\
\hline
\end{tabular}




\begin{tabular}{|c|c|c|c|c|c|c|c|c|}
\hline $\begin{array}{l}\text { Outcome } \\
\text { (Strength of } \\
\text { Evidence } \\
\text { Grade) } \\
\end{array}$ & $\begin{array}{l}\text { Author } \\
\text { Study Design: No } \\
\text { Studies (N) }\end{array}$ & Study Limitations & Directness & Consistency & Precision & $\begin{array}{l}\text { Reporting } \\
\text { Bias }\end{array}$ & $\begin{array}{l}\text { Other } \\
\text { Issues }\end{array}$ & Finding \\
\hline $\begin{array}{l}\text { LOS } \\
\text { (High) }\end{array}$ & $\begin{array}{l}\text { Van Craen et al. } \\
2010^{39} \\
7 \text { RCTs (4 of } 7 \text { US) } \\
(n=4,759)\end{array}$ & Low & Direct & Consistent & Precise & Undetected & None & $\begin{array}{l}\text { Geriatric evaluation unit } \\
\text { vs. usual care } \\
\text { Mean reduction } \\
\text { measured by Hedges g } \\
0.07 \text { days; } 95 \% \mathrm{Cl} \text { : } \\
-0.11 \text { to } 0.26, \text { no } \\
\text { difference } \\
\end{array}$ \\
\hline $\begin{array}{l}\text { Readmissions } \\
\text { (Moderate) }\end{array}$ & $\begin{array}{l}\text { Mabire et al } 2017^{15,30} \\
3 \text { US RCTs/pre-post } \\
\text { studies }(n=465)\end{array}$ & $\begin{array}{l}\text { Medium } \\
\text { ( } 1 \text { study answered yes to } \\
6 \text { of } 10 \text { questions, } 1 \text { study } \\
\text { answered yes to } 9 \text { of } 10 \text {, } \\
\text { and } 1 \text { study answered yes } \\
\text { to } 8 \text { of } 10 \text {. All studies } \\
\text { included in SR met criteria } \\
\text { for consistent and clear } \\
\text { measurement of outcomes } \\
\text { across groups and } \\
\text { analyzed appropriately.) }\end{array}$ & Direct & Consistent & Precise & Undetected & None & $\begin{array}{l}\text { Nursing discharge } \\
\text { planning intervention } \\
\text { OR: } 0.57 ; 95 \% \mathrm{Cl}: 0.40 \\
\text { to } 0.81, \mathrm{p}=0.01, \mathrm{I}^{2}=0 \% \text {, } \\
\text { favors intervention }\end{array}$ \\
\hline $\begin{array}{l}\text { Readmissions } \\
\text { (Low) }\end{array}$ & $\begin{array}{l}\text { Mabire et al } 2017^{15,30} \\
4 \text { RCTs ( } 3 \text { of } 4 \text { US) } \\
(n=1,030)\end{array}$ & $\begin{array}{l}\text { Medium } \\
\text { ( } 1 \text { study answered yes to } \\
6 \text { of } 10 \text { questions, } 1 \text { study } \\
\text { answered yes to } 8 \text { of } 10, \\
1 \text { study answered yes to } \\
9 \text { of } 10 \text {, and } 1 \text { study } \\
\text { answered yes to all } \\
\text { questions. All studies } \\
\text { included in SR met criteria } \\
\text { for consistent and clear } \\
\text { measurement of outcomes } \\
\text { across groups and } \\
\text { analyzed appropriately.) }\end{array}$ & Direct & $\begin{array}{l}\text { Inconsistent } \\
(>50 \% \\
\text { heterogeneity })\end{array}$ & $\begin{array}{l}\text { Imprecise } \\
\text { (wide Cl) }\end{array}$ & Undetected & None & $\begin{array}{l}\text { Nursing discharge } \\
\text { planning intervention } \\
\text { (transitional care) vs. } \\
\text { usual care } \\
\text { OR: } 0.70 ; 95 \% \mathrm{Cl}: 0.38 \\
\text { to } 1.27, \mathrm{I}^{2}=69.2 \% \text {, no } \\
\text { difference }\end{array}$ \\
\hline $\begin{array}{l}\text { Readmissions } \\
\text { (Moderate) }\end{array}$ & $\begin{array}{l}\text { Huntley et al. } 2016^{28} \\
12 \text { RCTs, } \\
1 \text { non-randomized } \\
\text { controlled study } \\
(8 \text { or } 13 \text { US) } \\
(n=3,346)\end{array}$ & Low & Direct & & Precise & Undetected & None & $\begin{array}{l}\text { Case management vs. } \\
\text { usual care } \\
\text { RR: } 0.74 ; 95 \% \mathrm{Cl}: 0.60 \\
\text { to } 0.92, \mathrm{I}^{2}=69 \% \text {, favors } \\
\text { intervention }\end{array}$ \\
\hline
\end{tabular}




\begin{tabular}{|c|c|c|c|c|c|c|c|c|}
\hline $\begin{array}{l}\text { Outcome } \\
\text { (Strength of } \\
\text { Evidence } \\
\text { Grade) }\end{array}$ & \begin{tabular}{|l|} 
Author \\
Study Design: No \\
Studies (N)
\end{tabular} & Study Limitations & Directness & Consistency & Precision & $\begin{array}{l}\text { Reporting } \\
\text { Bias }\end{array}$ & $\begin{array}{l}\text { Other } \\
\text { Issues }\end{array}$ & Finding \\
\hline $\begin{array}{l}\text { Early } \\
\text { Readmissions } \\
\text { (Low) }\end{array}$ & $\begin{array}{l}\text { Pannick et al. } 2015^{32} \\
2 \text { cluster RCTs, } \\
1 \text { non-RCT (all US) } \\
\text { (n=NR) }\end{array}$ & $\begin{array}{l}\text { High } \\
\text { (All studies high ROB) }\end{array}$ & Direct & Consistent & Precise & Undetected & None & $\begin{array}{l}\text { Altering interdisciplinary } \\
\text { team composition vs. } \\
\text { usual care } \\
\text { RR: } 1.341 ; 95 \% \mathrm{Cl} \text { : } \\
1.120 \text { to } 1.607, \\
\text { intervention tended to } \\
\text { increase early } \\
\text { readmissions (authors } \\
\text { noted there were } \\
\text { important confounding } \\
\text { factors, factors not } \\
\text { specified) }\end{array}$ \\
\hline $\begin{array}{l}\text { Early } \\
\text { Readmissions } \\
\text { (Low) }\end{array}$ & $\begin{array}{l}\text { Pannick et al. } 2015^{32} \\
2 \text { non-RCT cluster } \\
\text { studies, } \\
2 \text { interrupted time } \\
\text { series, } 1 \text { before/after } \\
\text { study (all US) ( } n=N R)\end{array}$ & $\begin{array}{l}\text { High } \\
\text { ( } 2 \text { studies medium ROB, } \\
3 \text { studies high } \mathrm{ROB} \text { ) }\end{array}$ & Direct & Consistent & Precise & Undetected & None & $\begin{array}{l}\text { Altering interdisciplinary } \\
\text { team practice vs. usual } \\
\text { care } \\
\text { RR: } 0.995 ; 95 \% \mathrm{Cl} \text { : } \\
0.912 \text { to } 1.085, \text { no } \\
\text { difference }\end{array}$ \\
\hline $\begin{array}{l}\text { Readmissions } \\
\text { (Low) }\end{array}$ & $\begin{array}{l}\text { Zhu et al. } 2015^{12} \\
10 \text { RCTs (5 of } 10 \text { US) } \\
(n=3,376)\end{array}$ & $\begin{array}{l}\text { Medium } \\
\text { (All studies low ROB for } \\
\text { random sequence } \\
\text { generation and allocation } \\
\text { concealment. } 5 \text { studies } \\
\text { unclear ROB for blinding of } \\
\text { participants, personnel, } \\
\text { and outcome assessors. } \\
1 \text { study high ROB and } \\
4 \text { studies low ROB for } \\
\text { blinding of participants and } \\
\text { personnel. } 2 \text { studies low } \\
\text { ROB and } 3 \text { studies unclear } \\
\text { ROB for blinding of } \\
\text { outcome assessors. } \\
7 \text { studies low ROB for } \\
\text { attrition bias. } 4 \text { studies low } \\
\text { ROB, } 4 \text { studies unclear } \\
\text { ROB for selective } \\
\text { reporting.) }\end{array}$ & Direct & $\begin{array}{l}\text { Inconsistent } \\
(>50 \% \\
\text { heterogeneity })\end{array}$ & Precise & Undetected & None & $\begin{array}{l}\text { Nurse-led early } \\
\text { discharge planning vs. } \\
\text { usual care } \\
\text { RR: } 0.72 ; 95 \% \mathrm{Cl}: 0.58 \\
\text { to } 0.89, p=0.002, \\
l^{2}=66 \% \text {, favors } \\
\text { intervention }\end{array}$ \\
\hline
\end{tabular}




\begin{tabular}{|c|c|c|c|c|c|c|c|c|}
\hline $\begin{array}{l}\text { Outcome } \\
\text { (Strength of } \\
\text { Evidence } \\
\text { Grade) } \\
\end{array}$ & \begin{tabular}{|l} 
Author \\
Study Design: No \\
Studies (N)
\end{tabular} & Study Limitations & Directness & Consistency & Precision & $\begin{array}{l}\text { Reporting } \\
\text { Bias }\end{array}$ & $\begin{array}{l}\text { Other } \\
\text { Issues }\end{array}$ & Finding \\
\hline $\begin{array}{l}\text { Readmissions } \\
\text { (Moderate) }\end{array}$ & $\begin{array}{l}\text { Zhu et al. } 2015^{12} \\
2 \text { US RCTs }(n=768)\end{array}$ & $\begin{array}{l}\text { Medium } \\
\text { (Both studies low ROB } \\
\text { random sequence } \\
\text { generation and allocation } \\
\text { concealment. 1 study high } \\
\text { ROB for blinding } \\
\text { participants and personnel } \\
\text { and unclear ROB for } \\
\text { blinding outcome } \\
\text { assessors, unclear ROB } \\
\text { for attrition bias and low } \\
\text { ROB for selective } \\
\text { reporting. } 1 \text { study unclear } \\
\text { ROB for blinding of } \\
\text { participants, personnel, } \\
\text { and outcome assessors, } \\
\text { low ROB for attrition bias, } \\
\text { and unclear ROB for } \\
\text { selective reporting.) }\end{array}$ & Direct & Consistent & Precise & Undetected & None & $\begin{array}{l}\text { Nurse-led early } \\
\text { discharge planning vs. } \\
\text { usual care } \\
\text { (Non-older adults } \\
<65 \text { years) } \\
\text { RR: } 0.69 ; 95 \% \mathrm{Cl}: 0.51 \\
\text { to } 0.92, p=0.010, \mathrm{I}^{2}=0 \% \text {, } \\
\text { favors intervention }\end{array}$ \\
\hline
\end{tabular}




\begin{tabular}{|c|c|c|c|c|c|c|c|c|}
\hline $\begin{array}{l}\text { Outcome } \\
\text { (Strength of } \\
\text { Evidence } \\
\text { Grade) } \\
\end{array}$ & $\begin{array}{l}\text { Author } \\
\text { Study Design: No } \\
\text { Studies (N) }\end{array}$ & Study Limitations & Directness & Consistency & Precision & $\begin{array}{l}\text { Reporting } \\
\text { Bias }\end{array}$ & $\begin{array}{l}\text { Other } \\
\text { Issues }\end{array}$ & Finding \\
\hline $\begin{array}{l}\text { Readmissions } \\
\text { at } 1 \text { month } \\
\text { (Low) }\end{array}$ & $\begin{array}{l}\text { Zhu et al. } 2015^{12} \\
3 \text { RCTs ( } 2 \text { of } 3 \text { US) } \\
(n=2,013)\end{array}$ & $\begin{array}{l}\text { Medium } \\
\text { (All studies low ROB } \\
\text { random sequence } \\
\text { generation, allocation } \\
\text { concealment, and selective } \\
\text { reporting. } 1 \text { study unclear } \\
\text { ROB for blinding of } \\
\text { participants, personnel, } \\
\text { and outcome assessors } \\
\text { but low ROB attrition bias. } \\
1 \text { study high ROB for } \\
\text { blinding participants and } \\
\text { personnel and low ROB } \\
\text { blinding outcome } \\
\text { assessors and unclear } \\
\text { ROB for attrition bias. } \\
1 \text { study low ROB for } \\
\text { blinding participants and } \\
\text { personnel, attrition bias, } \\
\text { selective reporting and } \\
\text { unclear ROB for blinding } \\
\text { outcome assessors.) }\end{array}$ & Direct & $\begin{array}{l}\text { Inconsistent } \\
(>50 \% \\
\text { heterogeneity })\end{array}$ & Precise & Undetected & None & $\begin{array}{l}\text { Nurse-led early } \\
\text { discharge planning vs. } \\
\text { usual care } \\
\text { RR: } 0.73 ; 95 \% \mathrm{Cl}: 0.46 \\
\text { to } 1.15, p=0.170 \text {, } \\
\mathrm{I}^{2}=75 \% \text {, no difference }\end{array}$ \\
\hline $\begin{array}{l}\text { Readmissions } \\
\text { at } 6 \text { months } \\
\text { (Moderate) }\end{array}$ & $\begin{array}{l}\text { Zhu et al. } 2015^{12} \\
2 \text { US RCTs }(n=393)\end{array}$ & $\begin{array}{l}\text { Medium } \\
\text { (1 study low ROB for all } \\
\text { domains. } 1 \text { study low ROB } \\
\text { for random sequence } \\
\text { generation, allocation } \\
\text { concealment, and attrition } \\
\text { bias and unclear ROB for } \\
\text { blinding of participants, } \\
\text { personnel, and outcome } \\
\text { assessors and selective } \\
\text { reporting.) }\end{array}$ & Direct & Consistent & Precise & Undetected & None & $\begin{array}{l}\text { Nurse-led early } \\
\text { discharge planning vs. } \\
\text { usual care } \\
\text { RR: } 0.48 ; 95 \% \mathrm{Cl}: 0.37 \\
\text { to } 0.63, \mathrm{p}<0.001, \mathrm{I}^{2}=0 \% \text {, } \\
\text { favors intervention }\end{array}$ \\
\hline
\end{tabular}




\begin{tabular}{|c|c|c|c|c|c|c|c|c|}
\hline $\begin{array}{l}\text { Outcome } \\
\text { (Strength of } \\
\text { Evidence } \\
\text { Grade) }\end{array}$ & \begin{tabular}{|l} 
Author \\
Study Design: No \\
Studies (N)
\end{tabular} & Study Limitations & Directness & Consistency & Precision & $\begin{array}{l}\text { Reporting } \\
\text { Bias }\end{array}$ & $\begin{array}{l}\text { Other } \\
\text { Issues }\end{array}$ & Finding \\
\hline $\begin{array}{l}\text { Readmissions } \\
\text { (Moderate) }\end{array}$ & $\begin{array}{l}\text { Kul et al. } 2012^{29} \\
2 \text { RCTs, } 1 \text { interrupted } \\
\text { time series, } \\
2 \text { non-randomized } \\
\text { controlled studies } \\
(3 \text { of } 5 \text { US) }(n=3,006)\end{array}$ & Medium & Direct & Consistent & Precise & Undetected & None & $\begin{array}{l}\text { Clinical pathways vs. } \\
\text { usual care } \\
\text { RR: } 0.81 ; 95 \% \mathrm{Cl} \text { : } 0.66 \\
\text { to } 0.99, \mathrm{I}^{2}=16 \% \text {, favors } \\
\text { intervention }\end{array}$ \\
\hline $\begin{array}{l}\text { Readmissions } \\
\text { (Moderate) }\end{array}$ & $\begin{array}{l}\text { Van Craen et al. } \\
2010^{39} \\
2 \text { RCTs ( } 1 \text { of } 2 \text { US) } \\
(n=668)\end{array}$ & Low & Direct & Consistent & Imprecise & Undetected & None & $\begin{array}{l}\text { Geriatric evaluation unit } \\
\text { vs. usual care } \\
\text { RR: } 0.85 ; 95 \% \mathrm{Cl}: 0.65 \\
\text { to } 1.11 \text {, no difference }\end{array}$ \\
\hline $\begin{array}{l}\text { In-hospital } \\
\text { Mortality } \\
\text { (Low) }\end{array}$ & $\begin{array}{l}\text { Eagles et al. } 2020^{41} \\
6 \text { retrospective cohort } \\
\text { studies (5 of } 6 \text { US) } \\
(n=7,408)\end{array}$ & $\begin{array}{l}\text { Medium } \\
\text { All } 6 \text { studies scored at } \\
3 \text { points for selection } \\
\text { domain (max } 4 \text { pts.) or } \\
\text { outcome domain (max } \\
3 \text { pts.). Only } 2 \text { studies } \\
\text { scored a max of } 2 \text { points } \\
\text { for the comparability } \\
\text { domain. }\end{array}$ & Direct & Consistent & $\begin{array}{l}\text { Imprecise } \\
\text { (wide } \mathrm{Cl} \text { ) }\end{array}$ & Undetected & None & $\begin{array}{l}\text { After vs. before } \\
\text { implementation of GTC } \\
\text { service } \\
\text { Unadjusted OR: } 0.91 \\
\text { 95\% Cl: } 0.70 \text { to } 1.18 \\
\mathrm{I}^{2}=18 \% \text {, no difference }\end{array}$ \\
\hline $\begin{array}{l}\text { In-hospital } \\
\text { Mortality } \\
\text { (Low) }\end{array}$ & $\begin{array}{l}\text { Eagles et al. } 2020^{41} \\
2 \text { US retrospective } \\
\text { cohort studies } \\
(n=482)\end{array}$ & $\begin{array}{l}\text { High } \\
\text { Both studies scored } 3 \text { out } \\
\text { of } 4 \text { for selection domain, a } \\
\text { max of } 3 \text { for the outcome } \\
\text { domain, and } 0 \text { out or } 2 \text { for } \\
\text { the comparability domain. }\end{array}$ & Direct & Consistent & Precise & Undetected & None & $\begin{array}{l}\text { GTC vs. without GTC } \\
\text { Unadjusted OR: } 0.24 ; \\
95 \% \text { Cl: } 0.12 \text { to } 0.52 \text {, } \\
I^{2=} 0 \% \text {, favors } \\
\text { intervention }\end{array}$ \\
\hline $\begin{array}{l}\text { In-hospital } \\
\text { Mortality } \\
\text { (Low) }\end{array}$ & $\begin{array}{l}\text { Baratloo et al. } 2018^{25} \\
15 \text { retrospective } \\
\text { controlled: studies, } \\
2 \text { prospective } \\
\text { controlled studies, } \\
1 \text { RCT (10 of } 18 \text { US) } \\
(n=4,907)\end{array}$ & $\begin{array}{l}\text { Medium } \\
\text { (Retrospective and } \\
\text { prospective studies low } \\
\text { ROB on Newottowa scale. } \\
\text { RCT low ROB for random } \\
\text { sequence generation, } \\
\text { incomplete outcome data, } \\
\text { selective reporting, but } \\
\text { high ROB for blinding } \\
\text { participants and } \\
\text { personnel.) }\end{array}$ & Direct & Consistent & $\begin{array}{l}\text { Imprecise } \\
\text { (wide } \mathrm{Cl} \text { ) }\end{array}$ & Undetected & None & $\begin{array}{l}\text { Telestroke-based } \\
\text { systems vs. bedside } \\
\text { (face-to-face) } \\
\text { OR: } 1.21 ; 95 \% \mathrm{Cl}: 0.98 \\
\text { to } 1.49, p=0.08, \mathrm{I}^{2}=0 \% \text {, } \\
\text { no difference }\end{array}$ \\
\hline
\end{tabular}




\begin{tabular}{|c|c|c|c|c|c|c|c|c|}
\hline $\begin{array}{l}\text { Outcome } \\
\text { (Strength of } \\
\text { Evidence } \\
\text { Grade) }\end{array}$ & \begin{tabular}{|l} 
Author \\
Study Design: No \\
Studies (N)
\end{tabular} & Study Limitations & Directness & Consistency & Precision & $\begin{array}{l}\text { Reporting } \\
\text { Bias }\end{array}$ & $\begin{array}{l}\text { Other } \\
\text { Issues }\end{array}$ & Finding \\
\hline $\begin{array}{l}\text { Early Mortality } \\
\text { (Low) }\end{array}$ & $\begin{array}{l}\text { Pannick et al. } 2015^{32} \\
4 \text { cluster RCTs, } \\
2 \text { non-RCTs, } 1 \text { RCT } \\
\text { ( } 4 \text { of } 7 \text { US) (n=NR) }\end{array}$ & $\begin{array}{l}\text { High } \\
\text { ( } 1 \text { study medium ROB, } \\
6 \text { studies high } \mathrm{ROB} \text { ) }\end{array}$ & Direct & Consistent & Precise & Undetected & None & $\begin{array}{l}\text { Altering interdisciplinary } \\
\text { team composition vs. } \\
\text { usual care } \\
\text { RR: } 0.925 ; 95 \% \mathrm{Cl} \text { : } \\
0.816 \text { to } 1.049, \text { no } \\
\text { difference }\end{array}$ \\
\hline $\begin{array}{l}\text { Early Mortality } \\
\text { (Low) }\end{array}$ & $\begin{array}{l}\text { Pannick et al. } 2015^{32} \\
2 \text { non-RCT cluster } \\
\text { studies ( } 1 \text { of } 2 \text { US) } \\
\text { ( } n=N R)\end{array}$ & $\begin{array}{l}\text { High } \\
\text { (Both studies high ROB) }\end{array}$ & Direct & Consistent & Precise & Undetected & None & $\begin{array}{l}\text { Altering interdisciplinary } \\
\text { team practice vs. usual } \\
\text { care } \\
\text { RR: } 0.665 ; 95 \% \mathrm{Cl} \text { : } \\
0.449 \text { to } 0.986, \\
\text { intervention tended to } \\
\text { reduce early mortality }\end{array}$ \\
\hline $\begin{array}{l}\text { All-cause } \\
\text { Mortality } \\
\text { (index } \\
\text { admission to } \\
\text { within } \\
30 \text { days) } \\
\text { (Moderate) }\end{array}$ & $\begin{array}{l}\text { Zhu et al. } 2015^{12} \\
5 \text { RCTs (3 of } 5 \text { US) } \\
(n=2,729)\end{array}$ & $\begin{array}{l}\text { Medium } \\
\text { (All studies low ROB } \\
\text { random sequence } \\
\text { generation and allocation } \\
\text { concealment. } 2 \text { studies } \\
\text { unclear ROB for blinding of } \\
\text { participants, personnel, } \\
\text { and outcome assessors. } \\
1 \text { study high ROB for } \\
\text { blinding participants and } \\
\text { personnel and low ROB for } \\
\text { blinding outcome } \\
\text { assessors. } 1 \text { study low } \\
\text { ROB for blinding } \\
\text { participants, personnel, } \\
\text { and outcome assessors. } \\
4 \text { studies low ROB for } \\
\text { attrition bias, } 3 \text { studies low } \\
\text { ROB for selective } \\
\text { reporting.) }\end{array}$ & Direct & Consistent & Precise & Undetected & None & $\begin{array}{l}\text { Nurse-led early } \\
\text { discharge planning vs. } \\
\text { usual care } \\
\text { RR: } 0.70 ; 95 \% \mathrm{Cl}: 0.52 \\
\text { to } 0.95, p=0.020, \mathrm{I}^{2}=0 \% \text {, } \\
\text { favors intervention }\end{array}$ \\
\hline
\end{tabular}




\begin{tabular}{|c|c|c|c|c|c|c|c|c|}
\hline $\begin{array}{l}\text { Outcome } \\
\text { (Strength of } \\
\text { Evidence } \\
\text { Grade) } \\
\end{array}$ & $\begin{array}{l}\text { Author } \\
\text { Study Design: No } \\
\text { Studies (N) }\end{array}$ & Study Limitations & Directness & Consistency & Precision & $\begin{array}{l}\text { Reporting } \\
\text { Bias }\end{array}$ & $\begin{array}{l}\text { Other } \\
\text { Issues }\end{array}$ & Finding \\
\hline $\begin{array}{l}\text { In-hospital } \\
\text { Mortality } \\
\text { (Low) }\end{array}$ & $\begin{array}{l}\text { Kul et al. } 2012^{29} \\
3 \text { RCTs, } 1 \text { interrupted } \\
\text { times series, } \\
1 \text { non-randomized } \\
\text { controlled study } \\
(3 \text { of } 5 \text { US })(n=2,343)\end{array}$ & Medium & Direct & $\begin{array}{l}\text { Inconsistent } \\
(>50 \% \\
\text { heterogeneity })\end{array}$ & Precise & Undetected & None & $\begin{array}{l}\text { Clinical pathways vs. } \\
\text { usual care } \\
\text { Hospital mortality } \\
\text { RR: } 0.45 ; 95 \% \mathrm{Cl}: 0.21 \\
\text { to } 0.94, I^{2}=73 \% \text {, favors } \\
\text { intervention }\end{array}$ \\
\hline $\begin{array}{l}\text { In-hospital } \\
\text { Mortality } \\
\text { (High) }\end{array}$ & $\begin{array}{l}\text { Van Craen et al. } \\
2010^{39} \\
6 \text { RCTs ( } 3 \text { of } 6 \text { US) } \\
(n=4,108)\end{array}$ & Low & Direct & Consistent & Precise & Undetected & None & $\begin{array}{l}\text { Geriatric evaluation unit } \\
\text { vs. usual care } \\
\text { Hospital Mortality at } \\
12 \text { months } \\
\text { RR: } 0.97 ; 95 \% \mathrm{Cl}: 0.88 \\
\text { to } 1.08, \text { no difference }\end{array}$ \\
\hline $\begin{array}{l}\text { Symptomatic } \\
\text { Intracranial } \\
\text { Hemorrhage } \\
\text { (Low) }\end{array}$ & $\begin{array}{l}\text { Baratloo et al. } 2018^{25} \\
14 \text { retrospective } \\
\text { controlled studies, } \\
6 \text { prospective } \\
\text { controlled studies, } \\
1 \mathrm{RCT}(10 \text { of } 21 \mathrm{US}) \\
(\mathrm{n}=4,022)\end{array}$ & $\begin{array}{l}\text { Medium } \\
\text { (Retrospective and } \\
\text { prospective studies low } \\
\text { ROB on Newottowa scale. } \\
\text { RCT low ROB for random } \\
\text { sequence generation, } \\
\text { incomplete outcome data, } \\
\text { selective reporting, but } \\
\text { high ROB for blinding } \\
\text { participants and } \\
\text { personnel.) }\end{array}$ & Direct & Consistent & $\begin{array}{l}\text { Imprecise } \\
\text { (wide } \mathrm{Cl} \text { ) }\end{array}$ & Undetected & None & $\begin{array}{l}\text { Telestroke-based } \\
\text { systems vs. bedside } \\
\text { (face-to-face) } \\
\text { OR: } 1.10 ; 95 \% \mathrm{Cl}: 0.79 \\
\text { to } 1.53, p=0.58, \mathrm{I}^{2}=0 \% \text {, } \\
\text { no difference }\end{array}$ \\
\hline $\begin{array}{l}\text { Functional } \\
\text { Decline at } \\
\text { Discharge } \\
\text { (High) }\end{array}$ & $\begin{array}{l}\text { Van Craen et al. } \\
2010^{39} \\
2 \text { US RCTs }(n=2,182)\end{array}$ & Low & Direct & Consistent & Precise & Undetected & None & $\begin{array}{l}\text { Geriatric evaluation unit } \\
\text { vs. usual care } \\
\text { Functional decline at } \\
\text { discharge } \\
\text { RR: } 0.87 ; 95 \% \mathrm{Cl}: 0.77 \\
\text { to } 0.99 \text {, favors } \\
\text { intervention }\end{array}$ \\
\hline
\end{tabular}




\begin{tabular}{|c|c|c|c|c|c|c|c|c|}
\hline $\begin{array}{l}\text { Outcome } \\
\text { (Strength of } \\
\text { Evidence } \\
\text { Grade) } \\
\end{array}$ & $\begin{array}{l}\text { Author } \\
\text { Study Design: No } \\
\text { Studies (N) }\end{array}$ & Study Limitations & Directness & Consistency & Precision & $\begin{array}{l}\text { Reporting } \\
\text { Bias }\end{array}$ & \begin{tabular}{|l|} 
Other \\
Issues
\end{tabular} & Finding \\
\hline $\begin{array}{l}\text { Functional } \\
\text { Decline at } \\
12 \text { months } \\
\text { (Moderate) }\end{array}$ & $\begin{array}{l}\text { Van Craen et al. } \\
2010^{39} \\
2 \text { US RCTs }(n=1,654)\end{array}$ & Low & Direct & Consistent & Imprecise & Undetected & None & $\begin{array}{l}\text { Geriatric evaluation unit } \\
\text { vs. usual care } \\
\frac{\text { Functional decline at }}{12 \text { months }} \\
\begin{array}{l}\text { RR: } 0.84 ; 95 \% \mathrm{Cl}: 0.69 \\
\text { to } 1.03, \text { no difference }\end{array}\end{array}$ \\
\hline
\end{tabular}

$\mathrm{CI}=$ confidence interval; GTC = geriatric trauma consultation; $\mathrm{LOS}=$ length of stay; $\mathrm{MD}=$ mean difference; $\mathrm{OR}=$ odds ratio; $\mathrm{RCT}=$ randomized controlled trial;

$\mathrm{ROB}=$ risk of bias; $\mathrm{RR}=$ risk ratio; $\mathrm{SMD}=$ standardized mean difference; $\mathrm{US}=$ United States; $\mathrm{WMD}=$ weighted mean difference 
Table C-7. Research in progress

\begin{tabular}{|c|c|c|c|c|}
\hline Title & Intervention & \begin{tabular}{|l|} 
Patient \\
Population
\end{tabular} & \begin{tabular}{|l|} 
Expected \\
Completion \\
Date \\
\end{tabular} & Source \\
\hline $\begin{array}{l}\text { Activity Monitor Feedback and Interactive } \\
\text { Tours to Improve Postoperative } \\
\text { Ambulation }\end{array}$ & $\begin{array}{l}\text { Technologically- } \\
\text { supported } \\
\text { feedback }\end{array}$ & $\begin{array}{l}\text { Older adults; } \\
\text { patients not fluent } \\
\text { in English }\end{array}$ & December 2019 & $\begin{array}{l}\text { ClinicalTrials. } \\
\text { gov }\end{array}$ \\
\hline $\begin{array}{l}\text { The Effect of Standardizing the Definition } \\
\text { of a Clinically Significant } \\
\text { Cardiopulmonary Event on Length of Stay }\end{array}$ & $\begin{array}{l}\text { Standardization } \\
\text { of care }\end{array}$ & Premature infants & December 2020 & $\begin{array}{l}\text { ClinicalTrials. } \\
\text { gov }\end{array}$ \\
\hline $\begin{array}{l}\text { Comparing Two Ways for Hospitals to } \\
\text { Help Patients Recover During and After } \\
\text { Stroke }\end{array}$ & $\begin{array}{l}\text { Integrated stroke } \\
\text { practice unit }\end{array}$ & $\begin{array}{l}\text { Patients with } \\
\text { socioeconomic } \\
\text { vulnerability }\end{array}$ & February 2024 & PCORI \\
\hline $\begin{array}{l}\text { Care in the CCP [Comprehensive Care } \\
\text { Physician] Program versus Care in the } \\
\text { C4P [Comprehensive Care, Community } \\
\text { and Culture] Program versus Care in } \\
\text { Traditional Care Coordinator Program }\end{array}$ & $\begin{array}{l}\text { Care } \\
\text { coordination }\end{array}$ & $\begin{array}{l}\text { Chronic co-morbid } \\
\text { illness; older } \\
\text { adults }\end{array}$ & April 2024 & PCORI \\
\hline
\end{tabular}

PCORI = Patient-Centered Outcomes Research Institute 